\author{
UNIVERSIDADE DE SÃO PAULO \\ FACULDADE DE ODONTOLOGIA DE RIBEIRÃO PRETO \\ DEPARTAMENTO DE MATERIAIS DENTÁRIOS E PRÓTESE
}

MARCO ANTONIO AMORIM VASCO

\title{
Análise tridimensional comparativa de reabilitações para a região posterior da mandíbula, por meio do Método de Elementos Finitos
}

Ribeirão Preto 
Análise tridimensional comparativa de reabilitações para a região posterior da mandíbula, por meio do Método de Elementos Finitos

Tese apresentada à Faculdade de Odontologia de Ribeirão Preto da Universidade de São Paulo para obtenção do título de Doutor em Odontologia Área de concentração: Reabilitação Oral

Orientador: Professor Titular Osvaldo Luiz Bezzon

Ribeirão Preto 
Autorizo a reprodução e divulgação total ou parcial deste trabalho, por qualquer meio convencional ou eletrônico, para fins de estudo e pesquisa, desde que citada a fonte.

\title{
FICHA CATALOGRÁFICA
}

\author{
Vasco, Marco Antonio Amorim \\ Análise tridimensional comparativa de reabilitações para \\ a região posterior da mandíbula, por meio do Método de \\ Elementos Finitos. \\ Ribeirão Preto, 2010 \\ p. 151
}

Tese de Doutorado, apresentada à Faculdade de Odontologia de Ribeirão Preto/USP, Departamento de Materiais Dentários e Prótese. Área de concentração Reabilitação Oral.

Orientador: Bezzon, Osvaldo Luiz.

1. Implante dentário, 2. Implante curto,3. Lateralização do nervo alveolar inferior. 4. Método dos Elementos Finitos. 
Nome: Marco Antonio Amorim Vasco

Título: Análise tridimensional comparativa de reabilitações para a região posterior da mandíbula por meio do método de elementos finitos.

Tese apresentada à Faculdade de Odontologia de Ribeirão Preto da Universidade de São Paulo para obtenção do título de Doutor em Odontologia, área de concentração: Reabilitação Oral

Aprovado em:

Banca examinadora

Prof. Dr.: Instituição:

Julgamento: Assinatura:

Prof. Dr.: Instituição:

Julgamento: Assinatura:

Prof. Dr.: Instituição:

Julgamento: Assinatura:

Prof. Dr.: Instituição: Julgamento: Assinatura:

Prof. Dr.: Instituição: Julgamento: Assinatura: 


\section{DEDICATÓRIA}

Aos meus pais, pelo amor, carinho, paciência e confiança que me permitiram realizar esse sonho.

A Deus, por tudo que tenho e sou, e por cuidar de mim e da minha família. 


\section{AGRADECIMENTOS ESPECIAIS}

Ao meu orientador, prof. Dr. Osvaldo Luiz Bezzon, por todo o auxílio depositado, toda confiança, liberdade e atenção que me permitiram aproveitar ao máximo a experiência de doutorado. Principalmente, por me encorajar a trilhar a linha de pesquisa que escolhi, com muita paciência, sem nunca desanimar pelos atrasos que cometi. Existe uma frase de Bertolt Brecht que se encaixa muito bem ao senhor: "Há homens que lutam um dia e são bons. Há outros que lutam um ano e são melhores. Há os que lutam muitos anos e são muito bons. Porém, há os que lutam toda a vida. Esses são os imprescindíveis”. Meu muito obrigado professor!

A profa. Dra. Mildred Ballin Hecke, por todos os conhecimentos transmitidos, e especialmente, pela paciência em transmiti-los. Eu sei que não é fácil ensinar alguém de outra área que muitas vezes não tem nem o conhecimento básico sobre um assunto. Agradeço do fundo do meu coração por toda a dedicação, carinho e, sobretudo, por acreditar em mim e no meu trabalho. 


\section{AGRADECIMENTOS}

Ao meu grande amigo, Dr. Sérgio Jorge Jayme, por todo o companheirismo e incentivos que me proporcionaram grandes oportunidades durante esse doutorado. Sobretudo, por ser a pessoa especial que é, motivando a todos, incluindo a mim, a procurar uma carreira de sucesso nessa profissão. Você tem um coração muito maior do que deixa transparecer, e fico feliz de poder the chamar de amigo.

A minha amiga e colega de orientação, Natércia Carreira Soriani e sua família, por toda ajuda e companheirismo, pela hospitalidade em me receber diversas vezes em sua casa e por cuidar da minha pequena Sophia quando tive que me ausentar. Agradeço do fundo do meu coração e desejo muito sucesso e felicidade a todos vocês.

Ao meu amigo, Dr. Éderson Áureo Gonçalves Betiol, por todo o incentivo que me ajudaram a perseguir a carreira acadêmica, em especial a pesquisa com elementos finitos. Agradeço pela confiança e paciência que sempre dispensou a mim e que me ajudaram a ser um melhor pesquisador. Meu muito obrigado.

Aos coordenadores e funcionários do Instituto Sérgio Jayme, por todo companheirismo a amizade, e por toda a ajuda que dispensaram a mim e que favoreceu o meu crescimento profissional durante esse curso.

Ao meu amigo, Dr. Antonio de Luna Malheiros, pela amizade sincera, e por toda a ajuda durante o curso.

Aos meus amigos e colegas da FORP: Paty, Ingrid, Janisse, Pamela, Humberto, Fabrício, Fabiano, Tiossi, Alessandra, Amanda, Abílio, Ana e demais que aqui não lembro, pelos momentos de companheirismo e solidariedade que nos estimula a sempre ir em frente.

Aos funcionários e professores da FORP, em especial ao prof. Dr. Vinícius Pedrazzi e a profa. Dra. Marilena Chinali Komesu, pelos conhecimentos 
transmitidos e pela solidariedade nos momentos difíceis. Tudo de bom a todos vocês.

A Nobel Biocare, pela doação dos implantes e componentes protéticos, gentilmente cedidos, para utilização nesta pesquisa.

A Capes, pela concessão da bolsa de estudos, que muito me ajudou durante esse curso. 
RESUMO

Vasco, M. A. A. Análise tridimensional comparativa de reabilitações para a região posterior da mandíbula, por meio do Método de Elementos Finitos. 2010. 167 f. Tese (Doutorado). Faculdade de Odontologia de Ribeirão Preto, Universidade de São Paulo, São Paulo, 2010.

A reabilitação da região posterior da mandíbula com implantes dentários é complexa, especialmente em casos de reabsorção óssea moderada a severa. Embora existam diversas possibilidades de tratamento para essa região, os implantes curtos e a lateralização tem se destacado como alternativas viáveis e de menor tempo de tratamento. O objetivo deste trabalho foi avaliar, comparativamente, o risco mecânico dos dois tratamentos mencionados, com especial atenção ao risco de perda óssea e de fratura do parafuso. Para tanto, foram processadas tomografias de mandíbulas e realizada engenharia reversa de implantes e componentes protéticos para reconstrução de modelos tridimensionais, a fim de simular o comportamento biomecânico de próteses parciais fixas de três elementos, suportadas por dois implantes, utilizando simulações com o Método dos Elementos Finitos. Os modelos de implantes utilizados foram baseados nos implantes MK III (Nobel Biocare), com 5 e 4 mm de diâmetro por 7 de comprimento, representando implantes curtos, e com 4 e $3.75 \mathrm{~mm}$ de diâmetro por 15 de comprimento, representando implantes sob tratamento de lateralização do nervo alveolar inferior. Modelos distintos foram confeccionados para representar implantes tratados em um estágio (carga imediata) e dois estágios (implantes osseointegrados). Todos os modelos receberam simulação prévia de pré-tensão, referente a tensão gerada pelo torque do parafuso. Um padrão de carga oclusal axial e outro com carga oclusal oblíqua em $45 \%$ foram simulados, resultando em 16 diferentes simulações. A análise dos resultados revelou que o risco mecânico para perda óssea na região periimplantar, quando analisados implantes colocados em dois estágios, é maior para tratamentos com implantes curtos. Entretanto, para implantes colocados em um estágio, o maior risco de perda óssea foi para os implantes colocados com lateralização do nervo alveolar inferior. Quanto aos resultados dos parafusos, 
embora não se observou claras tendências quando simuladas cargas axiais, sob cargas oblíquas, os implantes de maior diâmetro e menor comprimento tiveram o menor risco à fratura do parafuso.

Palavras-chave: Implante dentário, Implante curto, Lateralização do nervo alveolar inferior, Método dos Elementos Finitos. 


\section{ABSTRACT}

Vasco, M. A. A. Three-dimensional comparative analysis of rehabilitations for the posterior mandible, with the Finite Element Method. 2010. $167 \mathrm{f}$. Tese (Doutorado). Faculdade de Odontologia de Ribeirão Preto, Universidade de São Paulo, São Paulo, 2010.

The rehabilitation of the posterior region of the mandible with dental implants is complex, especially in cases of moderate to severe bone loss. While there are several treatment options for this region, the use of short implants and lateralization has emerged as viable alternatives with less treatment time. The objective of this study was to comparatively evaluate the mechanical risk of both treatments mentioned, with special attention to the risk of bone loss and screw fracture. For this, CT scans of mandibles were processed and implants and prosthetic components were reverse engineered for reconstruction of three dimensional models to simulate the biomechanical behavior of fixed partial dentures of three elements, supported by two implants, using simulations with the Finite Element Method. The models of implants were based on MK III implants (Nobel Biocare) with 5 and $4 \mathrm{~mm}$ in diameter by $7 \mathrm{~mm}$ in length, representing short implants, and 4 and $3.75 \mathrm{~mm}$ in diameter by 15 $\mathrm{mm}$ long, representing implants used in treatments with lateralization of the inferior alveolar nerve. Several models were modeled to represent implants treated in one stage (immediate load) and two stages (osseointegrated implants). All models were simulated with pre-stress concerning the stresses generated by the torque of the screw. Axial and oblique oclusal loads at $45 \%$ were simulated, resulting in 16 different simulations. The results showed that the mechanical risk for bone loss, when osseointegrated implants were analyzed, is greater for treatments with short implants. However, for implants placed in one stage, the increased risk of bone loss was for implants placed with lateralization of the inferior alveolar nerve. Concerning the results of screws, there were no clear trends when axial loads were simulated, however, under oblique loads, the implants of larger diameter and shorter length had the lowest risk of screw fracture. 
Keywords: Dental implant, short implant, Lateralization of the inferior alveolar nerve, Finite Element Method. 


\section{SUMÁRIO}

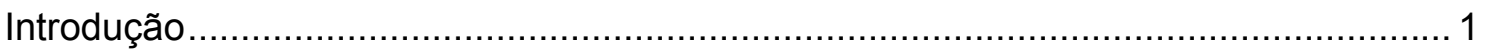

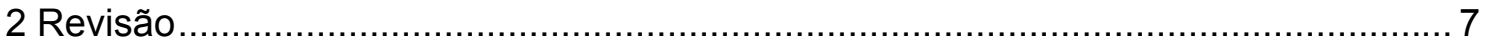

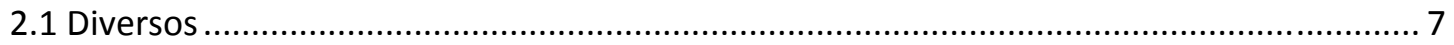

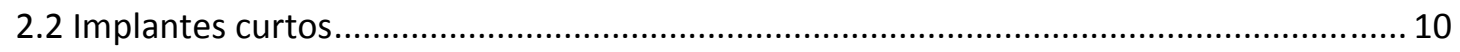

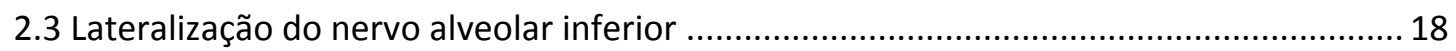

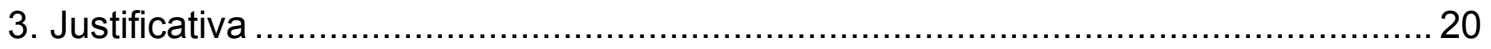

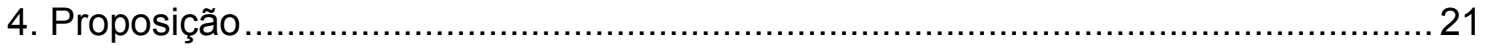

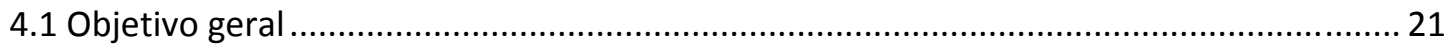

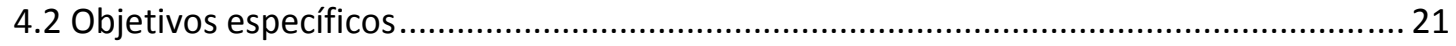

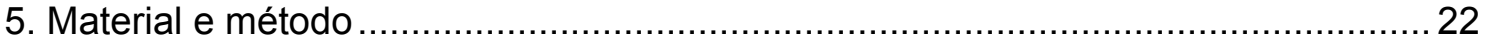

5.1 Reconstrução virtual de tomografia computadorizada ................................................... 22

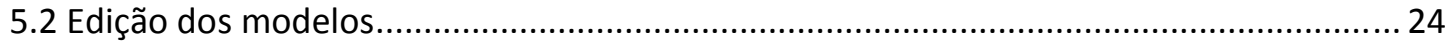

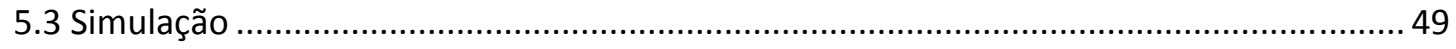

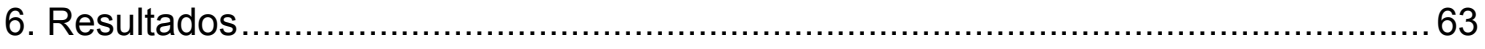

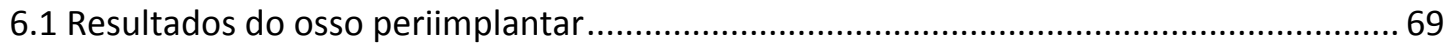

6.1.1 Resultados do osso periimplantar com implantes osseointegrados ......................... 74

6.1.2 Resultados do osso periimplantar em implantes submetidos à carga imediata ........88

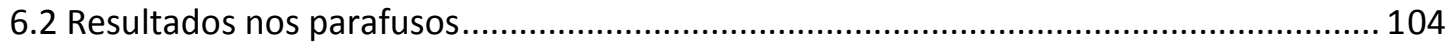

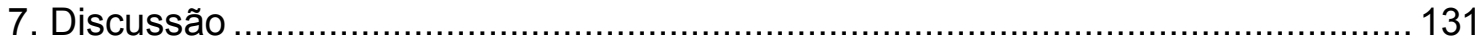

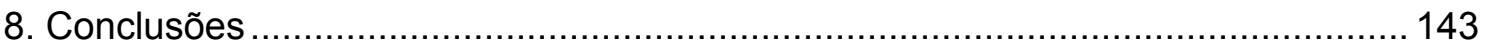

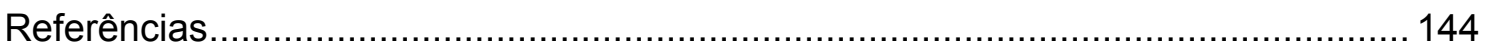


INDICE DE FIGURAS

Figura 1: Reconstrução digital da mandíbula a partir de tomografia. Vista do osso cortical. 23

Figura 2: Reconstrução digital da tomografia para reconstrução dos elementos 35,36 e 37 .

Figura 3: Transformação de um modelo com 98080 polifaces (A), em um modelo com 110 faces NURBS (B) e sobreposição dos dois modelos para demonstrar a mínima distorção ocorrida (C). Os modelos foram plotados com arestas para facilitar a visualização das faces.

Figura 4: Exemplo da diminuição do modelo de 98080 polifaces para 110 polifaces (A), e os modelos sobrepostos demonstrando a grande distorção ocorrida (B). Os modelos foram plotados com arestas para facilitar a visualização das faces.

Figura 5: Reconstrução digital dos dentes 35,36 e 37 . A: vista vestibular. B: vista oclusal. 28

Figura 6: Reconstrução das duas tomografias em modelos sólidos. A: modelo total. B: osso cortical e medular semitransparente para facilitar a visualização do feixe vásculo nervoso. 29

Figura 7: Mandíbula recortada para simulação de uma mandíbula atrófica. A: modelo total. $\mathrm{B}$ : osso cortical e medular semitransparente para facilitar a visualização do feixe vásculo nervoso.

Figura 8: Vista do segmento de mandíbula seccionado que foi utilizado neste trabalho. B: osso cortical e medular semitransparente para facilitar a visualização da relação entre as estruturas.

Figura 9: Vista do osso basal, com canal mandibular reeditado para não favorecer nenhuma das técnicas analisadas. $A=$ vista de perfil e $B=$ vista vestibular.

Figura 10: Materiais que foram utilizados para mensuração da geometria dos implantes e componentes protéticos. $\mathrm{A}=$ microscópio digital, $\mathrm{B}=$ lupa de aumento e $\mathrm{C}=$ paquímetro digital

Figura 11: Foto real dos implantes e componentes protéticos que foram utilizados como referência para a confecção dos modelos.

Figura 12: Mensuração com paquímetro digital.

Figura 13: Fotos do microscópio digital analisando um parafuso. A régua foi colocada para fins de referência.

Figura 14: $A=$ Foto tirada pelo microscópio digital e $B=$ mesma foto, com calibração do software de mensuração e diversas distâncias analisadas, para construção do modelo. A régua foi colocada para fins de referência

Figura 15: Foto da porção cervical do implante, com mensuração de diversas distâncias. A régua foi colocada para fins de referência. 
Figura 16: Modelo 3D do implante MK III de cinco mm de diâmetro por sete de comprimento, com componentes unidos. $A=$ vista vestibular e $B=$ vista lingual. Em verde o implante e em azul o intermediário.

Figura 17: Modelo 3D do implante MK III de cinco mm de diâmetro por sete de comprimento, com componentes separados. $A=$ vista vestibular, $B=$ vista inferior e $C=$ vista de perfil. Em verde o implante, em azul o intermediário e marrom o parafuso.

Figura 18: Modelos 3D dos diferentes implantes MK III utilizados nesta pesquisa. $A=$ Implante de cinco $\mathrm{mm}$ de diâmetro por sete de altura, $\mathrm{B}=$ Implante de quatro $\mathrm{mm}$ de diâmetro por sete de comprimento, $\mathrm{C}=$ Implante de quatro $\mathrm{mm}$ de diâmetro por 15 de comprimento e $\mathrm{D}=$ Implante de $3.75 \mathrm{~mm}$ de diâmetro por $15 \mathrm{~mm}$ de comprimento.

Figura 19: Vista do acesso ósseo na técnica de lateralização do nervo alveolar inferior com vista semitransparente para facilitar a visualização do canal alveolar inferior. $A / B=$ vista de perfil, $C / D=$ vista vestibular.

Figura 20: Vista do canal alveolar inferior lateralizado com osso semitransparente, para os modelos com técnica de lateralização do nervo alveolar inferior e implantes osseointegrados. Os centros dos nichos se referem à posição de colocação dos implantes.

Figura 21: Vista de perfil do modelo A. Com osso opaco e semitransparente para visualização da relação entre implante e canal alveolar inferior.

Figura 22 Vista de perfil do modelo B. Com osso opaco e semitransparente para visualização da relação entre implante e canal alveolar inferior.

Figura 23: Vista de perfil do modelo C. Com osso opaco e semitransparente para visualização da relação entre implante e canal alveolar inferior.

Figura 24: Vista de perfil do modelo D. Com osso opaco e semitransparente para visualização da relação entre implante e canal alveolar inferior.

Figura 25: Vista de perfil do modelo E. Com osso opaco e semitransparente para visualização da relação entre implante e canal alveolar inferior.

Figura 26: Vista de perfil do modelo F. Com osso opaco e semitransparente para visualização da relação entre implante e canal alveolar inferior.

Figura 27: Vista de perfil do modelo G. Com osso opaco e semitransparente para visualização da relação entre implante e canal alveolar inferior.

Figura 28: Vista de perfil do modelo $H$. Com osso opaco e semitransparente para visualização da relação entre implante e canal alveolar inferior.

Figura 29: Vista das estruturas antagonistas em roxo. $A=$ carga axial e $B=$ carga oblíqua 47

Figura 30: Diferentes vistas do modelo A.

Figura 31: Vista vestibular da infraestrutura nos modelos com plataforma do implante de 4.1

$\mathrm{mm}$. A cerâmica foi colocada como semitransparente para facilitar a visualização. 
Figura 32: Vista em corte do elemento 35 no modelo A para visualização da relação entre as diferentes estruturas.

Figura 33: Suportes rígidos configurados nas faces em azul. $A=$ vista posterior e $B=$ vista anterior.

Figura 34: Exemplo de utilização do recurso bolt pretension. A: modelo das estruturas em corte. B: recurso aplicado no parafuso. C: resultado com vista externa D: resultado com vista em corte. E: Escala de tensões referente a C e D.

Figura 35: Vista da carga de prétensão do parafuso. $A=$ vista do modelo completo e $B=$ vista com detalhe nos parafusos.

Figura 36: Diferentes condições de carga em um modelo. A aplicação de cargas isoladas pode levar a rotação do modelo devido ao princípio das alavancas ( $\mathrm{A}$ e B), entretanto ao se unir os componentes de aplicação de forças e limitar ser movimento no sentido superiorinferior, essa tendência a rotação é neutralizada (C), à semelhança da situação real.

Figura 37: Configuração da carga axial. $100 \mathrm{~N}$ foram aplicadas na área vermelha com vetor demonstrado pela seta. A área azul se refere ao suporte sem fricção para permitir ao corpo um movimento unicamente ocluso-gengival.

Figura 38: Configuração da carga oblíqua. $100 \mathrm{~N}$ foram distribuídos igualmente, entre os três elementos, com vetores demonstrados pelas setas vermelhas. $A=$ vista posterior e $B=$ vista anterior.

Figura 39: Vista da malha do modelo $A . A=$ modelo completo, $B=$ vista do refinamento de malha na região periimplantar e $\mathrm{C}=$ vista do refinamento de malha no parafuso. 59

Figura 40: Vista da malha do modelo $\mathrm{G} . \mathrm{A}=$ modelo completo, $\mathrm{B}=$ vista em corte do refinamento de malha na região periimplantar, $C=$ vista do refinamento de malha no implante e $\mathrm{D}=$ vista do refinamento de malha no parafuso

Figura 41: Gráfico de convergência de uma das simulações no Ansys, com a intensidade de penetração (vertical) e o numero de interações (horizontal). As linhas roxas se referem ao nível de penetração em cada convergência, a linha azul clara, a penetração calculada como aceitável pelo software e a linha azul escura, a divisão entre um passo de carga e outro...65

Figura 42:Tensões que podem ocorrer em um volume de matéria. A: Tensões de tração, compressão e cizalhamento. B: Volume rotacionado de forma a demonstrar apenas tensões de tração e compressão.

Figura 43: Vista do modelo $A$, com detalhes da região de plotagens das figuras 44 a $52 \ldots 75$

Figura 44: plotagem dos resultados no osso periimplantar pelo critério de Mohr-Coulomb, para implantes osseointegrados, submetidos à carga axial. As letras se referem aos resultados de cada modelo e o $\mathrm{X}$ a escala de cores para todos os resultados.

Figura 45 plotagem dos resultados no osso periimplantar pelo critério de tensão hidrostática, para implantes osseointegrados, submetidos à carga axial. As letras se referem aos resultados de cada modelo e o $\mathrm{X}$ a escala de cores para todos os resultados. 
Figura 46: plotagem dos resultados no osso periimplantar pelo critério de Mohr-Coulomb, para implantes osseointegrados e submetidos à carga oblíqua. As letras se referem aos resultados de cada modelo e o $\mathrm{X}$ a escala de cores para todos os resultados.

Figura 47: plotagem dos resultados no osso periimplantar pelo critério de tensão hidrostática, para implantes osseointegrados e submetidos à carga oblíqua. As letras se referem aos resultados de cada modelo e o X a escala de cores para todos os resultados. 86

Figura 48: plotagem dos resultados no osso periimplantar pelo critério de Mohr-Coulomb, para implantes sob carga imediata e submetidos à carga axial. As letras se referem aos resultados de cada modelo e o $\mathrm{X}$ a escala de cores para todos os resultados

Figura 49: plotagem dos resultados no osso periimplantar pelo critério de tensão hidrostática, para implantes sob carga imediata e submetidos à carga axial. As letras se referem aos resultados de cada modelo e o X a escala de cores para todos os resultados. 93

Figura 50: plotagem dos resultados no osso periimplantar pelo critério de Mohr-Coulomb, para implantes sob carga imediata e submetidos à carga oblíqua. As letras se referem aos resultados de cada modelo e o X a escala de cores para todos os resultados.

Figura 51: plotagem dos resultados no osso periimplantar pelo critério de tensão hidrostática, para implantes sob carga imediata e submetidos à carga oblíqua. As letras se referem aos resultados de cada modelo e o $\mathrm{X}$ a escala de cores para todos os resultados.

Figura 52: vista dos vetores de deslocamento nos modelos B (1 e 2) e F ( 3 e 4). Todos os resultados estão ajustados na mesma escala $(X)$. Observe como o fulcro de rotação (representado pelo circulo azul na região periimplantar) no modelo osseointegrado (1 e 2) está mais para inferior do que no modelo sob carga imediata ( 3 e 4 ) ............................... 103

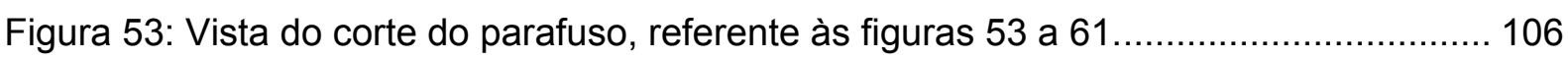

Figura 54: Plotagens dos resultados, no parafuso do elemento 37, para implantes osseointegrados, submetidos à carga axial, considerando a tensões pelo critério de von Mises. As letras se referem ao modelo de cada resultado. Todos os resultados estão ajustados na mesma escala $(\mathrm{X})$.

Figura 55: Plotagens dos resultados dos picos de cisalhamento, no parafuso do elemento 37 , referentes aos modelos B ( 1 e 4 ) e $F(2$ e 5$)$, com implantes osseointegrados. As setas indicam os locais de picos de tensão. A escala 3 se refere a 1 e 2 e a escala 6 se refere a 4 e 5. Note que em todas as plotagens, os picos se localizam no ângulo superior das roscas do parafuso.

Figura 56: Tendência de deformação dos implantes sob carga axial. $A=$ resultado do implante sem qualquer deformação. $B$ = resultado do implante com deformação multiplicada por 1000. Observe a tendência de expansão lateral do implante, quando a deformação é multiplicada para verificação das tendências. 114

Figura 57: Tendência de deformação dos parafusos sob carga axial. $A=$ resultado do parafuso sem qualquer deformação. $B=$ resultado do parafuso com deformação multiplicada 
por 300. Observe a tendência de aproximação entre a cabeça do implante e as roscas, quando a deformação é multiplicada para verificação das tendências.

Figura 58: Plotagens dos resultados, no parafuso do elemento 37, para implantes sob carga imediata, submetidos à carga axial, considerando a tensões pelo critério de von Mises. As letras se referem ao modelo de cada resultado. Todos os resultados estão ajustados na mesma escala $(X)$. 118

Figura 59: Plotagens dos resultados, no parafuso do elemento 37, para implantes osseointegrados, submetidos à carga oblíqua, considerando a tensões pelo critério de von Mises. As letras se referem ao modelo de cada resultado. Todos os resultados estão ajustados na mesma escala (X). 123

Figura 60: Tendência de deformação dos implantes sob carga oblíqua. $A=$ resultado do implante curto sem qualquer deformação. $\mathrm{B}=$ resultado do implante curto com deformação multiplicada por 300x. C = resultado do implante convencional sem qualquer deformação. $\mathrm{D}$ = resultado do implante convencional com deformação multiplicada por 300x. Observe a tendência de rotação de todo o implante curto $(B)$ e de apenas a sua porção superior no implante convencional (D). 124

Figura 61: Tendência de deformação dos implantes sob carga oblíqua. $A=$ Resultado do modelo $D$ (implante de $3.75 \times 15$ ) com deformação multiplicada por 300x. B = Resultado do modelo C (implante de $4 \times 15$ ) com deformação multiplicada por 300x. Observe a maior torção da porção superior do implante no modelo $\mathrm{D}$, devido a sua menor espessura 125

Figura 62: Plotagens dos resultados, no parafuso do elemento 37, para implantes sob carga imediata, submetidos à carga oblíqua, considerando a tensões pelo critério de von Mises. As letras se referem ao modelo de cada resultado. Todos os resultados estão ajustados na mesma escala $(\mathrm{X})$. 130

Figura 63: Vista do modelo implante de $5 \times 7 \mathrm{~mm}$, como foi utilizado na presente pesquisa (A e B) e como foi inicialmente modelado (C e D). 132

Figura 64: Resultados referentes à mesma simulação, mas sem padronização das roscas (A) e com padronização (B), ajustados na mesma escala $(X)$ sob o mesmo padrão de vista (Y). Observe a diferença nos resultados simplesmente pela mudança na localização da área de penetração da rosca no osso. 


\section{INDICE DE QUADROS}

Quadro 1: Propriedades mecânicas dos materiais

Quadro 2: Numero de nós ( $1^{\circ}$ número) e elementos em cada modelo

Quadro 3: Área de inserção óssea, do implante, referente ao elemento 37, nos diferentes modelos com implante osseointegrado, em $\mathrm{mm}^{2}$, e sua relação em percentual a inserção cortical do modelo $A$.

Quadro 4: Área de inserção óssea, do implante, referente ao elemento 37, nos diferentes modelos com implante sob carga imediata, em $\mathrm{mm}^{2}$, e sua relação em percentual a inserção cortical do modelo $\mathrm{E}$.

Quadro 5: Valores de picos dos resultados no osso periimplantar, para implantes osseointegrados, submetidos à carga axial e seu percentual em relação ao controle (modelo B).

Quadro 6: Valores de picos dos resultados no osso periimplantar, para implantes osseointegrados, submetidos à carga oblíqua e seu percentual em relação ao controle (modelo B)

Quadro 7: Valores de picos dos resultados no osso periimplantar, para implantes sob carga imediata e submetidos à carga axial e seu percentual em relação ao controle (modelo F). . 89

Quadro 8: Valores de picos dos resultados no osso periimplantar, para implantes sob carga imediata, submetidos à carga oblíqua e seu percentual em relação ao controle (modelo F).

Quadro 9: Valores de picos dos resultados no parafuso, para as simulações de calibragem de pré-tensão no parafuso.

Quadro 10: Valores de picos de tensões absolutas dos resultados no parafuso, para implantes osseointegrados, sob carga axial, submetidos à carga oblíqua e seu percentual em relação ao controle (modelo $B$ ). 107

Quadro 11: Valores de picos de tensões relativas ao segundo passo de carga, dos resultados no parafuso, para implantes osseointegrados, sob carga axial, e seu percentual em relação ao controle (modelo $\mathrm{B}$ ).

Quadro 12: Valores de picos de tensões absolutas dos resultados no parafuso, para implantes sob carga imediata, submetidos à carga axial e seu percentual em relação ao controle (modelo F).

Quadro 13: Valores de picos de tensões relativas ao segundo passo de carga, para implantes sob carga imediata, submetidos à carga axial e seu percentual em relação ao controle (modelo F). 
Quadro 14: Valores de picos de tensões absolutas dos resultados no parafuso, para implantes osseointegrados, submetidos à carga oblíqua submetidos à carga oblíqua e seu percentual em relação ao controle (modelo B).

Quadro 15: Valores de picos de tensões relativas ao segundo passo de carga, para implantes osseointegrados, submetidos à carga oblíqua e seu percentual em relação ao controle (modelo B).

Quadro 16: valores de picos de tensões absolutas dos resultados no parafuso, para implantes sob carga imediata, submetidos à carga oblíqua e seu percentual em relação ao controle (modelo F).

Quadro 17: Valores de picos de tensões relativas ao segundo passo de carga, para implantes sob carga imediata, submetidos à carga oblíqua e seu percentual em relação ao controle (modelo F). 
LISTA DE ABREVIATURAS E SIGLAS

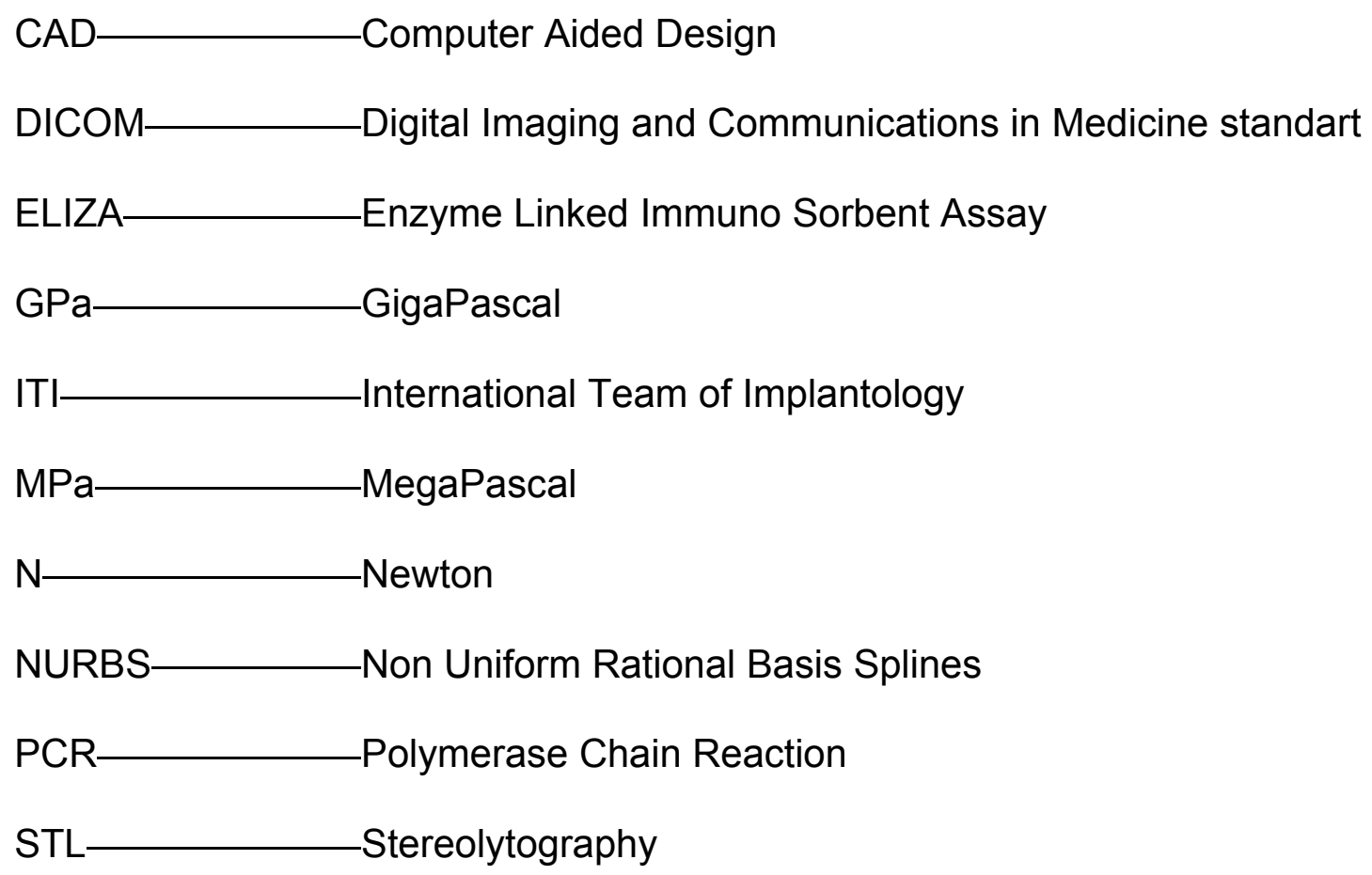


LISTA DE SÍMBOLOS (em ordem de aparição)

$\begin{array}{ll}\sigma_{1} & \text { tensão máxima principal } \\ \sigma_{2} & \text { tensão média principal } \\ \sigma_{3} & \text { tensão mínima principal } \\ \sigma_{\text {resistência a tração }} & \text { tensão máxima de fratura a tração } \\ \sigma_{\text {resistência a compressão }} & \text { tensão máxima de fratura a compressão } \\ \sigma_{\text {limite de escoamento a tração }} & \text { tensão máxima de escoamento a tração } \\ \sigma_{\text {limite de escoamento a compressão }} & \text { tensão máxima de escoamento a compressão } \\ \sigma_{\mathrm{R}} & \text { critério de Mohr Coulomb } \\ \sigma_{\mathrm{m}} & \text { tensão média = tensão hidrostática } \\ \sigma_{\mathrm{e}} & \text { tensão de von Mises }\end{array}$




\section{Introdução}

Com o advento dos implantes dentários, diversas possibilidades para reposição de dentes perdidos tornaram-se possíveis, no início, apenas utilizadas em desdentados totais, mas também aplicados em desdentados parciais, conforme houve evolução no conhecimento e técnicas empregadas. Porém, para próteses parciais fixas implanto suportadas, a redução do número de implantes unidos, e a possibilidade de fatores de risco, como hábitos parafuncionais, trouxeram desafios para o profissional reabilitador. Em especial, as regiões posteriores dos maxilares tem se mostrado desfavoráveis à colocação de implantes, quando comparadas com regiões anteriores (TOLSTUNOV, 2007).

Ao considerar a região posterior da mandíbula é necessário considerar a influência do aspecto anatômico sobre a possibilidade do tratamento com implantes. Por essa região passa um canal vásculo-nervoso chamado alveolar inferior. Embora por esse canal passe a artéria alveolar inferior, a combinação de problemas relacionados à idade, adicionado a diminuição do fluxo arterial, devido à perda dos dentes, torna a região desfavorável a colocação de implantes (TOLSTUNOV, 2007). Além disso, o canal limita o espaço vertical que pode ser utilizado para a colocação de implantes. Isso se torna especialmente importante em casos de perda óssea moderada a severa, com pequena altura óssea para a ancoragem de implantes.

Nesses casos, a colocação de implantes de comprimentos convencionais, pela técnica convencional, torna-se complexa e muitas vezes impossível. Com essas limitações, surgiram alternativas na implantodontia para o tratamento de mandíbulas atróficas, sendo as mais estudadas os enxertos ósseos, a distração osteogênica, a lateralização ou transposição do nervo alveolar inferior e o uso de implantes curtos. Contudo, essas duas últimas estão associadas a recentes avanços tecnológicos, que minimizam as suas desvantagens, atraindo especial atenção como alternativa para reabilitação da mandíbula posterior. 
A lateralização do nervo alveolar inferior, consiste numa técnica para reposicionar o feixe vásculo nervoso lateralmente, a fim de possibilitar o aproveitamento de toda a altura da mandíbula, sem trepanar o nervo durante a colocação do implante, e possui índices de sobrevivência semelhante a implantes colocados pela técnica convencional. Embora existam diversas variações do tratamento (BOVI, 2005; KAN, LOZADA et al., 1997; METZGER, BORMANN et al., 2006; PELEG, MAZOR et al., 2002; VASCONCELOS JDE, AVILA et al., 2008), essas podem ser divididas basicamente em dois tipos, chamadas técnica de lateralização e técnica de transposição do nervo.

A técnica de lateralização, consiste na osteotomia da região vestibular da zona posterior da mandíbula, a fim de criar uma janela ou acesso, soltar o feixe vásculo nervoso do osso periférico e tracioná-lo lateralmente com auxílio de algum dispositivo, no intuito de permitir a colocação de um implante de comprimento convencional, sem trepanar o nervo.

A técnica de transposição consiste numa osteotomia semelhante a da lateralização, mas estendendo-se até o forame mentual, conseqüentemente livrando o feixe em toda a sua extensão anterior e possibilitando o seu reposicionamento lateral, com menor força de tracionamento aplicada ao nervo.

Independente da técnica utilizada, perda sensorial temporária é normal no pós- cirúrgico (HIRSCH e BRANEMARK, 1995). Além disso, a fase cirúrgica exige alto grau de habilidade do profissional, para minimizar o dano ao nervo e evitar acidentes como sua secção.

Embora não seja uma técnica nova, já sendo descrita em 1987 (JENSEN e NOCK, 1987), essas dificuldades/limitações restringiram o seu uso, o que reflete no menor número de estudos, quando comparado com alternativas como implantes curtos. Entretanto, dois recentes avanços na terapia trouxeram maior interesse por, exatamente, minimizar essas dificuldades.

O primeiro seria a cirurgia piezo elétrica (BOVI, 2005). Com utilização de aparelho específico, essa técnica permite a realização da osteotomia, sem riscos ao feixe vásculo nervoso, uma vez que o aparelho seletivamente 
desgasta apenas tecidos mineralizados, com danos insignificantes a tecidos moles (EGGERS, KLEIN et al., 2004). Dessa forma, minimiza consideravelmente o risco de injúria ao nervo, bem como facilita o procedimento cirúrgico.

O segundo avanço se refere ao uso do laser de baixa potência no pósoperatório (KHULLAR, EMAMI et al., 1996), reduzindo o tempo de problemas sensoriais nos pacientes mesmo quando comparado com grupos tratados com placebo (KHULLAR, BRODIN et al., 1996). Essas inovações trouxeram nova atenção para a técnica, tornando-a mais acessível e viável, como alternativa, para colocação de implantes convencionais, na região posterior de mandíbulas atróficas.

Quanto aos implantes curtos, primeiro é necessário esclarecer que não existe uma convenção sobre a divisão de implantes entre curtos ou convencionais, sendo comum a divergência entre opiniões (DAS NEVES, FONES et al., 2006). Embora alguns autores citem comprimentos de até 10 mm (TAWIL e YOUNAN, 2003; TESTORI, WISEMAN et al., 2001; WENG, JACOBSON et al., 2003), outros autores preferem citar implantes de sete $\mathrm{mm}$ ou menos como implantes curtos (FRIBERG, GRONDAHL et al., 2000; FRIBERG, JEMT et al., 1991; JOHNS, JEMT et al., 1992).

Quando do início do seu uso, apresentavam índices de sobrevivência menores que implantes de comprimento convencional (NAERT, KOUTSIKAKIS et al., 2002; WENG, JACOBSON et al., 2003; WINKLER, MORRIS et al., 2000), contudo, os resultados se aproximaram quando implantes com novos desenhos e tratamentos de superfície, que melhoram a área de contato osso implante, foram utilizados (BROCARD, BARTHET et al., 2000; CHIAPASCO, FERRINI et al., 2006; FISCHER e STENBERG, 2006; ROMEO, GHISOLFI et al., 2006; STELLINGSMA, RAGHOEBAR et al., 2004). Embora sejam escassos os trabalhos de longo prazo utilizando esses novos implantes, com essas evoluções os implantes curtos encontraram resultados satisfatórios, quando considerados pacientes que passaram por critérios de seleção rigorosos, 
excluindo fatores de risco a implantes, excluindo até mesmo pacientes sob situação de stress (MALO, DE ARAUJO NOBRE et al., 2007).

Porém, muitas dessas pesquisas não utilizam critérios de sucesso, mas apenas a presença ou não do implante na boca, chamado de sobrevivência do implante. E mesmo as que utilizam critérios de sucesso (DEGIDI, PIATTELLI et al., 2007b; GOENE, BIANCHESI et al., 2005; GRANT, PANCKO et al., 2009; GRIFFIN e CHEUNG, 2004; NEDIR, BISCHOF et al., 2004; ROMEO, GHISOLFI et al., 2006; WENG, JACOBSON et al., 2003), esses critérios não foram adaptados a implantes curtos, podendo ser consideradas perdas ósseas aceitáveis em implantes convencionais, mas inaceitáveis em implantes curtos, devido à proporcionalidade que essa perda óssea representa em relação à área total de contato osso-implante.

Também, são limitados os trabalhos que consideram outros fatores de risco associados, que podem diminuir o índice de sucesso dos implantes curtos, quando comparados com implantes convencionais, sendo, inclusive, citado por alguns autores que, embora o implante curto represente um fator de risco, os índices de sucesso só são comprometidos quando associado a outros fatores de risco presentes (DAS NEVES, FONES et al., 2006). Somado ao fato que nem sempre o profissional dentista se encontra com pacientes ideais, como os atendidos nas pesquisas, essa falta de informação cria dúvidas quanto à indicação desses implantes.

Dessa forma, o profissional tem duas opções de tratamento interessantes para a reabilitação posterior de mandíbulas atróficas. Contudo, devido à ausência de estudos comparativos, principalmente os associados a fatores de risco, muitas vezes o cirurgião se vê em dúvida sobre qual tratamento indicar para determinado paciente, que atenda melhor suas necessidades. Nesse caso, a análise do impacto dos fatores de risco individualmente, trará grande contribuição para o entendimento e indicação dos tratamentos analisados.

Dentre os diversos fatores de risco existentes que afetam o prognóstico de uma reabilitação com implantes, o fator mecânico se destaca não só devido 
às possibilidades de fratura dos componentes, mas principalmente, pela perda óssea ao redor dos implantes, ambas levando ao fracasso do tratamento. Um método que permite essa comparação de forma controlada, sem incorrer em riscos aos pacientes é a simulação computacional por meio do Método dos Elementos Finitos, que consiste na construção de um modelo computacional representativo da situação real a ser analisada, que, com o uso de metodologia específica, permite prever mecanicamente o que acontece a determinada estrutura sob determinado estímulo.

Como exemplo, podemos citar a construção de diferentes reabilitações implanto suportadas e verificar seu funcionamento sob diversas condições, examinando qual delas tem melhor desempenho. Entre outras possibilidades, a análise com elementos finitos permite a quantificação das tensões e deformações internas de um corpo, possibilitando assim uma análise quantitativa, além da qualitativa, dos diferentes tratamentos discutidos. Dessa forma, fornece critérios e informações, que auxiliam o profissional na escolha da melhor opção de tratamento para determinado paciente.

Portanto, o estudo comparativo entre implantes convencionais colocados pela técnica de lateralização e implantes curtos trará fundamentação teórica, antes inexistente, dentro do conhecimento do autor, para a escolha do melhor tratamento, quando considerados tratamentos em dois estágios, com espera no tempo de reparo ósseo e osseointegração dos implantes. Ao analisarmos a literatura sob a viabilidade da lateralização sob um protocolo de carga imediata, dentro do conhecimento do autor, verifica-se a inexistência de estudos sobre o tema, não só comparativos, mas mesmo estudos que considerem a sua viabilidade.

Embora a carga imediata, nessas condições, não deva ser usada, por enquanto, por motivo de cautela, o estudo dessa possibilidade, com uma metodologia que não traga riscos a pacientes, não só permitirá a comparação entre técnicas, a semelhança da técnica de dois estágios, como fornecerá indícios importantes sobre a possibilidade do uso da carga imediata na 
lateralização. Isso justificará, dependendo do resultado, a evolução das pesquisas sobre o tema, com estudos animais e futuramente em humanos.

Torna-se importante, dessa maneira, a comparação entre as duas técnicas, para auxiliar o cirurgião na escolha da melhor opção, que ofereça o melhor prognóstico, para determinado caso. Similarmente, verificar a viabilidade de uma nova proposta de tratamento, como a lateralização com carga imediata, é igualmente importante, devido às possibilidades que essa técnica poderá oferecer para a reabilitação de desdentados na região posterior. 


\section{Revisão}

Para facilitar a consulta, a revisão foi dividida em tópicos, sendo que o tópico "diversos", foi colocado para abranger artigos imprescindíveis que não se encaixavam nos demais temas.

\subsection{Diversos}

Em 2002, Yokoyama e colaboradores publicaram um estudo in vitro, analisando a superfície e características metalúrgicas de um parafuso para implante dentário fraturado, de titânio, e compararam a um parafuso novo. Através de cromatografia gasosa, verificaram também a quantidade de hidrogênio absorvida pelo parafuso fraturado. Os resultados demonstraram grande quantidade de hidrogênio absorvida pelo titânio, que diminuiu sua capacidade dúctil, tornando-o material friável/frágil. A análise, com microscópio eletrônico de varredura, demonstrou várias defeitos no parafuso fraturado, compatíveis com defeitos causados por tensões de cisalhamento, todos localizados no ângulo superior entre rosca e corpo do parafuso. Um novo teste, colocando um novo parafuso, numa solução que induz a absorção de hidrogênio por um e 10 dias, modificou esse parafuso, resultando em propriedades semelhantes ao parafuso fraturado. Os autores concluíram que, a absorção de hidrogênio em um meio biológico, pode ser a razão de fratura precoce de componentes feitos com titânio. (YOKOYAMA, ICHIKAWA et al., 2002)

Em 2003, Winkler e colaboradores, publicaram uma revisão de literatura sobre o efeito de acomodação do parafuso em implantes dentários. Os autores descrevem esse efeito como resultante das faces não serem completamente lisas, o que evita o contato perfeito entre a superfície do parafuso com 0 implante e que uma parte da carga de torque é perdida devido à acomodação das tensões pelas estruturas. Os autores citam que fatores como, lisura de 
superfície, dureza superficial e intensidade das cargas afetam a intensidade do efeito. (WINKLER, RING et al., 2003)

Em 2003, Lang e colaboradores, publicaram um estudo, com o método de elementos finitos, analisando a pré-carga do parafuso nos implantes. Um implante unitário, de hexágono externo, com respectivo intermediário e dois parafusos, um de ouro e outro de titânio, foram modelados. Numa primeira etapa, foram submetidos a torques de 0 a $64 \mathrm{~N} / \mathrm{cm}$, em incrementos de um $\mathrm{N} / \mathrm{cm}$. Nas primeiras simulações o coeficiente de fricção foi ajustado em 0,2 para o contato entre parafuso de titânio e implante e 0,26 para o contato entre parafuso de ouro e titânio. Na segunda etapa, o mesmo foi realizado, mas o coeficiente de fricção foi ajustado para 0,12 entre o parafuso e o implante. Os resultados demonstraram que, considerando os coeficientes de fricção utilizados, um torque recomendado de $32 \mathrm{~N} / \mathrm{cm}$ gerou pré-carga menor que o indicado para balancear a resistência com a retenção do parafuso e que para essa intensidade de torque ser adequada, um coeficiente de fricção de 0,12 é necessário. (LANG, KANG et al., 2003)

Em 2004, Engelke e colaborados, publicaram um estudo in vitro, avaliando a micromovimentação de implantes dentários, através de um endoscópio de contato. Dez implantes de 3.75 de diâmetro por 15 de comprimento foram analizados, em 10 amostras de osso bovino, do tipo II (quatro amostras), III (três amostras), e IV (três amostras), segundo a classificação de Lekholm e Zarb, sob cargas horizontais de 5 a $30 \mathrm{~N}$ de intensidade. Os resultados demonstraram que a densidade óssea é inversamente proporcional e a carga diretamente proporcional a micromovimentação. Os autores concluíram que a endoscopia de contato pode ser utilizada dentro da fase operatória, para avaliação da micromovimentação do implante. (ENGELKE, DECCO et al., 2004)

Em 2007, Singh e Dahotre, publicaram uma revisão de literatura sobre o processo de corrosão em biomateriais. Em especial discutiram o processo nas ligas de titânio utilizadas para fins terapêuticos. Os autores citam que, devido à presença de vários óxidos relativamente inertes na superfície as ligas de titânio 
são relativamente resistentes a corrosão, mesmo nas ligas sem tratamento de superfície. Entretanto, além das características dessa camada protetora de óxidos poder variar de liga para liga, demonstrada em diversos estudos com implantes, ela também é danificada com estímulos mecânicos, como o atrito. Sua regeneração também é lenta em ambientes in vivo, o que pode acelerar o processo de corrosão, principalmente em ambientes com alta concentração de $\mathrm{H}_{2} \mathrm{O}_{2}$, ou de certas proteínas. A constituição da liga de titânio utilizada, também pode afetar de forma significativa o processo de corrosão. Por fim, os autores discutem trabalhos relacionados a tratamentos de superfície nos parafusos para diminuir/minimizar o processo de corrosão, sem conclusões entretanto, sobre o tratamento de superfície ideal (SINGH e DAHOTRE, 2007)

Em 2008, Koyama e colaboradores, publicaram um estudo in vitro, avaliando o efeito de forças compressivas sobre culturas de osteoblastos e seu efeito na expressão de citosinas que promovem a formação de osteoclastos e de seus receptores. As células foram cultivadas em soro fetal bovino modificado com e sem força compressiva contínua por 24 horas. Os níveis de citosinas foram avaliados através de PCR (polymerase chain reaction) em tempo real e de ELISA (Enzyme Linked Immuno Sorbent Assay) ou de pigmentação imunohistoquímica. Os resultados demonstraram que forças compressivas incitam a liberação de citosinas que estimulam a formação e função osteoclástica. (KOYAMA, MITSUI et al., 2008)

Em 2010, Hu e colaboradores, publicaram um estudo in vitro, avaliando o efeito da pressão contínua na função de osteoblastos. Para isso, aplicaram diferentes níveis de pressão estática em culturas de osteoblastos e compararam com uma cultura controle sem pressão. Os resultados demonstraram que, sob baixos níveis de pressão (20 kPa) a função osteogênica foi aumentada; em pressões intermediárias (50-100 kPa) a proliferação era inibida e apoptose era estimulada, mas os níveis celulares eram mantidos. Índices maiores de pressão (250-500 kPa) inibiram completamente a proliferação celular e induziram a necrose. Os autores também detectaram que vários genes, que participam da formação óssea, tinham sua produção aumentada em baixos níveis de pressão, mas suprimidos 
nos níveis mais altos. Os autores concluíram que altos níveis de pressão periprotética podem inibir a osteogênese e estimular a osteoclastogênese. (HU, WANG et al., 2010)

\subsection{Implantes curtos}

Em 1998, Bruggenkate e colaboradores, publicaram um estudo clínico multicentro, avaliando o desempenho de 253 implantes ITI, tratados com spray de plasma, com seis mm de comprimento, colocados em 126 pacientes por um período de um a sete anos. Nenhum dos pacientes tinha doenças sistêmicas "sérias", tratamentos prévios com radiação, alcoolismo ou abuso de drogas. Um total de sete implantes foram perdidos durante o período, resultando num índice de sobrevivência absoluto de $97 \%$, e relativo, quando o prognóstico do implante era ruim mesmo após tratamentos de intervenção, de 93,8\%. (TEN BRUGGENKATE, ASIKAINEN et al., 1998)

Em 2003, Weng e colaboradores, publicaram um estudo prospectivo multicentro, de 1179 implantes lisos, com comprimentos de 7 a $18 \mathrm{~mm}$, em 493 pacientes tratados com protocolo de dois estágios, e acompanhados por um tempo médio de 72 meses $( \pm 6,4)$. Os resultados demonstraram um índice de sucesso de $91,1 \%$ após seis anos. Ao separar os implantes de $10 \mathrm{~mm}$ ou menos dos de maior comprimento, obteve-se uma taxa de sucesso de $89 \%$ para os implantes com $10 \mathrm{~mm}$ ou menos de comprimento e $93,1 \%$ para os implantes de maior comprimento. Os autores concluíram que os implantes de menor comprimento e lisos do estudo tem maior índice de falhas que implantes convencionais. (WENG, JACOBSON et al., 2003)

Em 2003, Pierrisnard e colaboradores, publicaram um estudo com o método de elementos finitos tridimensional, avaliando o comprimento de implantes dentários e a ancoragem periimplantar, mono ou bicortical. Modelos de implantes com diâmetro de 3.75 mm e comprimento de 6, 7, 8, 9, 10,11 e 12 $\mathrm{mm}$ foram modelados e uma carga de $100 \mathrm{~N}$, com vetor de $30^{\circ}$ em relação ao plano oclusal foi simulada. Note que, na avaliação dos resultados, os autores 
consideraram as tensões de compressão como determinantes no processo de remodelação óssea, embora não forneceram nenhum embasamento para tal escolha. Os resultados, quanto ao osso periimplantar, demonstraram progressiva, mas pequena, diminuição nas tensões no osso periimplantar com aumento do comprimento dos implantes, e diminuição ainda maior quando o implante teve ancoragem bicortical. Quanto aos parafusos, tanto o aumento do comprimento quanto a bicorticalidade aumentaram os picos de tensões. Os autores concluíram que as tensões máximas no osso foram virtualmente constantes, independente do comprimento e ancoragem do implante e que o uso de implantes curtos deve ser encorajado em casos selecionados. Entretanto, cautela deve ser utilizada ao avaliar esses resultados, devido aos modelos e simulações lineares simplificadas, que pode alterar os resultados. A falta de análises de convergência para garantir precisão da malha, e os critérios de avaliação, onde o autor não defendeu/citou o porquê da utilização ou como exatamente foi calculado esse critério para as tensões ósseas periimplantares também podem alterar o resultado. (PIERRISNARD, RENOUARD et al., 2003)

Em 2004, Hagi e colaboradores, publicaram uma revisão de literatura sobre trabalhos utilizando implantes dentários curtos ( $\leq$ sete $\mathrm{mm}$ ), em pacientes parcialmente desdentados. Dos diversos estudos, 12 foram selecionados para a revisão, sendo 8 sobre implantes lisos rosqueados, 2 sobre implantes com tratamento de superfície a base de ataque ácido com roscas e 2 com superfície do tipo porosa sinterizada, mas sem roscas. A revisão revelou que os implantes lisos têm índice de fracasso maior que os com tratamento de superfície e, com exceção dos trabalhos com implantes com superfície porosa sinterizada sem roscas, implantes com sete $\mathrm{mm}$ de comprimento tem índice de fracasso maior que implantes de maior comprimento. Os autores concluíram que os tratamentos de superfície e o design do implante tem grande importância no tratamento com implante de sete $\mathrm{mm}$ e que mais estudos são necessários sobre o tema. (HAGI, DEPORTER et al., 2004) 
Em 2004, Nedir e colaboradores, publicaram um estudo prospectivo, sobre 528 implantes, com tratamento de superfície, colocados em 236 pacientes, com implantes variando o comprimento entre 6 a $13 \mathrm{~mm}$. Não foram relatados critérios de seleção dos pacientes, a não ser bom estado de saúde geral. Dentre os pacientes, havia bruxistas, fumantes, pacientes com risco médico como HIV ou diabetes controlada. Os resultados demonstraram uma taxa de sobrevivência cumulativa de 99,4\%, sem diferença significativa entre implantes menores que $10 \mathrm{~mm}$ e maiores. É importante ressaltar que, embora o controle tenha atingido até três anos, menos da metade dos pacientes teve o controle por um ano ou mais. Os autores concluíram que reabilitações com implantes curtos são tratamentos seguros e previsíveis. (NEDIR, BISCHOF et al., 2004)

Em 2005, Petrie e Williams, publicaram um estudo com o método de elementos finitos tridimensional, avaliando a influência do diâmetro, comprimento e conicidade de implantes unitários, osseointegrados, sob cargas oblíquas. Para isso, construíram 16 modelos, variando o diâmetro entre 3.5 a seis $\mathrm{mm}$, o comprimento de 5.75 a $23.5 \mathrm{~mm}$ e a conicidade de zero a $14^{\circ}$. Considerando a deformação máxima principal como critério de risco, os resultados demonstraram que aumentos no diâmetro causaram reduções nas deformação de até 3,5 vezes, aumento do comprimento reduziram em até 1,65 vezes, e aumento na conicidade aumentaram a deformação em até 1,65 vezes. Os autores concluíram que, aumentar o diâmetro e o comprimento dos implantes gera as opções mais favoráveis, e que implantes curtos cônicos devem ser evitados, especialmente quando presente osso de baixa densidade. Deve-se ressaltar que os autores utilizaram modelos extremamente simplificados, com prótese e implante em um único corpo, sem roscas. (PETRIE e WILLIAMS, 2005)

Em 2005, Gentile e colaboradores publicaram um estudo retrospectivo de cohort, analisando o desempenho clínico por um ano de 172 implantes, sendo 45 deles com conexão do tipo cone Morse e seis $\mathrm{mm}$ de diâmetro por $5,7 \mathrm{~mm}$ de comprimento. Note que os autores não citam os critérios de inclusão/exclusão. Os resultados demonstraram que o tamanho dos implantes 
não foi associado ao índice de falha, sendo de 92,2\% para implantes curtos (6 x 5,7 mm) e 95,2\% para implantes convencionais. Com esses resultados, os autores concluíram que os implantes curtos tem resultados comparáveis a implantes convencionais, entretanto cautela deve ser utilizada ao analisar essa hipótese devido à desfavorável significância da mesma $(p=.95)$. (GENTILE, CHUANG et al., 2005)

Em 2005, Goené e colaboradores, em um estudo retrospectivo, analisaram o desempenho de 311 implantes, com tratamento de superfície, de sete e $8,5 \mathrm{~mm}$ de comprimento, por um período de três anos. Os resultados mostraram insucesso em 13 implantes, com um índice de sucesso de 95,8\%. Os autores concluíram que, com o advento dos tratamentos de superfície, não é necessário mais restringir a indicação dos implantes curtos para reabilitações orais. (GOENE, BIANCHESI et al., 2005)

Em 2006, Renouard e Nisand, publicaram uma revisão de literatura, sobre o impacto do comprimento e diâmetro de implantes dentários no índice de sobrevivência. Dos estudos analisados, 53 foram utilizados. Os autores encontraram um índice de fracasso maior em implantes usinados curtos ( $\leq$ oito $\mathrm{mm}$ ) quando comparados a implantes usinados de comprimento convencional. Entretanto ao analisar trabalhos de implantes com tratamento de superfície, os resultados dos implantes curtos foram semelhantes aos dos implantes convencionais. Considerando o diâmetro dos implantes, os autores encontraram índices de sobrevivência piores para implantes de maior diâmetro ( $\geq 4,5 \mathrm{~mm}$ ) em trabalhos mais antigos, mas índices de sobrevivência semelhantes quando melhores critérios de indicação e implantes de melhor design foram utilizados. Os autores concluíram que, desde que corretamente indicados, e com implantes modernos que possuem melhor design e tratamento de superfície, os implantes curtos ( $\leq$ oito $\mathrm{mm}$ ) e de maior diâmetro ( $\geq 4,5 \mathrm{~mm}$ ) tem resultados comparáveis a implantes com maior comprimento e diâmetro convencional. (RENOUARD e NISAND, 2006)

Em 2006, Romeo e colaboradores, publicaram um estudo retrospectivo avaliando 265 implantes, com tratamento de superfície, de diferentes diâmetros 
e com oito ou $10 \mathrm{~mm}$ de comprimento, em um período de acompanhamento de 3 a 14 anos. Para inclusão na pesquisa, os pacientes estavam com boa saúde geral, e não poderiam ter histórico de abuso de álcool e drogas, radioterapia, doença do rim ou fígado grave, quimioterapia para tumores durante o período da cirurgia, diabetes descontrolada, doenças periodontais, doenças na mucosa, higiene oral ruim, e a necessidade de suporte da prótese com implantes convencionais e curtos. Os resultados demonstram a saída de 23 pacientes com 42 implantes, resultando em 223 implantes controlados, sendo que desses, oito falharam, metade de cada comprimento. Os índices de sobrevivência foram de $97,9 \%$ para implantes de oito $\mathrm{mm}$ de comprimento e $97,1 \%$ para implantes de $10 \mathrm{~mm}$. Os autores concluíram que a variação no comprimento não afetou de forma significativa a sobrevivência dos implantes. (ROMEO, GHISOLFI et al., 2006)

Em 2006, Misch e colaboradores, publicaram um estudo retrospectivo multicentro, relatando a experiência de reabilitações com prótese parciais fixas, utilizando 745 implantes de sete e nove mm de comprimento em 273 pacientes, após um acompanhamento de um a cinco anos. Note que os estudos não citaram os critérios de exclusão dos pacientes. O estudo relatou que, dos 505 implantes com protocolo de dois estágios, houve perda de dois implantes com taxa de sobrevivência de $99,6 \%$ e dos 240 implantes com protocolo de um estágio (carga imediata) houve perda de quatro implantes com taxa de sobrevivência de 98,3\%. Os autores concluíram que, com a utilização de métodos para redução de tensões biomecânicas, implantes curtos podem ser indicados com alto índice de sucesso. (MISCH, STEIGNGA et al., 2006)

Em 2006, Arlin publicou um estudo retrospectivo, relatando a experiência com 630 implantes Strauman, com tratamento de superfície, em 264 pacientes, sendo desses 35 com seis $\mathrm{mm}$ de comprimento, 141 com oito $\mathrm{mm}$ de comprimento e 454 com 10 a 16 mm de comprimento, após dois anos de controle. Os critérios de exclusão dos pacientes, incluía diabetes descontrolada, alcoolismo e doenças sistêmicas. Tabagismo não foi considerado como contraindicação, mas os pacientes tinham orientação que o fumo poderia levar a perda dos implantes. Os resultados demonstraram taxa de 
sobrevivência de $94,3 \%$ para os implantes de seis $\mathrm{mm}, 99,3 \%$ para os de oito $\mathrm{mm}$ e $97,4 \%$ para os de 10 a $16 \mathrm{~mm}$. O autor concluiu que implantes curtos não estão associados à redução da sobrevivência após dois anos. (ARLIN, 2006)

Em 2006, Neves e colaboradores publicaram uma revisão de literatura analisando implantes de $7,0,8,5$ e $10 \mathrm{~mm}$ quanto à sobrevivência, considerando o tempo de perda do implante, e fatores de risco associados. Dos estudos considerados, 33 passaram pelos critérios de exclusão e foram analisados. Do total de 16344 implantes, relataram falha de 786 (4,8\%). Os autores relataram que $54,9 \%$ das falhas ocorreram antes do carregamento dos implantes. Quanto às possíveis causas atribuídas ao insucesso, 66,7\% foram devido à pobre qualidade óssea, 45,4\% a localização quanto à mandíbula ou maxila, $27,2 \%$ a sobrecarga oclusal, $24,2 \%$ devido à localização no maxilar e $15,1 \%$ a infecção. Quanto ao índice de fracasso, para implantes de $3.75 \mathrm{~mm}$ de diâmetro e sete $\mathrm{mm}$ de comprimento, encontraram índice de perda de 9,7\%, diminuindo para $6,3 \%$ para implantes de $10 \mathrm{~mm}$ de comprimento, com mesmo diâmetro. Para implantes de quatro $\mathrm{mm}$ de diâmetro o índice de fracasso foi de 7,5\% para implantes de sete $\mathrm{mm}$ de comprimento e 5,4\% para implantes de 10 $\mathrm{mm}$. Para implantes de cinco $\mathrm{mm}$ de diâmetro, o índice de perda foi de $28,6 \%$ para implantes com sete $\mathrm{mm}$ de comprimento e 3,2 \% para implantes de 10 $\mathrm{mm}$ de comprimento. Os autores concluíram que implantes curtos devem ser considerados como uma alternativa a cirurgias de maior morbidade. (DAS NEVES, FONES et al., 2006)

Em 2007, Degidi e colaboradores, publicaram em estudo retrospectivo relatando a experiência com 133 implantes, de 10 marcas diferentes, com diâmetro variando de 3,3 a 5,5 mm e comprimento de 6,5 a $10 \mathrm{~mm}$, colocados com protocolo de carga imediata, e acompanhados por uma média de quatro anos. Os critérios de exclusão incluíam: volume ósseo insuficiente, alto nível de bruxismo, fumar mais que 20 cigarros por dia, consumo excessivo de álcool, radioterapia na região oral, quimioterapia antitumor, doenças do sangue, rim e fígado, imunossupressão, uso de corticóides, gravidez, doenças orais inflamatórias e auto-imunes, e higiene oral ruim. Os autores relataram perda de 
apenas três implantes, demonstrando taxa de sobrevivência de 97,7\%, mas a análise estatística não associou nenhuma característica específica ao índice de sobrevivência. Quando considerado a perda óssea da crista, os autores encontraram que implantes de maior diâmetro $(>3.75 \mathrm{~mm}$ ) e de maior comprimento (= a $10 \mathrm{~mm}$ ) tiveram perda óssea na crista menor que os demais implantes. Os autores concluíram que implantes curtos, com protocolo de carga imediata, têm índices de sobrevivência similares a implantes de dois estágios, mas que maior perda óssea na crista pode ser esperada quando implantes estreitos $(\leq 3.75 \mathrm{~mm}$ ) e curtos $(<10 \mathrm{~mm}$ ) forem utilizados. (DEGIDI, PIATTELLI et al., 2007a)

Em 2007, Degidi e colaboradores, publicaram um estudo retrospectivo avaliando 304 implantes, sendo 150 colocados com protocolo de dois estágios e 154 com carga imediata, com diâmetros entre cinco a 6,5 mm e comprimento variando entre 8 a $15 \mathrm{~mm}$, em 205 pacientes. Note que os autores citam quatro marcas de implantes, mas não mencionam se possuem ou não tratamento de superfície e a conexão utilizada. Os critérios de exclusão incluíam: volume ósseo insuficiente, alto nível de bruxismo, fumar mais que 20 cigarros por dia, consumo excessivo de álcool, radioterapia na região oral, quimioterapia antitumor, doenças do sangue, rim e fígado, imunossupressão, uso de corticóides, gravidez, doenças orais inflamatórias e auto-imunes, e higiene oral ruim. Os resultados mostraram que, em relação à sobrevivência, apenas cinco implantes falharam e nenhuma diferença foi detectada entre as variáveis, portanto, com sobrevivência de $98,4 \%$, Entretanto ao se analisar perda óssea na crista, implantes de diâmetro intermediário $(5,5 \mathrm{~mm})$, menor comprimento (menor que $13 \mathrm{~mm}$ ) e na região posterior estavam relacionados a menores índices de perda óssea. Os autores concluíram que a utilização de implantes de maior diâmetro é uma alternativa de tratamento viável para reabilitações orais, embora eles não devam ser utilizados na região anterior. (DEGIDI, PIATTELLI et al., 2007b)

Em 2007, Malo e colaboradores, publicaram um estudo retrospectivo relatando a experiência com 408 implantes, colocados com protocolo de carga imediata, com comprimentos de sete e $8,5 \mathrm{~mm}$, em 237 pacientes, após um 
período de acompanhamento de até cinco anos. Desses, 272 implantes são de superfície lisa, e 136 possuem tratamento de superfície. Os autores citam que além dos critérios normalmente utilizados para exclusão de terapia com implantes, foram excluídos os pacientes com imunodeficiência patológica, bruxismo, situação de stress (social ou profissional), instabilidade emocional e exigência estética não realística. Os resultados demonstraram que 14 dos implantes falharam após um período de acompanhamento de cinco anos, sendo todos eles de superfície lisa. Os autores concluíram que implantes curtos podem ser uma opção de tratamento viável, especialmente quando implantes com tratamento de superfície são utilizados. (MALO, DE ARAUJO NOBRE et al., 2007)

Em 2009, Grant e colaboradores, publicaram um estudo retrospectivo sobre 335 implantes de oito $\mathrm{mm}$ de comprimento, com diâmetros variando entre 3,5 a seis $\mathrm{mm}$, colocados em 124 pacientes na região posterior da mandíbula. Os autores não relataram os critérios de inclusão/exclusão dos pacientes. Todos os implantes foram tratados segundo protocolo de dois estágios. Apenas quatro implantes falharam após um período de controle de dois anos, sendo três desses de um único paciente que era tabagista compulsivo, resultando num índice de sucesso de 98,8\%. Os autores concluíram que implante curto é um tratamento previsível para pacientes com perda óssea na região posterior da mandíbula. (GRANT, PANCKO et al., 2009)

Em 2009, Kotsovilis e colaboradores, publicaram uma revisão sistemática de literatura, avaliando a sobrevivência entre implantes com tratamento de superfície com oito $\mathrm{mm}$ ou mais, mas menores que $10 \mathrm{~mm}$, comparada a sobrevivência com implantes de $10 \mathrm{~mm}$ ou mais de comprimento. Do total de artigos analisados, 22 estudos de cohort em 37 artigos foram selecionados. A análise estatística não encontrou diferença estatisticamente significante na sobrevivência dos dois grupos. Os autores concluíram que a colocação de implantes com tratamento de superfície entre oito e $10 \mathrm{~mm}$ não constitui uma modalidade de tratamento menos eficaz que implantes de maior comprimento. (KOTSOVILIS, FOURMOUSIS et al., 2009) 


\subsection{Lateralização do nervo alveolar inferior}

Em 1994, Rosenquist relatou, em um estudo retrospectivo, a experiência com 100 casos de transposição do nervo alveolar inferior, utilizando 250 implantes lisos e protocolo de dois estágios. Note que os autores não citaram os critérios de exclusão de pacientes na pesquisa. A pesquisa relatou índice de sobrevivência de 93,6\% após 18 meses da cirurgia, com acompanhamento de 72 pacientes. $\mathrm{O}$ autor concluiu que o método é uma alternativa cirúrgica útil, e que o procedimento está indicado em casos selecionados. (ROSENQUIST, 1994)

Em 1995, Hirsch e Branemark, publicaram um estudo retrospectivo, relatando a experiência com lateralização e transposição do nervo alveolar inferior. Nesse estudo, 63 implantes foram colocados, sendo 18 anteriores ao forame e 45 posterior. Note que os autores não citaram o tipo de implante utilizado. Dos 17 implantes colocados posterior ao forame na técnica de transposição, quatro falharam, resultando num índice de sobrevivência de $76,5 \%$ e dos 28 implantes colocados posterior ao forame pela técnica de lateralização, nenhum falhou. Os autores concluíram que dentre as técnicas analisadas, a lateralização é o método de escolha para tratamento de mandíbulas atróficas na região posterior. (HIRSCH e BRANEMARK, 1995)

Em 2005, Ferrigno e colaboradores, relataram em um estudo retrospectivo, a experiência com 19 cirurgias de transposição utilizando 46 implantes Straumann com tratamento de superfície, e acompanhamento de 12 a 78 meses. Apenas pacientes saudáveis, que não tinham higiene oral pobre, bruxismo, tabagismo compulsivo, histórico de abuso de drogas ou álcool, histórico de radioterapia prévia, e histórico de perda de implantes dentários foram selecionados. A pesquisa relata um índice de sobrevivência de 95,7\% e de sucesso de $90,5 \%$. Os autores concluíram que a transposição do nervo alveolar inferior pode ser usada como opção no tratamento de mandíbulas extremamente reabsorvidas. (FERRIGNO, LAURETI et al., 2005) 
Em 2005, Bovi, em um relato de caso clínico, descreve uma variação da técnica de transposição, utilizando o aparelho de cirurgia piezoelétrica. $O$ autor relata a possibilidade de preparação de uma janela óssea vestibular de 5 a 6 $\mathrm{mm}$ de altura devido a segurança oferecida pelo aparelho piezoelétrico. $\mathrm{O}$ autor conclui que o dispositivo piezo elétrico pode ser útil, por permitir melhor controle cirúrgico durante a osteotomia (BOVI, 2005)

Em 2009, Chrcanovic e Custódio, em um estudo clínico retrospectivo, avaliaram o desempenho de 18 procedimentos de transposição do nervo alveolar inferior, colocando 25 implantes em 15 pacientes. Foi utilizada terapia com laser de baixa potência no póscirúrgico, para diminuir o tempo de recuperação sensorial dos pacientes. Dos 25 , três não osseointegraram, resultando num índice de sobrevivência de $88 \%$. Todos os pacientes tiveram recuperação sensorial completa num período de até seis meses. Note que não foram relatados os critérios de exclusão dos pacientes no trabalho. Os autores concluíram que a transposição do nervo alveolar inferior pode ser utilizada de forma segura e previsível, mas que meios alternativos também devem ser considerados. (CHRCANOVIC e CUSTODIO, 2009) 


\section{Justificativa}

Embora para tratamento da região posterior de mandíbulas atróficas, os implantes curtos ou implantes convencionais, colocados pela técnica de lateralização de nervo alveolar inferior, apresentem índices de sucesso encorajadores, dentro do nosso conhecimento, não existem estudos comparativos entre as duas metodologias.

Portanto, os resultados desta pesquisa podem ser decisivos na escolha, entre as técnicas pesquisadas, da melhor opção referente a um determinado paciente, auxiliando o cirurgião a indicar o melhor tratamento possível, favorecendo o prognóstico. Este fator, torna-se especialmente importante, ao salientarmos que as variações entre os dois tratamentos, não reside apenas na diferença de comprimento dos implantes, mas nas indicações clássicas de implantes de menor diâmetro e ancoragem bicortical, no caso do tratamento de lateralização, com implantes de maior diâmetro e ancoragem em uma cortical apenas, no caso dos implantes curtos.

Considerando que um dos principais fatores de risco está associado à sobrecarga mecânica, demonstrado parcialmente pelos menores índices de sucesso, com implantes dentais, em pacientes com bruxismo/apertamento (BALSHI e WOLFINGER, 1997; BRANEMARK, ENGSTRAND et al., 1999; GRUNDER, 2001; MALO, NOBRE MDE et al., 2006; MALO, RANGERT et al., 2005), a análise do fator de risco mecânico nas duas técnicas, pode ser decisivo na preservação do osso peri-implantar e da integridade estrutural das reabilitações.

Além da análise do osso periimplantar, em relação à integridade estrutural das reabilitações, especial atenção foi dada a análise do parafuso de conexão entre intermediário e implante, devido ao impacto que a fratura que esse tem no tratamento, podendo levar até a perda do implante. Dentro do nosso conhecimento, não existem estudos comparativos, com o método de elementos finitos, dessa natureza, considerando implantes curtos e convencionais. 


\section{Proposição}

\subsection{Objetivo geral}

Analisar a distribuição de tensões, em próteses parciais fixas de três elementos, suportadas por implantes, por meio de modelos geométricos tridimensionais, obtidos a partir de tomografias e simulação computacional pelo método dos elementos finitos tridimensional. Para efeito de comparação, foram simuladas próteses parciais fixas de três elementos, sobre implantes curtos e implantes convencionais colocados por técnica de lateralização do nervo alveolar inferior, tanto para implantes colocados sob protocolo de carga imediata quanto para implantes osseointegrados. Em especial, foram comparadas as tensões no osso periimplantar e nos parafusos de união entre o intermediário e implante.

\subsection{Objetivos específicos}

Verificar o tratamento que oferece a distribuição de tensões mais uniforme no osso periimplantar, tendo, portanto, menor risco de perda óssea por sobrecarga mecânica, em tratamentos de um (carga imediata) e dois estágios, tanto quando utilizados implantes de mesmo diâmetro, quanto implantes de indicação clássica de cada técnica, no caso, implantes de menor diâmetro nos tratamentos de lateralização, comparados a implantes de maior diâmetro nos tratamentos com implantes curtos.

Verificar o tratamento que oferece menor risco de fratura no parafuso que une intermediário ao implante, tanto em tratamentos de um (carga imediata), quanto de dois estágios.

Verificar a viabilidade do tratamento de lateralização do nervo alveolar inferior, quando realizado com protocolo de carga imediata. 


\section{Material e método}

Ao consideramos pesquisas com técnicas ou modificações de técnicas inovadoras, onde não se sabe a segurança do tratamento, como é o caso do tratamento com técnica de lateralização com carga imediata, é prudente a utilização de estudos que não incorram em riscos ao paciente, até mesmo para justificar a evolução da pesquisa e minimizar danos possíveis. Dessa forma, um método que permita avaliar diversos aspectos de um tratamento, como o Método dos Elementos Finitos, é indicado até mesmo eticamente.

A análise com elementos finitos constitui na construção de um modelo virtual, manualmente ou com auxílio de exames e registros, como uma tomografia computadorizada, por exemplo, representativo das estruturas e/ou situação a ser analisada. Com uso de software específico, que utiliza formulações matemáticas validadas, as diferentes estruturas analisadas são carregadas com propriedades reais, como módulo de elasticidade por exemplo, e o software calcula através das formulações mencionadas, o impacto que determinado estímulo acarreta no modelo proposto. Dessa forma, é possível a análise de diferentes estruturas, com riqueza de detalhes, uma vez que todas as características do processo são calculados/analisados no próprio software, fornecendo resultados, sem a necessidade de causar riscos a animais ou mesmo seres humanos.

\subsection{Reconstrução virtual de tomografia computadorizada}

Duas tomografias computadorizadas (I-CAT, Xoran Technologies, Ann Arbor, USA) foram utilizadas no presente trabalho. A primeira tomografia foi proveniente de um desdentado total, usada para confecção de guia cirúrgico em atendimento odontológico e teve o objetivo de fornecer a base óssea da região posterior da mandíbula. O exame de tomografia foi realizado analisando o terço ântero-inferior da face, com objetivo de analisar a região da mandíbula, em cortes transversais de 0,4 $\mathrm{mm}$ de distância, perfazendo um total de 139 
cortes. Esses cortes foram gravados no formato Dicom (digital imaging and communications in medicine standart) e importados para um programa de processamento de imagens e reconstrução digital (Invesalius 3.064 bits, Centro de Tecnologia de Informação Renato Archer, Brasil). Para essa tomografia, o programa reconstruiu digitalmente a mandíbula, resultando em um modelo tridimensional, como mostra a figura 1. Esse modelo foi dividido na porção do osso cortical, osso medular e feixe vásculo nervoso para facilitar o processamento futuro. O modelo foi salvo no formato STL (stereolithography, 3D Systems, Rock Hill, USA).

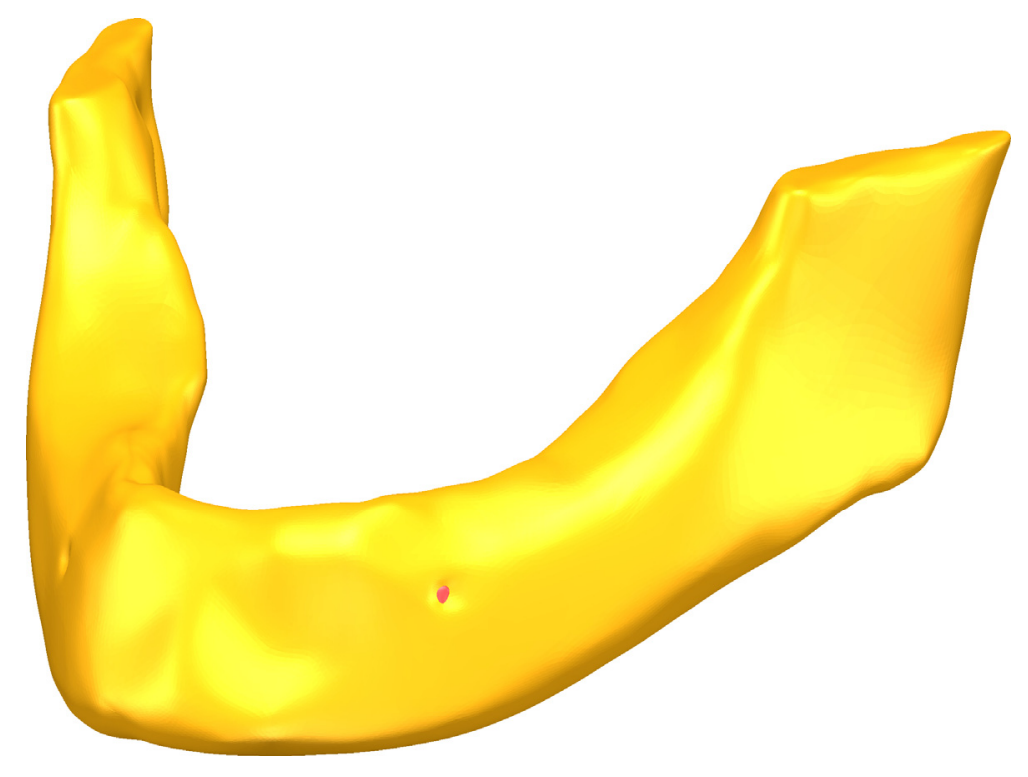

Figura 1: Reconstrução digital da mandíbula a partir de tomografia. Vista do osso cortical.

A segunda tomografia utilizada consistiu de um voluntário com todos os dentes na boca, com exceção dos $3^{\circ}$ molares e teve o objetivo de fornecer a forma dos dentes para futura confecção das próteses na simulação. O exame de tomografia foi realizado analisando o terço ântero-inferior da face, com objetivo de abranger a região da mandíbula, em cortes transversais de 0,25 $\mathrm{mm}$ de distância, perfazendo um total de 212 cortes. O processamento foi semelhante à primeira tomografia, resultando no modelo da figura 2 . 


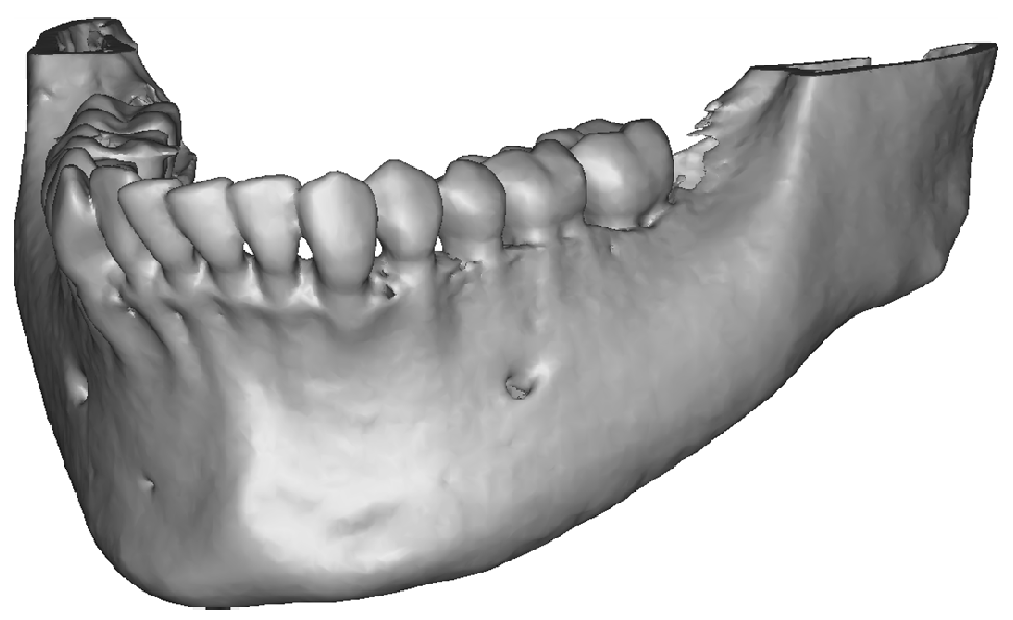

Figura 2: Reconstrução digital da tomografia para reconstrução dos elementos 35,36 e 37.

Desse modelo, foram extraídas as partes correspondentes aos dentes 35, 36 e 37 . Esses foram salvos no formato STL (stereolithography) para posterior processamento.

\subsection{Edição dos modelos}

Após a reconstrução virtual, os modelos 3D foram exportados para o software tipo CAD (Computer Aided Design) Solidworks 2009 (Dassault Systemes, Solidworks Corps, USA), para edição dos modelos virtuais. Para reconstrução de tomografias, os softwares específicos como o Invesalius reconstroem o modelo em uma malha de polifaces de superfície. Essas polifaces são exclusivamente triangulares e planas, e para definir um modelo com precisão adequada, muitas vezes são necessárias dezenas ou centenas de milhares de polifaces. Nos modelos, acima descritos, a mandíbula desdentada possui 273808 polifaces, sendo 98080 na superfície externa do osso cortical, 51226 polifaces no osso medular e 141416 polifaces no feixe alveolar inferior. Entretanto a maioria dos softwares tipo CAD, para edição dos modelos, não aceitam a importação de modelos com mais de 10 mil faces. $A$ simples diminuição do número de polifaces acarretaria em grande distorção dos modelos. 
Para resolver esse problema, foi utilizado um suplemento de importação do Solidworks chamado "Scan to 3D". Com ele é possível a transformação das polifaces em superfícies do tipo NURBS (Non Uniform Rational Basis Splines), para geração de modelos sólidos, tendo essas superfícies a capacidade de serem curvas e registrarem detalhes geométricos na própria face. Dessa forma, permitiu a drástica redução do número de superfícies necessárias, sem comprometer a precisão do modelo. A figura 3 mostra a transformação da superfície do osso cortical de 98080 polifaces em 110 faces NURBS e a figura 4 demonstra a grande distorção ocorrida quando simplesmente diminuídos o numero de polifaces. 
P á g in a

26

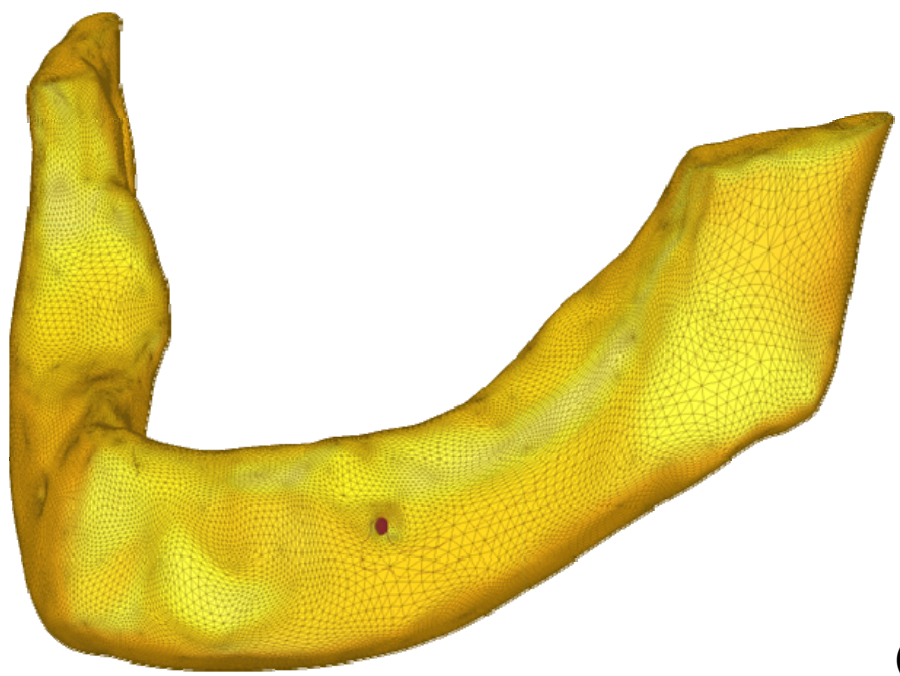

(A)

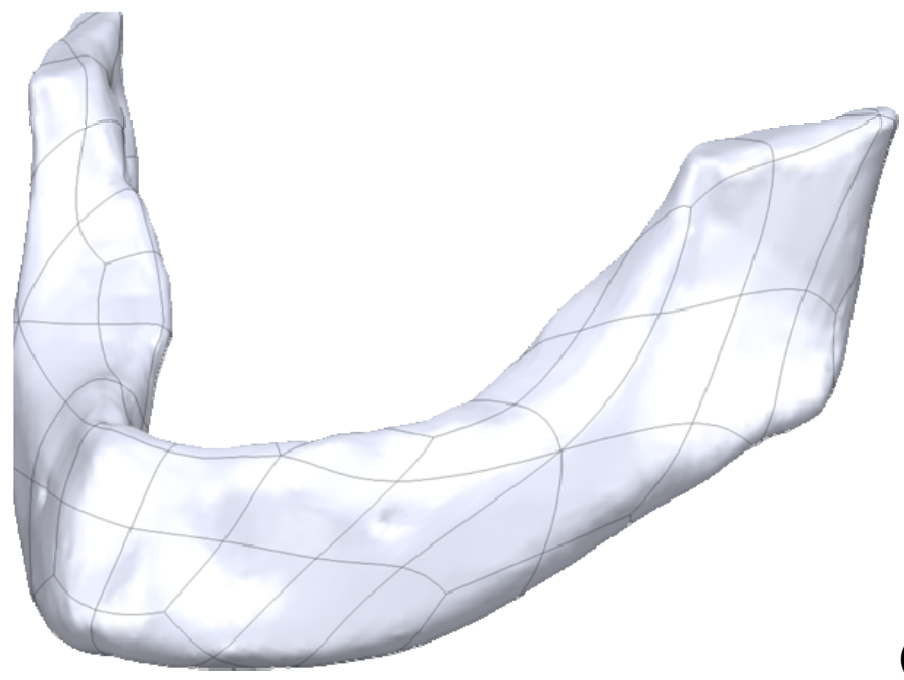

(B)

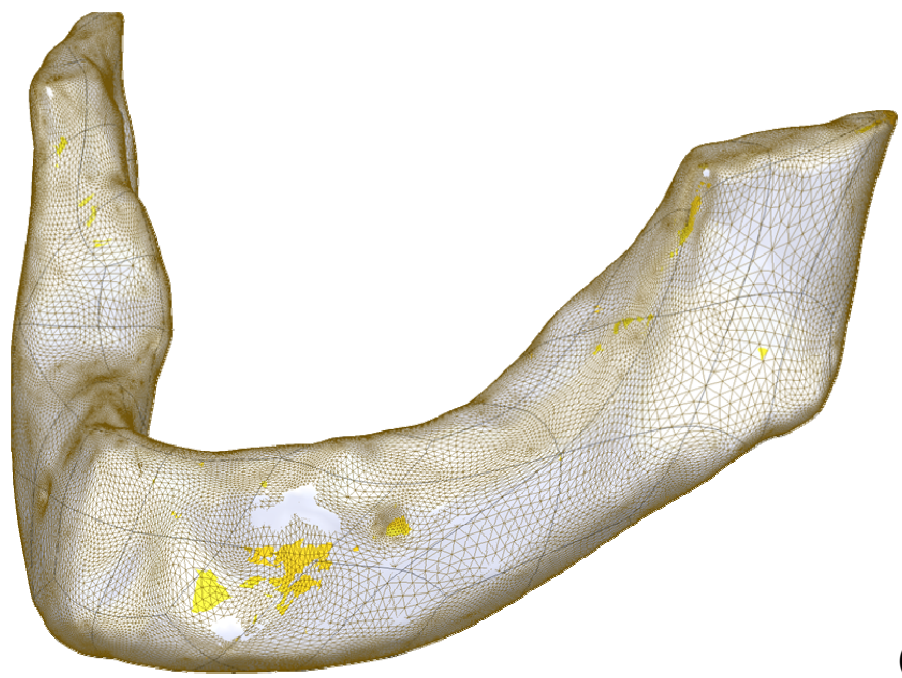

(C)

Figura 3: Transformação de um modelo com 98080 polifaces (A), em um modelo com 110 faces NURBS (B) e sobreposição dos dois modelos para demonstrar a mínima distorção ocorrida (C). Os modelos foram plotados com arestas para facilitar a visualização das faces. 


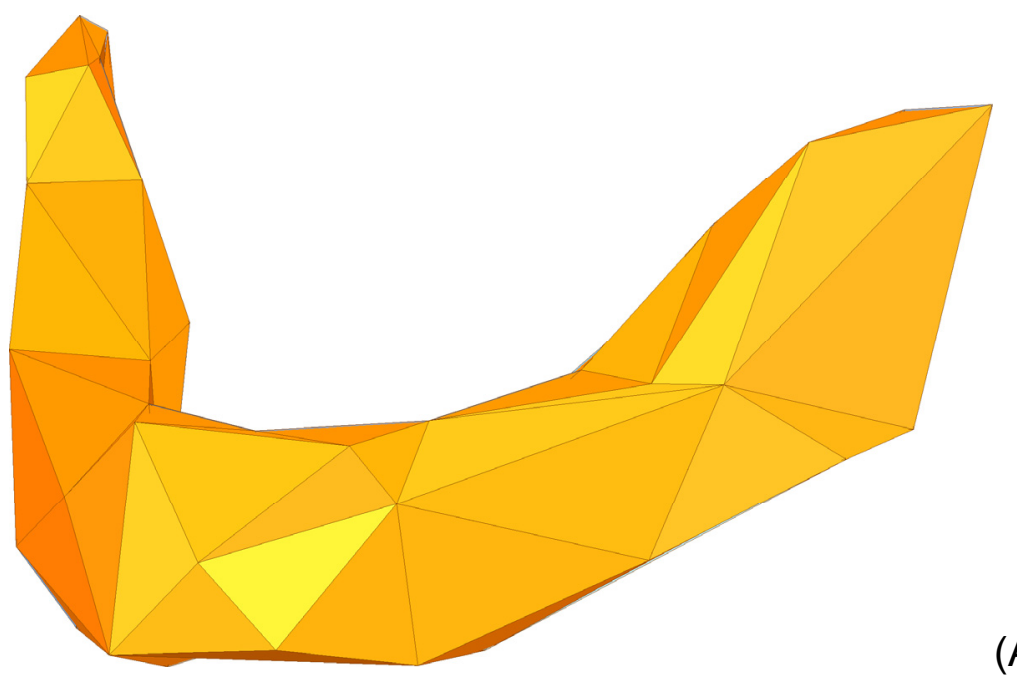

(A)

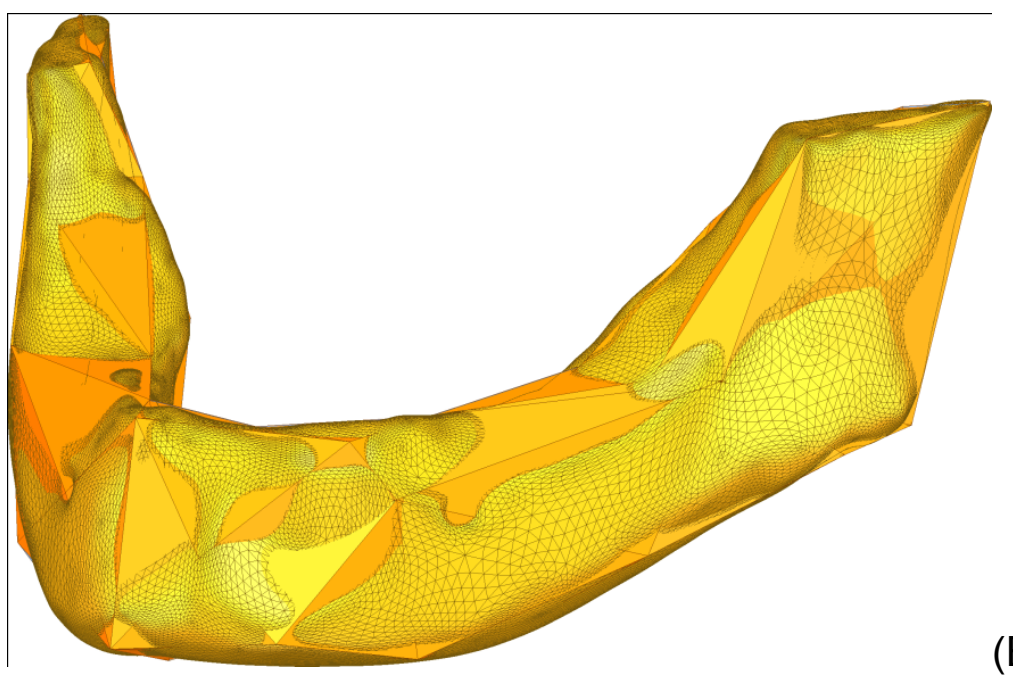

(B)

Figura 4: Exemplo da diminuição do modelo de 98080 polifaces para 110 polifaces (A), e os modelos sobrepostos demonstrando a grande distorção ocorrida (B). Os modelos foram plotados com arestas para facilitar a visualização das faces.

Os modelos provenientes da segunda tomografia sofreram processo semelhante a primeira. Sendo reconstruídos apenas os elementos 35,36 e 37, resultando em modelos como mostra a figura 5. 


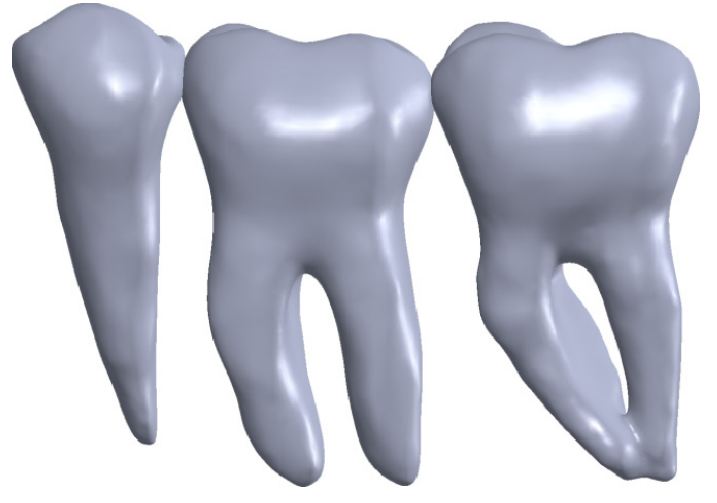

(A)

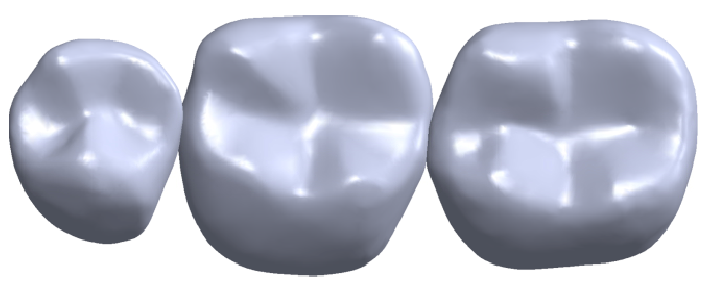

(B)

Figura 5: Reconstrução digital dos dentes 35,36 e 37. A: vista vestibular. B: vista oclusal.

Após processamento dos modelos de polifaces em modelos sólidos, as diferentes partes foram unidas como mostra a figura 6. Note que, com o intuito de construir um modelo padronizado, que evite beneficiar uma das técnicas, e também evitar a exposição desnecessária de mais pacientes à radiação do exame de tomografia, os modelos dos dentes tiveram sua escala de tamanho ajustada, de forma a preencher a região posterior da mandíbula, entre o forame mentual e a região retromolar. Para manter a proporção, o recurso de escala foi aplicado em igual valor nas três dimensões. Observe que, esses dentes foram utilizados para dar forma às coroas da prótese parcial fixa, onde normalmente um dos intuitos da escultura protética é preencher o espaço necessário da reabilitação, a semelhança da situação apresentada. 


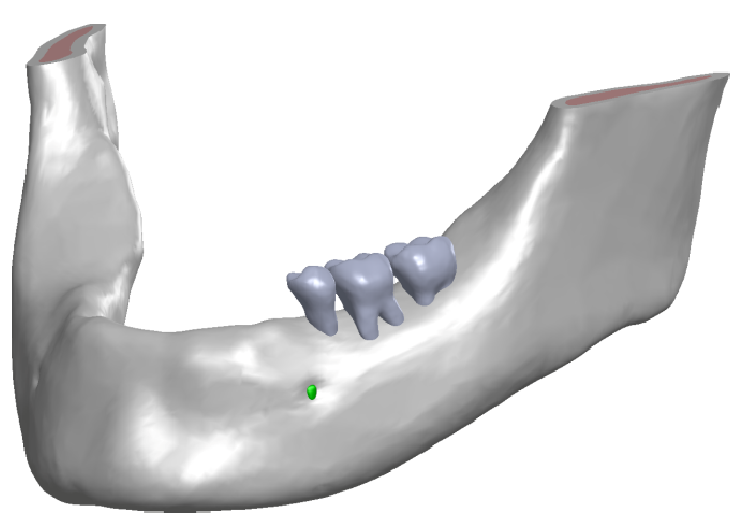

(A)

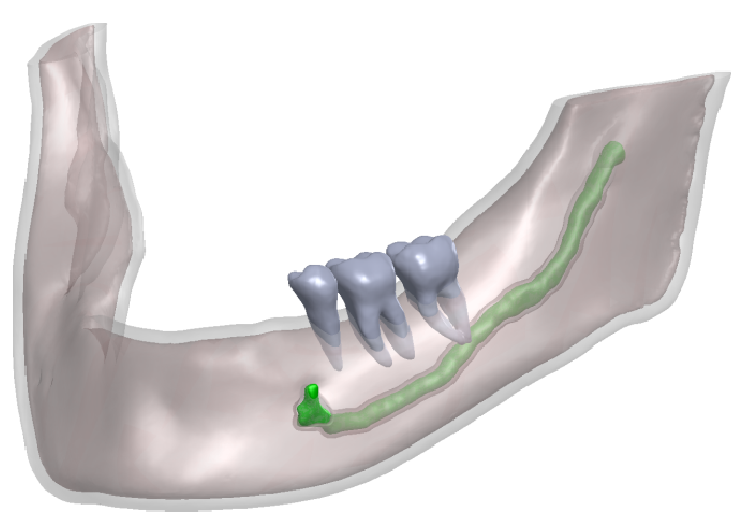

(B)

Figura 6: Reconstrução das duas tomografias em modelos sólidos. A: modelo total. B: osso cortical e medular semitransparente para facilitar a visualização do feixe vásculo nervoso.

Para padronização do rebordo ósseo e simulação de condição atrófica, que indicaria implantes curtos como os utilizados nesta pesquisa, os modelos foram cortados de forma a manter uma altura entre a superfície cortical da crista basal e o osso cortical que circunda o feixe vásculo nervoso de $8,5 \mathrm{~mm}$ aproximadamente, no ponto mais distal dos implantes colocados, sendo a superfície do osso cortado reeditado, com espessura de dois $\mathrm{mm}$ de osso cortical. Esse valor se deve ao fato de que o implante curto de sete $\mathrm{mm}$, na verdade, possui $6,5 \mathrm{~mm}$ de altura ao se desconsiderar a zona de perfuração da broca, com $0,5 \mathrm{~mm}$ a mais de comprimento, e que a distância mínima recomendada entre implante e nervo alveolar inferior é de aproximadamente dois mm para evitar danos ao nervo (GREENSTEIN e TARNOW, 2006). Essas alterações podem ser vistas na figura 7 . 


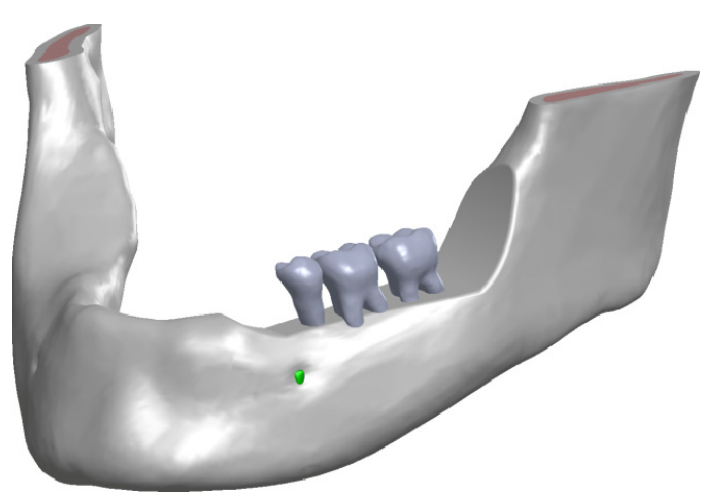

(A)

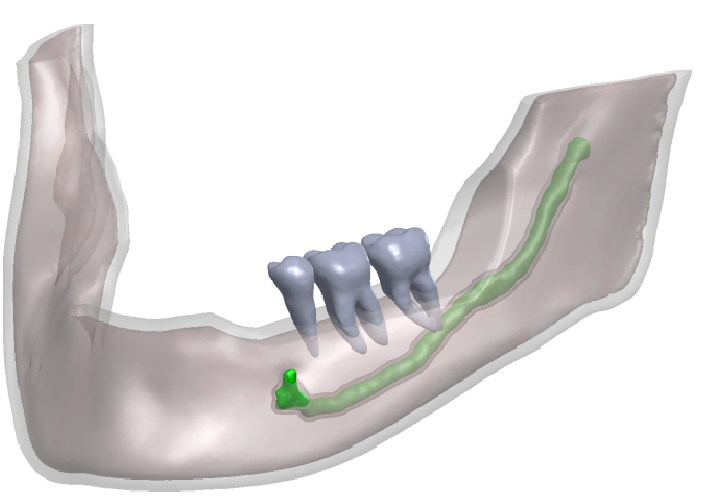

(B)

Figura 7: Mandíbula recortada para simulação de uma mandíbula atrófica. A: modelo total. B: osso cortical e medular semitransparente para facilitar a visualização do feixe vásculo nervoso.

Para diminuir o peso computacional, os modelos foram cortados dois $\mathrm{mm}$ antero mesial ao forame mentual esquerdo e três $\mathrm{mm}$ posteriormente a distal do elemento 37 . Um exemplo do segmento de mandíbula resultante pode ser visto na figura 8 .

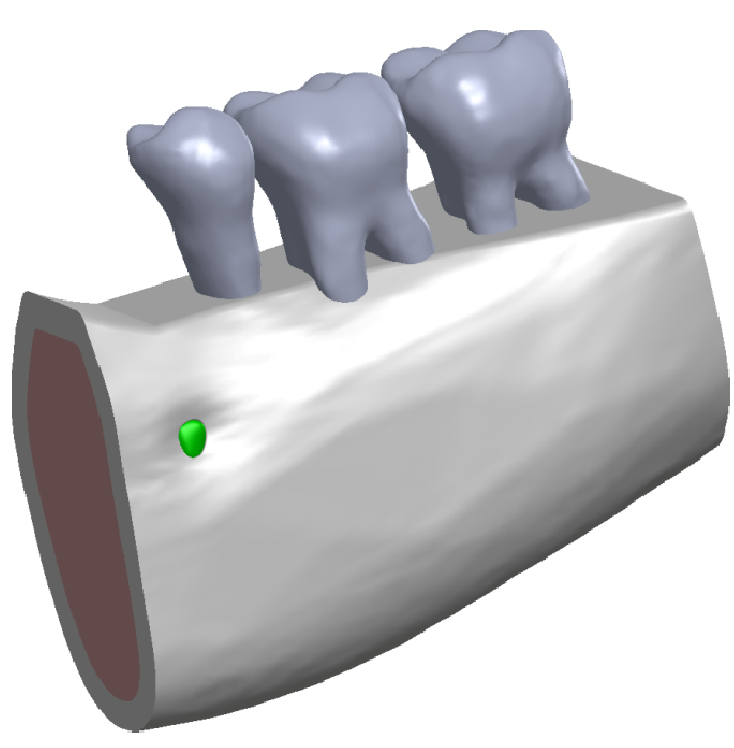

(A)

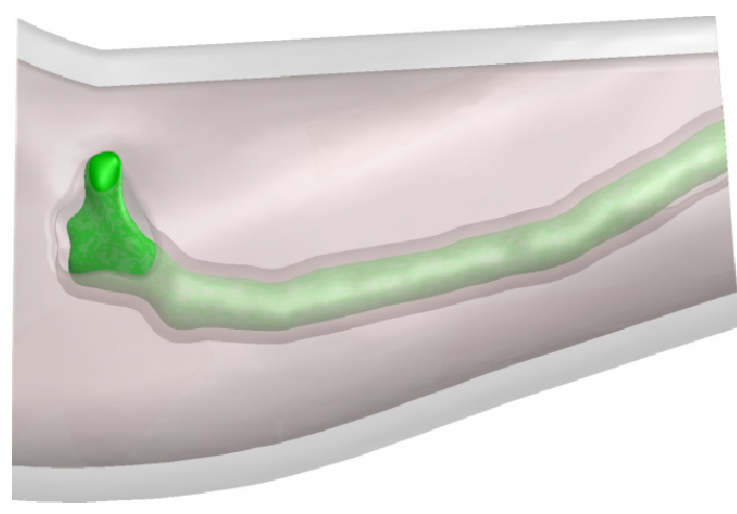

(B)

Figura 8: Vista do segmento de mandíbula seccionado que foi utilizado neste trabalho. B: osso cortical e medular semitransparente para facilitar a visualização da relação entre as estruturas.

Ainda no contexto de proporcionar um modelo que não favoreça 
nenhuma das técnicas analisadas, o trajeto do canal alveolar inferior foi alterado de forma a manter uma distância no sentido superior-inferior de dois $\mathrm{mm}$ dos futuros implantes curtos e ao mesmo tempo, proporcionar uma janela óssea padronizada, que afete a inserção óssea na região média dos implantes utilizados, nos modelos de lateralização do nervo alveolar inferior, como pode ser visto na figura 9. É importante ressaltar que o trajeto do canal mandibular é bastante variado na população e que o modelo final está dentro de padrões normais (LEVINE, GODDARD et al., 2007; WADU, PENHALL et al., 1997).

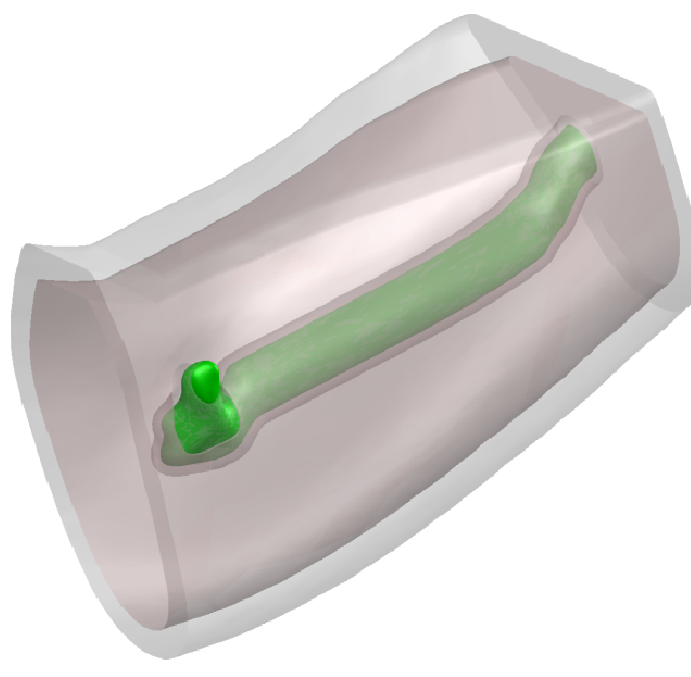

(A)

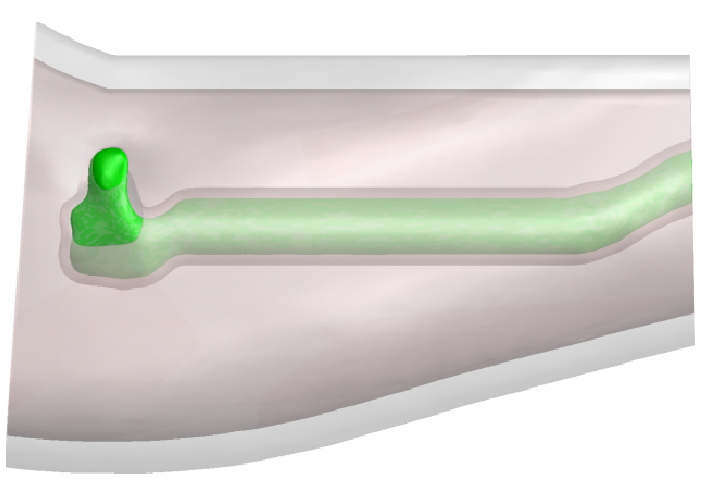

(B)

Figura 9: Vista do osso basal, com canal mandibular reeditado para não favorecer nenhuma das técnicas analisadas. $A=$ vista de perfil e $B=$ vista vestibular.

Foram modelados implantes e componentes protéticos, em conjunto com os modelos provenientes das tomografias, para simular uma prótese parcial fixa de três elementos, implanto-suportada e cimentada, tendo os elementos 35 e 37 como implantes pilares e o elemento 36 como pôntico. Para padronização do trabalho, todos os implantes e componentes protéticos foram baseados em produtos do fabricante Nobel Biocare AB (Goteburg, Sweden). Com exceção dos fatores de variação, todos os modelos possuem as seguintes características:

- Implantes do tipo Branemark Mk III, com conexão do tipo 
hexágono externo, de diâmetros e comprimentos variáveis dependendo do modelo, com a plataforma posicionada na altura da crista óssea, sendo o implante anterior posicionado três $\mathrm{mm}$ posterior ao forame mentual e o implante posterior no centro do elemento 37, com referência no plano oclusal. Os dois implantes foram posicionados paralelos, em relação ao seu longo eixo;

- Intermediário personalizável com conexão do tipo hexágono externo, plataforma variável de acordo com o modelo e porção superior cônica;

- Parafuso de titânio, com diâmetro variável de acordo com o modelo, e roscas apenas no terço inferior;

- Infraestrutura de cromo cobalto, com um mínimo de 0,3 mm de espessura sobre o intermediário, e de forma semelhante a coroa cerâmica;

- Porcelana feldspática recobrindo a infraestrutura e modelando a forma coronária da prótese, com um mm de espessura;

- Camada de cimento de fosfato de zinco, de aproximadamente 0,1 $\mathrm{mm}$ de espessura, entre as coroas e os intermediários (BELSER, MACENTEE et al., 1985; KARLSSON, 1993; MCLEAN e VON FRAUNHOFER, 1971; SULAIMAN, CHAI et al., 1997);

- Osso cortical recobrindo a superfície externa do osso e ao redor do feixe vásculo nervoso;

- Osso medular recobrindo as porções internas do osso cortical;

- Estrutura para simular o terço oclusal dos dentes antagonistas, nos modelos de carga axial, em porcelana feldspática, cilíndricas com um mm de diâmetro. com três pontos de contato por dente; na cúspide vestibular com um ponto na vertente vestibular e um na vertente lingual e na cúspide lingual com um ponto na vertente vestibular de cada elemento.

- Estruturas para padronizar a aplicação da carga oblíqua, em porcelana feldspática, cilíndricas com um $\mathrm{mm}$ de diâmetro, posicionadas na vertente lingual da cúspide vestibular 
Note-se que diversos modelos de simulações de análise com elementos finitos utilizam geometrias simplificadas, que muitas vezes podem comprometer os resultados da pesquisa. Isso é especialmente importante em simulações como a do presente estudo, que detalhes como as roscas do implante podem afetar significativamente o resultado. Por esse motivo, e para garantir uma simulação precisa, técnicas avançadas de reconstrução de tomografia das partes ósseas e engenharia reversa dos implantes foram realizadas a fim de replicar com precisão adequada as geometrias analisadas.

Para possibilitar a reconstrução fiel dos implantes e componentes protéticos, nesta pesquisa, implantes reais foram adquiridos e analisados através de paquímetro digital (Litz professional, Alemanha), com lupa de aumento (Bio Art, São Carlos, Brasil), e microscópio digital, modelo DM-130U, com aumento de 10x - 200X e software de mensuração proprietário (Miview, China). As figuras 10 a 18 mostram os equipamentos que foram utilizados para reconstrução, algumas mensurações realizadas no processo e os modelos obtidos. Note-se que a régua foi colocada apenas como referência. Para a calibração do microscópio, a fim de realizar as mensurações, partes de fácil mensuração, como o hexágono da figura 12 são mensurados com paquímetro digital e essa mensuração permite a calibragem do software de mensuração a fim de medir as demais características da estrutura. 


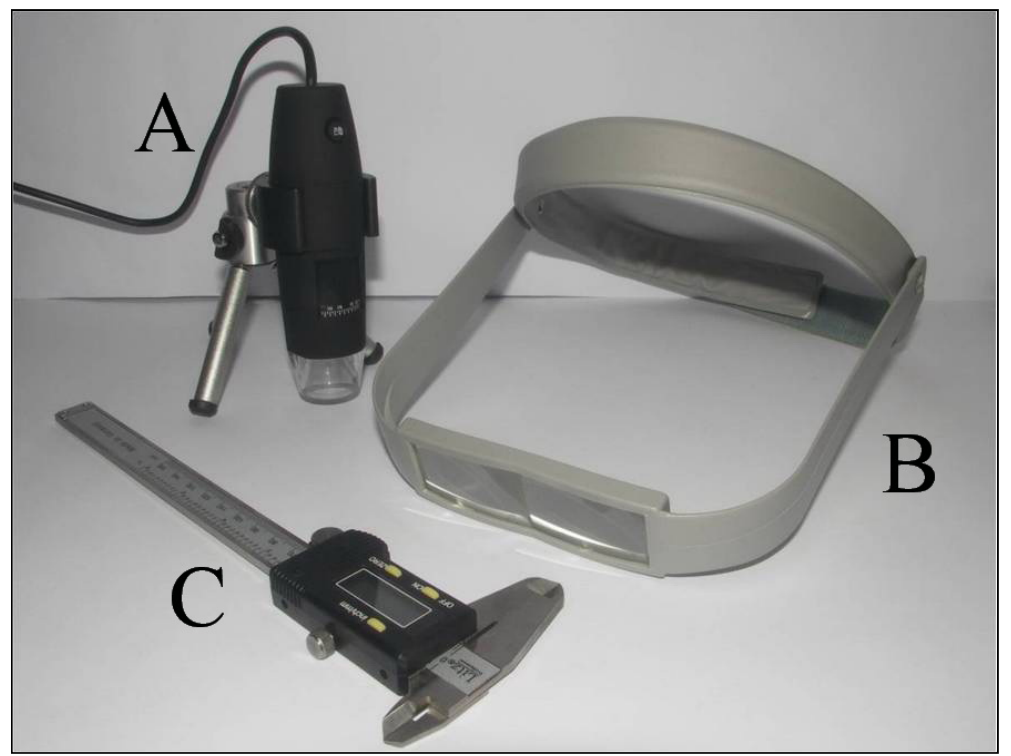

Figura 10: Materiais que foram utilizados para mensuração da geometria dos implantes e componentes protéticos. $A=$ microscópio digital, $B=$ lupa de aumento e $\mathrm{C}=$ paquímetro digital

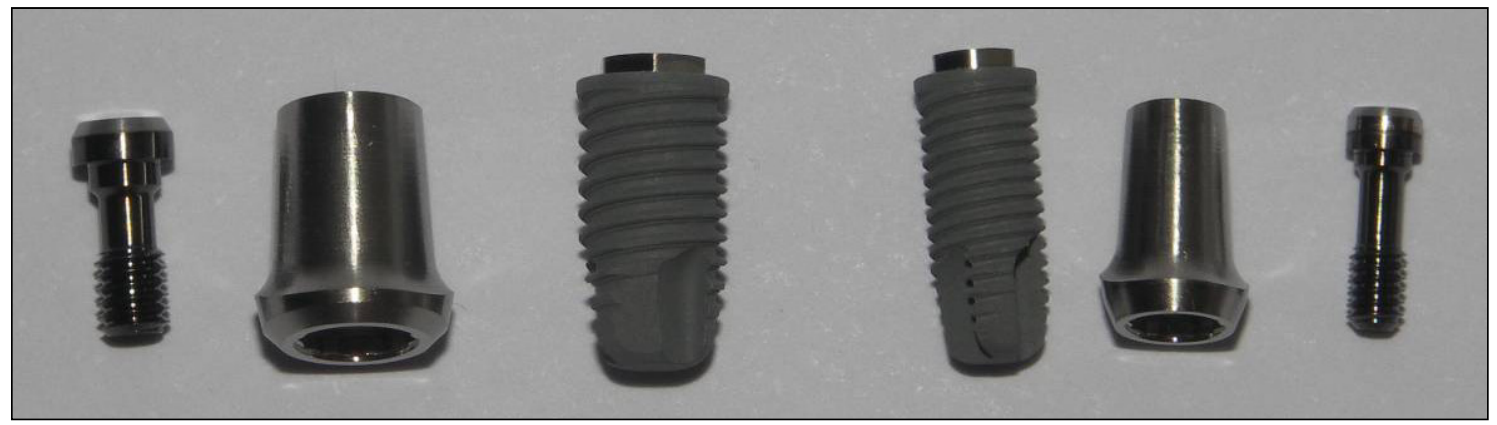

Figura 11: Foto real dos implantes e componentes protéticos que foram utilizados como referência para a confecção dos modelos. 


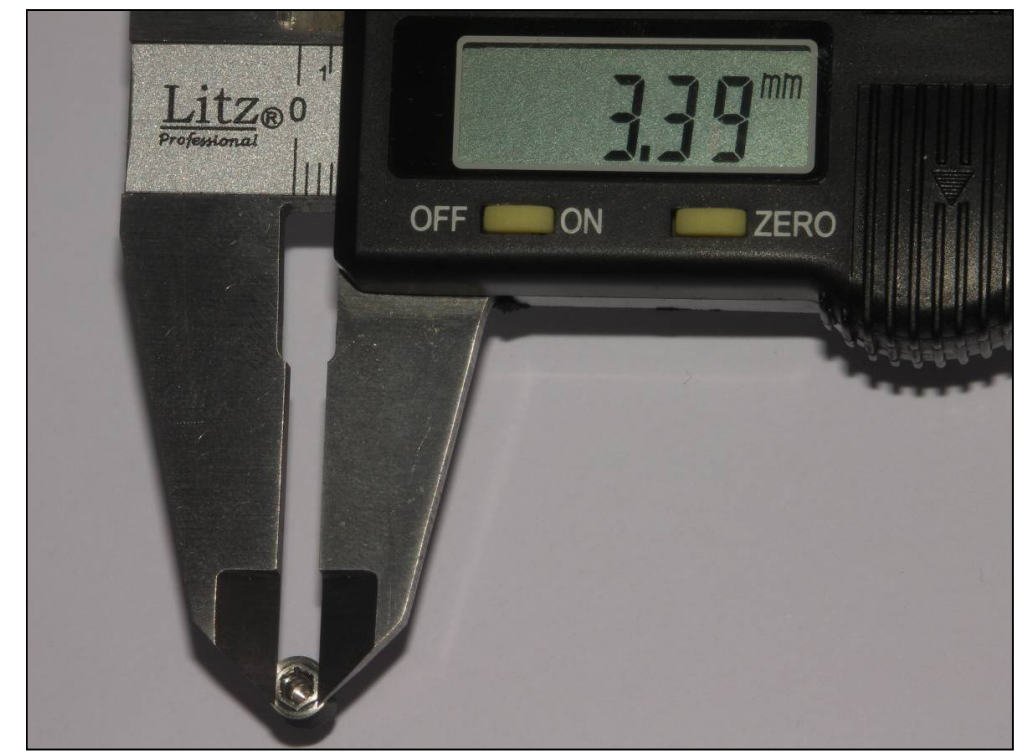

Figura 12: Mensuração com paquímetro digital.

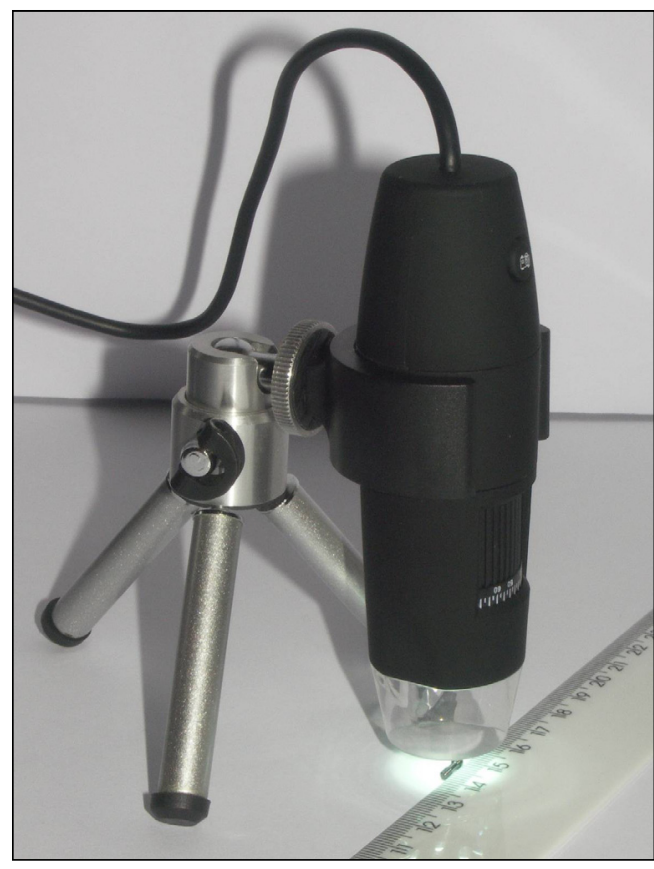

(A)

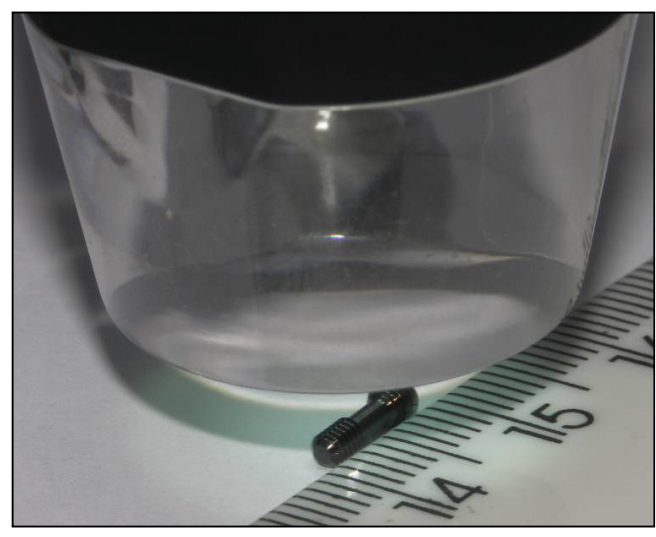

Figura 13: Fotos do microscópio digital analisando um parafuso. A régua foi colocada para fins de referência. 

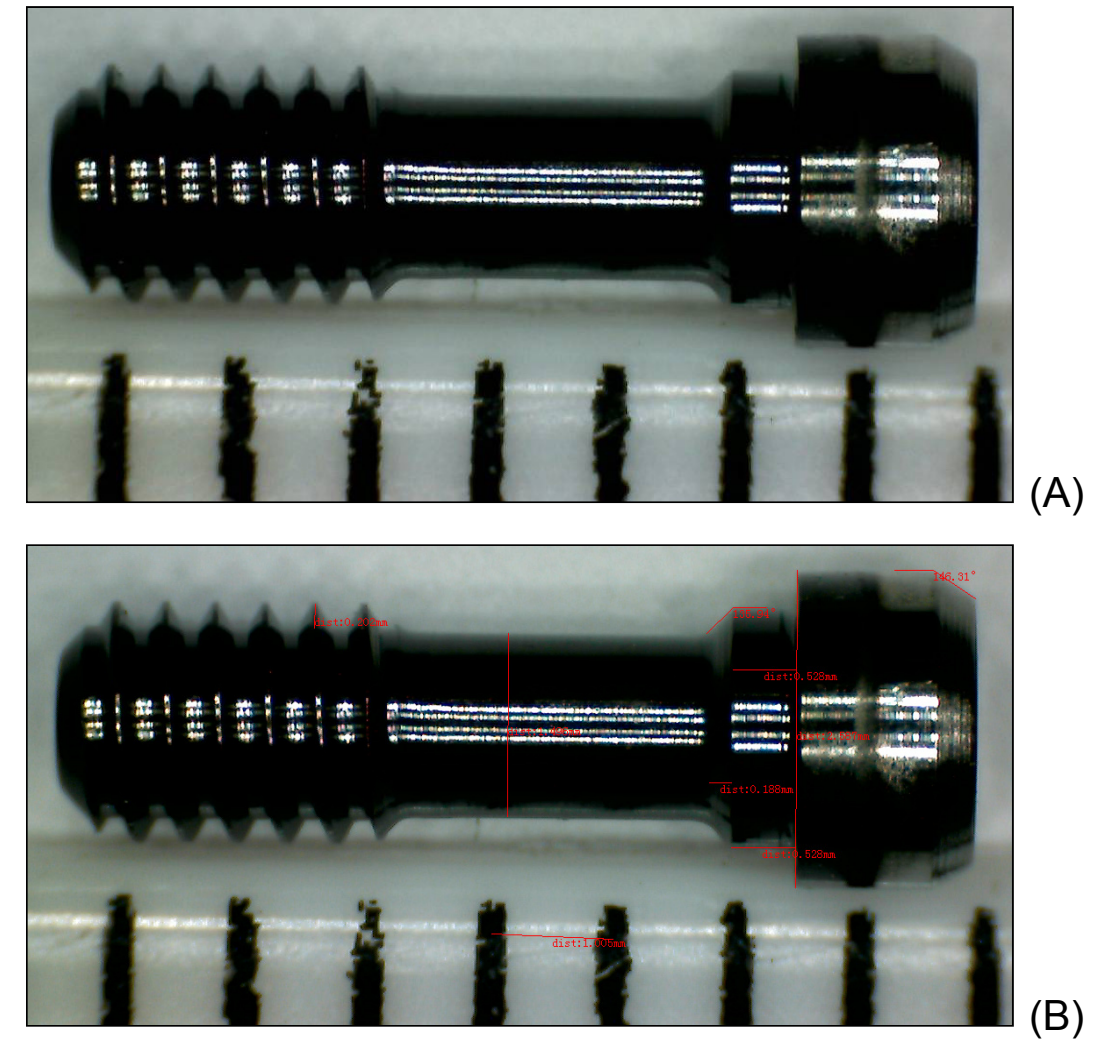

Figura 14: $A$ = Foto tirada pelo microscópio digital e $B=$ mesma foto, com calibração do software de mensuração e diversas distâncias analisadas, para construção do modelo. A régua foi colocada para fins de referência. 


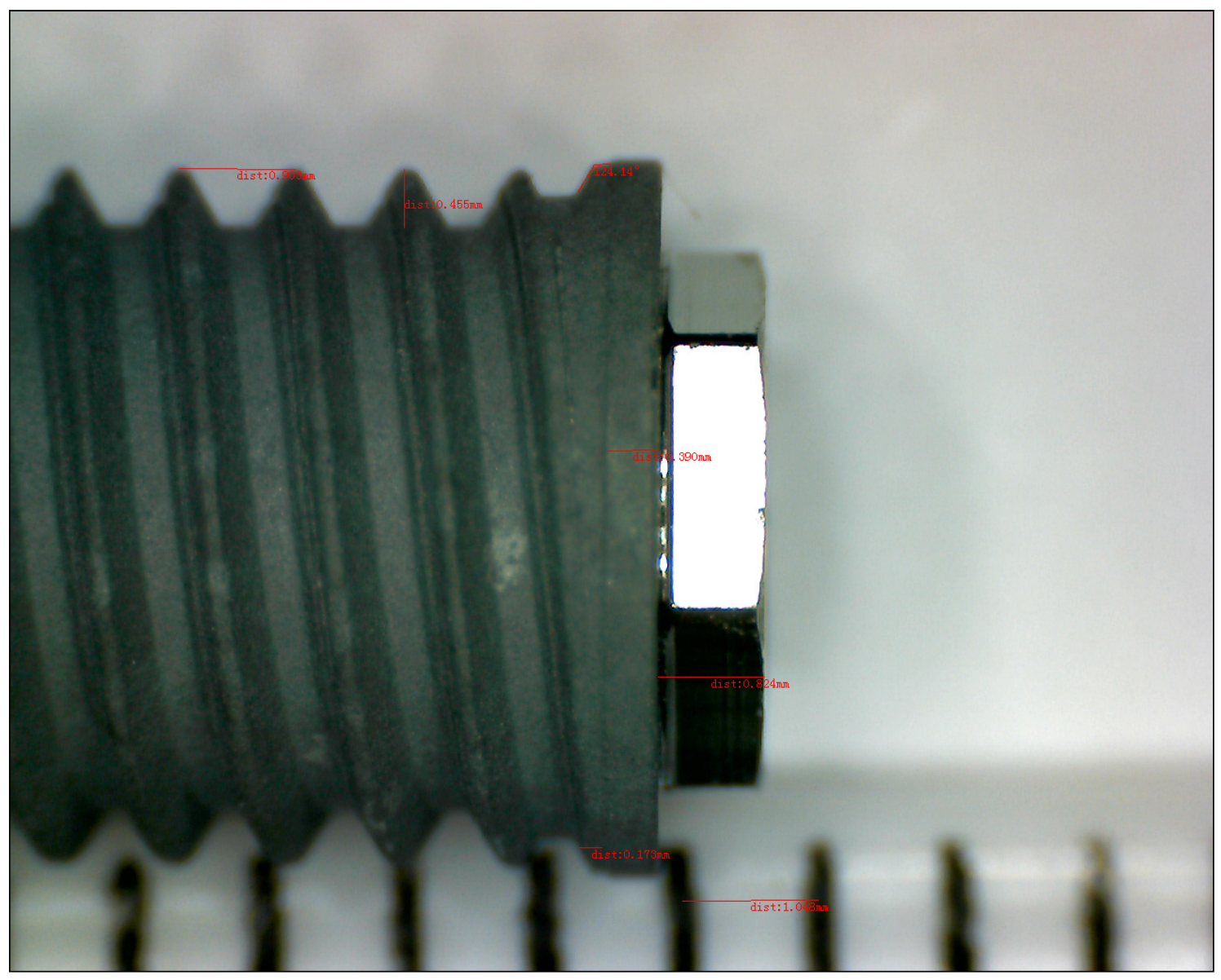

Figura 15: Foto da porção cervical do implante, com mensuração de diversas distâncias. A régua foi colocada para fins de referência. 

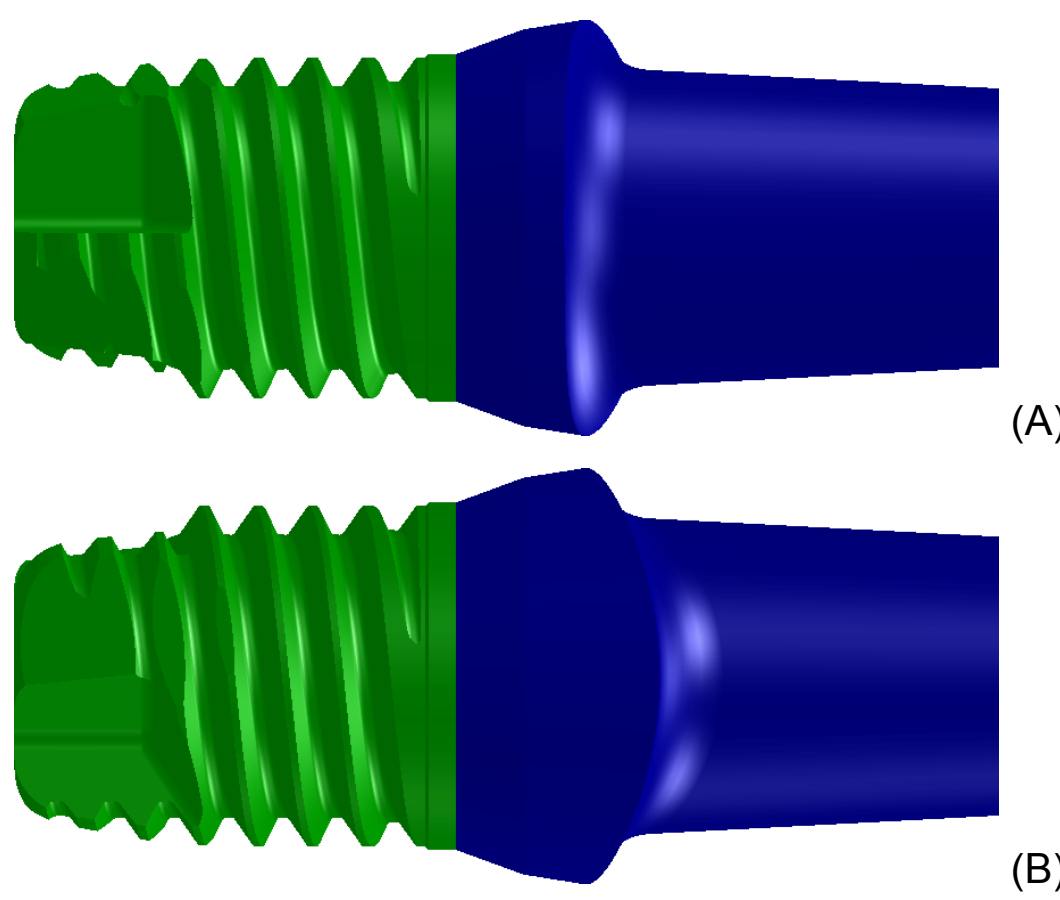

Figura 16: Modelo 3D do implante MK III de cinco $\mathrm{mm}$ de diâmetro por sete de comprimento, com componentes unidos. $A=$ vista vestibular e $B=$ vista lingual. Em verde o implante e em azul o intermediário. 

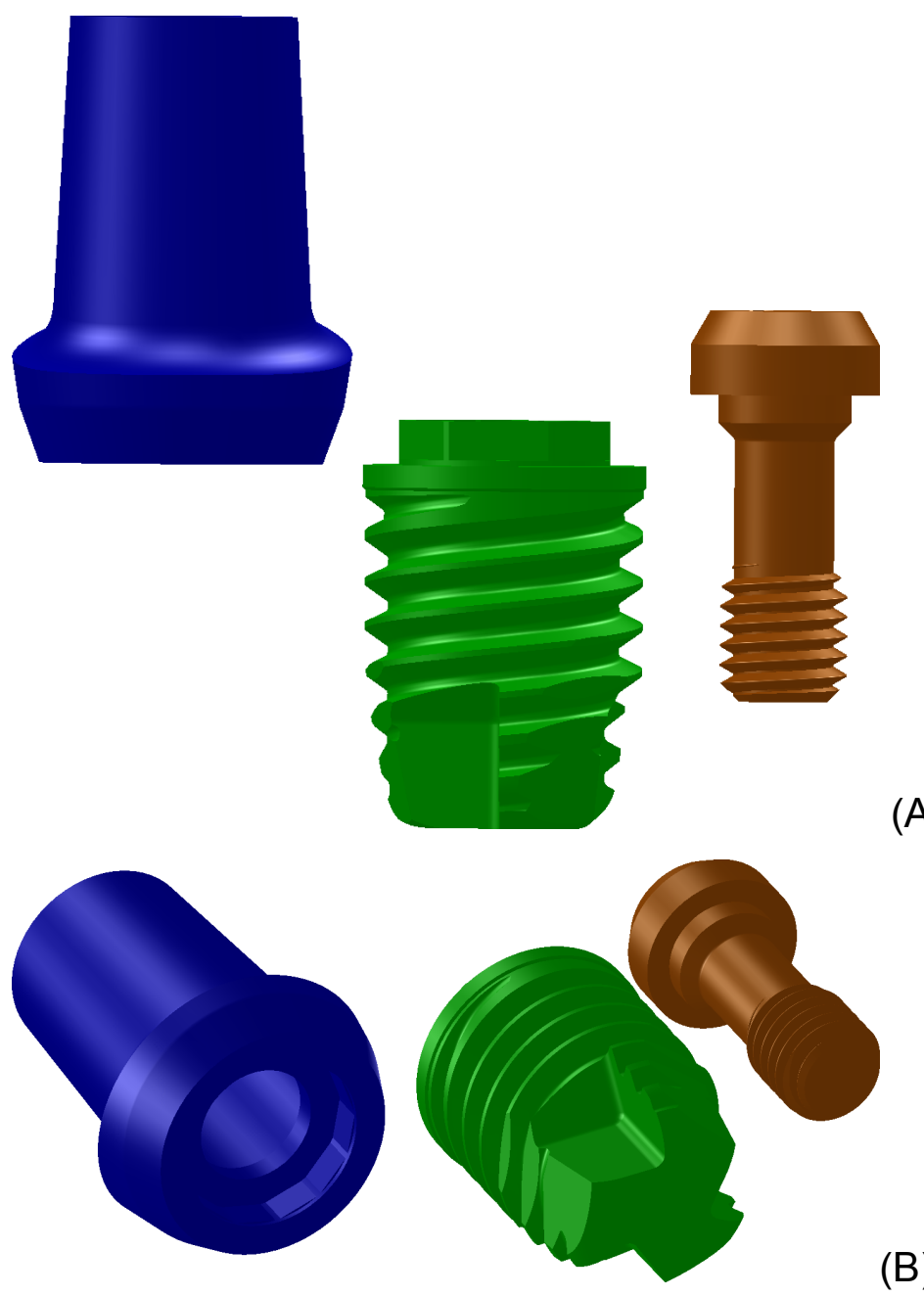

(A)

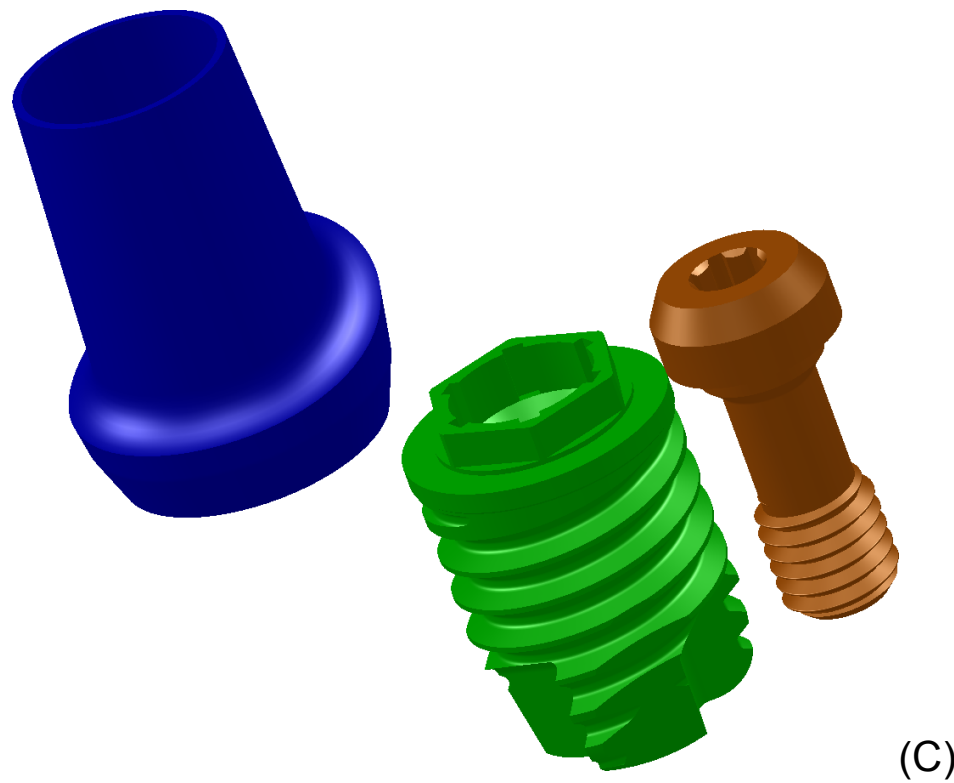

Figura 17: Modelo 3D do implante MK III de cinco $\mathrm{mm}$ de diâmetro por sete de comprimento, com componentes separados. $A=$ vista vestibular, $B=$ vista inferior e $C=$ vista de perfil. Em verde 0 implante, em azul 0 intermediário e marrom o parafuso. 


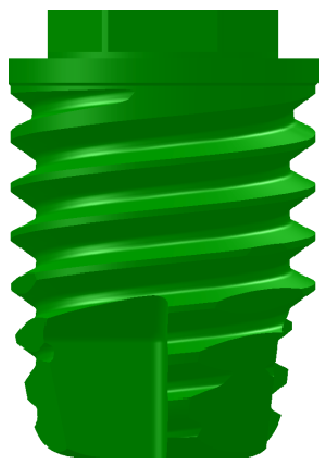

(A)

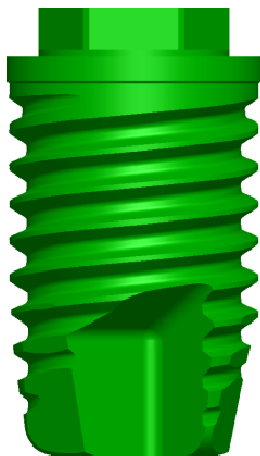

(B)

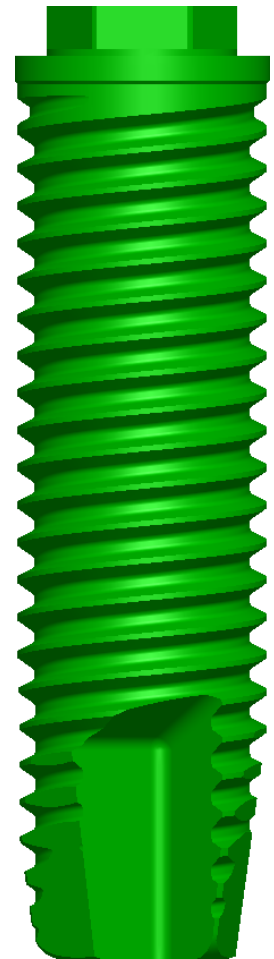

(C)

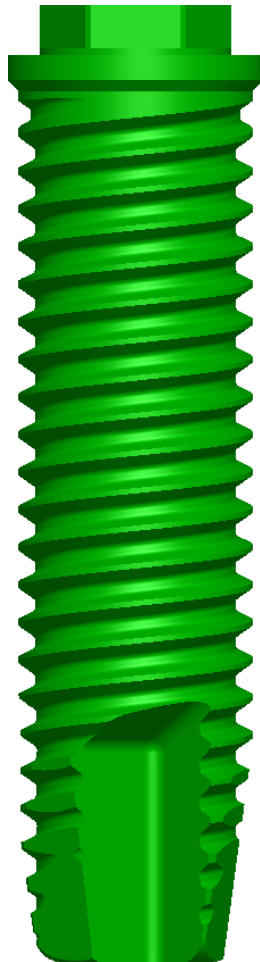

(D)

Figura 18: Modelos 3D dos diferentes implantes MK III utilizados nesta pesquisa. $\mathbf{A}=$ Implante de cinco $\mathrm{mm}$ de diâmetro por sete de altura, $\mathbf{B}=$ Implante de quatro $\mathrm{mm}$ de diâmetro por sete de comprimento, $\mathrm{C}=$ Implante de quatro $\mathrm{mm}$ de diâmetro por 15 de comprimento e $\mathbf{D}=$ Implante de $3.75 \mathrm{~mm}$ de diâmetro por $15 \mathrm{~mm}$ de comprimento.

Os diferentes modelos desta pesquisa tiveram o objetivo de avaliar 0 impacto na distribuição de tensões do osso periimplantar e do parafuso protético, em implantes colocados sob condições de tratamento de implantes curtos e em implantes convencionais sob condições de tratamento de lateralização do nervo alveolar inferior. Adicionalmente, foram considerados modelos para ambos os tratamentos sob protocolo de carga imediata (um estágio) e osseointegrados (dois estágios).

Para os modelos de implantes curtos, implantes de sete $\mathrm{mm}$ de comprimento foram utilizados. Note-se que, de acordo com a classificação do fabricante, esse comprimento se refere à altura considerando a perfuração da broca, sendo que a porção com tratamento de superfície é na verdade de 6,5 $\mathrm{mm}$ de altura. Para os modelos sob protocolo de lateralização do nervo alveolar inferior, foram utilizados implantes de $15 \mathrm{~mm}$ de comprimento. Note-se que o 
implante de $15 \mathrm{~mm}$, corresponde ao implante do fabricante, capaz de proporcionar uma ancoragem bicortical do implante, sem entretanto, perfurar a superfície óssea inferior, no modelo de mandíbula utilizado.

Os diâmetros dos implantes foram selecionados por serem modelos do fabricante comumente utilizados nos tratamentos analisados. Os comprimentos foram definidos exclusivamente pela anatomia do segmento da mandíbula.

Nos modelos de lateralização, nos implantes sob carga imediata, as osteotomias necessárias para o procedimento foram simuladas. Uma osteotomia, realizada a dois $\mathrm{mm}$ posterior ao forame mentual, estendendo-se até três $\mathrm{mm}$ posterior ao último implante distal, com limites superior e inferior de dois $\mathrm{mm}$ de distância do nervo e limite vestíbulo lingual até na metade da posição dos futuros implantes foi confeccionada para caracterização do acesso, como mostra a figura 19.

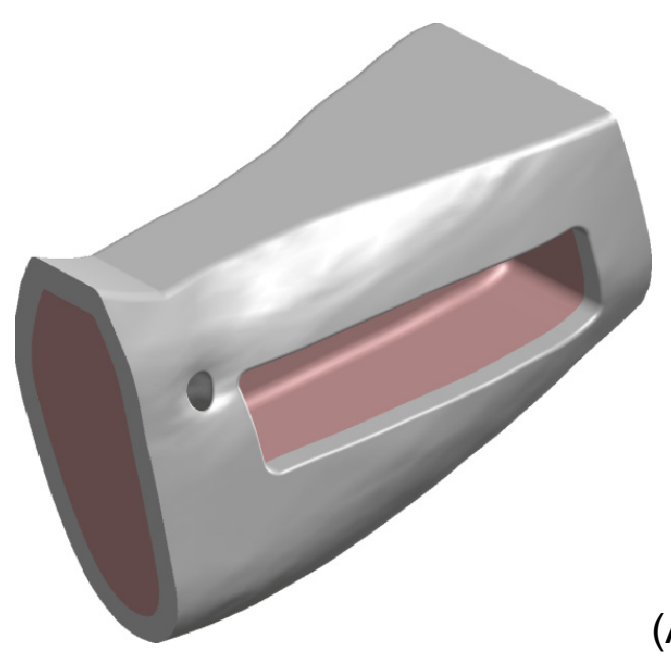

(A)
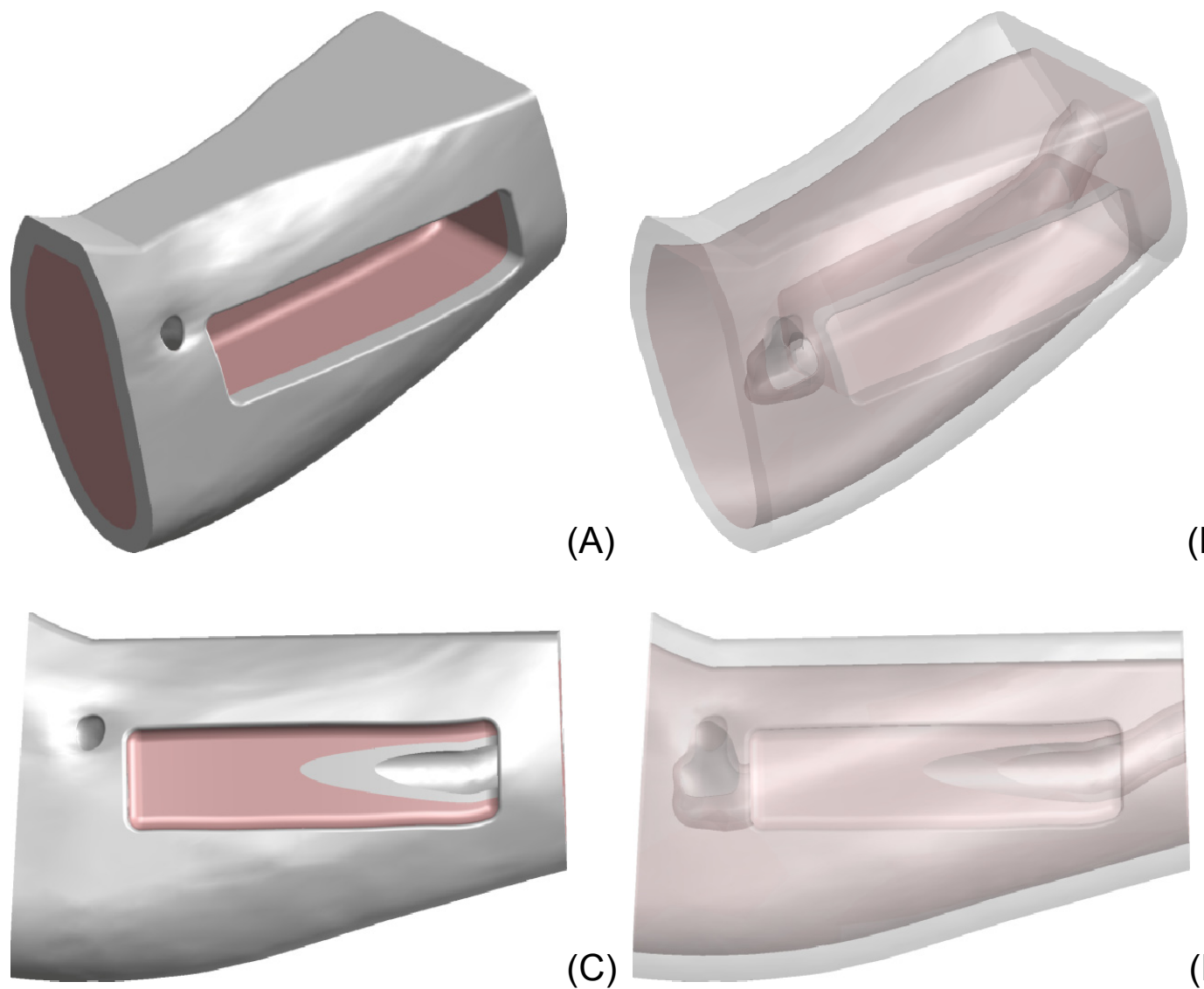

(C)

Figura 19: Vista do acesso ósseo na técnica de lateralização do nervo alveolar inferior com vista semitransparente para facilitar a visualização do canal alveolar inferior. $A / B=$ vista de perfil, $C / D=$ vista vestibular. 
Nas simulações com implantes osseointegrados, a mandíbula foi considerada como reparada quanto às osteotomias, entretanto, foi simulada uma perda óssea de 1,5 $\mathrm{mm}$ ao redor da plataforma dos implantes (WHEELER, 2007).

Quanto ao feixe vásculo nervoso, nos protocolos de lateralização com implante osseointegrado, o feixe foi posicionado vestibular ao implante, a semelhança de modelos animais em coelhos (YOSHIMOTO, KONIG et al., 2008), como mostra a figura 20.

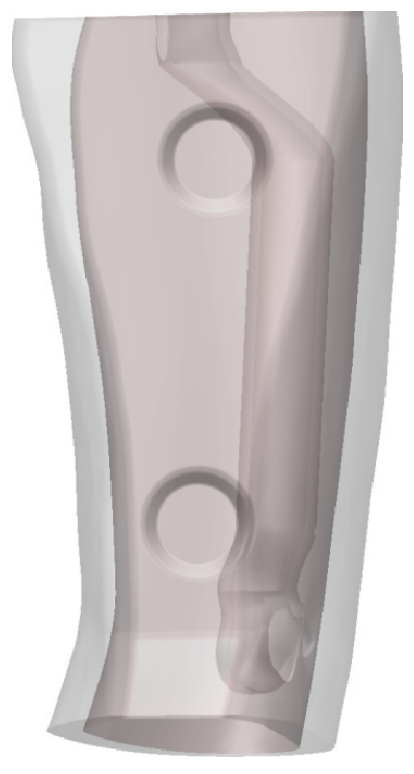

(A)

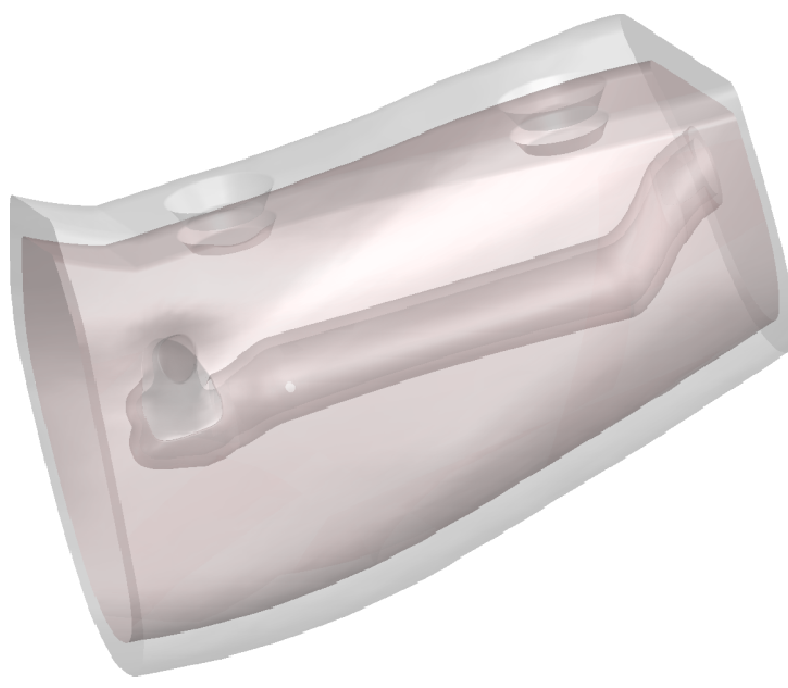

(B)

Figura 20: Vista do canal alveolar inferior lateralizado com osso semitransparente, para os modelos com técnica de lateralização do nervo alveolar inferior e implantes osseointegrados. Os centros dos nichos se referem à posição de colocação dos implantes.

Os diferentes modelos analisados nesta pesquisa foram listados abaixo:

Modelo A: Implante curtos, osseointegrados, com diâmetro do implante de $5,0 \mathrm{~mm}$, como mostra a figura 21 ; 

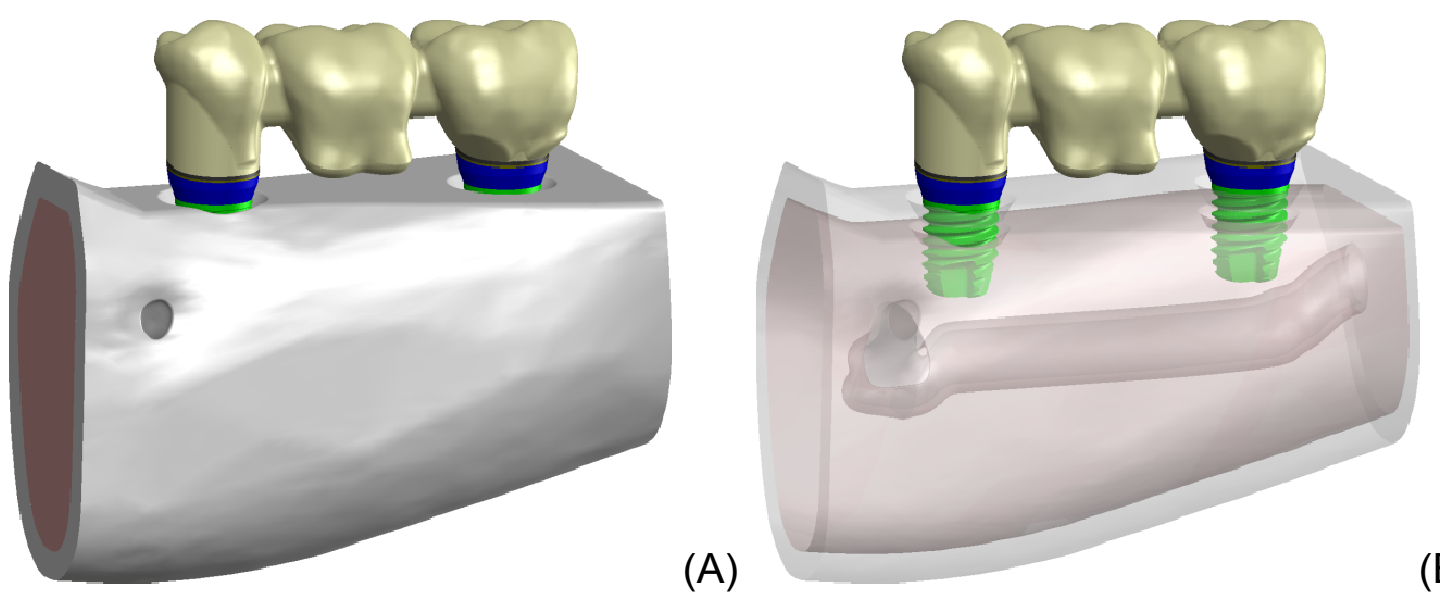

(A)

(B)

Figura 21: Vista de perfil do modelo A. Com osso opaco e semitransparente para visualização da relação entre implante e canal alveolar inferior.

Modelo B: Implante curtos, osseointegrados, com diâmetro do implante de $4,0 \mathrm{~mm}$, como mostra a figura 22 ;
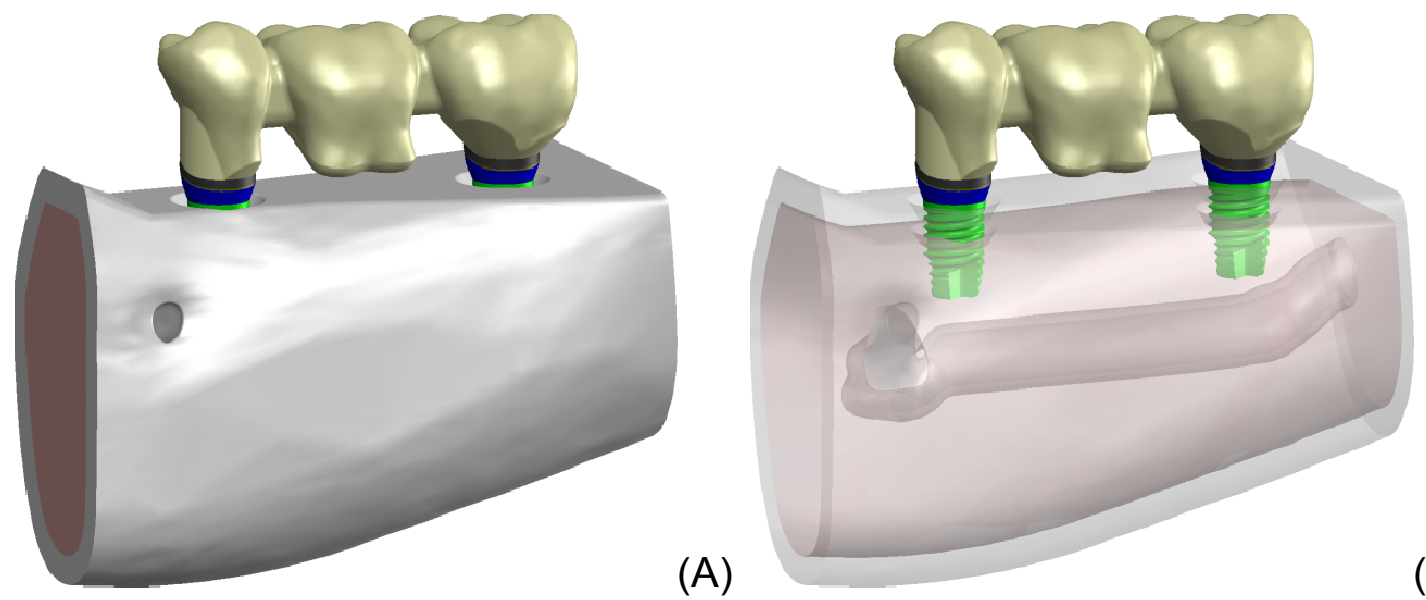

(B)

Figura 22 Vista de perfil do modelo B. Com osso opaco e semitransparente para visualização da relação entre implante e canal alveolar inferior.

Modelo C: Implantes colocados com protocolo de lateralização do nervo alveolar inferior, osseintegrados, com diâmetro do implante de 4,0 mm, como mostra a figura 23 : 

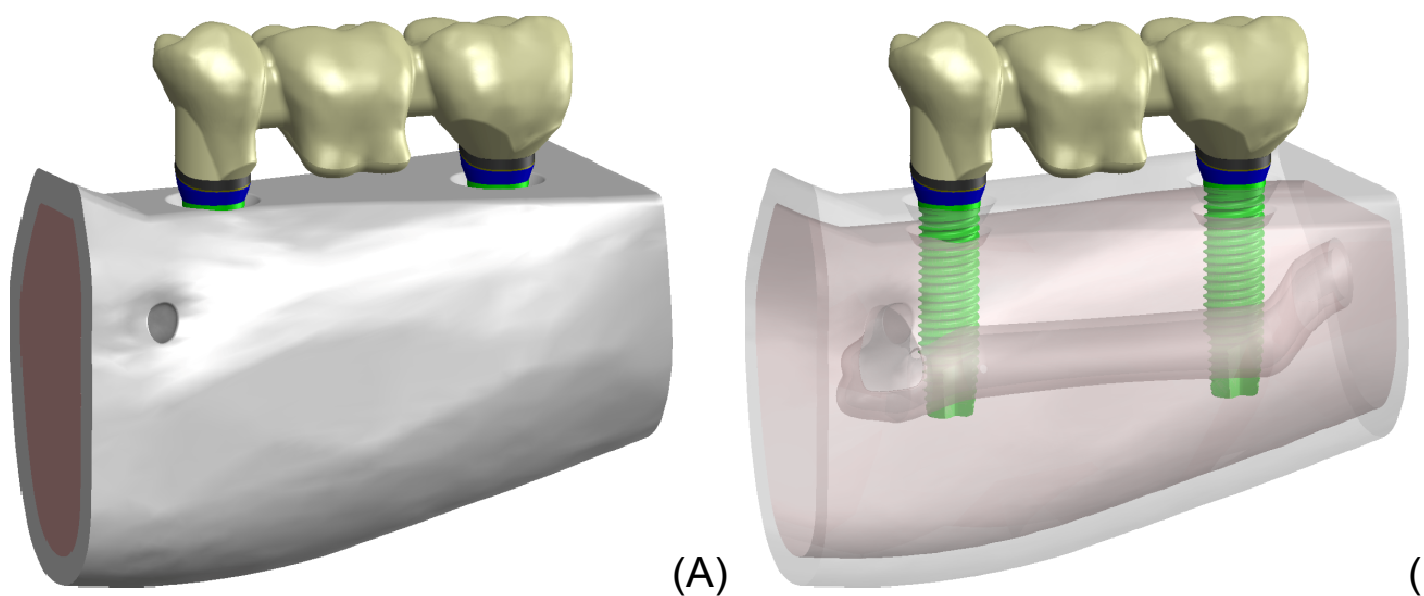

(B)

Figura 23: Vista de perfil do modelo C. Com osso opaco e semitransparente para visualização da relação entre implante e canal alveolar inferior.

Modelo D: Implantes colocados com protocolo de lateralização do nervo alveolar inferior, osseintegrados, com diâmetro do implante de $3,75 \mathrm{~mm}$, como mostra a figura 24 :
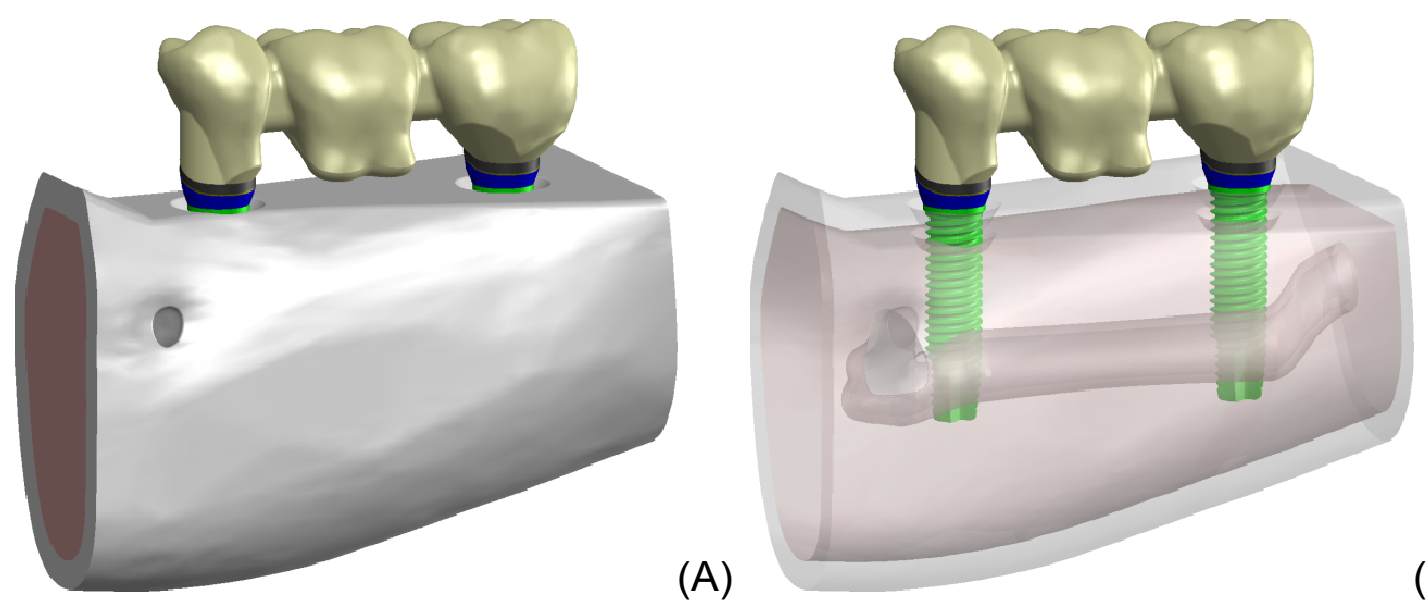

Figura 24: Vista de perfil do modelo D. Com osso opaco e semitransparente para visualização da relação entre implante e canal alveolar inferior.

Modelo E: Implantes curtos, sob carga imediata, com diâmetro do implante de 5,0 mm, como mostra a figura 25 ; 

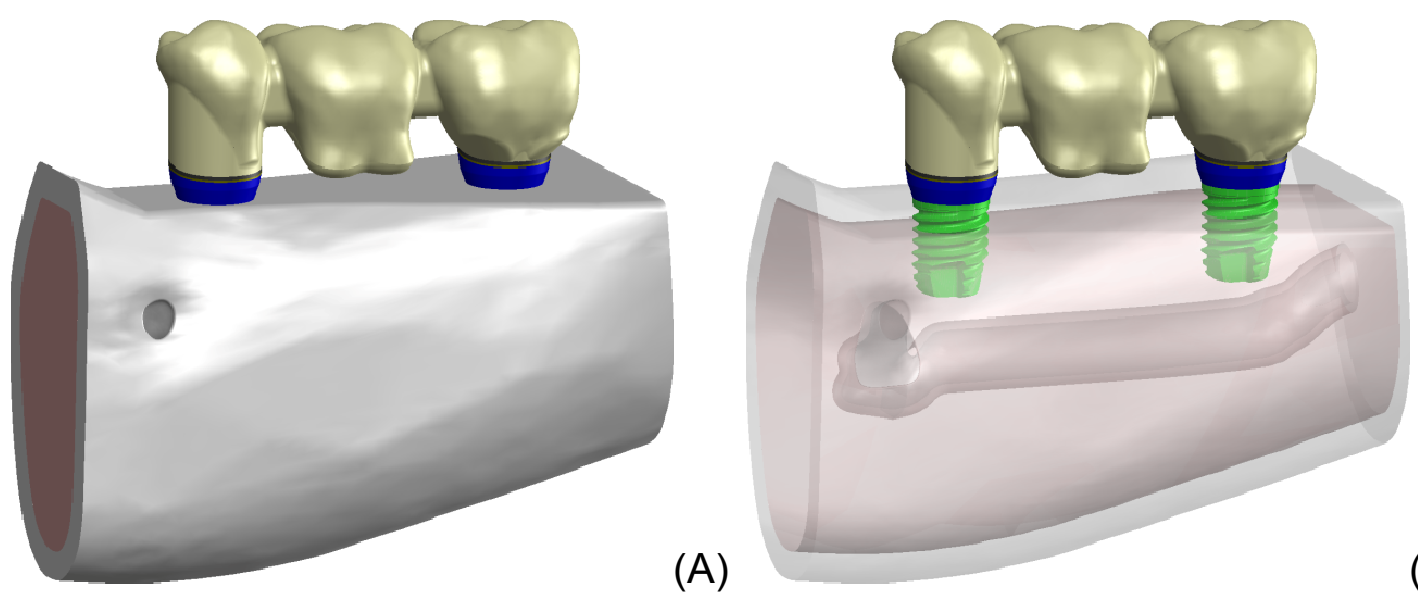

(B)

Figura 25: Vista de perfil do modelo E. Com osso opaco e semitransparente para visualização da relação entre implante e canal alveolar inferior.

Modelo F: Implantes curtos, sob carga imediata, com diâmetro do implante de $4,0 \mathrm{~mm}$, como mostra a figura 26 ;
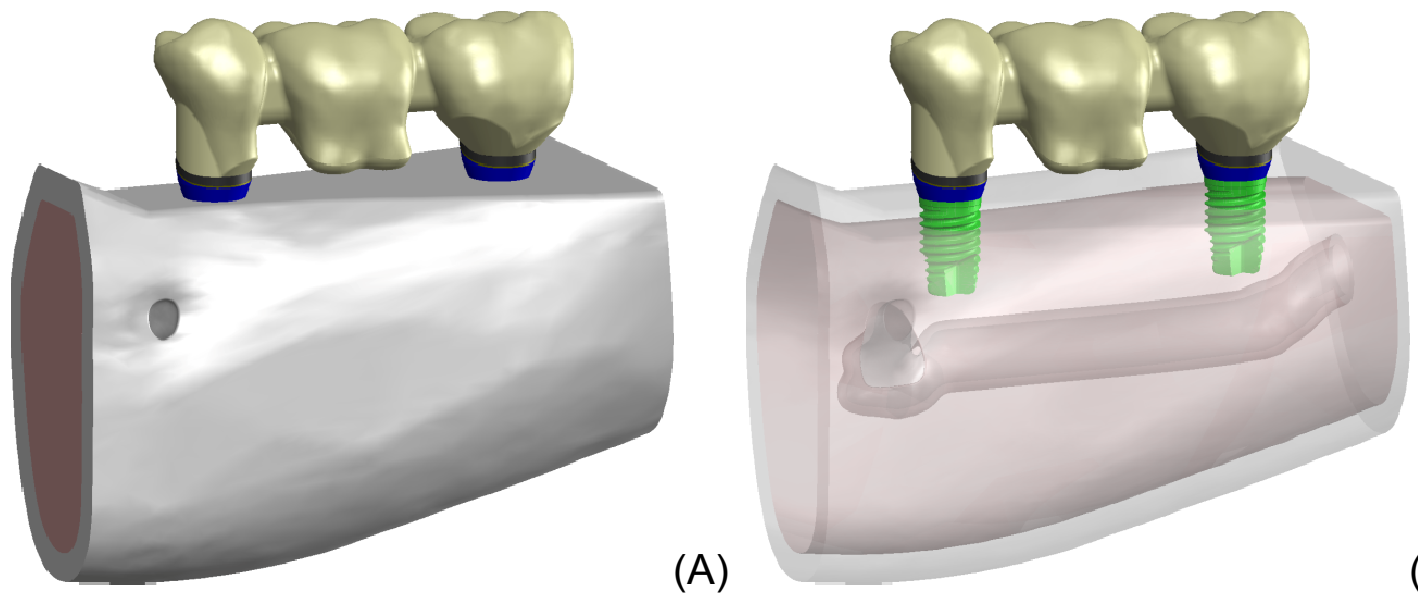

(B)

Figura 26: Vista de perfil do modelo F. Com osso opaco e semitransparente para visualização da relação entre implante e canal alveolar inferior.

Modelo G: Implantes colocados com protocolo de lateralização do nervo alveolar inferior, sob carga imediata, com diâmetro do implante de 4,0 mm, como mostra a figura 27 ; 

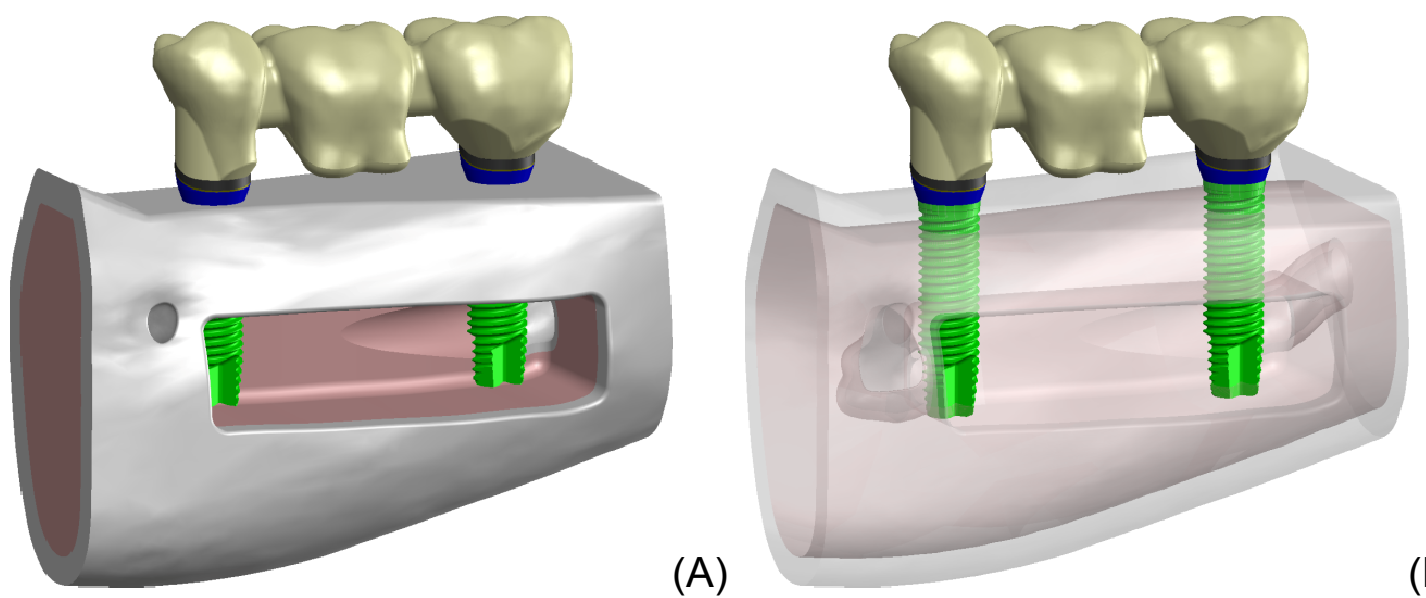

(B)

Figura 27: Vista de perfil do modelo G. Com osso opaco e semitransparente para visualização da relação entre implante e canal alveolar inferior.

Modelo H: Implantes colocados com protocolo de lateralização do nervo alveolar inferior, sob carga imediata, com diâmetro do implante de $3,75 \mathrm{~mm}$, como mostra a figura 28 ;
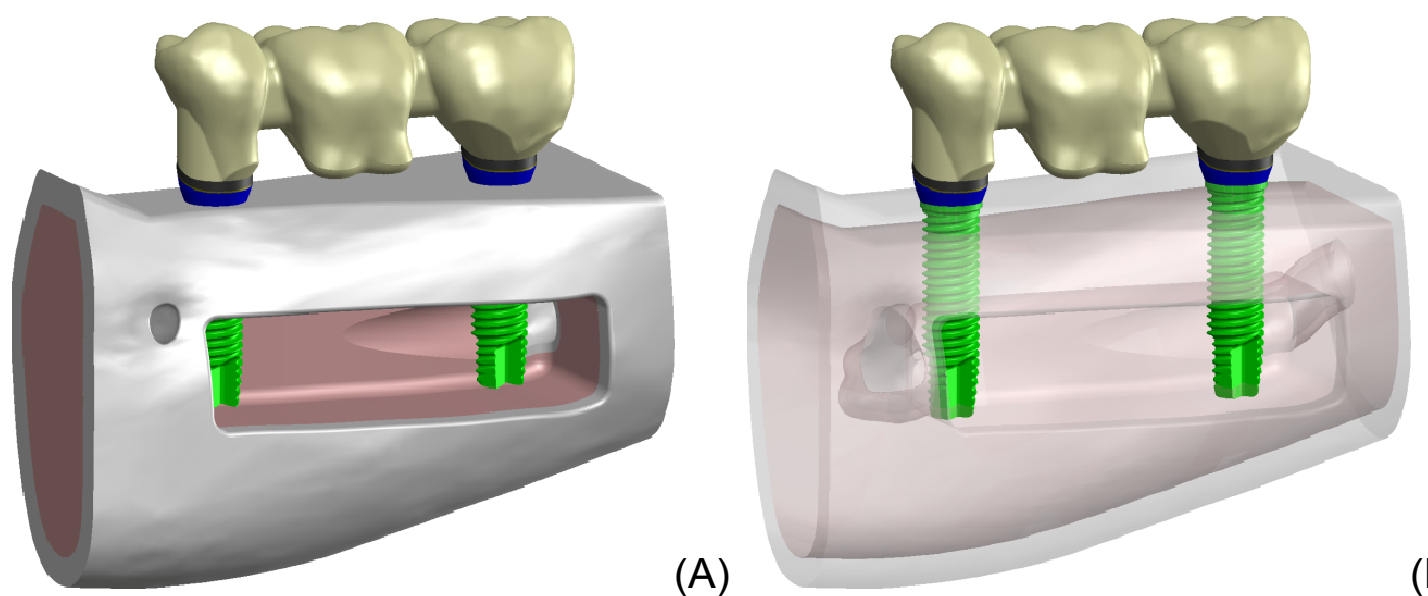

Figura 28: Vista de perfil do modelo H. Com osso opaco e semitransparente para visualização da relação entre implante e canal alveolar inferior.

As figuras 29 a 32 mostram diversas imagens do modelo A e B, para visualização das estruturas. 

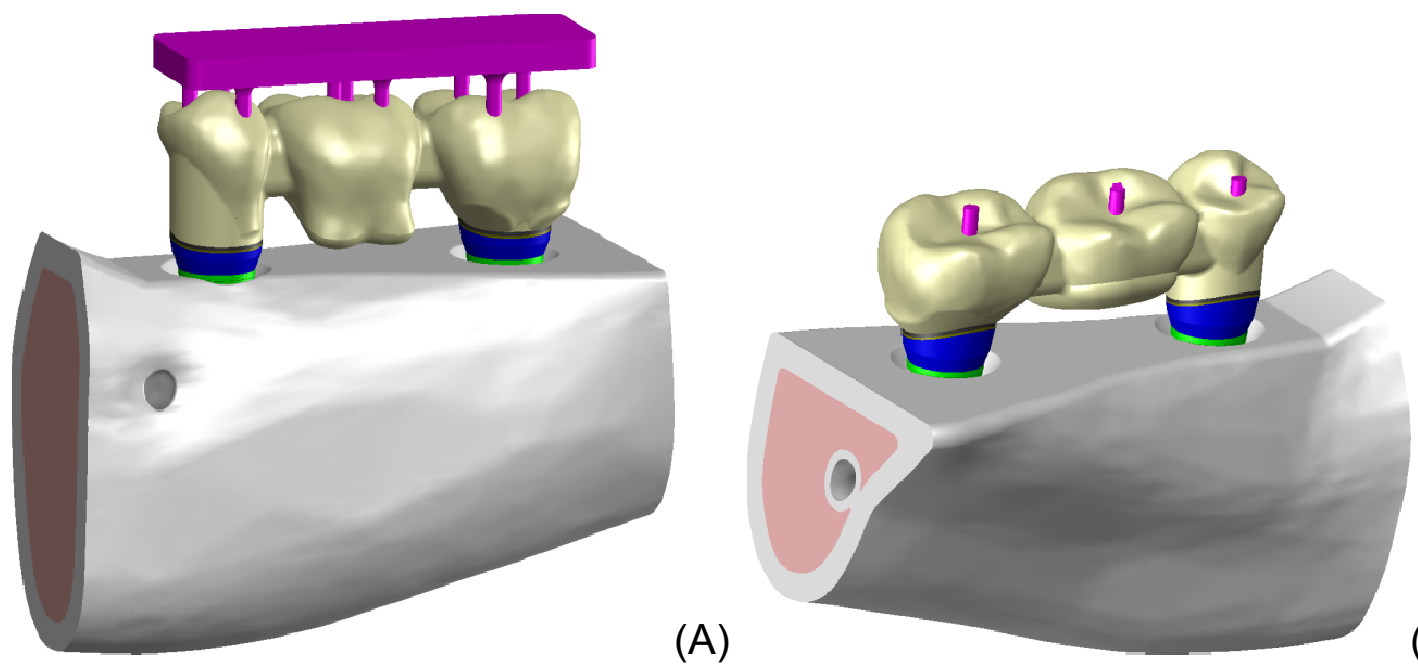

(B)

Figura 29: Vista das estruturas antagonistas em roxo. $A=$ carga axial e $B$ = carga oblíqua
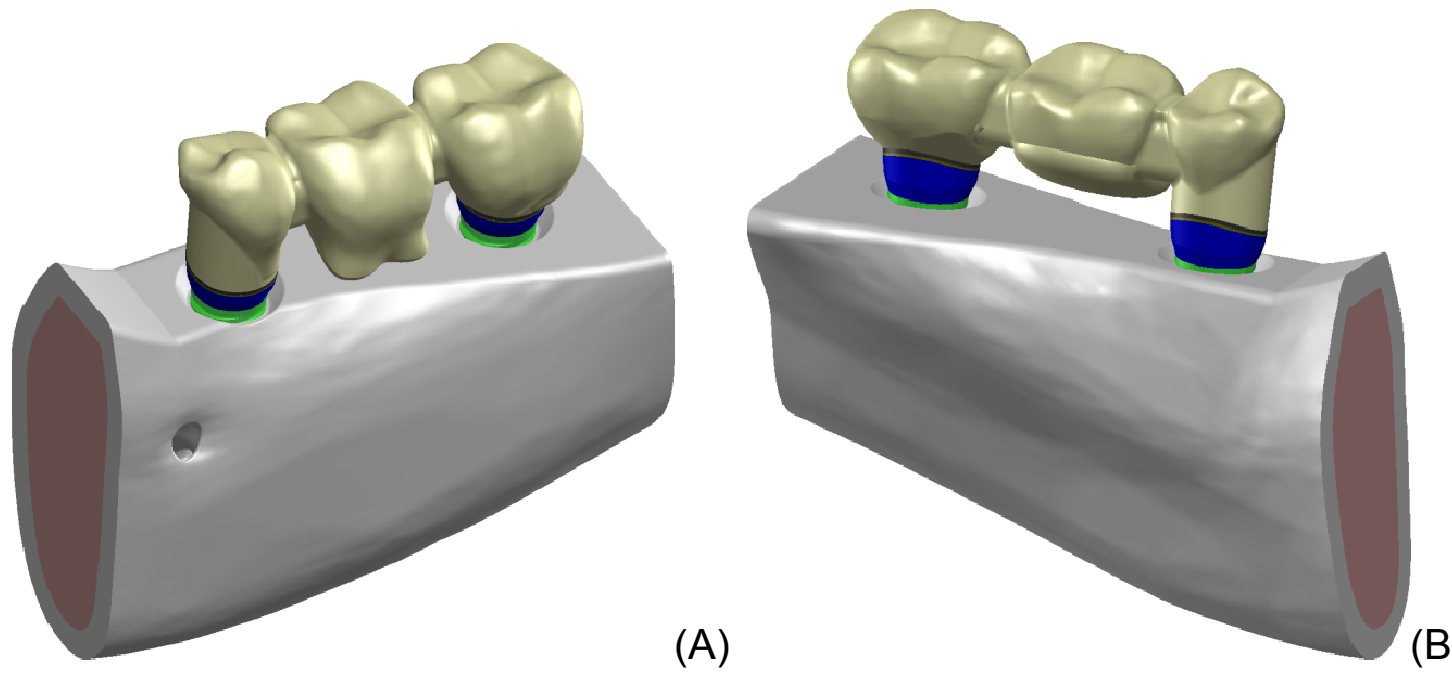

Figura 30: Diferentes vistas do modelo A. 


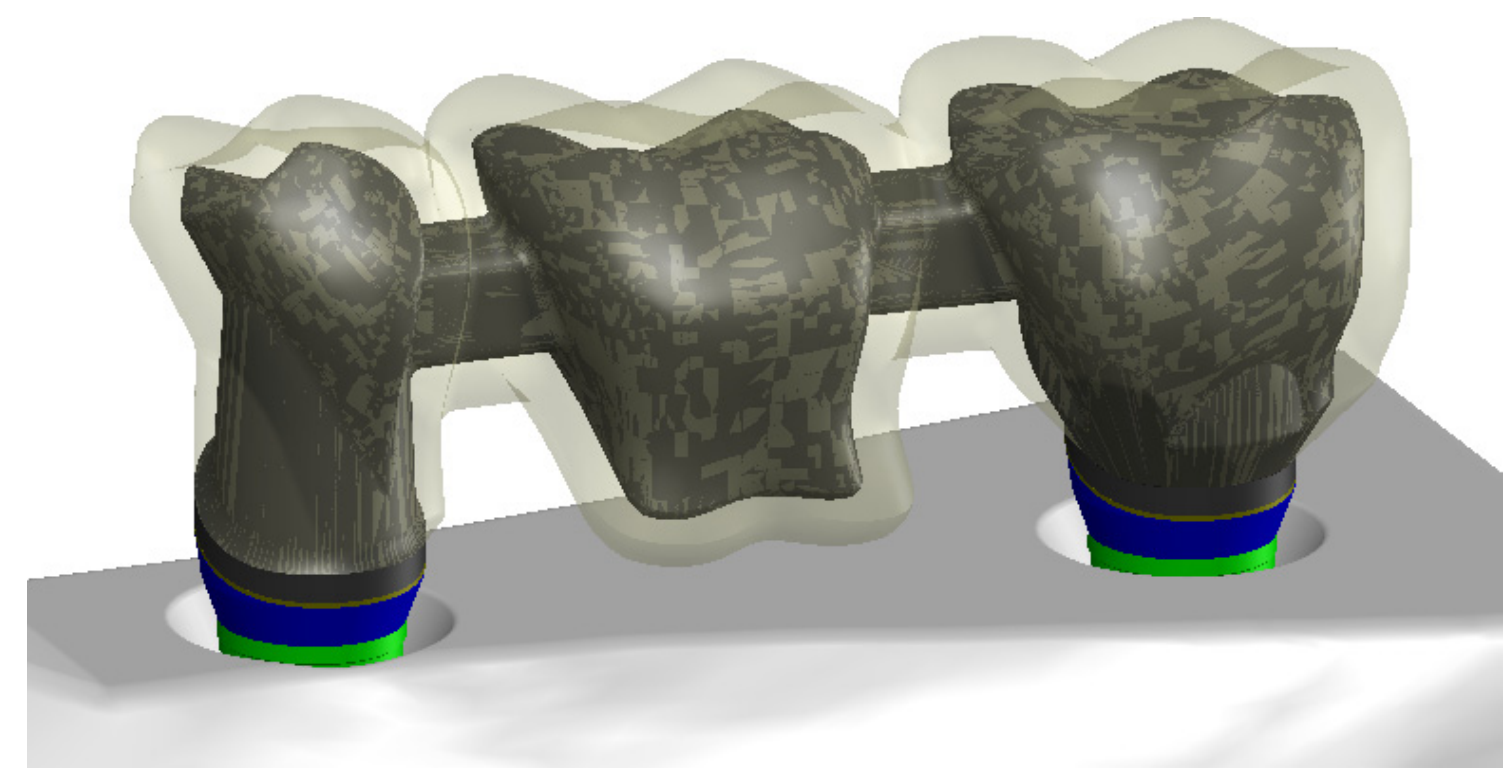

Figura 31: Vista vestibular da infraestrutura nos modelos com plataforma do implante de $4.1 \mathrm{~mm}$. A cerâmica foi colocada como semitransparente para facilitar a visualização.
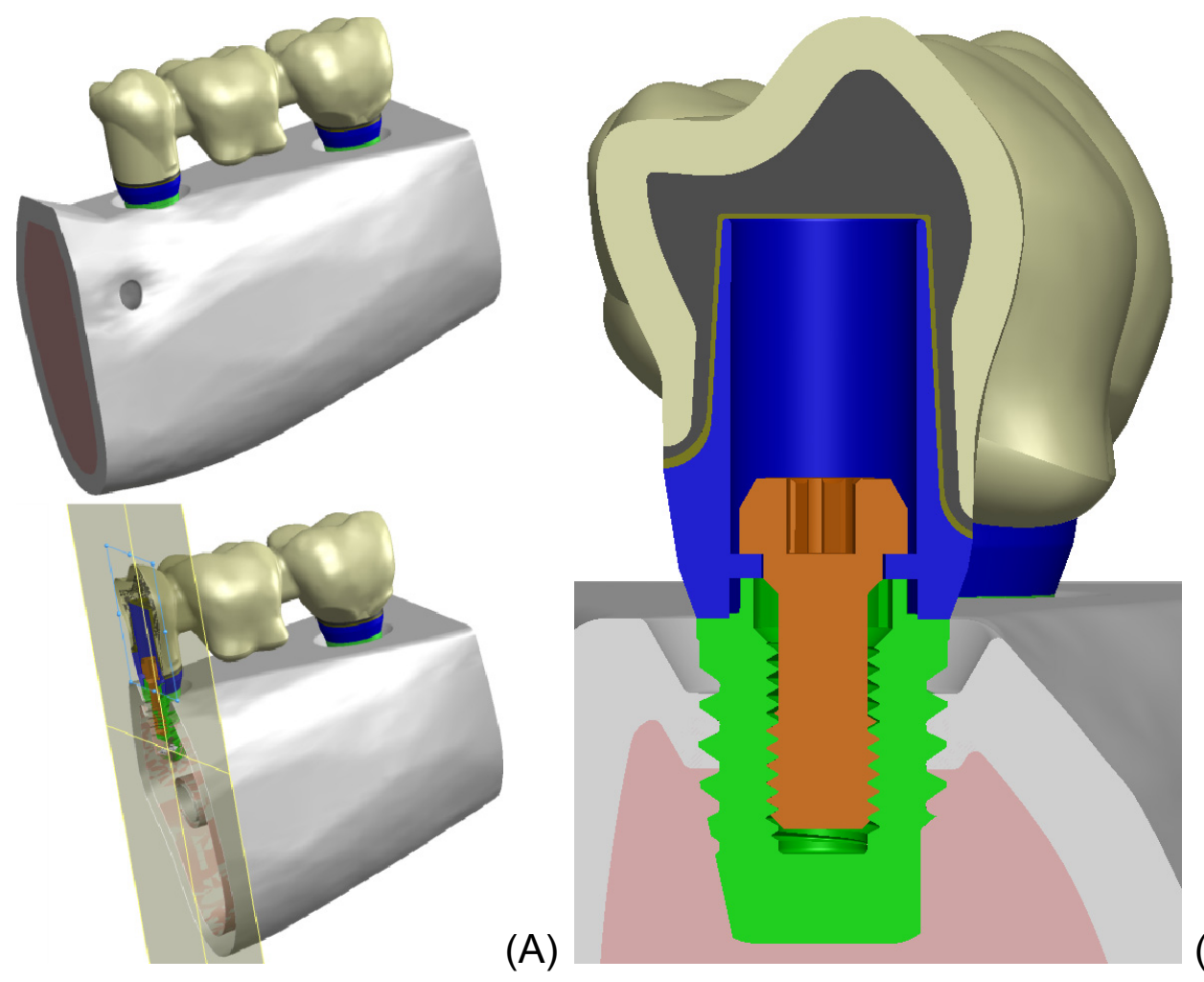

(B)

Figura 32: Vista em corte do elemento 35 no modelo A para visualização da relação entre as diferentes estruturas. 


\subsection{Simulação}

Todos os modelos foram exportados do Solidworks, para o software de simulação de elementos finitos Ansys Workbench V11 (Ansys Inc., Canonsburg, PA, USA), diretamente através do suplemento de interface de geometria, próprio do Ansys.

Cada elemento dos modelos foi configurado com módulo de elasticidade e coeficiente de Poisson retirados da literatura, conforme mostra o quadro 1. Todos os materiais foram considerados como homogêneos, isotrópicos e linearmente elásticos.

\begin{tabular}{|l|l|l|}
\hline \multicolumn{2}{|l|}{ Quadro 1: Propriedades mecânicas dos materiais } \\
\hline material \ propriedade & $\begin{array}{l}\text { Módulo de elasticidade. } \\
(\mathrm{GPa})\end{array}$ & Coeficiente de Poisson \\
\hline $\begin{array}{l}\text { Cimento de fosfato de } \\
\text { zinco(HALL, NAKAYAMA } \\
\text { et al., 1973) }\end{array}$ & 76 & 0,35 \\
\hline $\begin{array}{l}\text { Osso Medular(HOLMES, } \\
\text { DIAZ-ARNOLD et al., } \\
\text { 1996) }\end{array}$ & 1,37 & 0.3 \\
\hline $\begin{array}{l}\text { Osso cortical(HOLMES, } \\
\text { DIAZ-ARNOLD et al., } \\
\text { 1996) }\end{array}$ & 13,7 & 0.3 \\
\hline $\begin{array}{l}\text { Liga de cromo cobalto } \\
\text { (ESKITASCIOGLU, } \\
\text { USUMEZ et al., 2004) }\end{array}$ & 218 & 0.33 \\
\hline $\begin{array}{l}\text { Titânio (BENZING, GALL } \\
\text { et al., 1995) }\end{array}$ & 110 & 0.35 \\
\hline $\begin{array}{l}\text { Porcelana al., } \\
\text { feldspática(ZARONE, } \\
\text { SORRENTINO et al } \\
\text { 2006) }\end{array}$ & 69 & 0.3 \\
\hline
\end{tabular}


Considerando os diversos parâmetros e configurações existentes em uma simulação, as configurações de contato entre as superfícies dos diferentes materiais devem ser cuidadosamente analisadas, uma vez que a alteração de apenas um contato pode afetar drasticamente o resultado da pesquisa, levando a conclusões erradas sobre o assunto.

Para simulação do protocolo de carga imediata, um contato do tipo "rough"1 foi utilizado (configuração: elemento de contato Ansys conta174targe170 keyopt(12) - 1) $)^{2}$ entre osso e implante. Esse modelo de contato permite a formação de espaços, mas não permite deslizamentos entre as superfícies, sendo considerado um coeficiente de fricção infinito. A escolha desse tipo de contato se deve ao fato que um implante, para ser indicado para carga imediata, necessita ter um travamento mínimo durante sua colocação (HORIUCHI, UCHIDA et al., 2000; VAN DEN BOGAERDE, PEDRETTI et al., 2002), travamento esse que impede o deslizamento entre superfícies em cargas mastigatórias normais. Entretanto, pelo fato do implante não estar osseointegrado, é possível a formação de espaços, como esse modelo de contato selecionado permite. Note-se que outros autores preferem a utilização de contatos do tipo friccionais para simulação de carga imediata, que permitem além da formação de espaços, a ocorrência de deslizamento entre as superfícies (ESER, AKCA et al., 2009; KONG, GU et al., 2009), Contudo, o autor desta pesquisa selecionou outro tipo de contato, devido aos fatores mencionados acima. Para simulação dos implantes osseointegrados, um contato osso-implante do tipo "bonded" (configuração: elemento de contato Ansys conta174-targe170 keyopt(12) - 5) foi utilizado, sendo que esse modelo não permite formação de espaços ou deslizamentos entre superfícies, a semelhança da situação de implantes osseointegrados.

O contato entre parafuso e implante e entre parafuso e intermediário foi considerado como "rough", devido ao fato de que um parafuso, depois de aplicado o torque, não deve deslizar/soltar com forças mastigatórias normais.

\footnotetext{
${ }^{1}$ Os nomes entre aspas se referem aos utilizados pelo software Ansys V11.

${ }^{2}$ Configurações internas de contato do software Ansys v11.
} 
No contato entre implante e intermediário, entretanto, por simplificação, foi considerado um contato "frictionless" (configuração: elemento de contato Ansys conta174-targe170 keyopt(12) - 0), que permite deslizamentos entre superfícies e formação de espaços, devido à possibilidade das cargas mastigatórias formarem espaços entre as estruturas e promoverem deslizamentos entre as superfícies.

O contato entre cimento de fosfato de zinco e infraestrutura foi configurado como "frictional". Também por simplificação, um coeficiente de fricção de 0,2 foi utilizado, baseado em aproximações com outros materiais (LUDEMA, 1996; TILLITSON, CRAIG et al., 1971). O contato friccional foi selecionado devido ao cimento não ter adesão a metais, mas apenas embricamento mecânico (ANUSAVICE, 2003). Todos os demais contatos, com exceção dos referentes ao antagonista na carga axial, como explicado adiante, foram simulados como "bonded".

Suportes rígidos foram simulados nas superfícies ósseas anteriores e posteriores seccionadas, para simular a junção da parte óssea ao resto da mandíbula, como mostra a figura 33 .
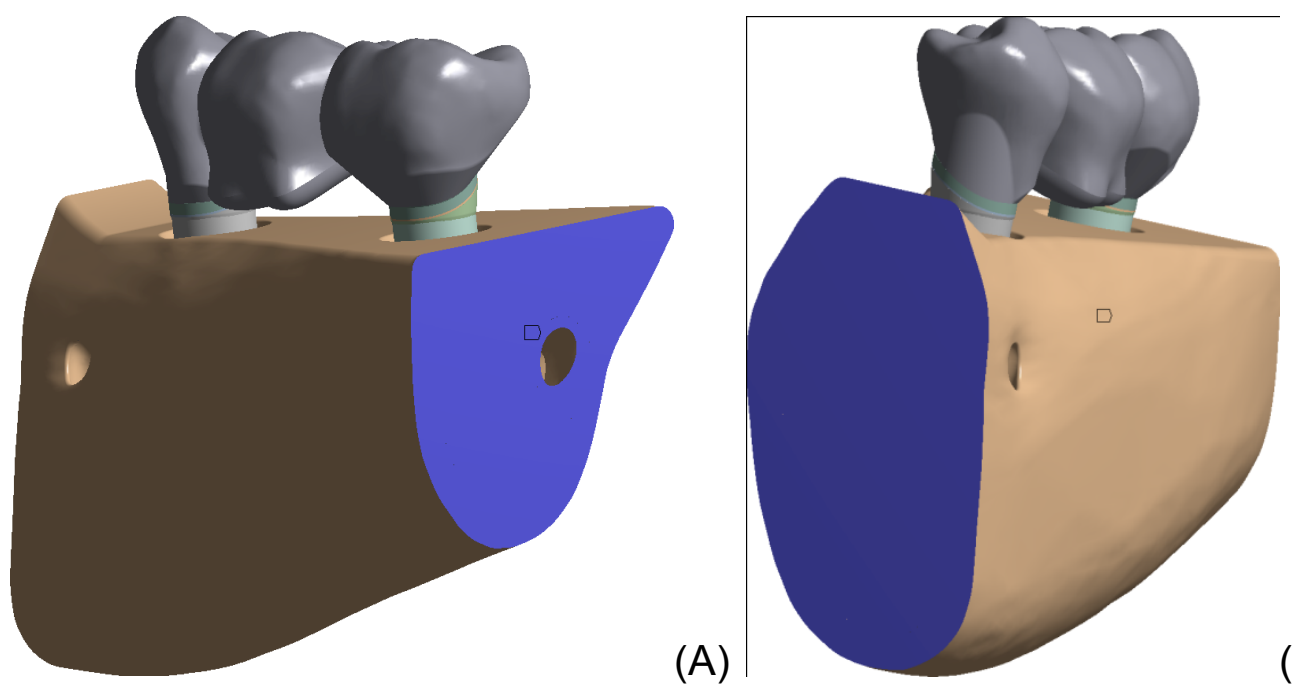

(B)

Figura 33: Suportes rígidos configurados nas faces em azul. $A=$ vista posterior e $\mathrm{B}=$ vista anterior 
Os modelos foram simulados em dois passos. O primeiro passo se refere à aplicação da pré-tensão nos parafusos. Durante um torque aplicado no parafuso, esse idealmente deve gerar tensões de 65\% (HAACK, SAKAGUCHI et al., 1995) a 75\% (MCGLUMPHY, MENDEL et al., 1998) das tensões do seu limite de escoamento, para balancear a retenção com a resistência do parafuso.

Entretanto, para uma mesma intensidade de torque no parafuso existem grandes variações nas tensões, dependo de fatores como coeficiente de atrito, lubrificação e calibragem dos instrumentos utilizados (DELLINGES e TEBROCK, 1993; GOHEEN, VERMILYEA et al., 1994; GROSS, KOZAK et al., 1999). Portanto, para melhor padronização da simulação de pré-tensão no parafuso, um recurso específico do Ansys para esse fim, chamado de "bolt pretension", foi utilizado. Esse utiliza o elemento de précarga Ansys Prets179, e permite aplicar a tensão do prétorque com uma força pré-determinada ou com um ajuste no comprimento do parafuso (OATIS, 2007).

Entretanto, o modelo adotado possui a limitação de ser incapaz de simular tensões de torção parasitas, que ocorrem devido à maior área de contato entre as roscas do parafuso e o implante, em relação à área de contato da cabeça do implante e o intermediário, que ocasiona torção do corpo do parafuso durante a aplicação do torque (SKF, 2001) . Entretanto, devido ao efeito de acomodação dos parafusos para implantes dentários descrito na literatura (WINKLER, RING et al., 2003), é provável que essas tensões, se ocorrerem, desapareçam na situação real.

Por outro lado, diferente da aplicação de um momento de carga para simular o torque do parafuso, como adotado em outros estudos (LANG, KANG et al., 2003; WANG, KANG et al., 2009), esse recurso tem peso computacional muito inferior, o que permite o seu uso em simulações muito mais complexas e com maior refinamento da malha de elementos finitos, que melhora a precisão do modelo, em contraste a outros trabalhos sobre pré-tensões no parafuso, que se limitam a modelos simplificados com implantes unitários (GUDA, ROSS et al., 2008; LANG, KANG et al., 2003; WANG, KANG et al., 2009). 
Para o presente trabalho, foi verificado o refinamento de malha (explicado adiante) com uma pré-carga ${ }^{3}$ no parafuso de $300 \mathrm{~N}$, nos modelos A e $B$ e após o refinamento, todas as estruturas foram suprimidas com exceção do implante do elemento 37 , e seu respectivo parafuso e intermediário protético. Nessa pré-simulação, a carga no parafuso foi ajustada até representar um valor de pico de $75 \%$ do limite de escoamento do titânio, pelo critério de tensões equivalentes de von Mises (explicado adiante), com um intervalo de tolerância de $0,5 \%$. O limite de escoamento utilizado foi de $520 \mathrm{MPa}$ para o titânio de grau três (BOYER, WELSCH et al., 1994).

A carga de pré-tensão final para os modelos com plataforma de $5.1 \mathrm{~mm}$ foi de $270.8 \mathrm{~N}$, que resultou num pico de tensão de $389.09 \mathrm{MPa}$ e para os modelos com plataforma de $4.1 \mathrm{~mm}$ foi de $208.8 \mathrm{~N}$, resultando num pico de tensão de $389.95 \mathrm{MPa}$. Note-se que essa carga não deve ser confundida com a carga de momento/torque, normalmente expressa em $\mathrm{N} / \mathrm{cm}$, que possui outra unidade. A aplicação da pré-tensão no parafuso finaliza o primeiro passo de simulação. A figura 34 mostra um exemplo da utilização do recurso "bolt pretension", e a figura 35 sua configuração na presente pesquisa.

\footnotetext{
${ }^{3}$ Esse valor foi selecionado por ser de maior intensidade do que o necessário, descoberto através de simulações piloto.
} 


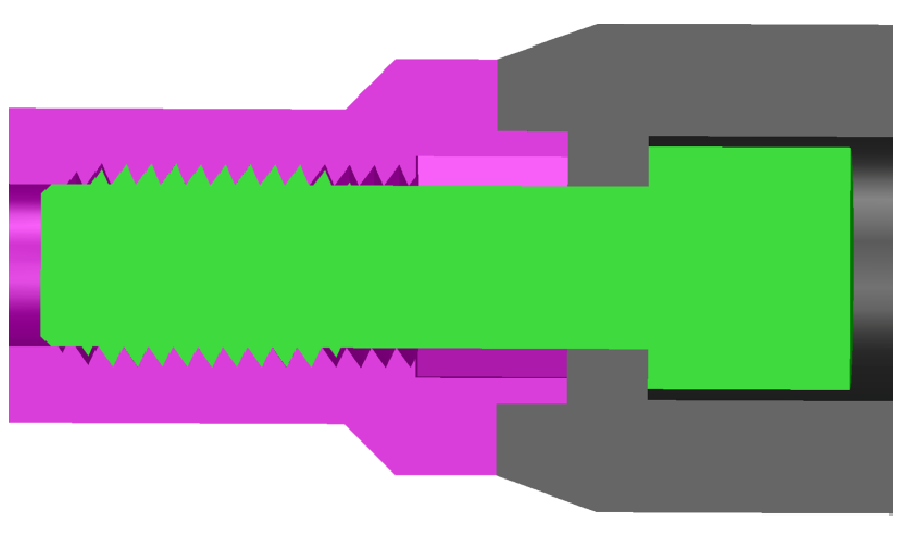

(A)

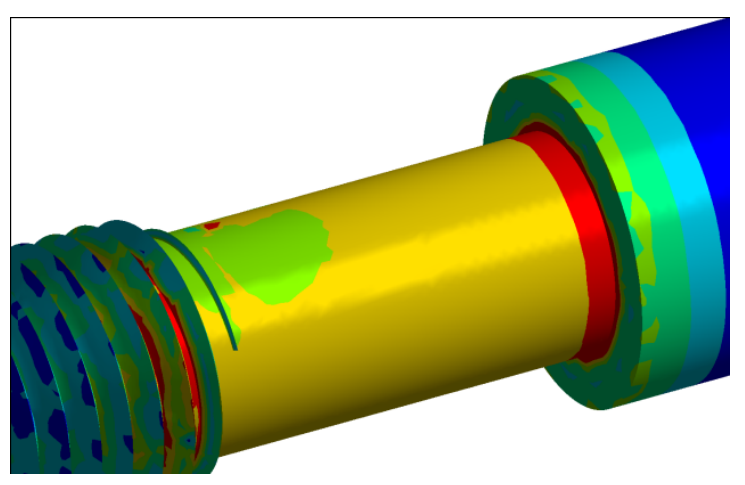

(C)

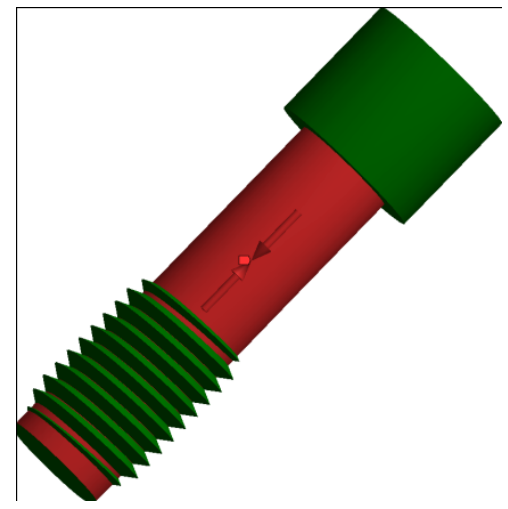

(B)

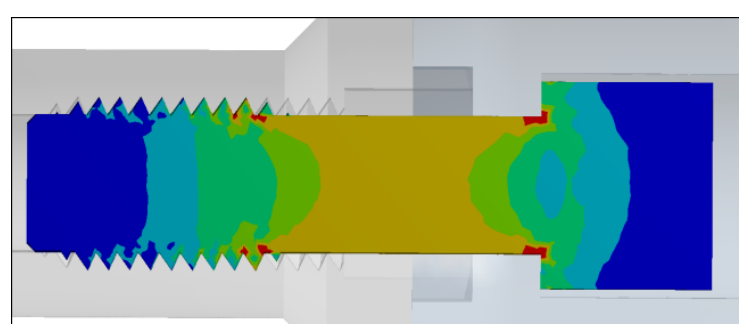

(D)

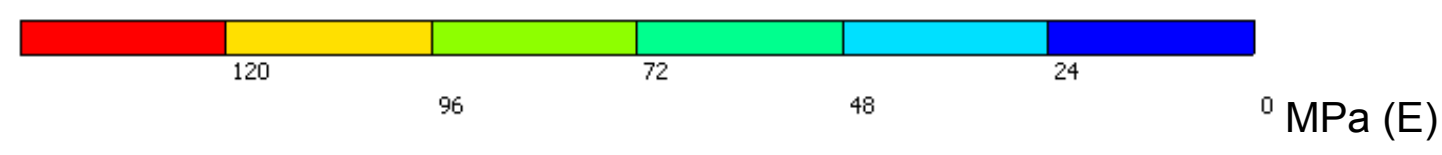

Figura 34: Exemplo de utilização do recurso bolt pretension. A: modelo das estruturas em corte. B: recurso aplicado no parafuso. C: resultado com vista externa D: resultado com vista em corte. E: Escala de tensões referente a C e $D$. 


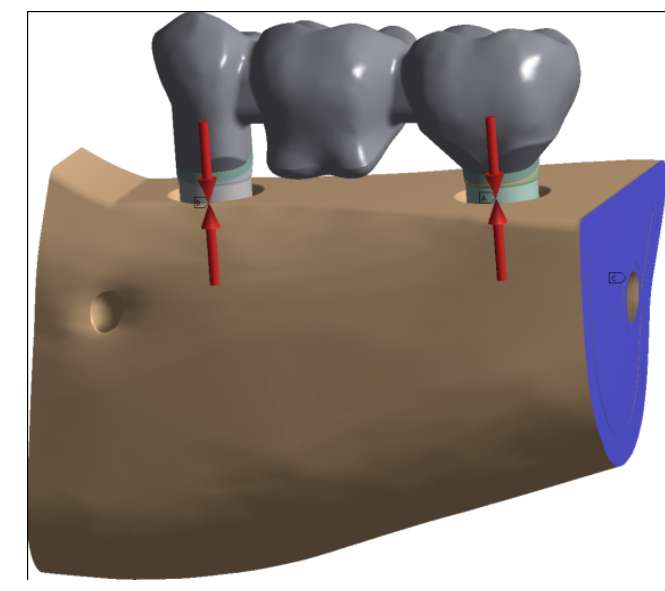

(A)

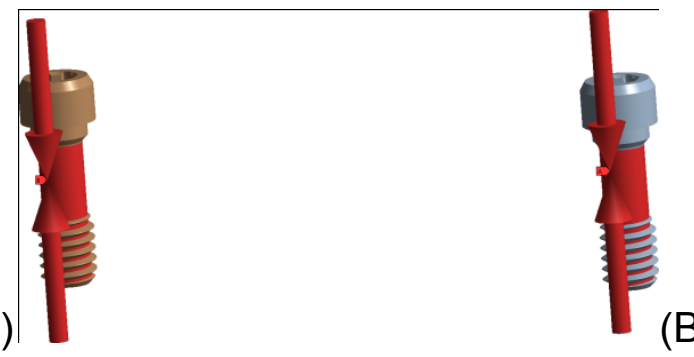

(B)

Figura 35: Vista da carga de prétensão do parafuso. $A=$ vista do modelo completo e $B=$ vista com detalhe nos parafusos.

Para o segundo passo de simulação, foram simuladas cargas mastigatórias, sendo que dois padrões de carga foram analisadas neste trabalho.

No primeiro padrão, ou carga axial, para simular o contato oclusal, a estrutura antagonista foi configurada com suportes sem fricção nas suas laterais, de forma a permitir um movimento unicamente ocluso gengival. Os contatos entre a estrutura antagonista e as coroas foram configurados como "frictionless", sendo que esses permitem deslizamentos e formação de gaps, de forma a possibilitar além da intrusão, um movimento vestíbulo-lingual dos implantes, à semelhança da situação real.

Note-se que, ao simularmos pontos de carga em diferentes regiões da superfície oclusal, é possível que uma carga isolada acarrete uma intrusão maior em determinado lado do dente devido a um efeito de alavanca, proporcionando um movimento de rotação que não ocorre na situação real. Entretanto, na oclusão normal, pelos contatos partirem de um ou no máximo dois dentes, um contato pode limitar o outro, com distribuição mais balanceada das cargas e menor rotação do implante. A figura 36 mostra o princípio desse fenômeno. 


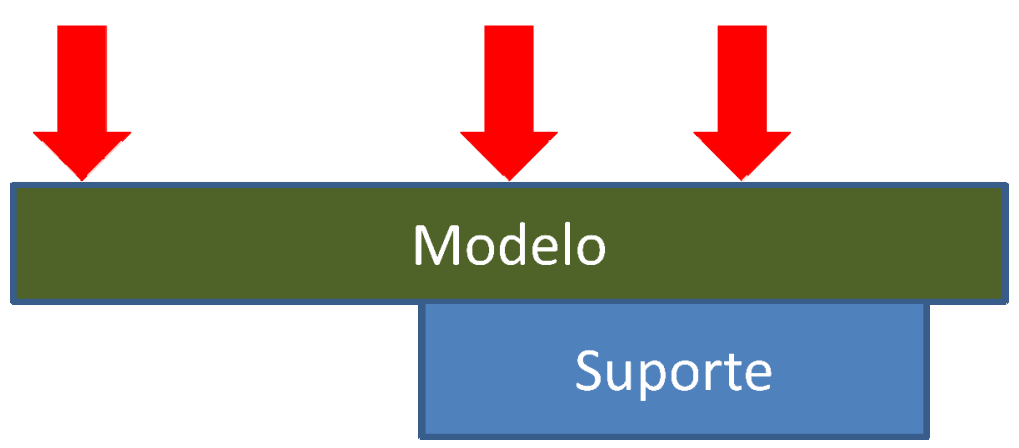

(A)

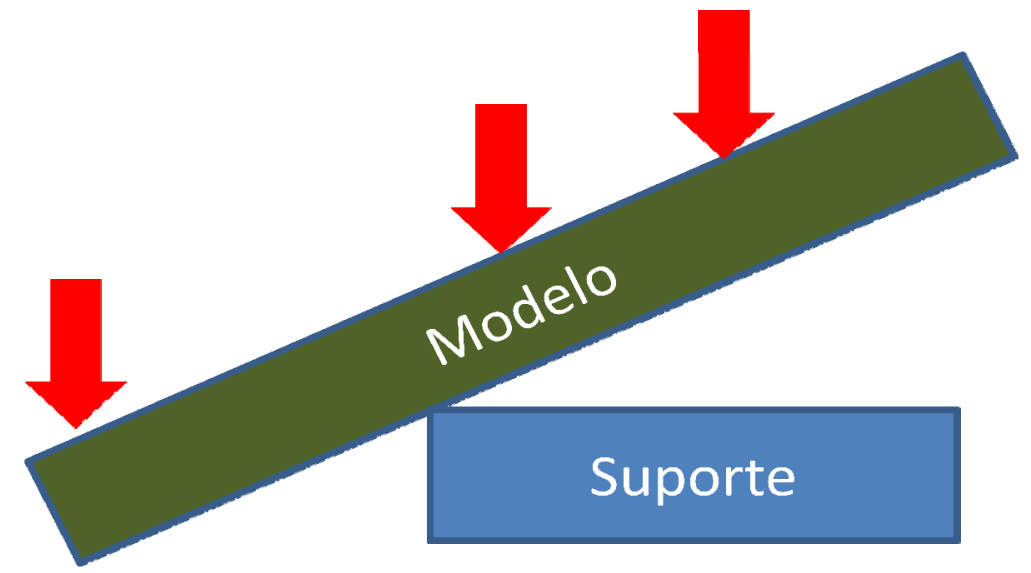

(B)

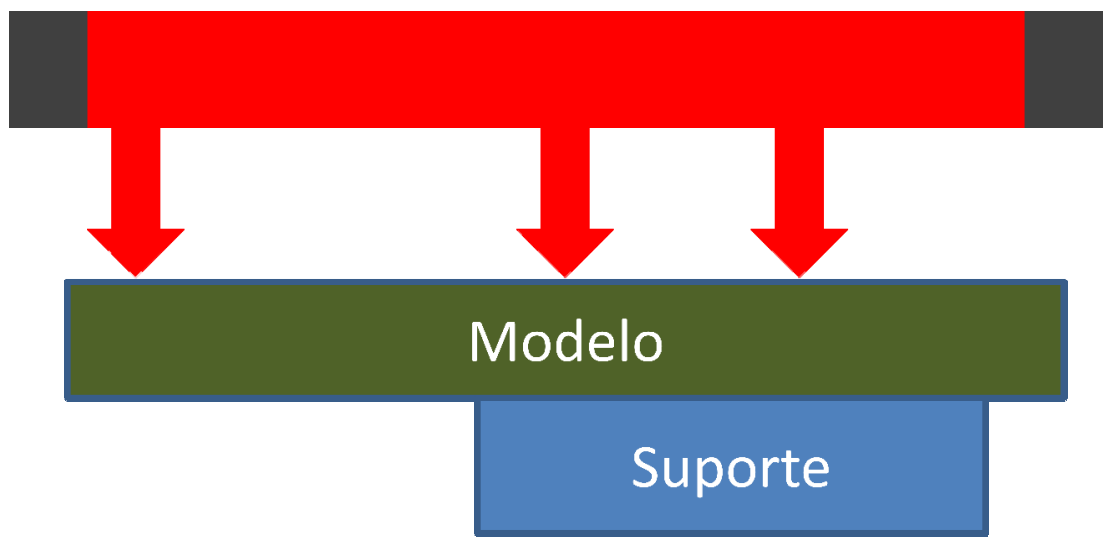

(C)

Figura 36: Diferentes condições de carga em um modelo. A aplicação de cargas isoladas pode levar a rotação do modelo devido ao princípio das alavancas (A e B), entretanto ao se unir os componentes de aplicação de forças e limitar ser movimento no sentido superior-inferior, essa tendência a rotação é neutralizada $(C)$, à semelhança da situação real.

Uma carga foi adicionada sobre a porção superior da estrutura que simula os dentes antagonistas, com intensidade de $100 \mathrm{~N}$, sendo esse valor selecionado por se encontrar dentro de limites de mastigação normal não forçada (CRAIG, 1985). E esse mesmo valor já foi utilizado em outros estudos 
para carga mastigatória em implantes. (SCHROTENBOER, TSAO et al., 2009). A figura 37 mostra o vetor de força e a área de aplicação da carga axial.

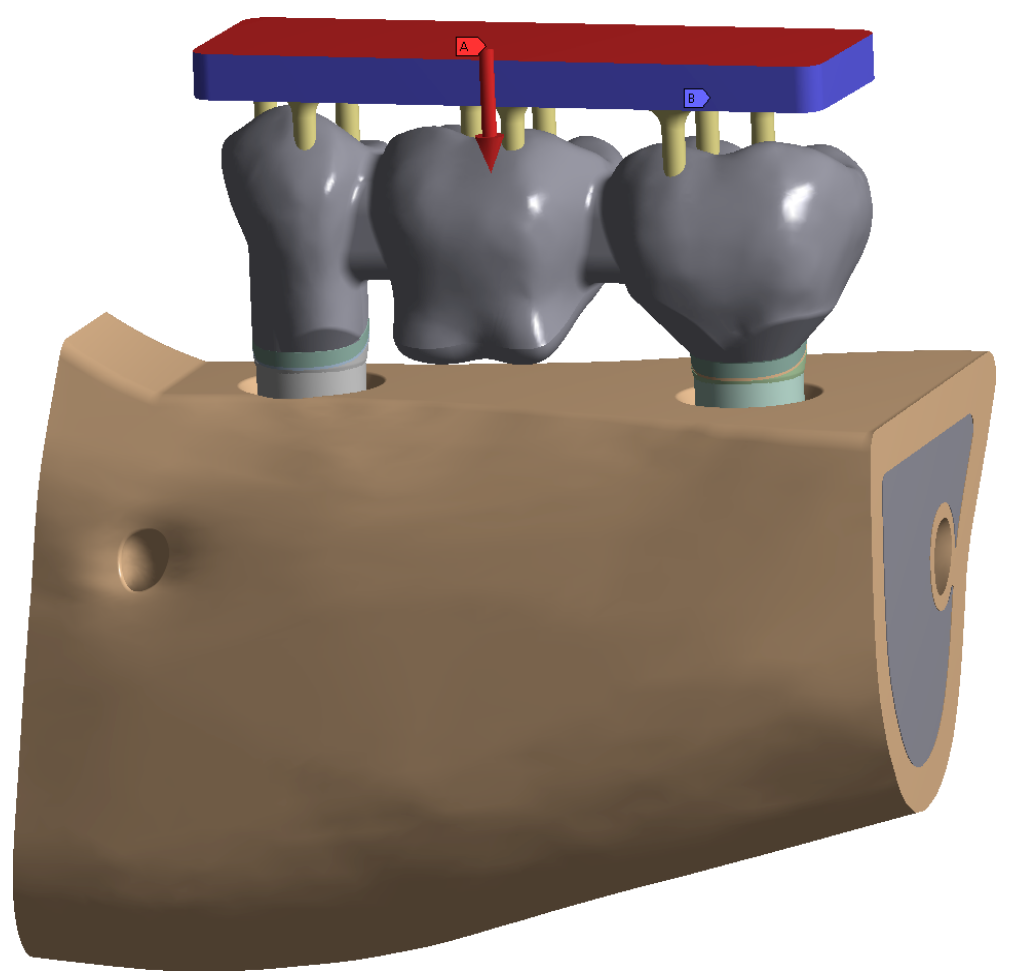

Figura 37: Configuração da carga axial. $100 \mathrm{~N}$ foram aplicadas na área vermelha com vetor demonstrado pela seta. A área azul se refere ao suporte sem fricção para permitir ao corpo um movimento unicamente ocluso-gengival

No segundo padrão de carga, ou carga oblíqua, para padronizar o contato oclusal, um ponto de contato em cada elemento, com formato cilíndrico e um $\mathrm{mm}$ de diâmetro, foi simulado no centro da coroa de cada elemento, sendo aplicada carga de $100 \mathrm{~N}$, distribuída igualmente pelos três pontos de contato, com vetor de carga no sentido linguo-vestibular, fazendo ângulo de $45^{\circ}$ com o plano oclusal. O objetivo dessa aplicação de carga não é a verificação de movimento de lateralidade, mas do efeito de vetores de carga oblíquos durante a mastigação do bolo alimentar. Note que a aplicação da carga não é acima da superfície antagonista, como no caso da carga axial, mas na superfície da prótese, conforme mostra a figura 38 . 

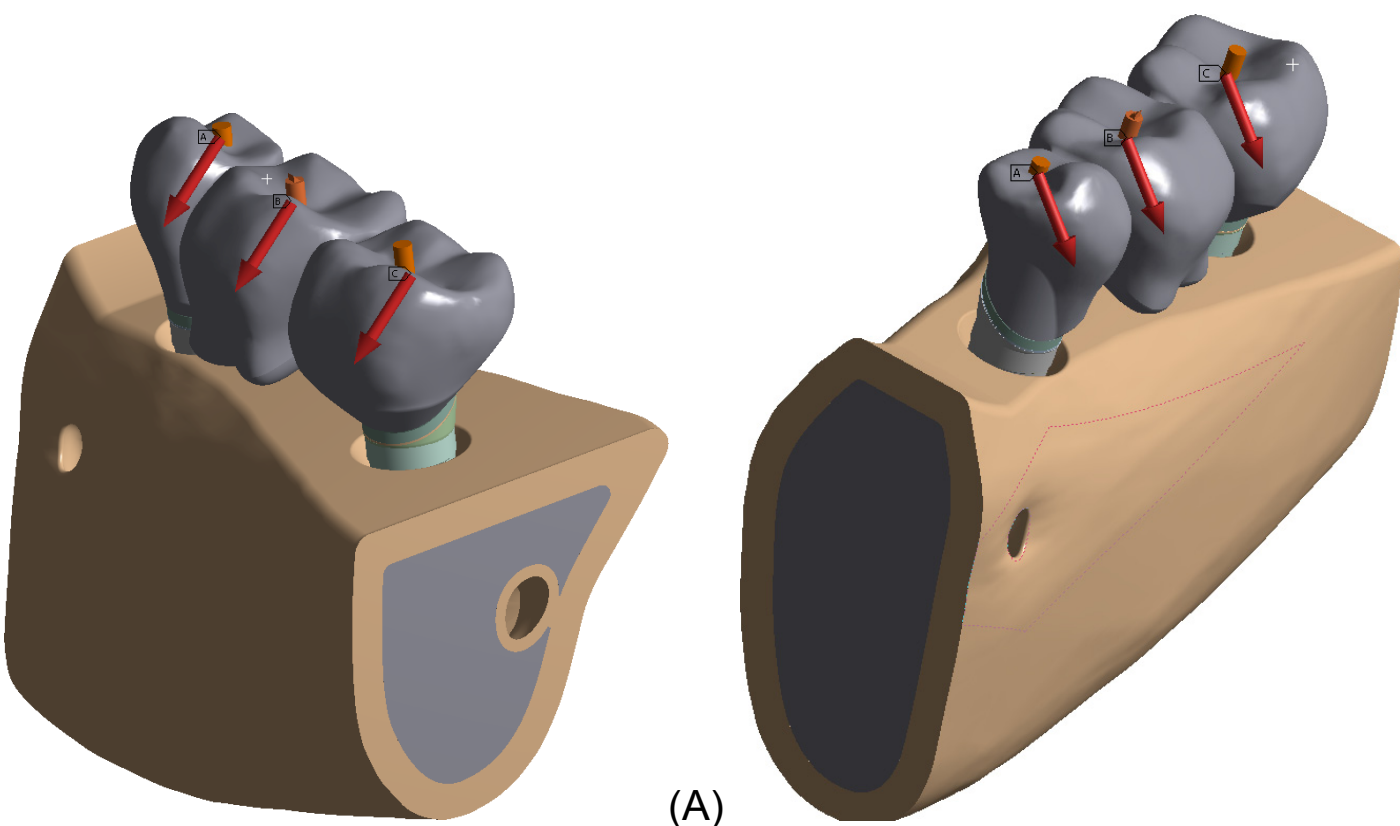

Figura 38: Configuração da carga oblíqua. $100 \mathrm{~N}$ foram distribuídos igualmente, entre os três elementos, com vetores demonstrados pelas setas vermelhas. $A=$ vista posterior $\mathrm{e} B=$ vista anterior.

Referente à geração da malha, processo denominado discretização, para melhorar a precisão do trabalho e assegurar análise comparativa válida, as malhas foram geradas e validadas através de um processo de refinamento de malha, verificando-se a convergência dos resultados. O número de nós e elementos foi gradualmente aumentado nas regiões de picos de tensão, até que a diferença nos picos dos resultados, entre um refinamento de malha e outro, fosse de $5 \%$ ou menor. Com essas medidas, o erro da simplificação, característico do processo de discretização foi minimizado. A malha foi gerada com elementos tetraédricos quadráticos ${ }^{4}$ de 10 nós (Ansys solid187), que possibilitaram a simulação de estruturas irregulares como a do presente trabalho. As figuras 39 e 40 mostram vistas da malha do modelo A e G respectivamente, e o quadro 2 o numero de nós e elementos de cada modelo. As simulações foram então resolvidos (Windows $7 \times 64$, processador Intel 17 920, 12 Gb RAM). A análise foi do tipo não linear em relação ao contato. A plotagem gráfica e numérica dos dados foi registrada, avaliada e comparada.

\footnotetext{
${ }^{4}$ Elementos de segunda ordem
} 


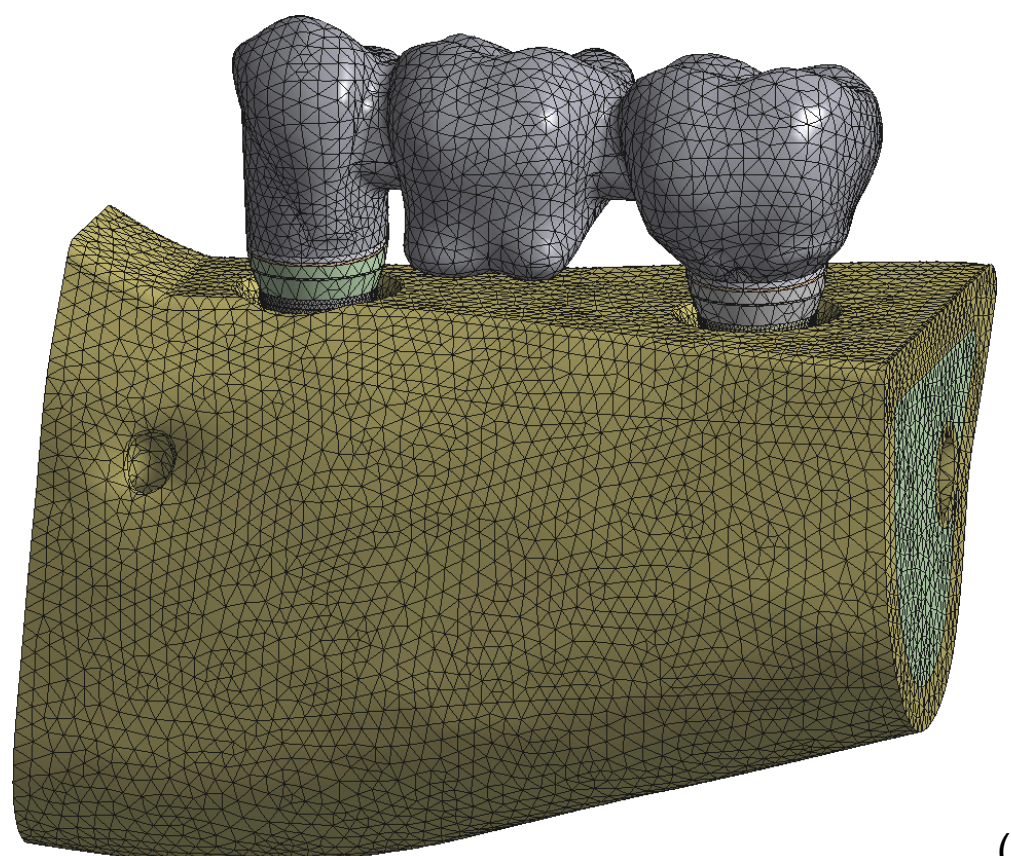

(A)

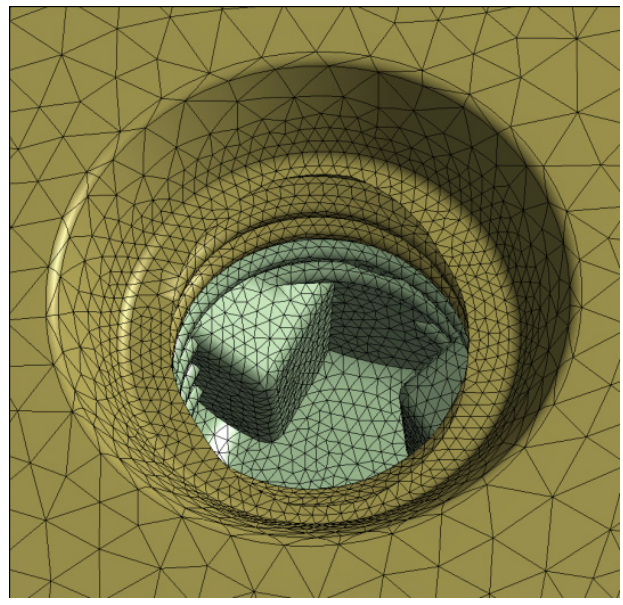

(B)

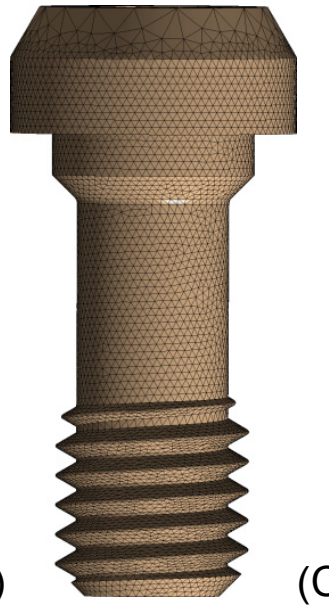

(C)

Figura 39: Vista da malha do modelo $\mathrm{A} . \mathrm{A}=$ modelo completo, $\mathrm{B}=$ vista do refinamento de malha na região periimplantar e $C=$ vista do refinamento de malha no parafuso 


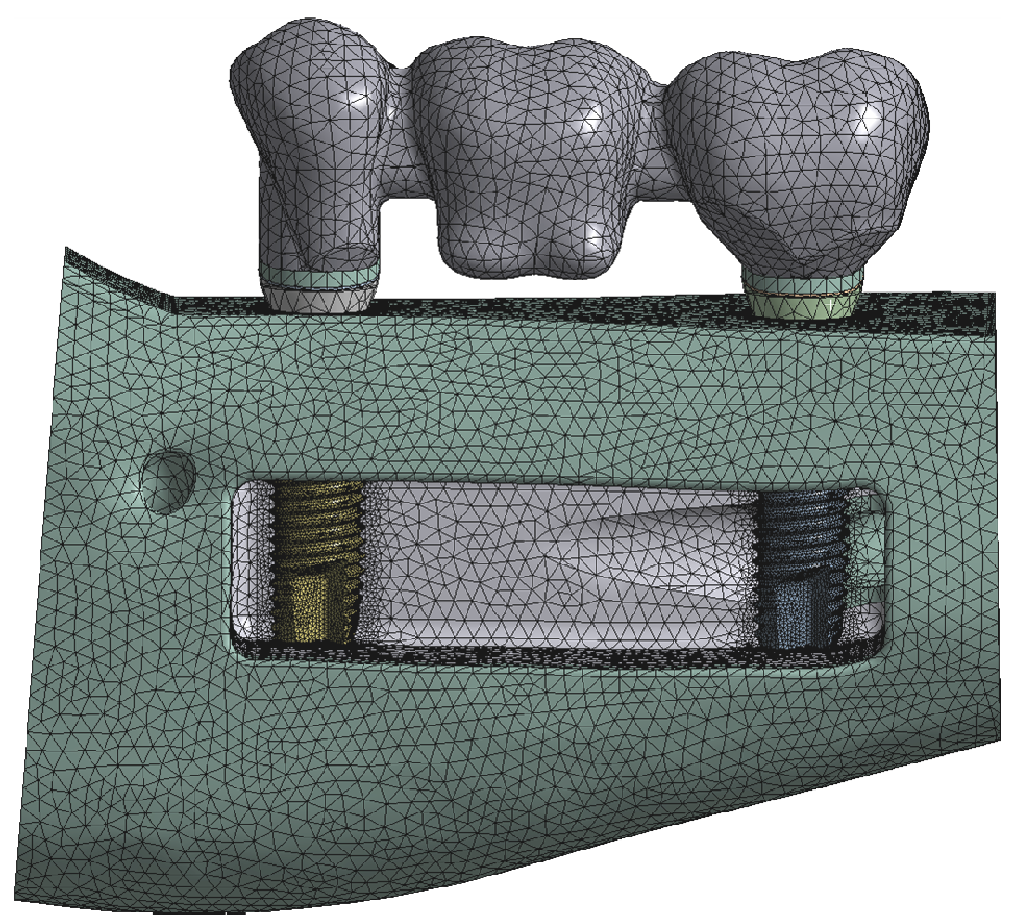

(A)

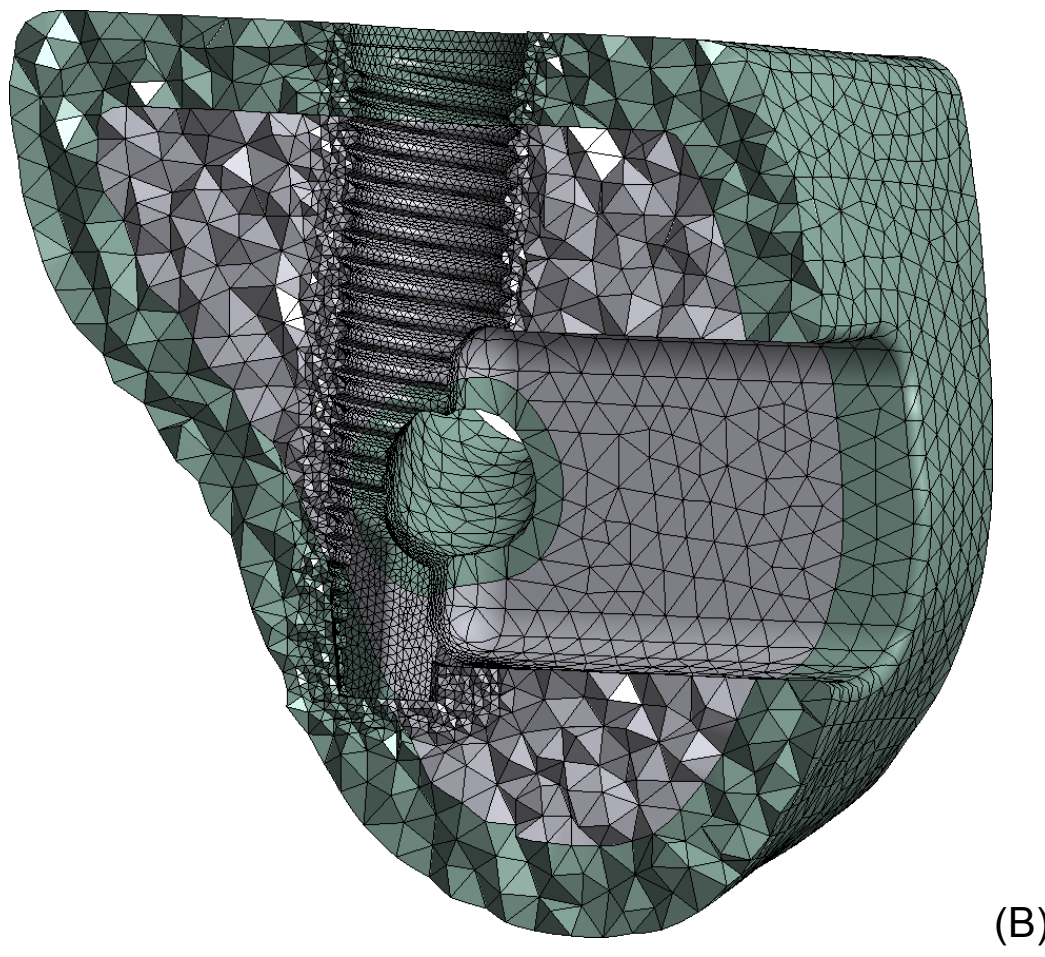




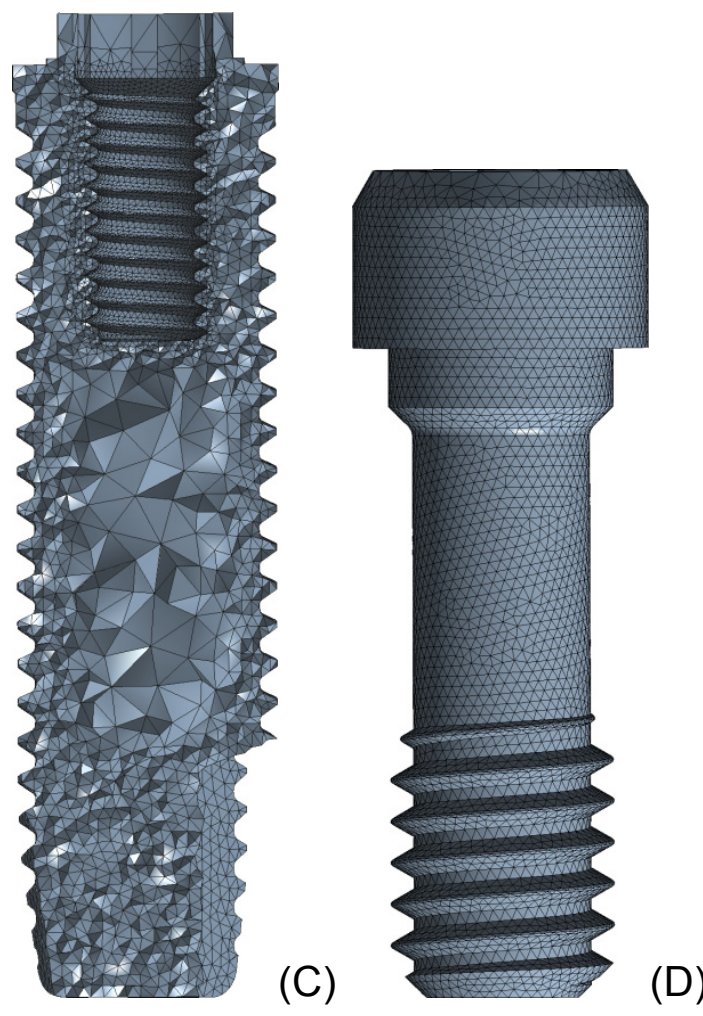

Figura 40: Vista da malha do modelo $\mathbf{G}$. $A=$ modelo completo, $B=$ vista em corte do refinamento de malha na região periimplantar, $C=v i s t a ~ d o$ refinamento de malha no implante $e=$ vista do refinamento de malha no parafuso 


\begin{tabular}{|c|c|c|}
\hline \multicolumn{3}{|c|}{ Quadro 2: Numero de nós ( $1^{\circ}$ número) e elementos em cada modelo } \\
\hline & Carga Axial & Carga Oblíqua \\
\hline $\begin{array}{l}\text { Modelo } A \\
\text { (implante de cinco } x \text { sete } \\
\mathrm{mm} \text { ) }\end{array}$ & 1578981 / 1055277 & $1559542 / 1043418$ \\
\hline $\begin{array}{l}\text { Modelo } B \\
\text { (implante de quatro } x \\
\text { sete } \mathrm{mm} \text { ) }\end{array}$ & 1240212 / 828844 & 1274545 / 853712 \\
\hline $\begin{array}{l}\text { Modelo C } \\
\text { (implante de quatro x } 15 \\
\mathrm{~mm} \text { ) }\end{array}$ & 1601917 / 1067391 & 1582478 / 1055532 \\
\hline $\begin{array}{l}\text { Modelo D } \\
\text { (implante de } 3.75 \times 15 \\
\mathrm{~mm} \text { ) }\end{array}$ & $1567408 / 1045283$ & 1547969 / 1033424 \\
\hline $\begin{array}{l}\text { Modelo } \mathrm{E} \\
\text { (implante de cinco } \times \text { sete } \\
\mathrm{mm} \text { ) }\end{array}$ & 1622680 / 1086942 & $1603241 / 1075083$ \\
\hline $\begin{array}{l}\text { Modelo } F \\
\text { (implante de quatro } x \\
\text { sete } \mathrm{mm} \text { ) }\end{array}$ & 1274545 / 853712 & 1255106 / 841853 \\
\hline $\begin{array}{l}\text { Modelo G } \\
\text { (implante de quatro x } 15 \\
\mathrm{~mm} \text { ) }\end{array}$ & 1456407 / 966190 & 1436968 / 954331 \\
\hline $\begin{array}{l}\text { Modelo } \mathrm{H} \\
\text { (implante de } 3.75 \times 15 \\
\mathrm{~mm} \text { ) }\end{array}$ & 1423735 / 944995 & 1404296 / 933136 \\
\hline
\end{tabular}




\section{Resultados}

Os resultados das simulações numérico-computacionais, objeto deste trabalho, no osso periimplantar e no parafuso foram processados gráfica e numericamente, para uma análise qualitativa e quantitativa.

A análise da porção óssea seguiu critérios distintos, para avaliar as diversas características que determinam o processo de remodelação óssea. Sabendo do efeito do dano ósseo na remodelação (TAYLOR, HAZENBERG et al., 2007), o critério de Mohr-Coulomb foi utilizado para quantificar a nível estrutural, o risco ao dano, e levando em consideração a diferença no impacto das tensões de tração e compressão num material friável como o osso (BAYRAKTAR, MORGAN et al., 2004). A tensão hidrostática foi utilizada para avaliar as alterações nas tensões ósseas que afetam o volume e fluxo dos fluidos internos, que por sua vez, afetam as células responsáveis pelo processo de remodelação óssea (HU, WANG et al., 2010; KOYAMA, MITSUI et al., 2008). Adicionalmente, como referência, foi considerado o deslocamento do osso periimplantar, devido a intensidade da micro-movimentação do implante ser um parâmetro clínico utilizado para mensurar o índice de sucesso da osseointegração (BRUNSKI, PULEO et al., 2000).

Para a análise do parafuso, o critério de fratura de von Mises, recomendado para materiais dúcteis foi utilizado. Além desse, foi utilizada a análise das tensões de cisalhamento, devido a possibilidade de fratura após o processo de corrosão nos parafusos dos implantes dentários (YOKOYAMA, ICHIKAWA et al., 2002). Adicionalmente, como referência, as tensões máximas principais foram relatadas, devido ao processo de friabilidade que o titânio sofre após a corrosão, entretanto não serão discutidas porque não é comprovado que essas tensões desempenham papel significativo no processo de fratura.

Antes mesmo de discutir os resultados, é interessante realizar uma explicação sobre o critério utilizado em cada resultado e as particularidades do método de elementos finitos, que possam afeta-los. 
O método de análise com elementos finitos, como o nome já cita, necessita transformar um domínio, corpo ou peça, em um conjunto de partes finitas, sendo uma simplificação necessária ao método, uma vez que um domínio de infinitas partes, pelo método, ocorreria num cálculo numérico infinito, e, portanto, sem solução. Dessa forma, o processo de discretização, que é a transformação das geometrias em nós e elementos, acarreta numa necessária simplificação do modelo, principalmente em geometrias complexas como as apresentadas neste trabalho.

Dentre os diferentes métodos de análise numérica/computacional, o método se destaca por permitir a variação na precisão desejada no domínio, dependendo do lugar a ser analisado. Dessa forma, quanto maior o numero de nós e elementos numa determinada região, menor será o desvio no resultado dessa região. Por esse motivo é que refinamentos de malha foram realizados nas áreas de interesse, e corpos circunvizinhos, para garantir que essa simplificação, natural ao método, não conduzisse a resultados inválidos.

De forma semelhante, a penetração existente em interações de convergência nas simulações não lineares, como as do presente trabalho, pode acarretar em desvios nos resultados. As análises deste trabalho utilizaram um método chamado de Newton-Raphson (de Isaac Newton e Joseph Raphson), em que uma solução é idealizada e ajustada após sucessivas interações, até que um resultado obtido tenha todas as condições atendidas válidas. Em outras palavras, ele define um resultado inicial, normalmente impreciso, e ajusta o resultado até que o nível de precisão desejado seja obtido. Essa imprecisão no resultado inicial é resultante normalmente da penetração existente entre os corpos, de forma que as sucessivas interações diminuirão essa imprecisão a níveis aceitáveis. Note-se que é possível a configuração da simulação de forma a não permitir nenhum tipo de penetração entre os corpos, entretanto, esse tipo de simulação é de difícil convergência e computacionalmente pesada, sendo que dessa forma, a configuração de malhas mais densas, com ajuste de um mínimo de penetração, normalmente leva a resultados mais precisos, com o mesmo peso computacional, além de diminuir o risco de não se obter um resultado (não ocorrer à convergência do 
resultado). A figura 41 mostra um gráfico de convergência do Ansys para visualização.

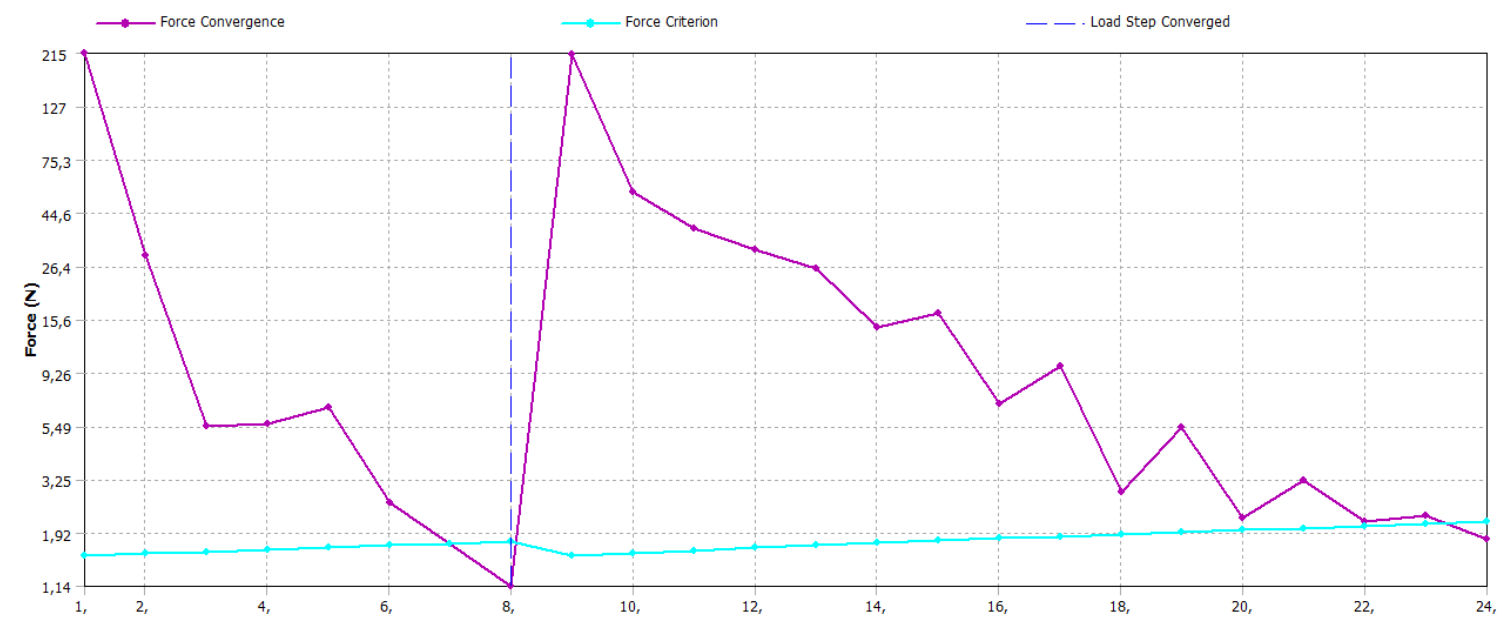

Figura 41: Gráfico de convergência de uma das simulações no Ansys, com a intensidade de penetração (vertical) e o numero de interações (horizontal). As linhas roxas se referem ao nível de penetração em cada convergência, a linha azul clara, a penetração calculada como aceitável pelo software e a linha azul escura, a divisão entre um passo de carga e outro.

Quanto aos tipos de resultados, e suas indicações, devemos primeiro entender o que são tensões principais e como essas são utilizadas para fornecer o resultado do critério de Mohr Coulomb, tensão hidrostática, von Mises e das tensões de cisalhamento. Considerando a teoria da elasticidade, pode-se obter as componentes de tensões em um ponto, imaginando-se um volume infinitesimal ao redor desse ponto que poderá ser alinhado a um sistema de coordenadas, de maneira que suas faces estarão submetidas a diferentes componentes de tensões (normais e tangenciais).

Esse volume pode ser rotacionado, de maneira que nessas faces existam apenas tensões normais e as tensões de cisalhamento sejam nulas, como mostra a figura 42. Essas faces são chamadas de faces ou planos principais. Aos separamos as tensões que ocorrem no ponto, pelos três planos principais, obteremos três valores distintos. A tensão de maior intensidade, 
normalmente positiva, ou seja, a maior tensão entre as três é definida como a tensão máxima principal, a tensão intermediária como tensão média principal, e a menor como tensão mínima principal, conforme mostra a figura 42. Note que no volume ainda ocorrem tensões de cizalhamento, elas apenas não ocorrem nos planos principais.
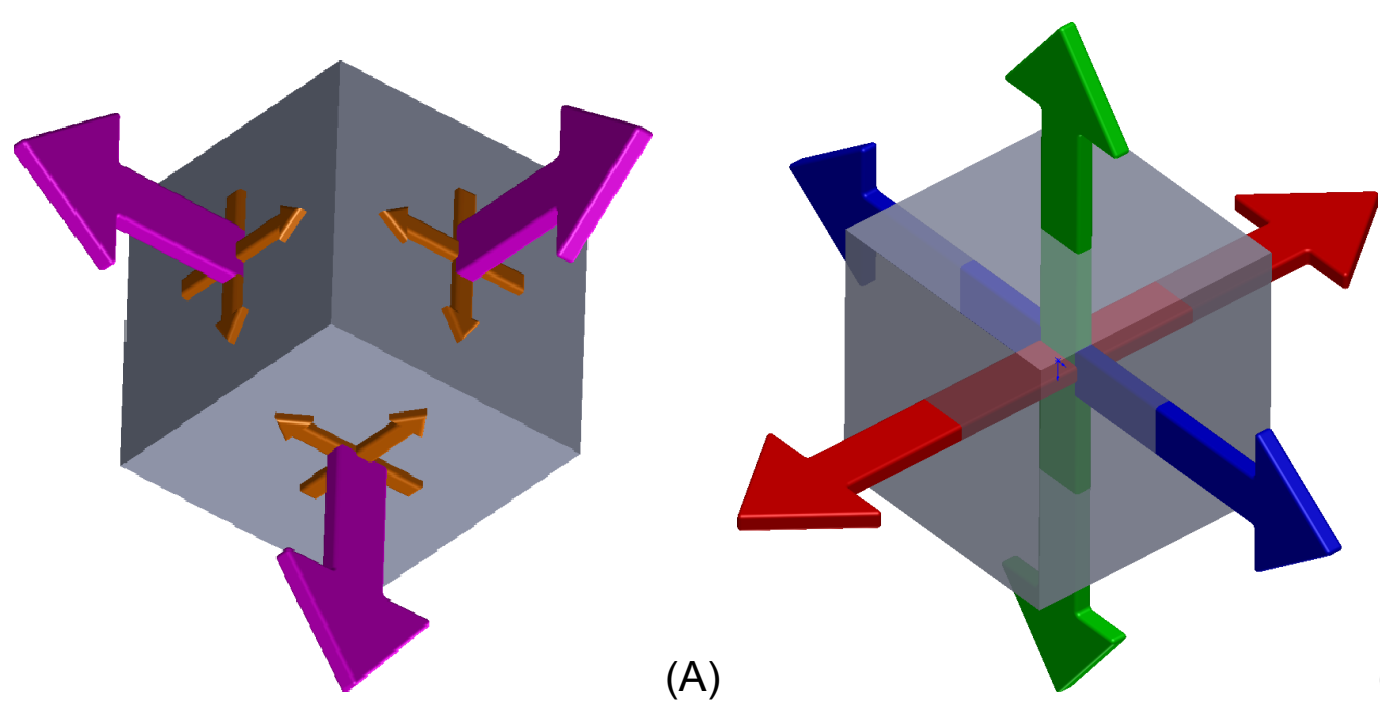

Figura 42:Tensões que podem ocorrer em um volume de matéria. A: Tensões de tração, compressão e cizalhamento. B: Volume rotacionado de forma a demonstrar apenas tensões de tração e compressão.

Se, por exemplo, os três resultados obtidos forem $50 \mathrm{MPa}, 10 \mathrm{MPa}$ e -23 $\mathrm{MPa}$, o resultado de $50 \mathrm{MPa}$ se refere à tensão máxima principal, $10 \mathrm{MPa}$ a média e -23 MPa a tensão mínima principal. É convenção que as tensões de tração tenham valores positivos $\mathrm{e}$ as tensões de compressão valores negativos. Portanto, em engenharia, ao citar que existe uma tensão de -34 $\mathrm{MPa}$ é o equivalente a definir como uma tensão de compressão de $34 \mathrm{MPa}$, similarmente, uma tensão de $60 \mathrm{MPa}$ é equivalente a uma tensão de tração de $60 \mathrm{MPa}$.

Note-se que, embora seja possível, em um ponto, a existência de tensões exclusivamente de tração ou de compressão, normalmente, o maior resultado entre as tensões máximas principais se refere ao pico de tração e o menor resultado (maior módulo, mas negativo) entre as tensões mínimas principais, se refere ao pico das tensões de compressão. Essa divisão é 
importante ao analisarmos materiais que reagem diferentes a tensões de tração e compressão, mesmo que seu módulo seja o mesmo, como é o caso dos materiais friáveis/frágeis, além de entender as bases pelos quais diversos critérios de fratura são utilizados.

Essas tensões principais são fundamentais para o cálculo da maioria dos resultados apresentados nesta pesquisa.

Os modelos controle, B (implante de $4 \times 7 \mathrm{~mm}$ ) e F (implante de $4 \times 7$ $\mathrm{mm}$ ) foram selecionados como os protocolos de dois e um estágio respectivamente. Normalmente, os tratamentos de maior utilização e mais estudados são os utilizados como controle, entretanto, não existe um consenso na literatura sobre o assunto. Por esse motivo e por simplificação, os modelos citados foram selecionados.

Embora seja possível a avaliação dos resultados tanto do elemento 35 como do 37, para simplificar a discussão, apenas os resultados do elemento distal serão demonstrados e discutidos, uma vez que a análise do elemento anterior leva a conclusões semelhantes ao do elemento posterior. Os quadros 3 e 4 contêm a área de inserção óssea do elemento 37 e foram colocadas para auxiliar na interpretação dos resultados. 


\begin{tabular}{|c|c|c|c|c|}
\hline & $\begin{array}{l}\text { Cortical na } \\
\text { crista }\end{array}$ & $\begin{array}{l}\text { Cortical na } \\
\text { região apical }\end{array}$ & Medular & $\begin{array}{ll}\text { Total de } & \text { de } \\
\text { inserção } & \\
\text { cortical } & \end{array}$ \\
\hline $\begin{array}{l}\text { Modelo } A \\
\text { (implante de } \\
\text { cinco x sete } \\
\mathrm{mm} \text { ) }\end{array}$ & $34,0 / 130 \%$ & & 73,1 & $34,0 / 130 \%$ \\
\hline $\begin{array}{l}\text { Modelo B } \\
\text { (implante de } \\
\text { quatro } x \text { sete } \\
\text { mm) }\end{array}$ & $26,0 / 100 \%$ & & 58,0 & $26 / 100 \%$ \\
\hline $\begin{array}{l}\text { Modelo C } \\
\text { (implante } \\
\text { quatro } \times 15 \\
\mathrm{~mm} \text { ) }\end{array}$ & $26,0 / 100 \%$ & 8,3 & 183,4 & $34,3 / 132 \%$ \\
\hline $\begin{array}{ll} & \text { Modelo D } \\
\text { (implante } & \text { de } \\
3.75 \quad x \quad 15 \\
\mathrm{~mm} \text { ) }\end{array}$ & $24,2 / 93 \%$ & 6,9 & 171,7 & $31,1 / 119 \%$ \\
\hline
\end{tabular}




\begin{tabular}{|c|c|c|c|c|}
\hline & $\begin{array}{l}\text { Cortical na } \\
\text { crista }\end{array}$ & $\begin{array}{l}\text { Cortical na } \\
\text { região apical }\end{array}$ & Medular & $\begin{array}{ll}\text { Total de } & \text { de } \\
\text { inserção } & \\
\text { cortical } & \end{array}$ \\
\hline $\begin{array}{l}\text { Modelo } \mathrm{E} \\
\text { (implante de } \\
\text { cinco x sete } \\
\mathrm{mm} \text { ) }\end{array}$ & $40,3 / 130 \%$ & & 95,7 & $40,3 / 130 \%$ \\
\hline $\begin{array}{l}\text { Modelo } \mathrm{F} \\
\text { (implante de } \\
\text { quatro x sete } \\
\mathrm{mm} \text { ) }\end{array}$ & $30,9 / 100 \%$ & & 75,4 & $30,9 / 100 \%$ \\
\hline $\begin{array}{l}\text { Modelo G } \\
\text { (implante de } \\
\text { quatro x } 15 \\
\mathrm{~mm} \text { ) }\end{array}$ & $30,9 / 100 \%$ & 13,6 & 120,4 & $44,5 / 144 \%$ \\
\hline $\begin{array}{l}\text { Modelo } \mathrm{H} \\
\text { (implante } \\
3.75 \quad \mathrm{de} \\
\mathrm{mm} \text { ) }\end{array}$ & $29,8 / 96 \%$ & 12,4 & 111,9 & $42,2 / 136 \%$ \\
\hline
\end{tabular}

\subsection{Resultados do osso periimplantar}

É conhecido e bem aceito pela comunidade científica que estímulos mecânicos podem levar a processos de remodelação óssea (HART, DAVY et al., 1984; LIN, LI et al., 2009; NATALI, PAVAN et al., 2006), entretanto, os mecanismos exatos que regulam essa reorganização estrutural é tema de muito debate. Frost propôs a teoria do Mecanostato (FROST, 1987), em que, dependendo da deformação a que é submetido, o osso pode sofrer atrofia por desuso, manter sua massa óssea sobre cargas fisiológicas, aumentar sua massa óssea por estímulos maiores que os fisiológicos ou sofrer reabsorção quando a deformação passa do limite tolerável pelo organismo. Embora a teoria seja muito discutida quanto aos estímulos que determinam a resposta óssea, é bem aceito o conceito de perda, manutenção ou ganho de massa óssea pela comunidade científica, dependendo da intensidade do estímulo. 
Ao consideramos essa teoria, a princípio, um implante sob função teoricamente não sofre processo de atrofia. A manutenção e aumento da massa óssea não são processos deletérios, portanto a sobrecarga representa o risco real de perda óssea ao redor dos implantes analisados. Considerando essa discussão, para a compreensão das implicações clínicas envolvidas em simulações ósseas, uma compreensão dos mecanismos que regulam os fenômenos de remodelação óssea é necessária (NATALI, PAVAN et al., 2006).

Quanto aos critérios utilizados no osso na presente pesquisa, a teoria do critério de Mohr Coulomb define que um material fratura quando a combinação das tensões principais se igualam ou excedem os limites de resistência. $O$ critério clássico pode ser definido pela fórmula:

$\frac{\sigma_{1}}{\sigma_{\text {resistência a tração }}}+\frac{\sigma_{3}}{\sigma_{\text {resistência a compressão }}}<1$

onde $\sigma_{1}$ é a tensão máxima principal, $\sigma_{3}$ a tensão mínima principal e $\sigma_{\text {resistência }}$ a tensão máxima de fratura a compressão e tração. Dessa forma, o critério analisa o impacto das tensões de tração e sua relação com a resistência a tração, bem como as tensões de compressão e sua relação com a resistência a compressão, sendo indicada para análise de materiais friáveis, exatamente por distinguir a diferença de resistência entre tração e compressão, típica desses materiais.

Entretanto, o presente trabalho não se concentra na análise do risco a fratura, por ser raro esse acontecimento nas condições analisadas por esse estudo, mas na análise do risco a dano, considerado importante fator no processo de remodelação óssea. $O$ excesso pode levar a reabsorção óssea local (TAYLOR, HAZENBERG et al., 2007). Portanto, para a análise do presente trabalho uma adaptação foi realizada e pode ser definida pela fórmula:

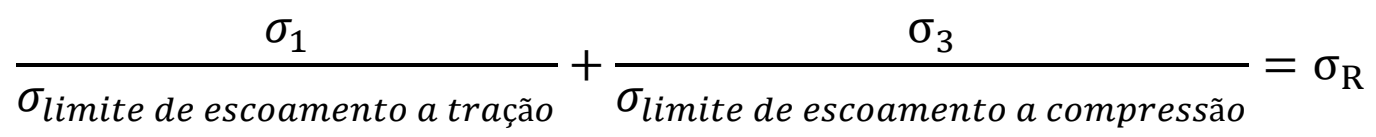


onde $\sigma_{\mathrm{R}}$ é o resultado, $\sigma_{1}$ é a tensão máxima principal, $\sigma_{3}$ a tensão mínima principal e $\sigma_{\text {limite }}$ a tensão máxima de escoamento à compressão e a tração. Pela formula, quanto maiores às tensões principais, maior será o resultado e conseqüentemente maior o risco de reabsorção óssea por sobrecarga. Dessa forma, ao consideramos que o dano ocorre após o limite de escoamento, mas antes do limite de fratura, os limites de escoamento tornam-se mais interessantes para mensuração do risco ao dano e o resultado pode avaliar o impacto proporcional de cada tipo de tensão nesse risco.

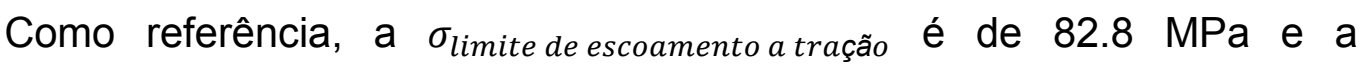

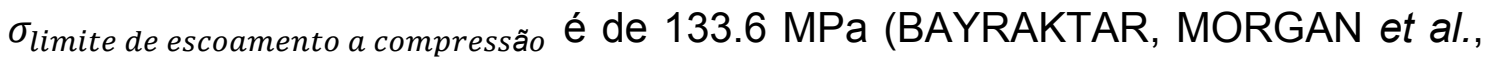
2004). Note-se que esses valores são baseados no osso trabecular, uma vez que não foram encontrados valores de referência, dentro de um mesmo estudo, para os índices do osso cortical. Porém, por serem materiais similares, os valores provavelmente terão proporção semelhante.

Outro critério utilizado para análise do osso se refere à tensão hidrostática. Ao considerarmos um material qualquer, sobre aplicação de cargas, as tensões incidentes sobre este corpo podem ser divididas em tensões que causam alteração no volume e tensões que distorcem o volume. Ao consideramos que a nível microscópico, as células imersas nos fluidos intraósseos tem a capacidade de reagirem a diferenças na pressão interna dos fluidos, bem como o fluxo desses fluidos, e que aumento demasiados nessa tensão hidrostática pode levar a inibição de atividades em células osteoprogenitoras e estimular a função dos osteoclastos (HU, WANG et al., 2010; KOYAMA, MITSUI et al., 2008), a análise da tensão hidrostática torna-se interessante para avaliar o processo de remodelação óssea a nível celular e considerar um fator que pode levar a perda óssea periimplantar.

A tensão hidrostática é definida pela fórmula:

$$
\sigma_{m}=\frac{\sigma_{1}+\sigma_{2}+\sigma_{3}}{3}
$$


onde $\sigma_{m}$ é a tensão hidrostática ou tensão média, e $\sigma_{1}, \sigma_{2}$ e $\sigma_{3}$ as tensões principais máxima, média e mínima respectivamente. Embora existam estudos analisando tensões trativas (YOU, YELLOWLEY et al., 2000) e compressivas (HU, WANG et al., 2010; KOYAMA, MITSUI et al., 2008) na influência a células pertinentes ao processo de remodelação óssea, não está definido, dentro do conhecimento do autor, qual tipo de tensão é mais ou menos deletéria a nível celular. Considerando que a intensidade das tensões de compressão foi superior em todos os modelos, este trabalho se concentrará na discussão das tensões hidrostáticas compressivas, mas fornecerá os resultados dos picos de tensão hidrostática trativa para futuros estudos.

Os resultados de micromovimentação referem-se à movimentação total do corpo durante a simulação e não apenas a movimentação relativa entre osso e implante. Embora essa movimentação relativa possa ser interessante sob alguns aspectos, ela forneceria resultados mínimos em locais de compressão óssea pelo implante, onde processos de remodelação óssea podem ocorrer. Por outro lado, a micromovimentação total do osso periimplantar pode levar a falsos resultados, uma vez que não considera o movimento do ramo da mandíbula e, em contrapartida, se aproxima mais de mensurações realizadas clinicamente.

Foi sugerido que $50 \mu \mathrm{m}$ é um valor de micromovimentação tolerável, podendo ser ainda maior, dependendo do tipo de superfície do implante (DACULSI, LEGEROS et al., 1990; STEFLIK, HANES et al., 1992), entretanto, não existem, dentro do conhecimento do autor, valores cientificamente comprovados de segurança para a micromovimentação. Ademais, embora seja um critério clínico relevante, até mesmo para estudos comparativos, por fornecer um resultado numérico quantificável clinicamente, o autor não discutiu os referidos resultados devido às limitações acima expostas, porém serão citados para possibilitar comparações com outras metodologias.

Estabelecendo um paralelo entre os critérios de Mohr Coulomb e tensão hidrostática, com a teoria do mecanostato de Frost (FROST, 1987), e considerando que, dentro do conhecimento dos autores, atrofia óssea por 
desuso não acontece em implantes dentários sob função, o maior risco de perda óssea está na sobrecarga fisiológica do organismo. Por esse motivo, os resultados de maior intensidade representam maior risco para perda óssea na região periimplantar. Note que não existem valores seguros de referência para as variáveis analisadas, e considerando a grande variabilidade de situações presentes na prática clínica, como força mastigatória, posição do implante, qualidade óssea, entre outras, este trabalho tem intuito de discutir quais tratamentos tem maior risco de perda por sobrecarga.

Em análises de elementos finitos, diversos estudos se propõem a representar matematicamente e/ou simular o mecanismo de remodelação óssea, não apenas com análise estática do problema, como a do presente trabalho, mas com variações na estrutura óssea ao longo do tempo (DAVIDSON, MILBURN et al., 2004; HAZELWOOD, BRUCE MARTIN et al., 2001; LI, LI et al., 2007; MCNAMARA, TAYLOR et al., 1997; REINA, GARCIAAZNAR et al., 2007). Teoricamente, essas análises realizam simulação mais apropriada do problema. Embora os autores não tenham dúvida que essa forma de simulação é o futuro das análises biomecânicas, no momento, existem poucos e relativamente limitados estudos que possam determinar os mecanismos envolvidos e quantificar o fenômeno, de forma a alimentar as configurações da simulação com dados precisos da realidade. Essas simulações são computacionalmente pesadas também, de forma que dificulta a simulação de estruturas mais complexas, como a do presente trabalho.

A maioria dos trabalhos que se propõem a representar matematicamente a remodelação óssea se baseia em diversas informações empíricas. Por esses motivos, os autores preferiram uma análise mais simples, baseando-se em fatores de risco, até que os fenômenos envolvidos nos mecanismos de reparo e remodelação óssea sejam descritos de forma mais precisa. É importante ressaltar que muitos desses estudos apresentam dados comparáveis a realidade, ou validados, em determinados momentos/tempos da simulação, entretanto para que os modelos sejam confiáveis, essa correlação deve ser duradoura e durante todo, ou pelo menos na maior parte, do processo de simulação, para ser clinicamente aceitável. 
Outro fator que deve ser mencionado, é que boa parte dos estudos sobre remodelação óssea, utiliza as deformações como estímulo indutor, e não as tensões, nas suas análises. Embora as deformações possam ser interessantes no mecanismo de remodelação óssea, em análises estáticas, utilizando mecânica do contínuo, picos de deformação existentes no osso medular podem levar a interpretações errôneas sobre o resultado, uma vez que esses picos não levam necessariamente a um comprometimento estrutural, mas, muitas vezes, apenas a uma remodelação da estrutura interna, sem efeitos significativos e sem perda de massa óssea, como ocorreu na simulação de Lian e colaboradores (LIAN, GUAN et al., 2010).

Por outro lado, a remodelação no osso cortical superficial possibilita, quase que exclusivamente, a diminuição da altura e não o ganho, sendo que essa perda de altura implica na perda de massa óssea para o sistema. Além disso, sabe-se que o osso medular tem impacto bem menor no suporte estrutural do que o osso cortical, que inclusive pode ser visualizado nos resultados do presente trabalho. Por esses motivos, foi utilizado um critério de tensões, em vez de deformações, no presente trabalho. Note que diversos estudos analisando implantes dentários, também utilizam critérios de tensões em suas análises (PETRIE e WILLIAMS, 2005; PIERRISNARD, RENOUARD et al., 2003; QIAN, TODO et al., 2009).

\subsubsection{Resultados do osso periimplantar com implantes osseointegrados}

Deve-se ressaltar que a presente pesquisa foi realizada considerando inserção óssea ao redor de todo o implante. Embora o cirurgião possa colocar implantes de maior diâmetro, mesmo negando inserção óssea vestibular ou lingual ao implante, essa forma de tratamento não foi avaliada pela presente pesquisa.

Quanto aos resultados propriamente ditos, o quadro 5, e as figuras 43 a 46 se referem aos resultados no osso periimplantar, dos modelos com 
osseointegração dos implantes, sob carga axial. Como discutido anteriormente, os resultados de tensão hidrostática trativa e micromovimentação foram colocados apenas como referência e não serão discutidos/analisados.

Quadro 5: Valores de picos dos resultados no osso periimplantar, para implantes osseointegrados, submetidos à carga axial e seu percentual em relação ao controle (modelo $\mathrm{B}$ ).

\begin{tabular}{|l|l|l|l|l|}
\hline & $\begin{array}{l}\text { Mohr- } \\
\text { Coulomb } \\
\left(\sigma_{\mathrm{R}}\right)\end{array}$ & $\begin{array}{l}\text { tensão } \\
\text { hidrostática } \\
\text { compressiva } \\
(\mathrm{MPa})\end{array}$ & $\begin{array}{l}\text { tensão } \\
\text { hidrostática } \\
\text { trativa } \\
(\mathrm{MPa})\end{array}$ & $\begin{array}{l}\text { Micromovimentação } \\
(\mu \mathrm{m})\end{array}$ \\
\hline $\begin{array}{l}\text { Modelo A } \\
\text { (implante } \\
\text { de cinco } \\
\text { sete mm) }\end{array}$ & $0,101 / 99 \%$ & $6,03 / 92 \%$ & $2,13 / 75 \%$ & $2,95 / 91 \%$ \\
\hline $\begin{array}{l}\text { Modelo B } \\
\text { (implante } \\
\text { de quatro } \\
\text { sete mm) }\end{array}$ & $0,102 / 100 \%$ & $6,57 / 100 \%$ & $2,83 / 100 \%$ & $3,23 / 100 \%$ \\
\hline $\begin{array}{l}\text { Modelo C } \\
\text { (implante } \\
\text { de quatro x } \\
15 \text { mm) }\end{array}$ & $0,084 / 82 \%$ & $5,51 / 84 \%$ & $1,85 / 65 \%$ & $2,43 / 75 \%$ \\
\hline $\begin{array}{l}\text { Modelo D } \\
\text { (implante } \\
\text { de 3.75 } \\
15 \text { mm) }\end{array}$ & $0,088 / 86 \%$ & $5,92 / 90 \%$ & $2.61 / 92 \%$ & $2,53 / 78 \%$ \\
\hline
\end{tabular}

A figura 43 se refere às perspectivas das figuras 44 a 52 .

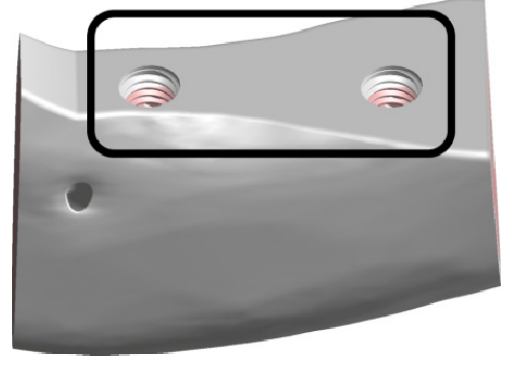

(A)

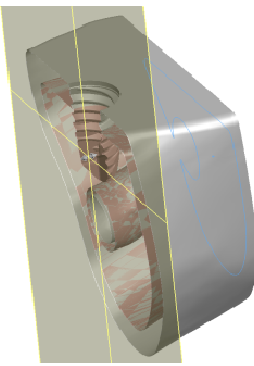

(B)

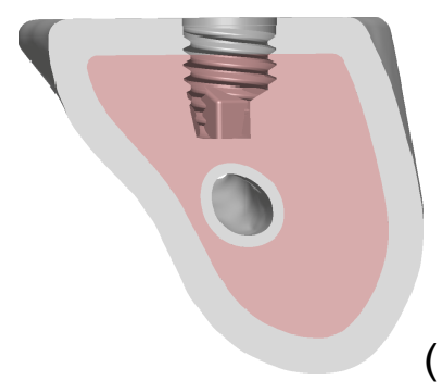

(C)

Figura 43: Vista do modelo $A$, com detalhes da região de plotagens das figuras 44 a 52 . 

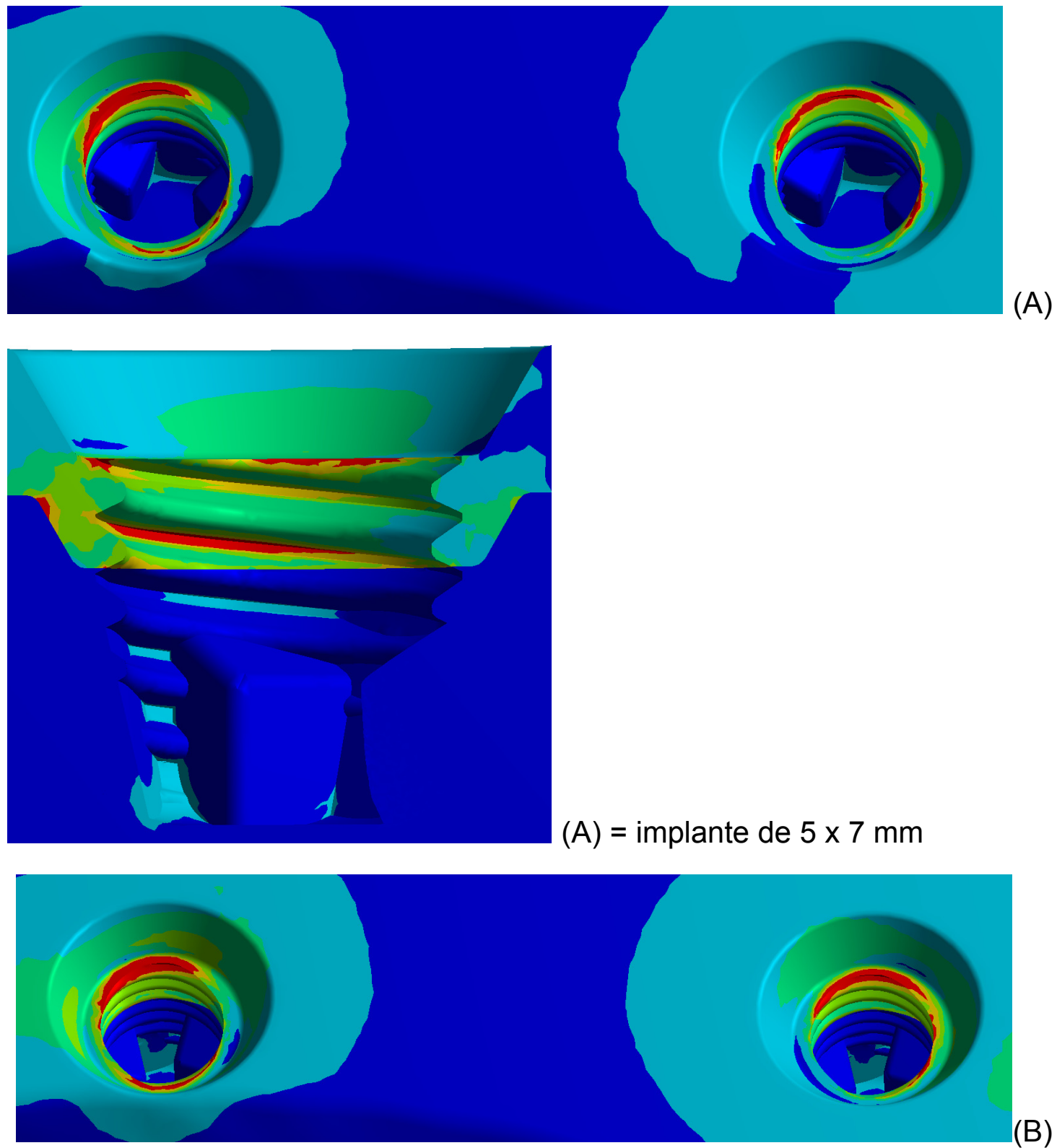

(B)

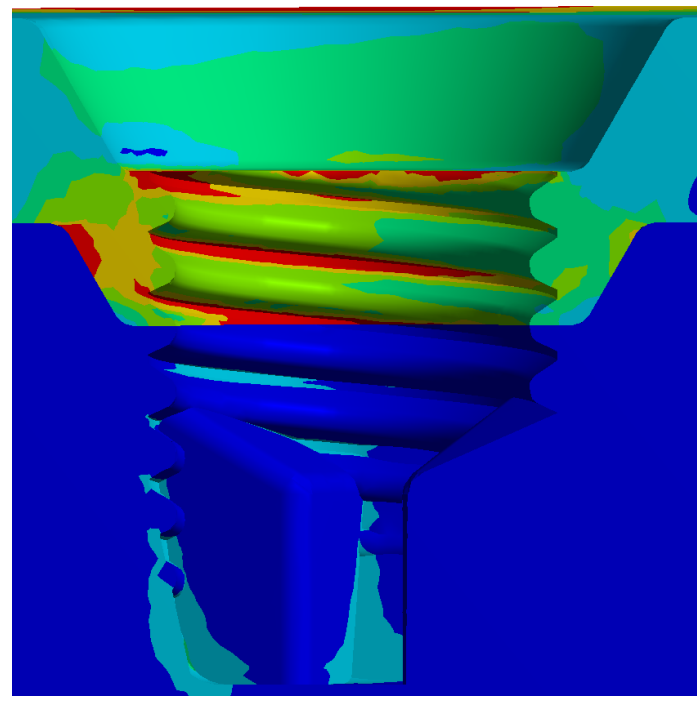

(B) = implante de $4 \times 7 \mathrm{~mm}$ 

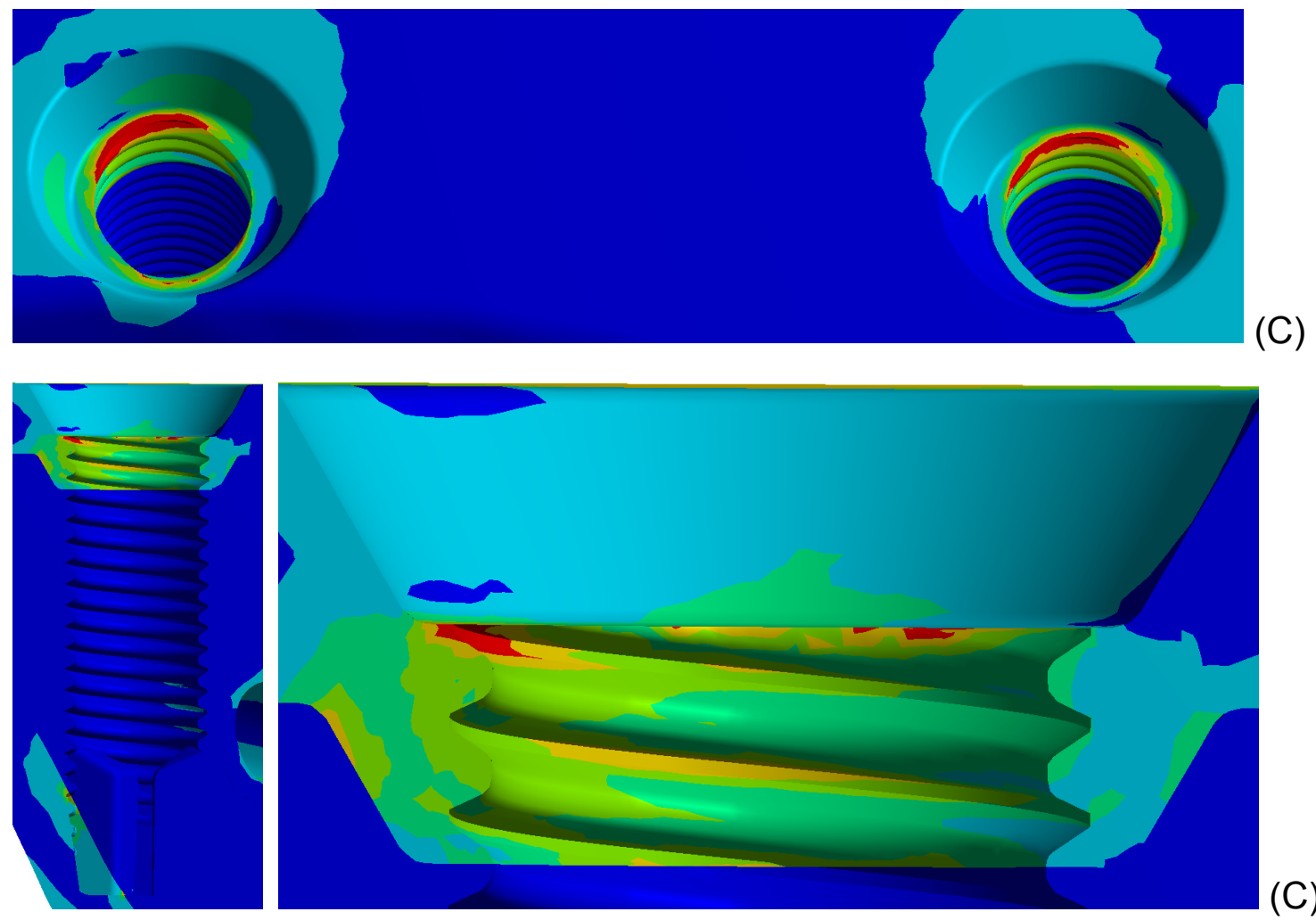

(C)

$(C)=$ implante de $4 \times 15 \mathrm{~mm}$

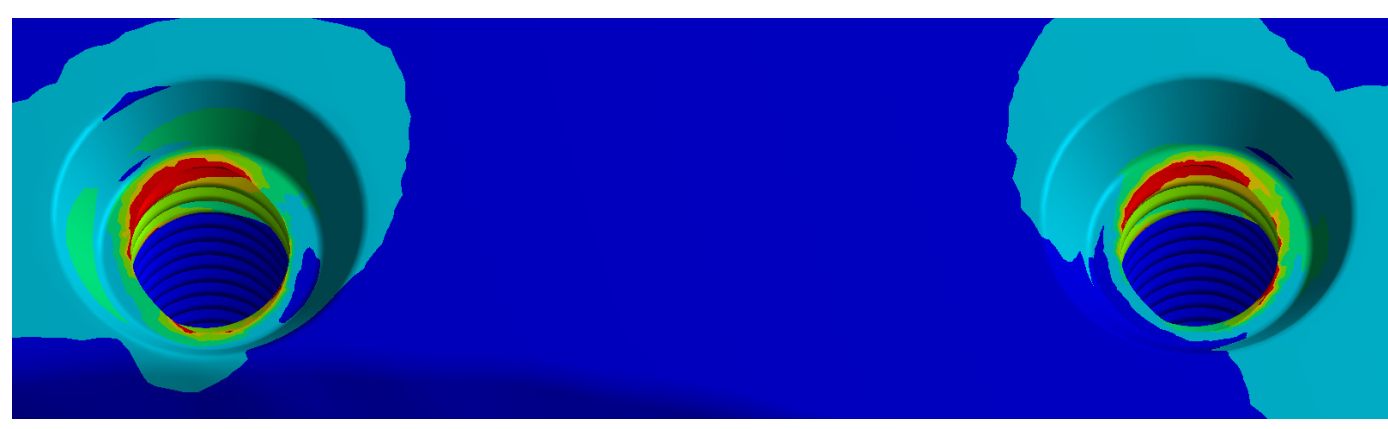

(D)
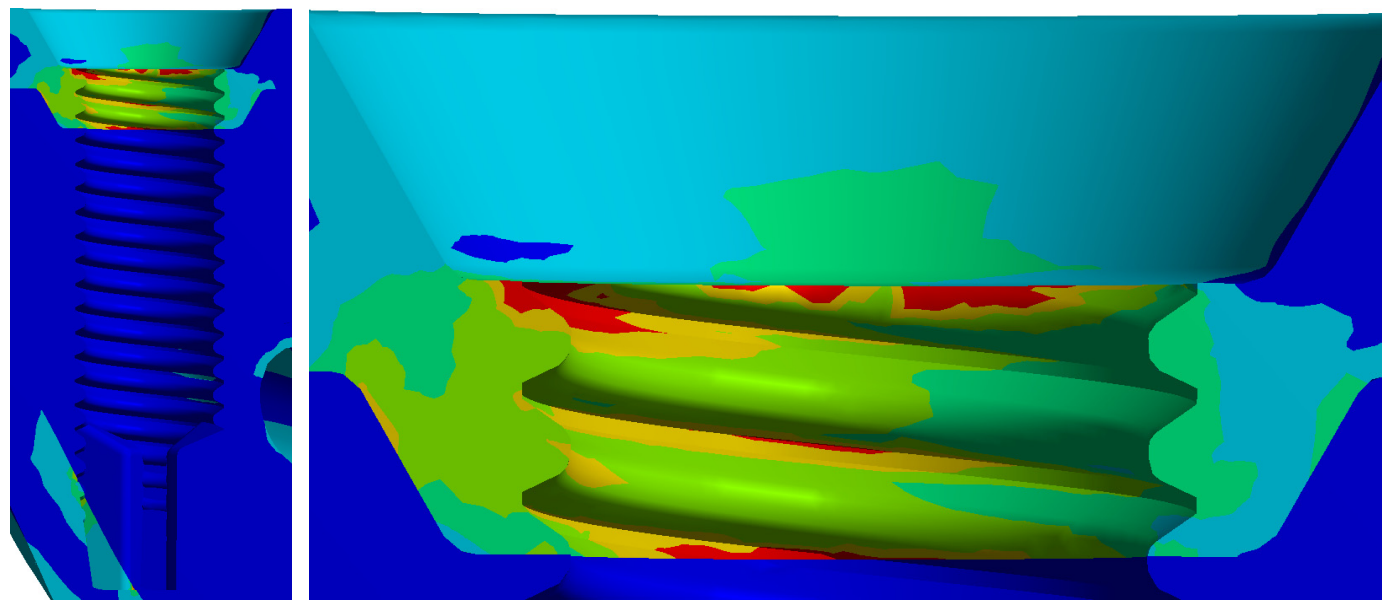

(D)

(D) $==$ implante de $3.75 \times 15 \mathrm{~mm}$ 


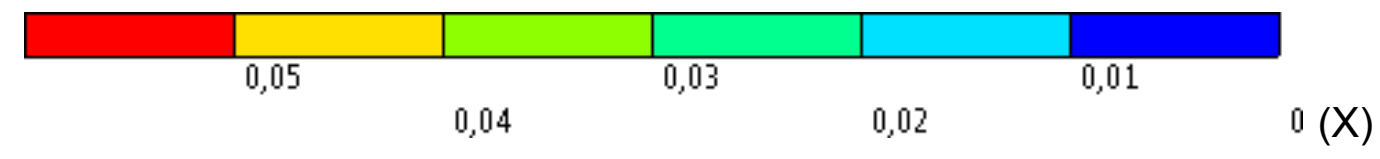

Figura 44: plotagem dos resultados no osso periimplantar pelo critério de Mohr-Coulomb, para implantes osseointegrados, submetidos à carga axial. As letras se referem aos resultados de cada modelo e o $\mathrm{X}$ a escala de cores para todos os resultados.
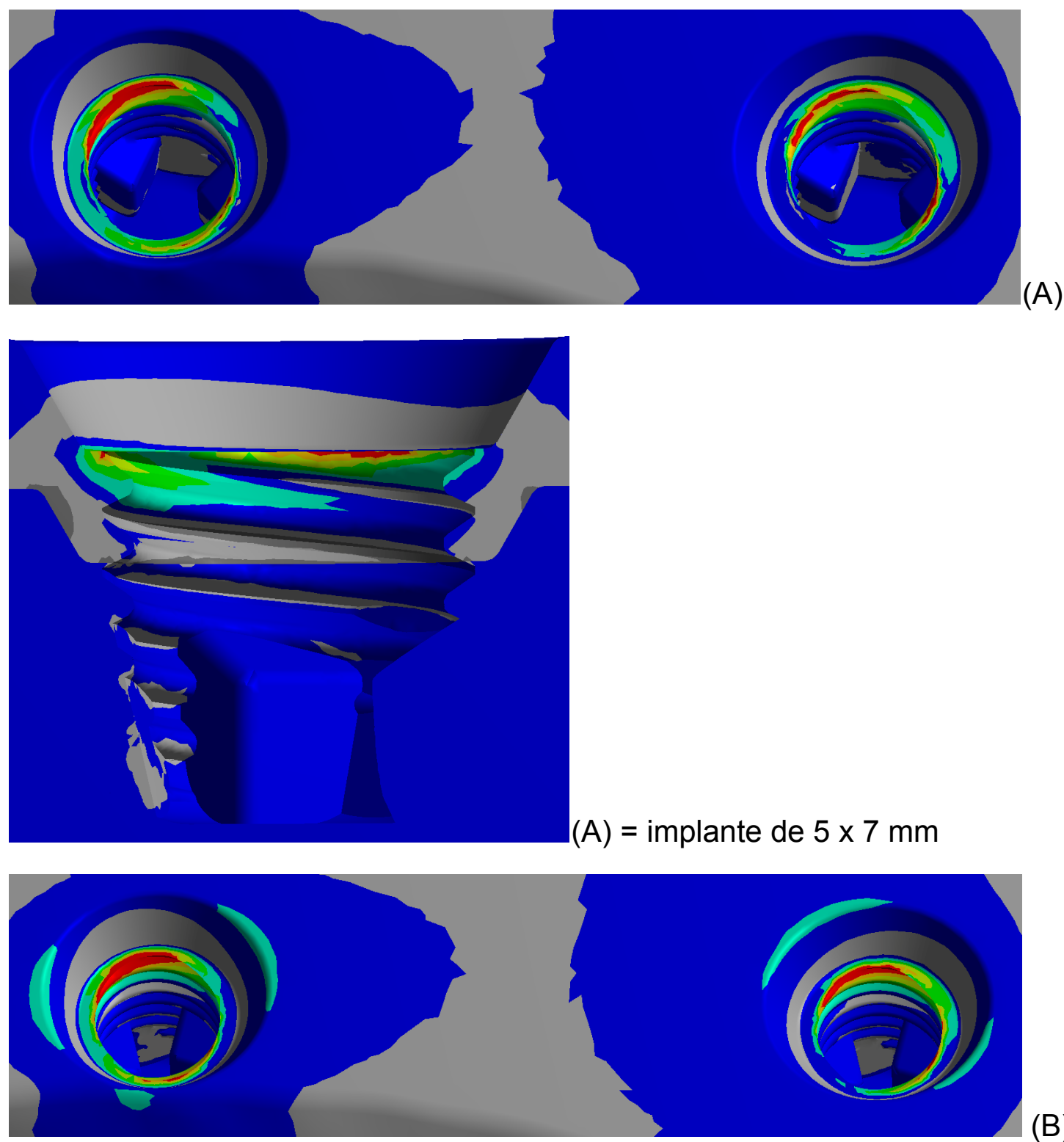

(B) 


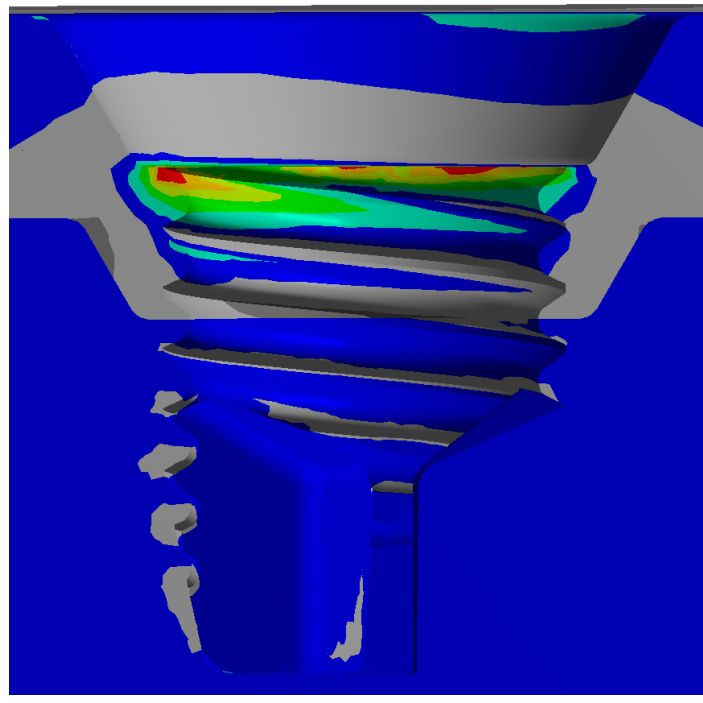

(B) = implante de $4 \times 7 \mathrm{~mm}$
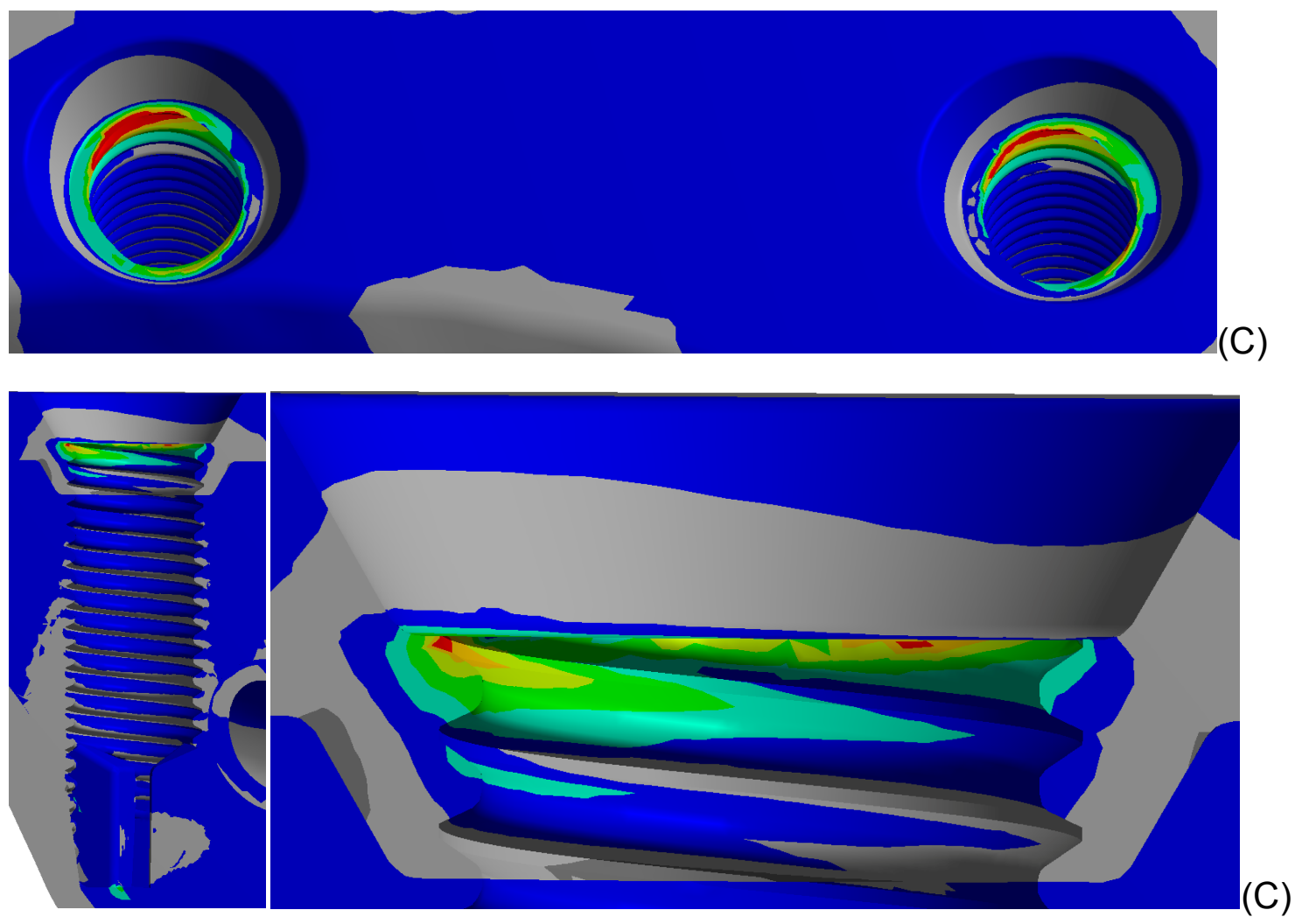

(C) = implante de $4 \times 15 \mathrm{~mm}$

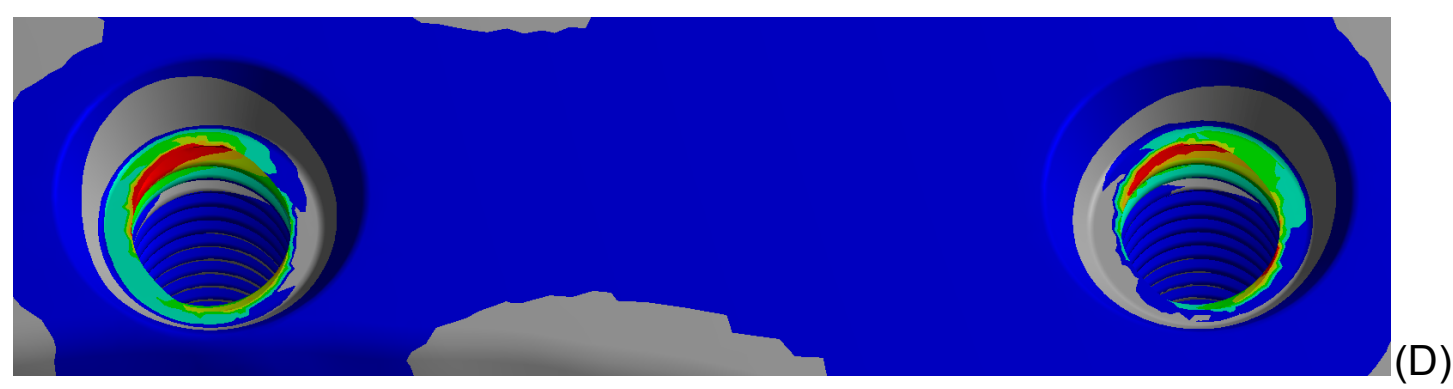



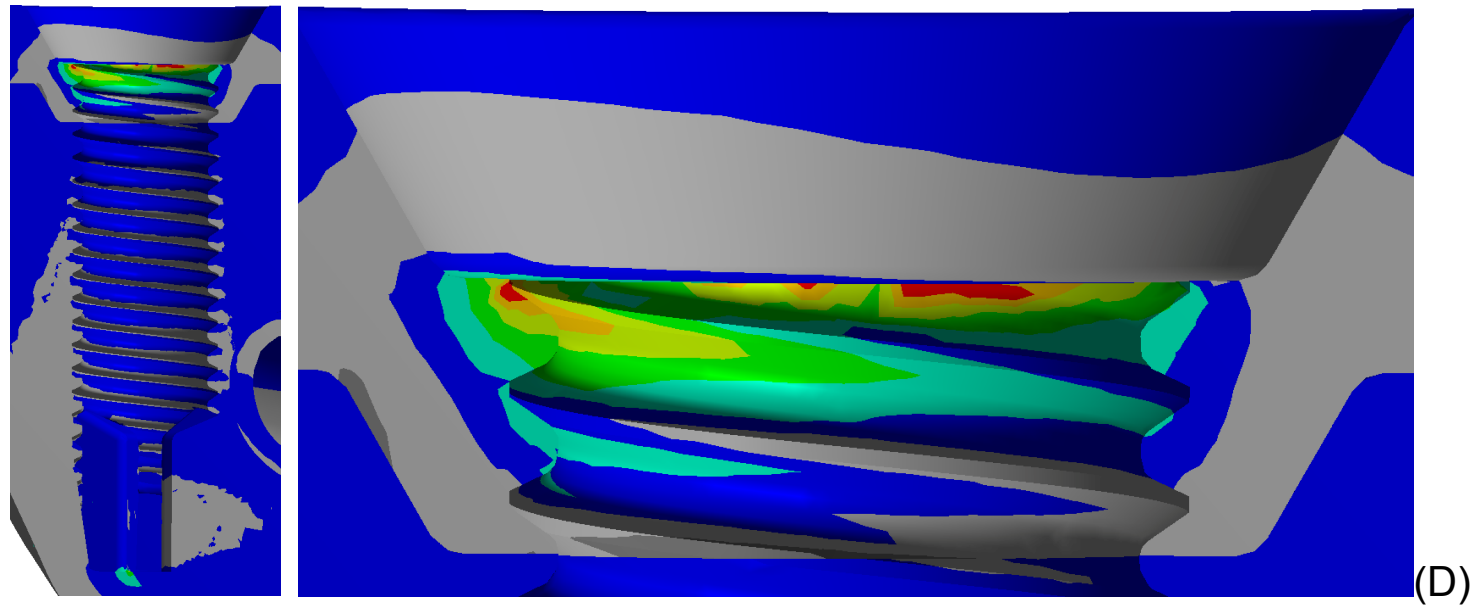

(D) = implante de $3.75 \times 15 \mathrm{~mm}$

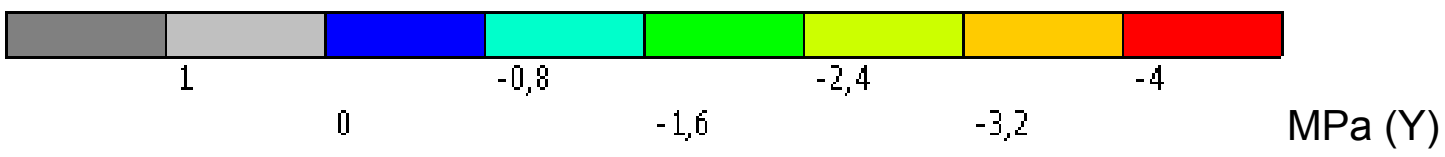

Figura 45 plotagem dos resultados no osso periimplantar pelo critério de tensão hidrostática, para implantes osseointegrados, submetidos à carga axial. As letras se referem aos resultados de cada modelo e o $X$ a escala de cores para todos os resultados.

Primeiramente é importante salientar que todos os picos, em todos os resultados discutidos para osso periimplantar, se localizaram na região superior da crista óssea. Dessa forma, não serão discutidas diferenças na localização, mas apenas nas intensidades dos resultados.

Quando analisamos os resultados dos implantes osseointegrados sob carga axial, pelo critério do Mohr Coulomb e da tensão hidrostática compressiva, comparando os resultados do modelo A (implante $5 \times 7 \mathrm{~mm}$ ) com os do modelo $B$ (implante $4 \times 7 \mathrm{~mm}$ ), pode-se observar pequena vantagem do modelo com implante de maior diâmetro. Similarmente, comparando o modelo C (implante $4 \times 15$ ) com o modelo D (implante de 3.75 por 15), a mesma tendência é observada, com pequena vantagem dos implantes de maior diâmetro, ou seja, o aumento do diâmetro do implante, segundo os critérios utilizados, traz pequena melhora no risco mecânico dos implantes osseointegrados sob carga axial, com variações nos picos entre 1 a $8 \%$ (com 
referência no controle). Entretanto, ao compararmos os resultados do modelo $B$ (implante de $4 \times 7 \mathrm{~mm}$ ) com os do modelo $\mathrm{C}$ (implante de $4 \times 15 \mathrm{~mm}$ ), pode-se observar diferença mais expressiva, demonstrando efeito mais significativo, do aumento do comprimento somado a influência da bicorticalidade, nos resultados, ou seja, o aumento do comprimento trouxe melhora significativa nos dois critérios utilizados, em relação ao aumento do diâmetro, com variações nos picos entre 16 a 18\% (com referência no controle).

De forma geral, para implantes osseointegrados sob carga axial, o aumento no comprimento do implante, somado a bicorticalidade, demonstrouse mais significativo para diminuir o risco a reabsorção óssea do que o aumento do diâmetro do implante, tanto sob o critério de Mohr Coulomb, quando da tensão hidrostática. Isso pode ser parcialmente explicado pela carga axial carregar o implante no seu longo eixo, o que teoricamente favorece implantes com maior inserção óssea, principalmente em implantes osseointegrados, onde a porção superior da rosca favorece o suporte do implante.

O quadro 6 , e as figuras 46 e 47 se referem aos resultados no osso periimplantar, dos implantes osseointegrados submetidos à carga oblíqua. 


\begin{tabular}{|c|c|c|c|c|}
\hline \multicolumn{5}{|c|}{$\begin{array}{l}\text { Quadro 6: Valores de picos } \\
\text { implantes osseointegrados, sub } \\
\text { relação ao controle (modelo B). }\end{array}$} \\
\hline & $\begin{array}{l}\text { Mohr- } \\
\text { Coulomb } \\
\left(\sigma_{\mathrm{R}}\right)\end{array}$ & $\begin{array}{l}\text { tensão } \\
\text { hidrostática } \\
\text { compressiva } \\
\text { (MPa) }\end{array}$ & $\begin{array}{l}\text { tensão } \\
\text { hidrostática } \\
\text { trativa } \\
(\mathrm{MPa})\end{array}$ & $\begin{array}{l}\text { Micromovimentação } \\
(\mu \mathrm{m})\end{array}$ \\
\hline $\begin{array}{l}\text { Modelo A } \\
\text { (implante de } \\
5 \times 7 \mathrm{~mm} \text { ) }\end{array}$ & $0,54 / 80 \%$ & $32,25 / 84 \%$ & $19,83 / 70 \%$ & $5,57 / 84 \%$ \\
\hline $\begin{array}{l}\text { Modelo B } \\
\text { (implante de } \\
4 \times 7 \mathrm{~mm} \text { ) }\end{array}$ & $0,67 / 100 \%$ & $38,31 / 100 \%$ & $28,04 / 100 \%$ & $6,62 / 100 \%$ \\
\hline $\begin{array}{l}\text { Modelo C } \\
\text { (implante de } \\
4 \times 15 \mathrm{~mm} \text { ) }\end{array}$ & $0,55 / 82 \%$ & $29,11 / 76 \%$ & $21,37 / 76 \%$ & $5,14 / 77 \%$ \\
\hline $\begin{array}{l}\text { Modelo D } \\
\text { (implante de } \\
3.75 \times 15 \\
\mathrm{~mm} \text { ) }\end{array}$ & $0,60 / 89 \%$ & $33,99 / 88 \%$ & $25,12 / 89 \%$ & $5,6 / 84 \%$ \\
\hline
\end{tabular}
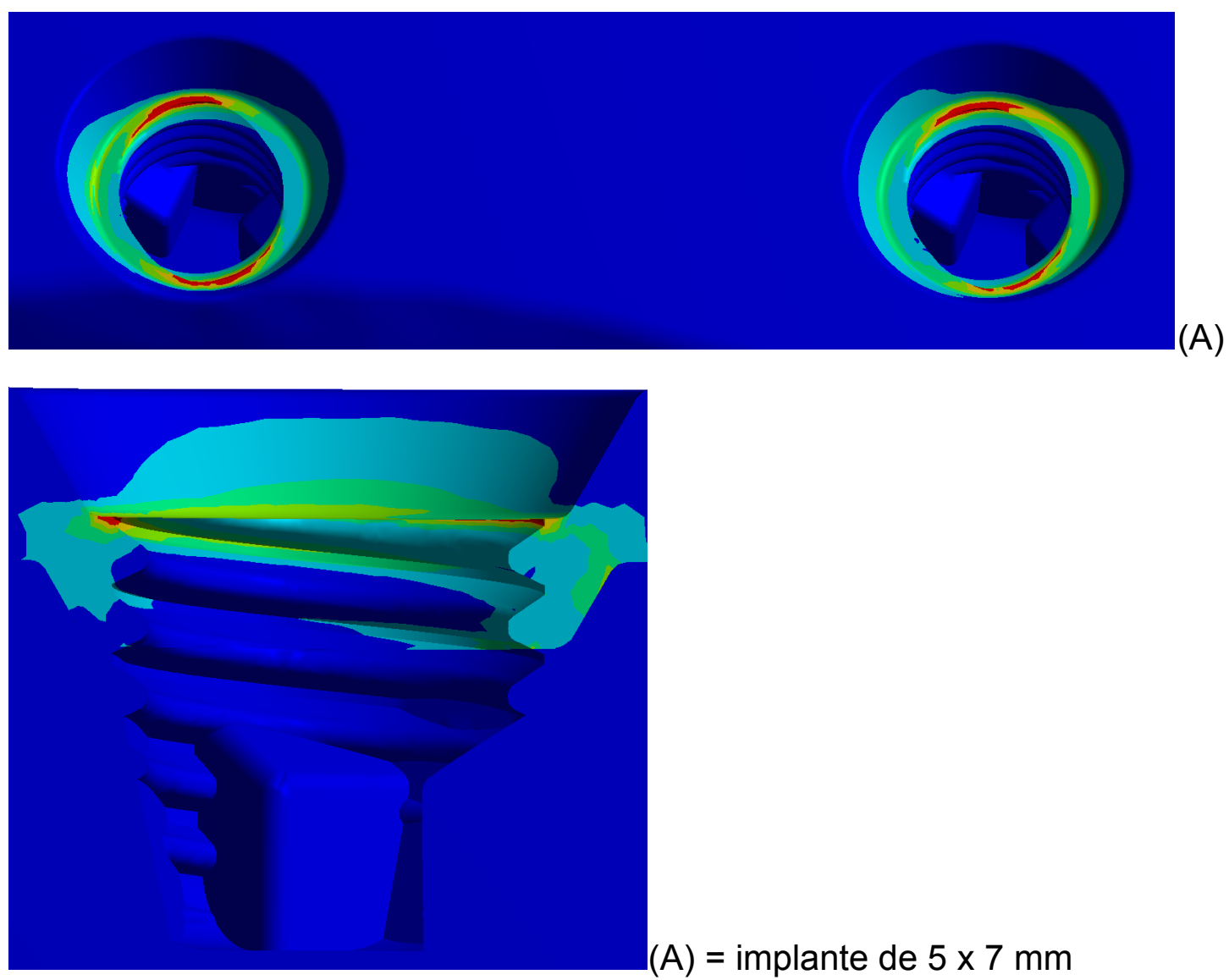


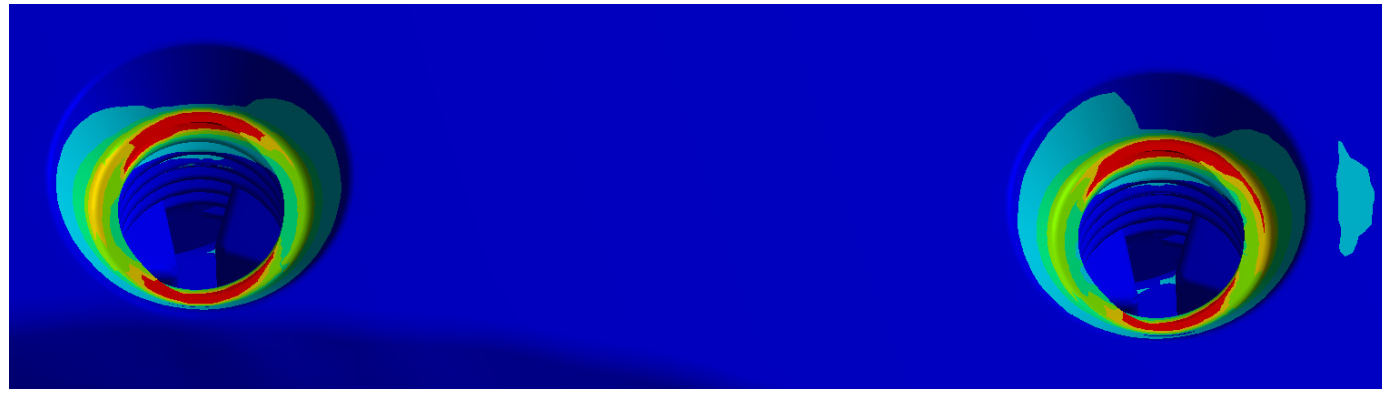

(B)

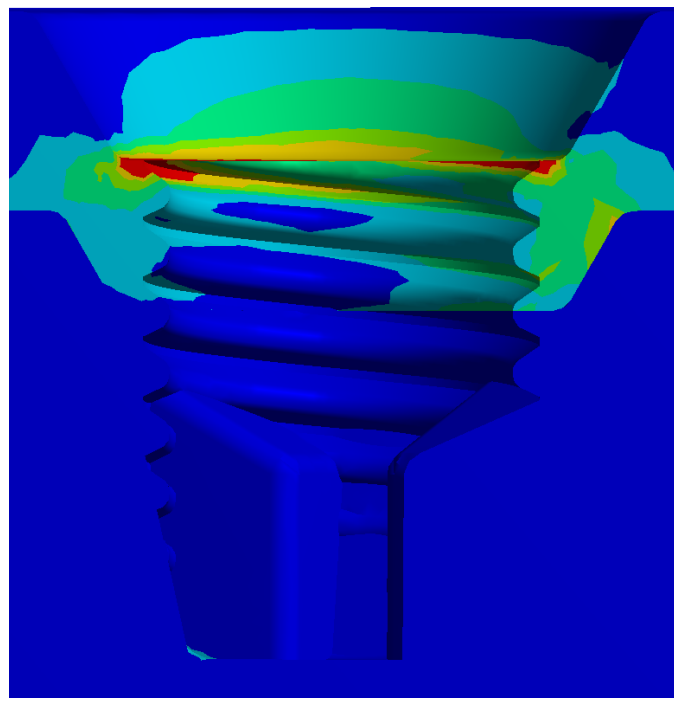

(B) = implante de $4 \times 7 \mathrm{~mm}$
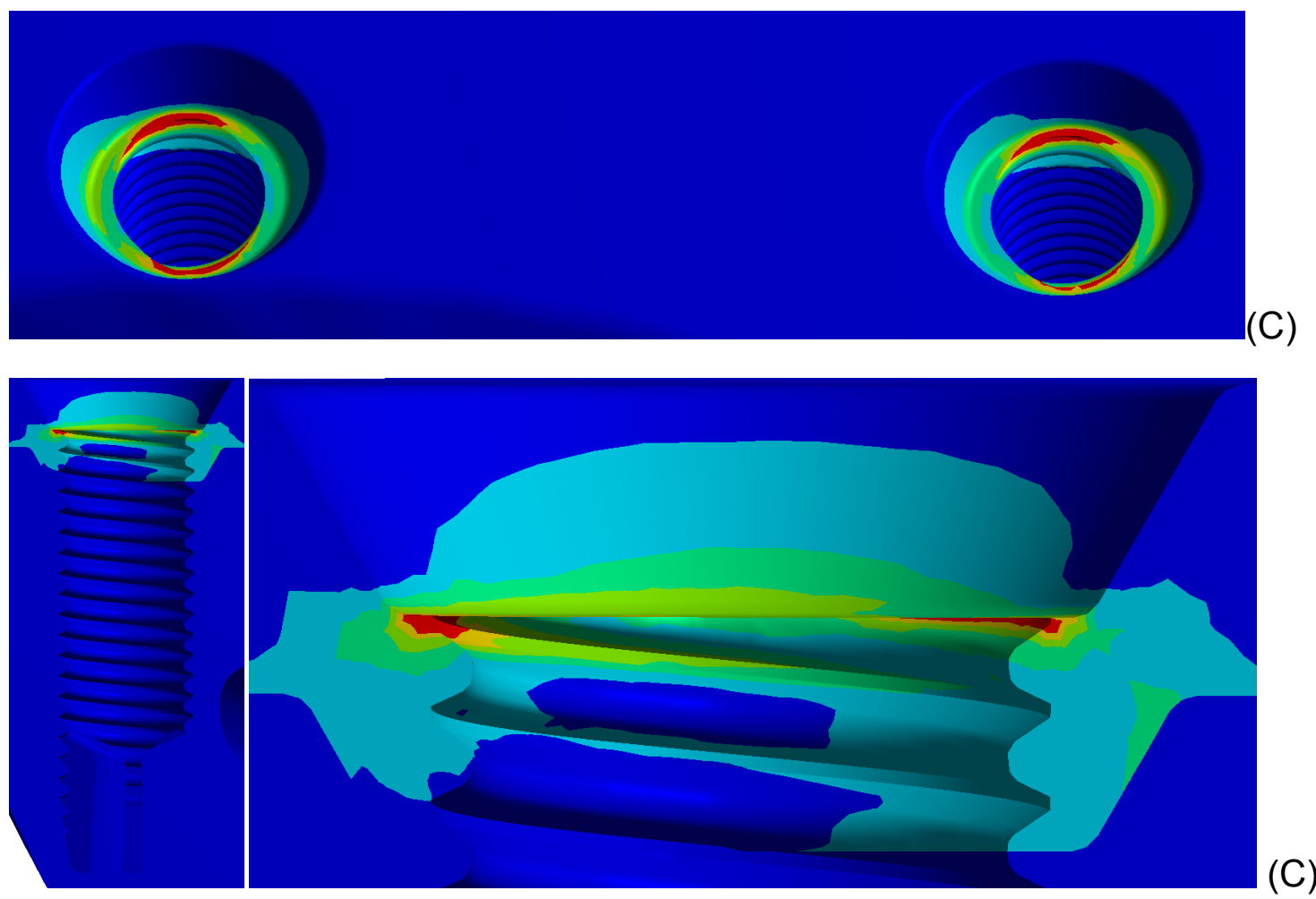

(C) = implante de $4 \times 15 \mathrm{~mm}$ 

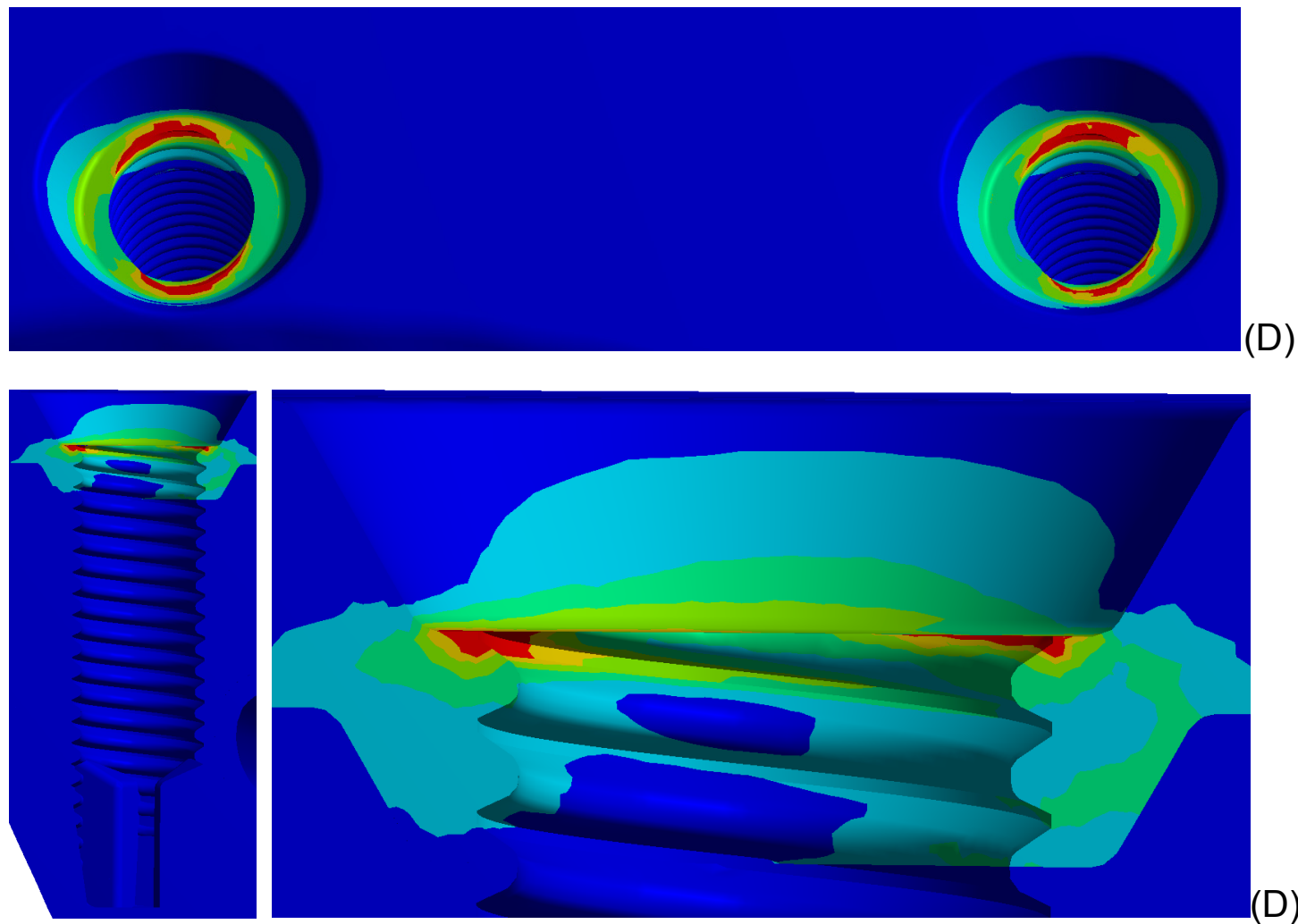

(D) $=$ implante de $3.75 \times 15 \mathrm{~mm}$

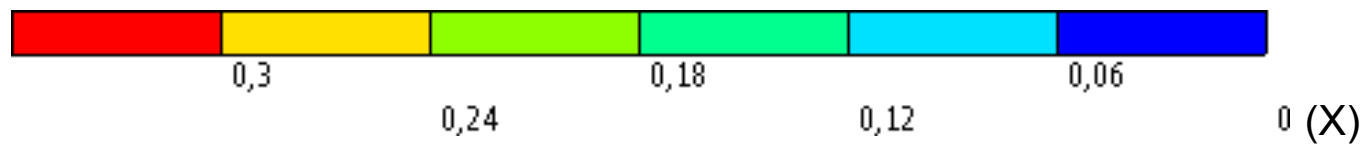

Figura 46: plotagem dos resultados no osso periimplantar pelo critério de Mohr-Coulomb, para implantes osseointegrados e submetidos à carga oblíqua. As letras se referem aos resultados de cada modelo e o X a escala de cores para todos os resultados.

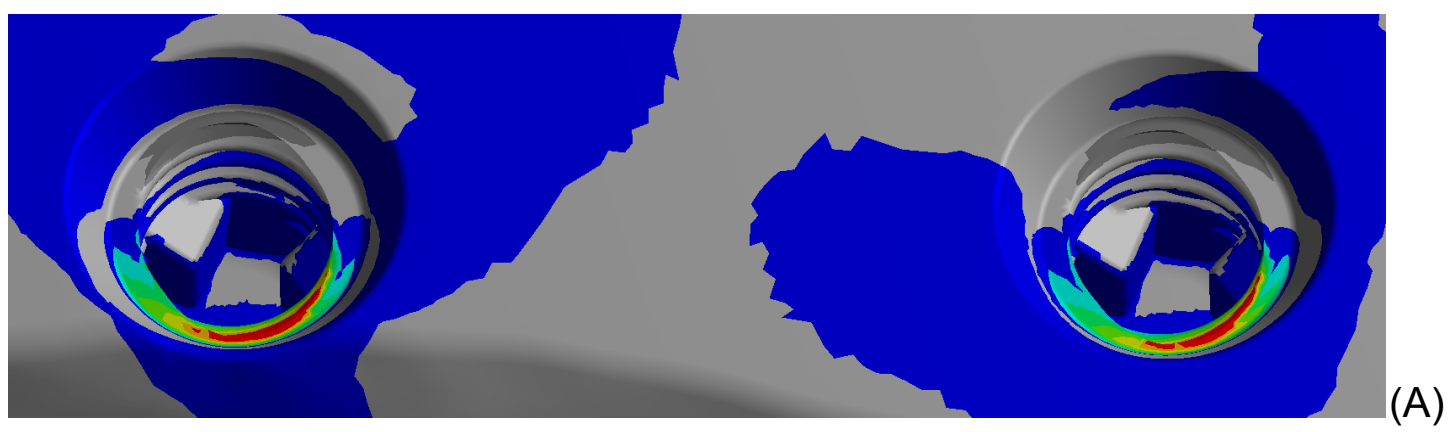



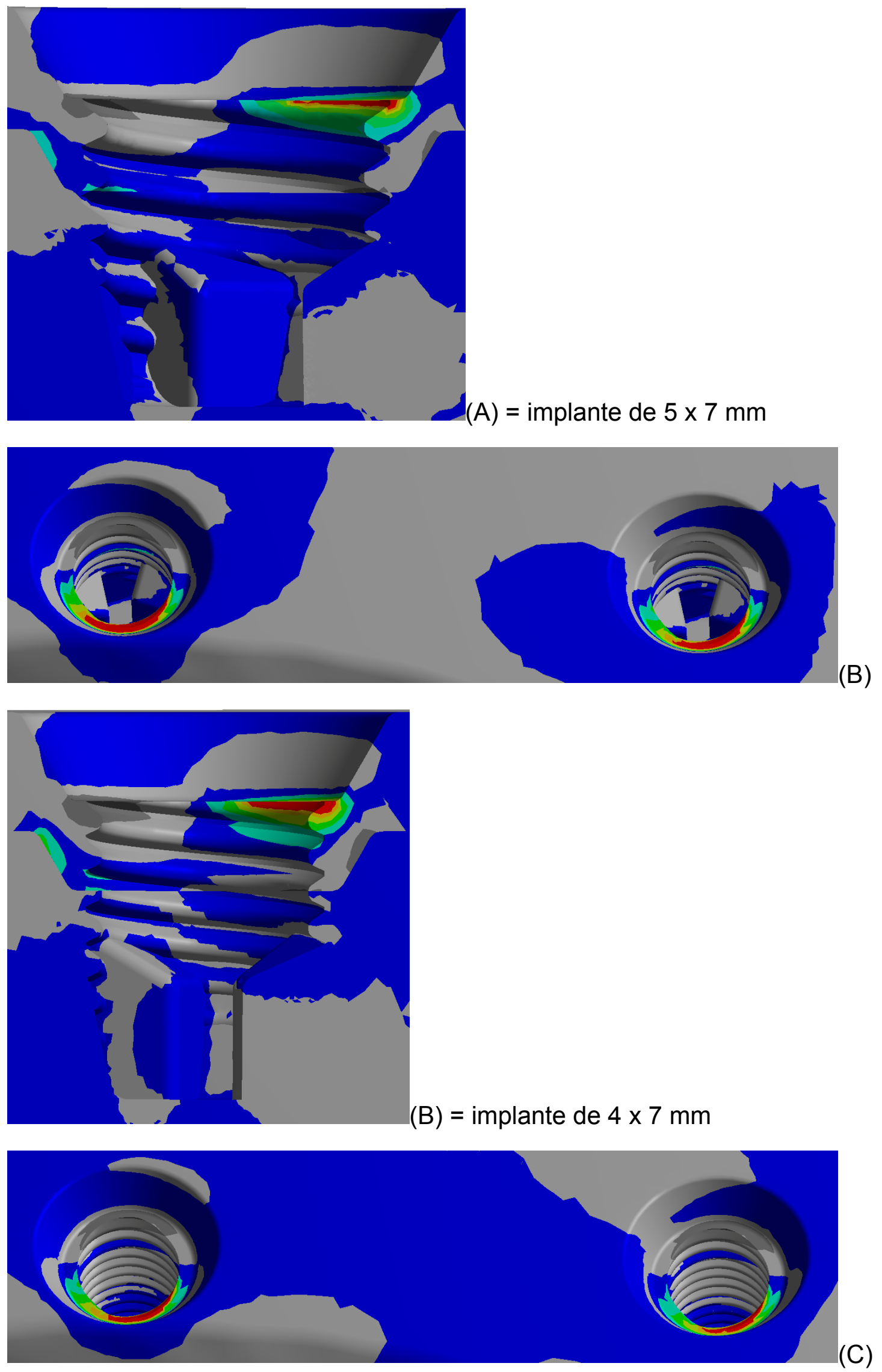

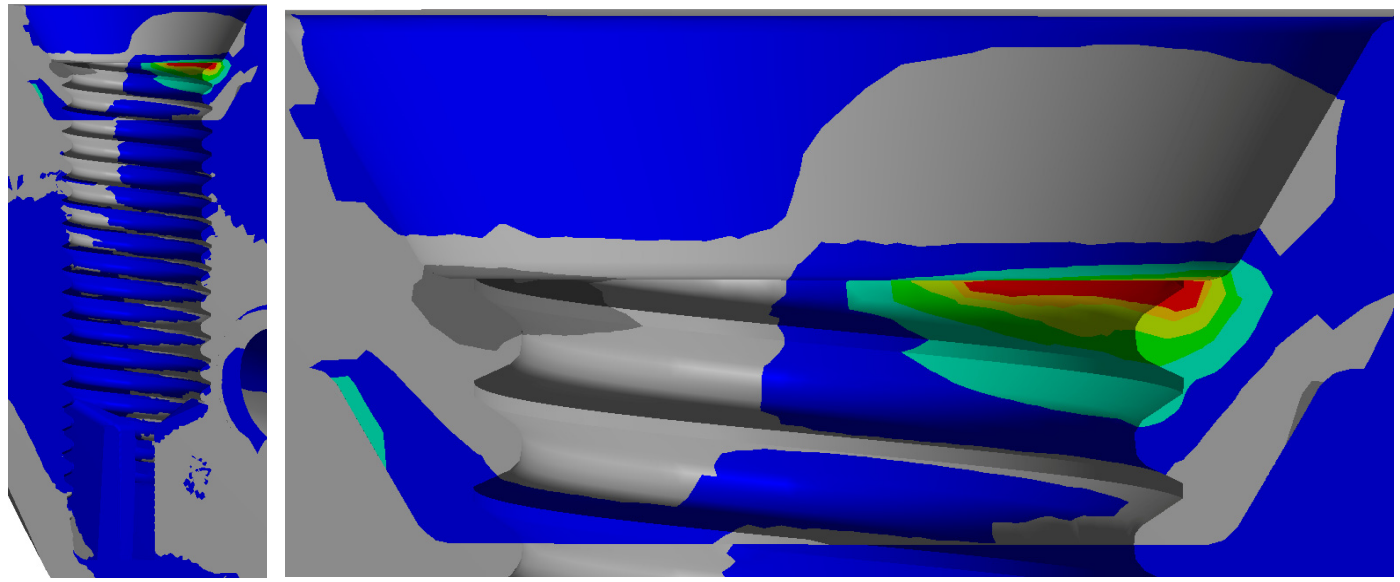

(C)

(C) $=$ implante de $4 \times 15 \mathrm{~mm}$
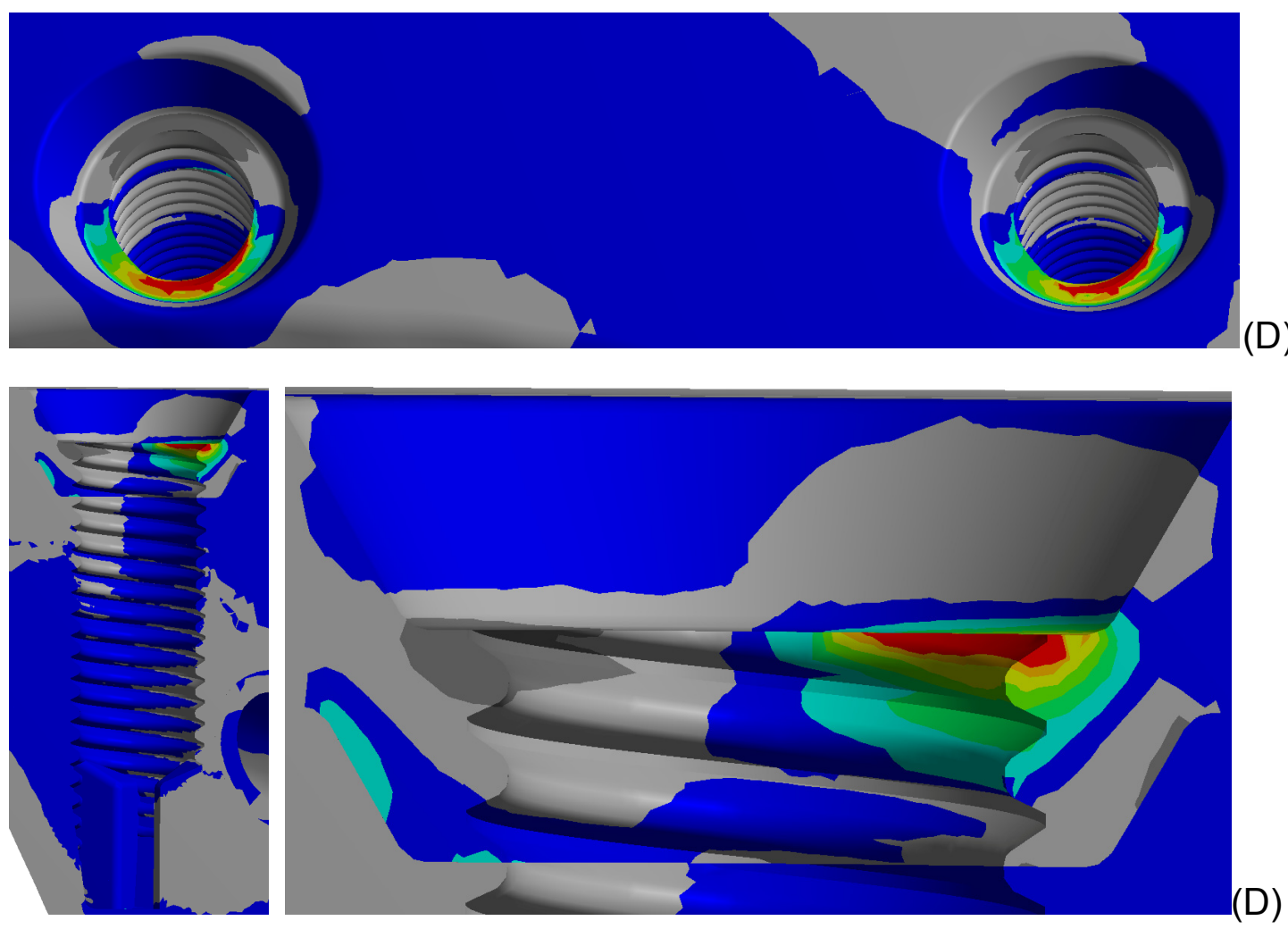

(D) = implante de $3.75 \times 15 \mathrm{~mm}$

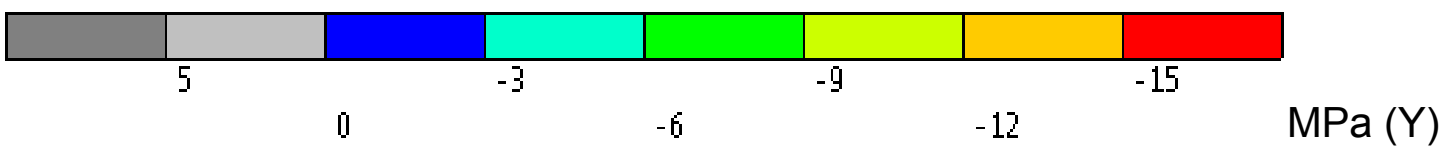

Figura 47: plotagem dos resultados no osso periimplantar pelo critério de tensão hidrostática, para implantes osseointegrados e submetidos à carga oblíqua. As letras se referem aos resultados de cada modelo e o $\mathrm{X}$ a escala de cores para todos os resultados. 
Ao analisar os resultados dos implantes osseointegrados sob carga obliqua, pelo critério do Mohr Coulomb da tensão hidrostática compressiva, referente a variação de diâmetro, comparando os resultados do modelo $\mathrm{A}$ (implante de $5 \times 7 \mathrm{~mm}$ ) com os resultados do modelo B (implante de $4 \times 7 \mathrm{~mm}$ ), pode-se observar significante diminuição nos picos, com variações de 16 a $20 \%$. Similarmente ao se comparar os resultados do modelo C (implante de $4 \mathrm{x}$ $15 \mathrm{~mm}$ ) com os do modelo $\mathrm{D}$ (implante de $3,75 \times 15 \mathrm{~mm}$ ), o aumento no diâmetro resultou em diminuição do risco, embora em menor intensidade do que os modelo A e B, sendo de 7 a $12 \%$ (em relação ao controle).

A comparação entre o modelo B (implante de $4 \times 7 \mathrm{~mm}$ ) com o modelo $\mathrm{C}$ (implante de $4 \times 15 \mathrm{~mm}$ ) também demonstra significativa diminuição dos picos, com aumento do comprimento somado a bicorticalidade, com variações de 18 a $24 \%$.

Fazendo um paralelo entre os resultados do quadro $6 \mathrm{com}$ as áreas de inserção óssea dos implantes no quadro 3 , os resultados estiveram razoavelmente proporcionais à inserção cortical total dos implantes, sendo os melhores resultados, os do modelo $G$ (implante de $4 \times 15 \mathrm{~mm}$ ), que também possui a maior inserção cortical total, seguidos pelos modelo $\mathrm{A}$ (implante de $5 \mathrm{x}$ $7 \mathrm{~mm}$ ), D (implante de $3.75 \times 15 \mathrm{~mm}$ ) e B (implante de $4 \times 7 \mathrm{~mm}$ ), que é a ordem decrescente de área de inserção cortical total. Dentre os limites da atual pesquisa, essa relação pode ter sido estabelecida apenas ao acaso, mas considerando a importância da inserção óssea na sustentação dos implantes, é provável que isso seja mais que mera coincidência.

De forma geral, quando considerados implantes osseointegrados sob carga obliqua, tanto o aumento do comprimento dos implantes somado a bicorticalidade, quanto o aumento do diâmetro dos implantes se mostrou significativo para diminuição do risco de reabsorção óssea, segundo os critérios utilizados, sendo nos implantes analisados, o aumento do comprimento somado a bicorticalidade ligeiramente mais eficaz.

Quanto ao impacto das diferentes cargas mastigatórias, primeiro devemos explicar que é da opinião do autor que, tanto a análise da carga axial 
quanto da carga oblíqua são importantes para o tratamento. Embora os ajustes na prótese sejam feitos de forma a excluir cargas oblíquas, durante a mastigação de um bolo alimentar, devido à forma irregular do bolo e devido à dinâmica mastigatória, é provável que cargas obliquas carreguem a prótese. Ademais, devido aos picos das cargas oblíquas serem muito maiores do que da carga axial, mesmo que ocorram com menor freqüência, elas podem influenciar o processo de reabsorção óssea periimplantar.

Considerando os diferentes modelos analisados com implantes osseointegrados, tratamentos com lateralização e inserção bicortical, têm risco mecânico menor do que implantes curtos, mesmo que o aumento do diâmetro seja significativamente benéfico.

\subsubsection{Resultados do osso periimplantar em implantes submetidos à carga imediata}

O quadro 7 , e as figura 48 e 49 se referem aos resultados no osso periimplantar, dos implantes sob carga imediata, submetidos à carga axial. 


\begin{tabular}{|c|c|c|c|c|}
\hline \multicolumn{5}{|c|}{$\begin{array}{l}\text { Quadro 7: Valores de picos dos resultados no osso periimplantar, para } \\
\text { implantes sob carga imediata e submetidos à carga axial e seu percentual } \\
\text { em relação ao controle (modelo F). }\end{array}$} \\
\hline & $\begin{array}{l}\text { Mohr- } \\
\text { Coulomb } \\
\left(\sigma_{\mathrm{R}}\right)\end{array}$ & $\begin{array}{l}\text { tensão } \\
\text { hidrostática } \\
\text { compressiva } \\
\text { (MPa) }\end{array}$ & $\begin{array}{l}\text { tensão } \\
\text { hidrostática } \\
\text { trativa } \\
\text { (MPa) }\end{array}$ & $\begin{array}{l}\text { Micromovimentação } \\
(\mu \mathrm{m})\end{array}$ \\
\hline $\begin{array}{l}\text { Modelo E } \\
\text { (implante de } \\
5 \times 7 \mathrm{~mm} \text { ) }\end{array}$ & $0,095 / 74 \%$ & $6,17 / 72 \%$ & $3,00 / 82 \%$ & $2,86 / 90 \%$ \\
\hline $\begin{array}{l}\text { Modelo F } \\
\text { (implante de } \\
4 \times 7 \mathrm{~mm} \text { ) }\end{array}$ & $0,128 / 100 \%$ & $8,59 / 100 \%$ & $3,65 / 100 \%$ & $3,16 / 100 \%$ \\
\hline $\begin{array}{l}\text { Modelo } \mathrm{G} \\
\text { (implante de } \\
4 \times 15 \mathrm{~mm} \text { ) }\end{array}$ & $0,122 / 95 \%$ & $8,03 / 93 \%$ & $3,36 / 92 \%$ & $3,10 / 98 \%$ \\
\hline $\begin{array}{l}\text { Modelo } \mathrm{H} \\
\text { (implante de } \\
3.75 \times 15 \\
\mathrm{~mm} \text { ) }\end{array}$ & $0,131 / 102 \%$ & $8,47 / 98 \%$ & $3,52 / 96 \%$ & $3,23 / 102 \%$ \\
\hline
\end{tabular}
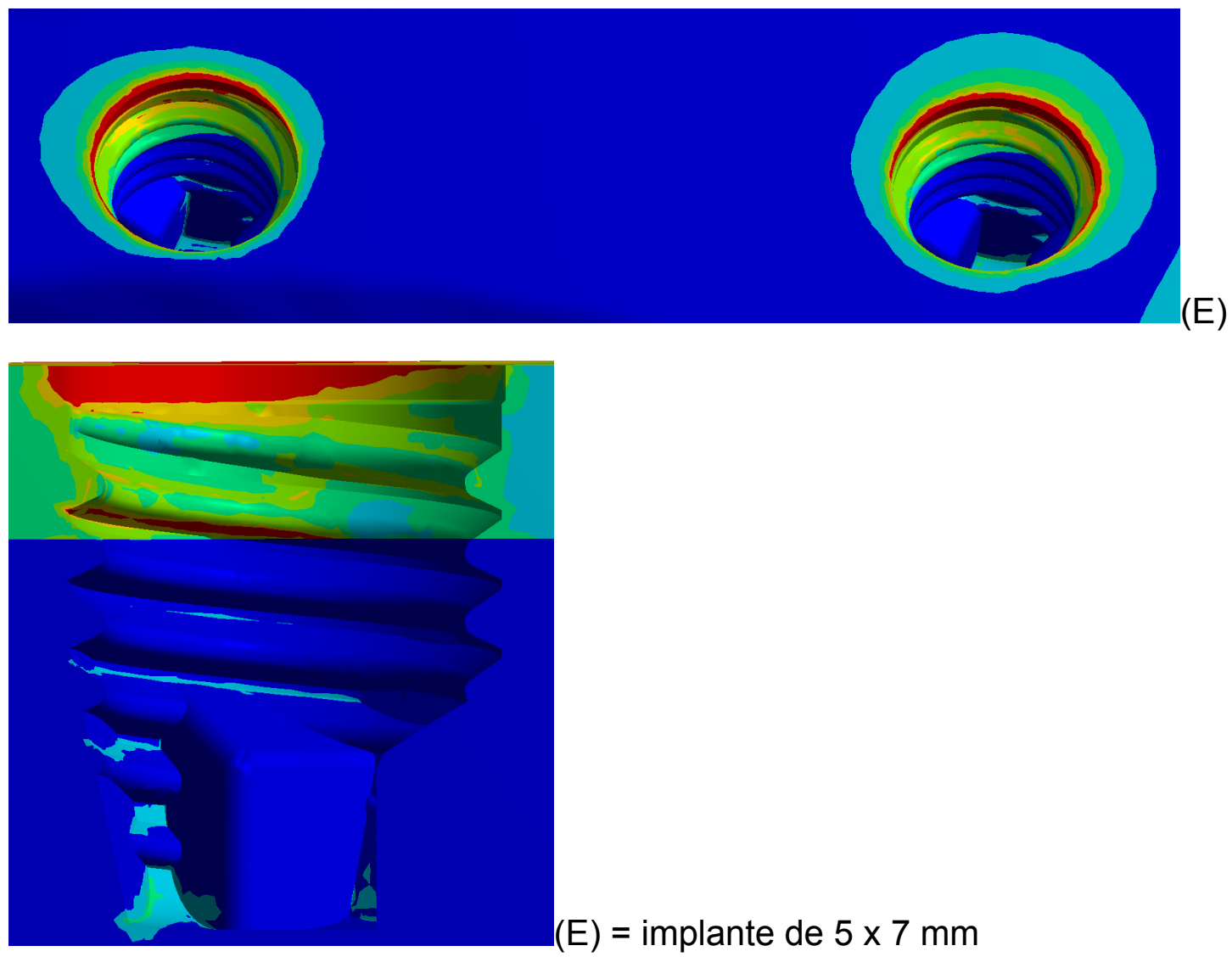

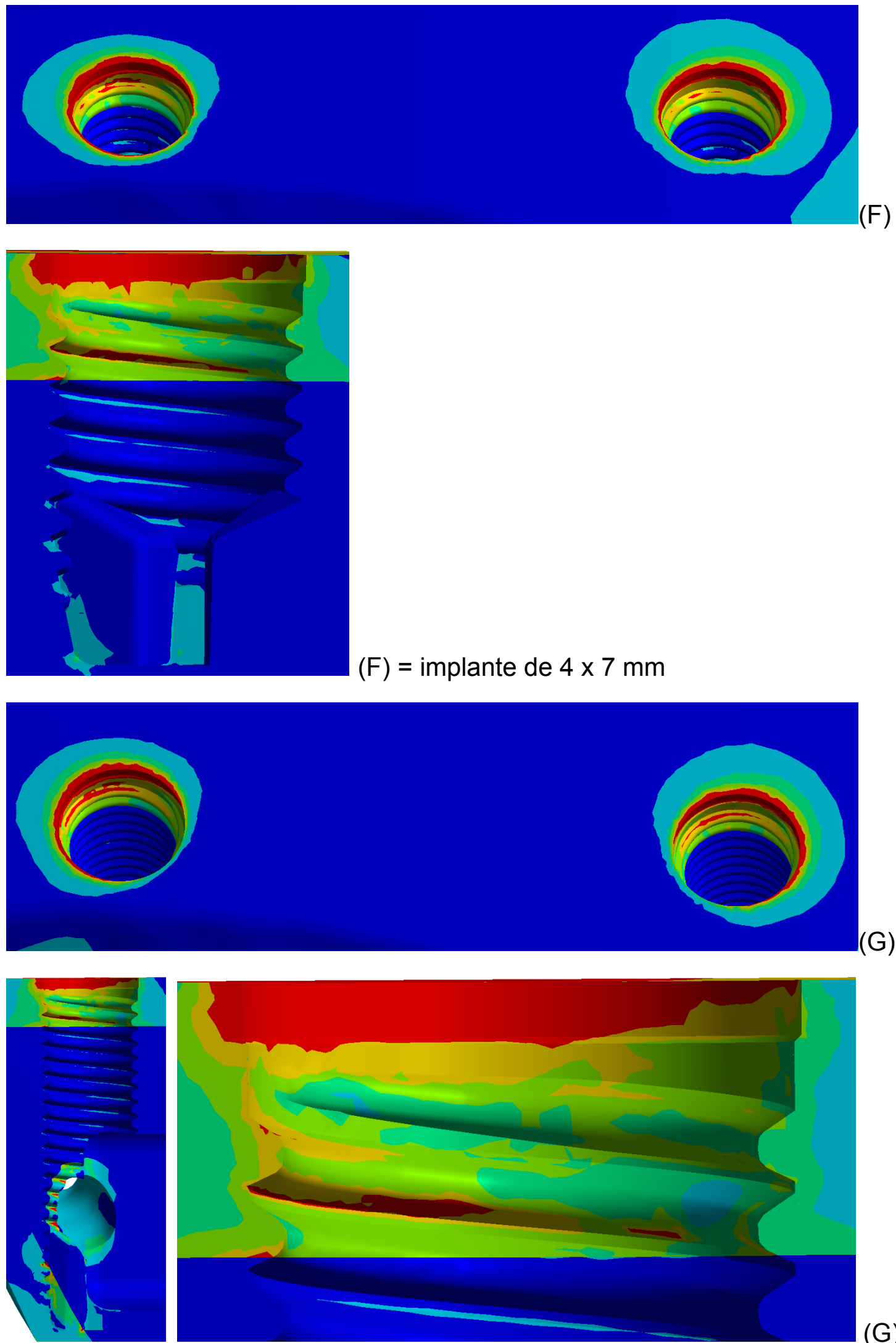

(G)

$(G)=$ implante de $4 \times 15 \mathrm{~mm}$ 


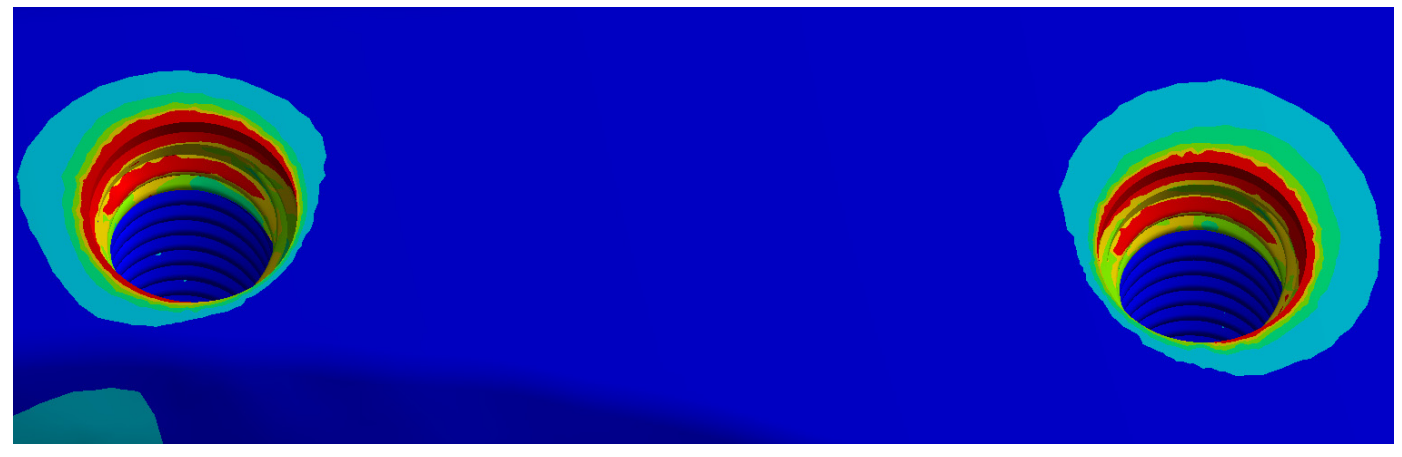

(H)
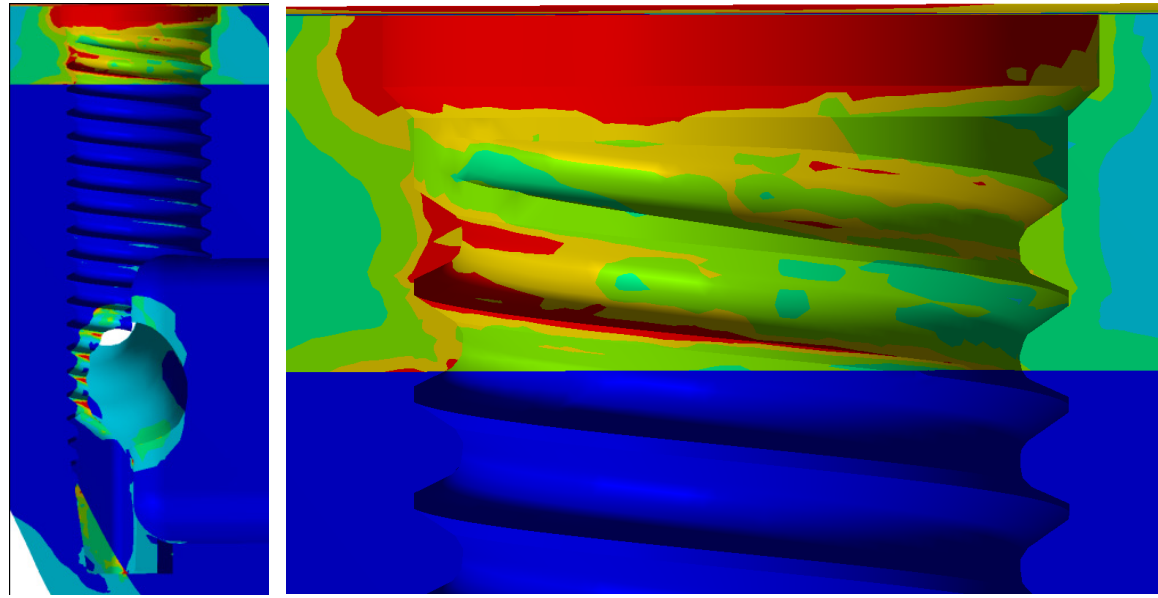

$(\mathrm{H})$

$(\mathrm{H})=$ implante de $3.75 \times 15 \mathrm{~mm}$

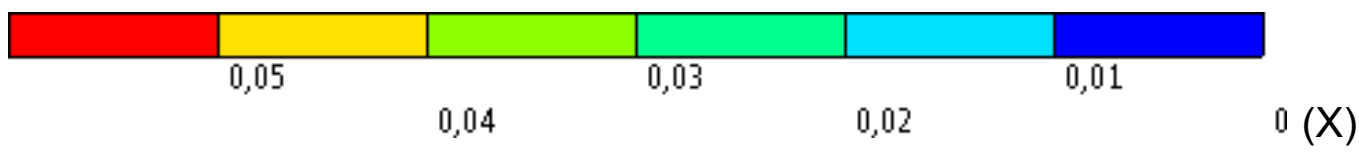

Figura 48: plotagem dos resultados no osso periimplantar pelo critério de Mohr-Coulomb, para implantes sob carga imediata e submetidos à carga axial. As letras se referem aos resultados de cada modelo e o $\mathrm{X}$ a escala de cores para todos os resultados.

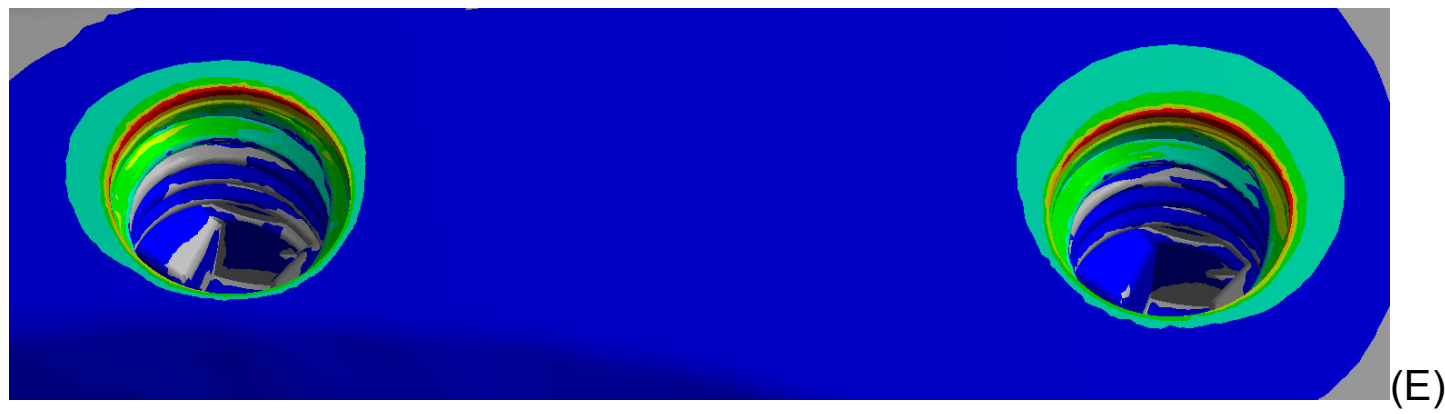

(E) 


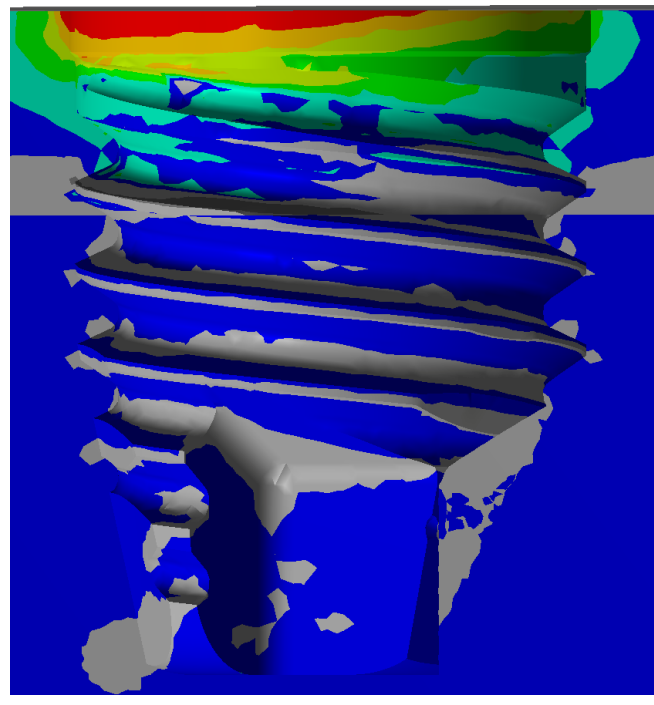

$(E)=$ implante de $5 \times 7 \mathrm{~mm}$
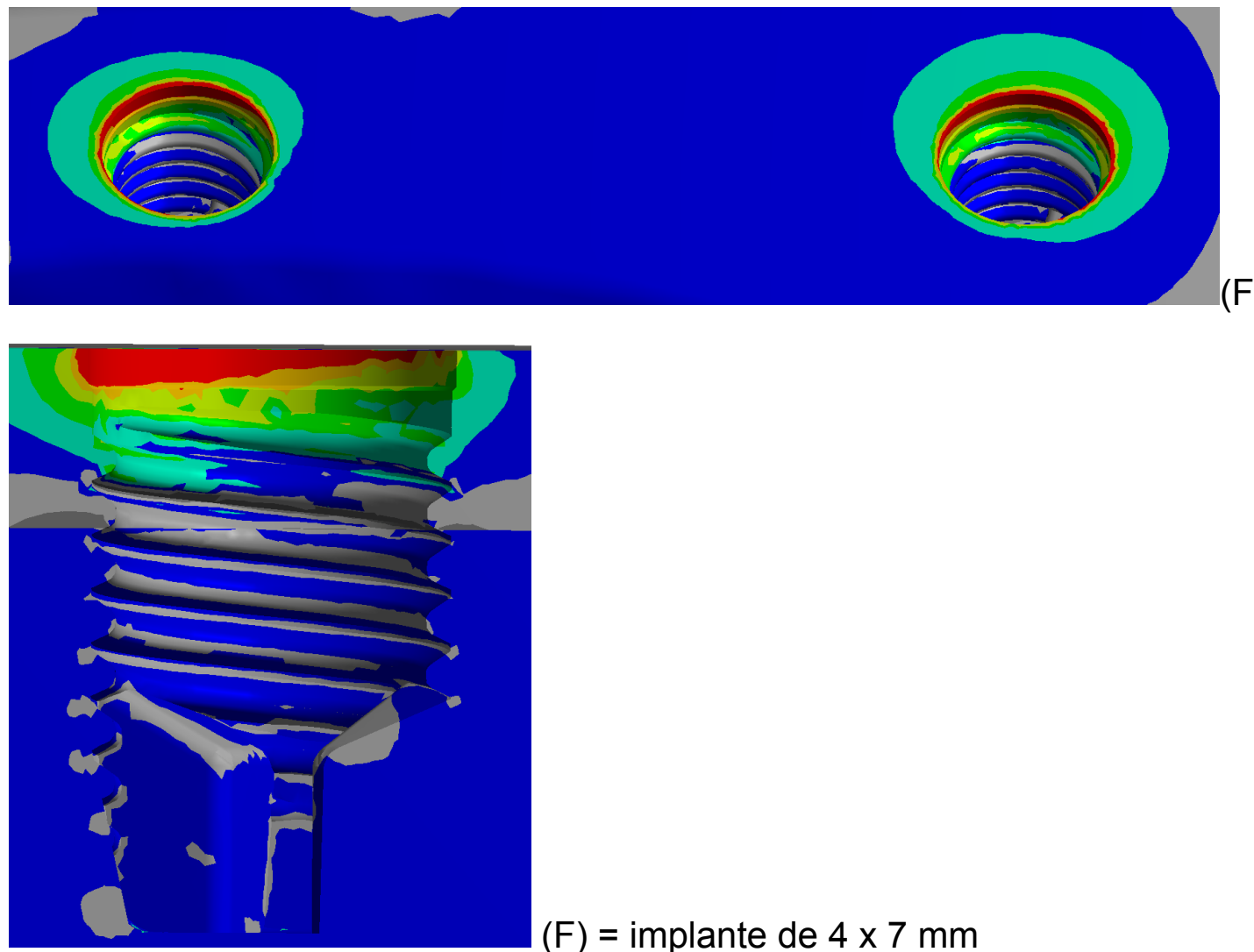

$(F)=$ implante de $4 \times 7 \mathrm{~mm}$

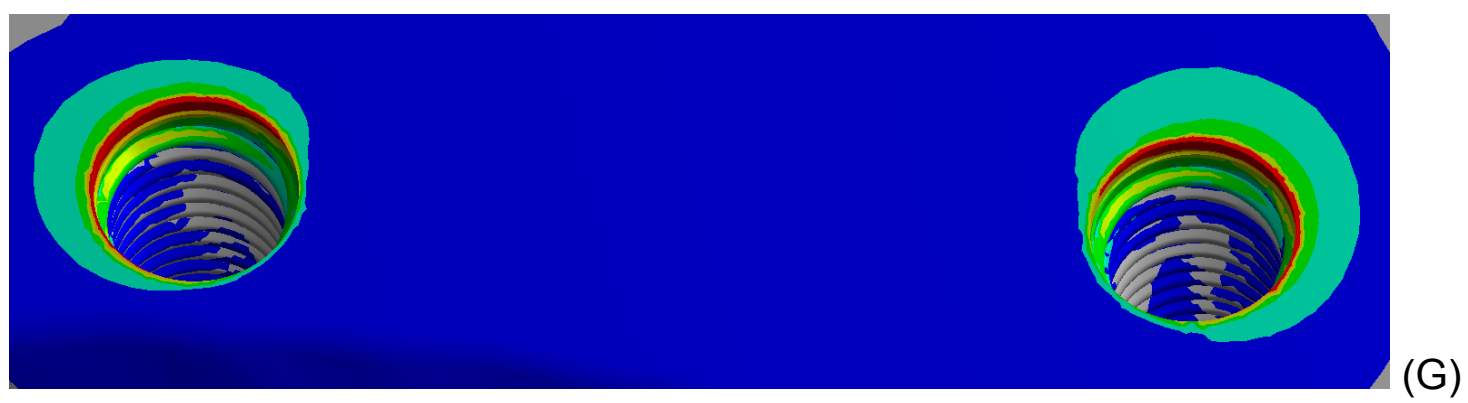



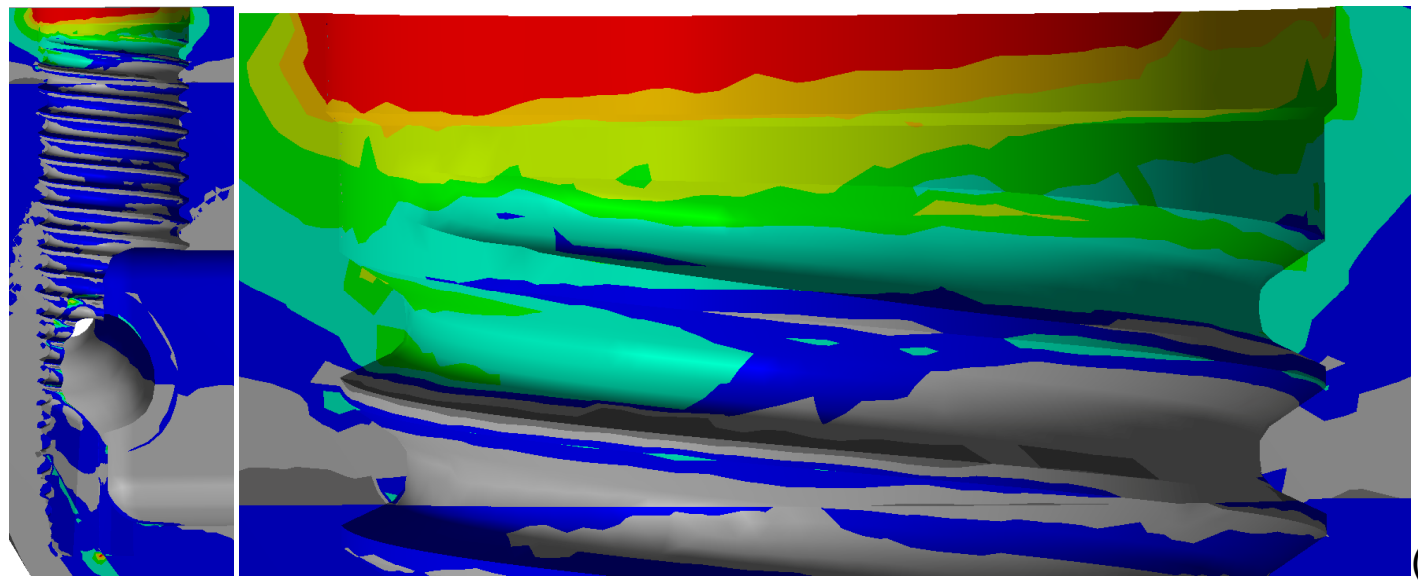

(G)

(G) = implante de $4 \times 15 \mathrm{~mm}$
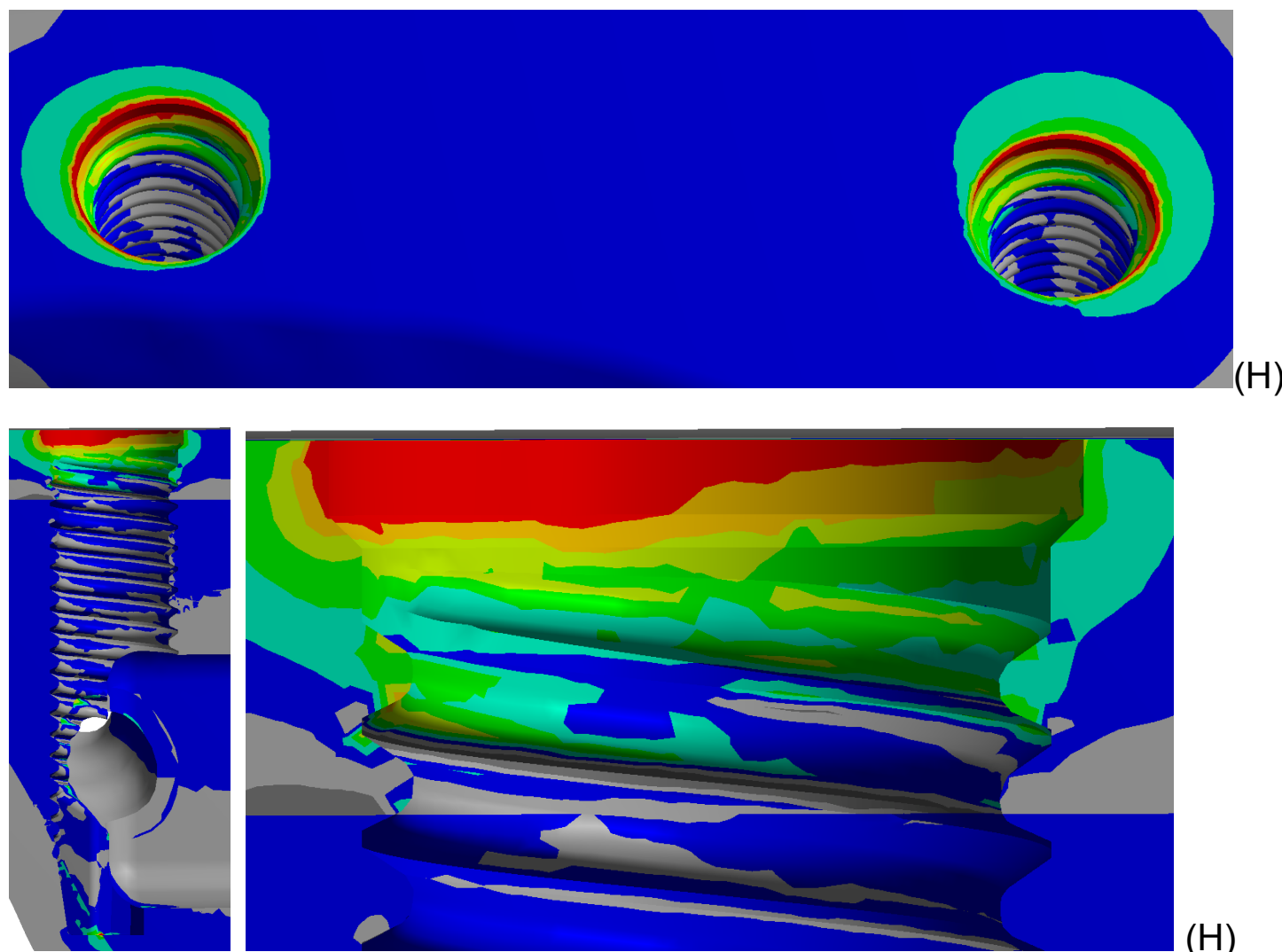

$(\mathrm{H})$

$(\mathrm{H})=$ implante de $3.75 \times 15 \mathrm{~mm}$

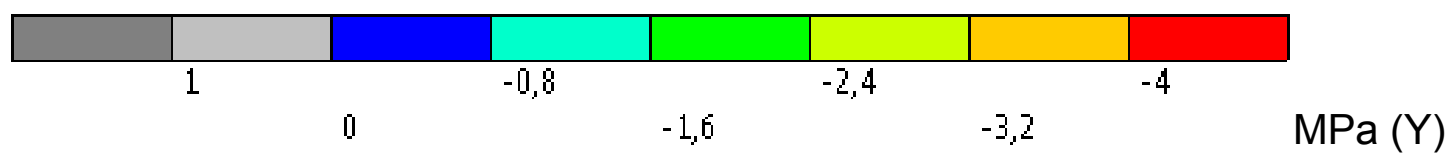

Figura 49: plotagem dos resultados no osso periimplantar pelo critério de tensão hidrostática, para implantes sob carga imediata e submetidos à carga axial. As letras se referem aos resultados de cada modelo e o $\mathrm{X}$ a escala de cores para todos os resultados. 
Ao analisar os resultados dos implantes sob carga imediata, submetidos à carga axial, pelo critério do Mohr Coulomb e da tensão hidrostática compressiva, referente a variação de diâmetro, comparando os resultados do modelo $E$ (implante $5 \times 7 \mathrm{~mm}$ ) com os do modelo $F$ (implante de $4 \times 7 \mathrm{~mm}$ ), pode-se observar uma significativa diminuição nos picos, com o aumento do diâmetro do implante. Ao comparar os resultados do modelo $\mathrm{G}$ (implante de $4 \mathrm{X}$ $15 \mathrm{~mm}$ ), com os resultados do modelo $\mathrm{H}$ (implante de $3,75 \times 15 \mathrm{~mm}$ ), uma melhora nos resultados pode ser observada com o aumento do diâmetro, entretanto numa escala muito menor do que entre os modelos $E$ (implante de 5 x $7 \mathrm{~mm}$ ) e $\mathrm{F}$ (implante de $4 \times 7 \mathrm{~mm}$ ).

Uma possível explicação a esse fenômeno está na comparação da área de inserção óssea de cada modelo, como pode ser visto no quadro 4. Considerando que o osso cortical é o tipo de osso considerado de maior suporte para os implantes dentários, enquanto o aumento do diâmetro de 4 para $5 \mathrm{~mm}$ acarreta num aumento de $30 \%$ da área de inserção de osso cortical na crista, o aumento de 3.75 para $4 \mathrm{~mm}$ de diâmetro acarreta num aumento de apenas 4\% (em relação ao controle) na inserção de osso cortical da crista e $8 \%$ de inserção cortical total. Os resultados apresentaram relação inversamente proporcional entre o risco e a inserção óssea cortical da crista.

Entretanto, para análise, ao compararmos o modelo $\mathrm{F}$ (implante de $4 \times 7$ $\mathrm{mm}$ ) com o modelo $\mathrm{G}$ (implante de $4 \times 15 \mathrm{~mm}$ ), pode-se observar melhora pequena nos picos com o aumento do comprimento somado a bicorticalidade.

De forma geral, para implantes sob carga imediata submetidos à carga axial, tanto pelo critério de Mohr Coulomb quanto o critério de tensão hidrostática, o aumento no diâmetro demonstrou-se mais significativo, para diminuição do risco, do que o aumento de comprimento somado a bicorticalidade.

Ao comparamos os resultados do quadro 6 com informações das área de inserção dos implantes (quadro 4) pode-se notar que a inserção de osso cortical na crista foi o fator , aparentemente, de maior impacto nos resultados. Um aumento de $30 \%$ de inserção de osso cortical na crista, entre o modelo $\mathrm{E}$ 
(implante de $5 \times 7 \mathrm{~mm}$ ) e o modelo $\mathrm{F}$ (implante de $4 \times 7 \mathrm{~mm}$ ), gerou diminuição nos picos de 26 a $28 \%$, e aumento de $4 \%$ na inserção de osso cortical da crista, entre os modelos H (implante de $3.75 \times 15 \mathrm{~mm}$ ) e G (implante de $4 \times 15$ $\mathrm{mm}$ ), gerou uma diminuição nos picos entre 5 a $7 \%$ (com base no modelo controle). Em contraste, ao consideramos a inserção medular e a inserção total dos implantes, mesmo que os modelos $\mathrm{G}$ (implante de $4 \times 15 \mathrm{~mm}$ ) e H (implante de $3.75 \times 15 \mathrm{~mm}$ ) possuam inserção de osso medular e inserção de osso cortical total maiores do que as do modelo $\mathrm{E}$, os resultados do modelo $\mathrm{E}$ foram muito mais favoráveis, sugerindo dois fatos distintos.

O primeiro é que a inserção cortical na crista tem maior impacto que as demais inserções na condição analisada. A segunda é que, considerando que a perda de inserção óssea da janela vestibular, em implantes colocados com técnica de lateralização do nervo alveolar inferior é geralmente de osso medular, essa janela não representa grande impacto na distribuição de tensões. Conseqüentemente, e considerando os resultados do quadro 6 , a carga imediata com técnica de lateralização representa um risco mecânico menor do que a carga imediata em implantes curtos, quando utilizado implantes de mesmo diâmetro.

O quadro 8, e as figuras 50 e 51 se referem aos resultados no osso periimplantar, dos implantes sob carga imediata, submetidos à carga oblíqua. 


\begin{tabular}{|c|c|c|c|c|}
\hline \multicolumn{5}{|c|}{$\begin{array}{l}\text { Quadro 8: Valores de picos dos resultados no osso periimplantar, para } \\
\text { implantes sob carga imediata, submetidos à carga oblíqua e seu } \\
\text { percentual em relação ao controle (modelo F). }\end{array}$} \\
\hline & $\begin{array}{l}\text { Mohr- } \\
\text { Coulomb } \\
\left(\sigma_{\mathrm{R}}\right)\end{array}$ & $\begin{array}{l}\text { tensão } \\
\text { hidrostática } \\
\text { compressiva } \\
\text { (MPa) }\end{array}$ & $\begin{array}{l}\text { tensão } \\
\text { hidrostática } \\
\text { trativa } \\
\text { (MPa) }\end{array}$ & $\begin{array}{l}\text { Micromovimentação } \\
(\mu \mathrm{m})\end{array}$ \\
\hline $\begin{array}{l}\text { Modelo E } \\
\text { (implante de } \\
5 \times 7 \mathrm{~mm})\end{array}$ & $0,33 / 82 \%$ & $17,73 / 66 \%$ & $14,06 / 87 \%$ & $4,58 / 83 \%$ \\
\hline $\begin{array}{l}\text { Modelo F } \\
\text { (implante de } \\
4 \times 7 \mathrm{~mm} \text { ) }\end{array}$ & $0,40 / 100 \%$ & $26,88 / 100 \%$ & $16,17 / 100 \%$ & $5,48 / 100 \%$ \\
\hline $\begin{array}{l}\text { Modelo } G \\
\text { (implante de } \\
4 \times 15 \mathrm{~mm}) \\
\end{array}$ & $0,37 / 92 \%$ & $24,57 / 91 \%$ & $15,39 / 95 \%$ & $5,81 / 106 \%$ \\
\hline $\begin{array}{l}\text { Modelo } \mathrm{H} \\
\text { (implante de } \\
3.75 \times 15 \\
\mathrm{~mm} \text { ) }\end{array}$ & $0,41 / 102 \%$ & $28,26 / 105 \%$ & $12,85 / 79 \%$ & $6,17 / 112 \%$ \\
\hline
\end{tabular}

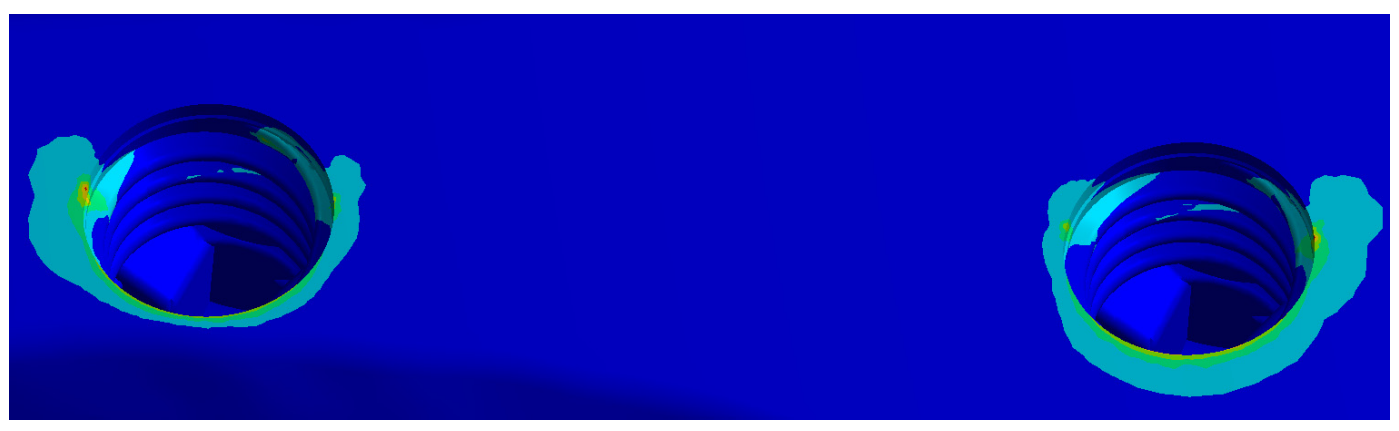

(E)

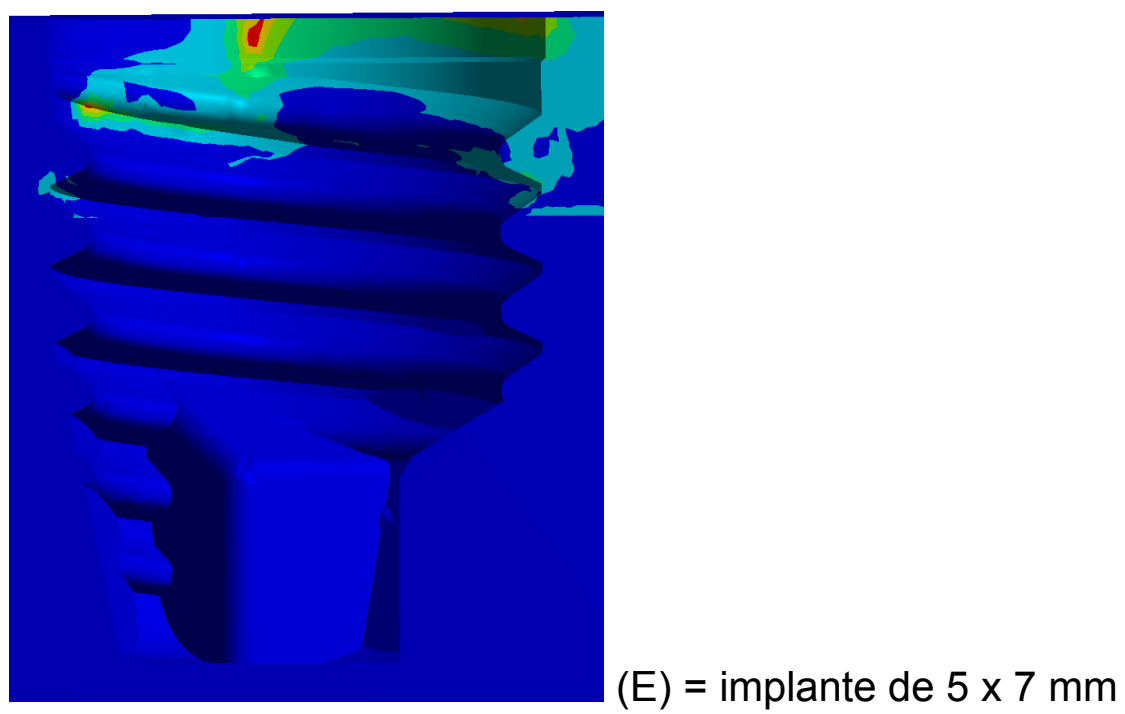



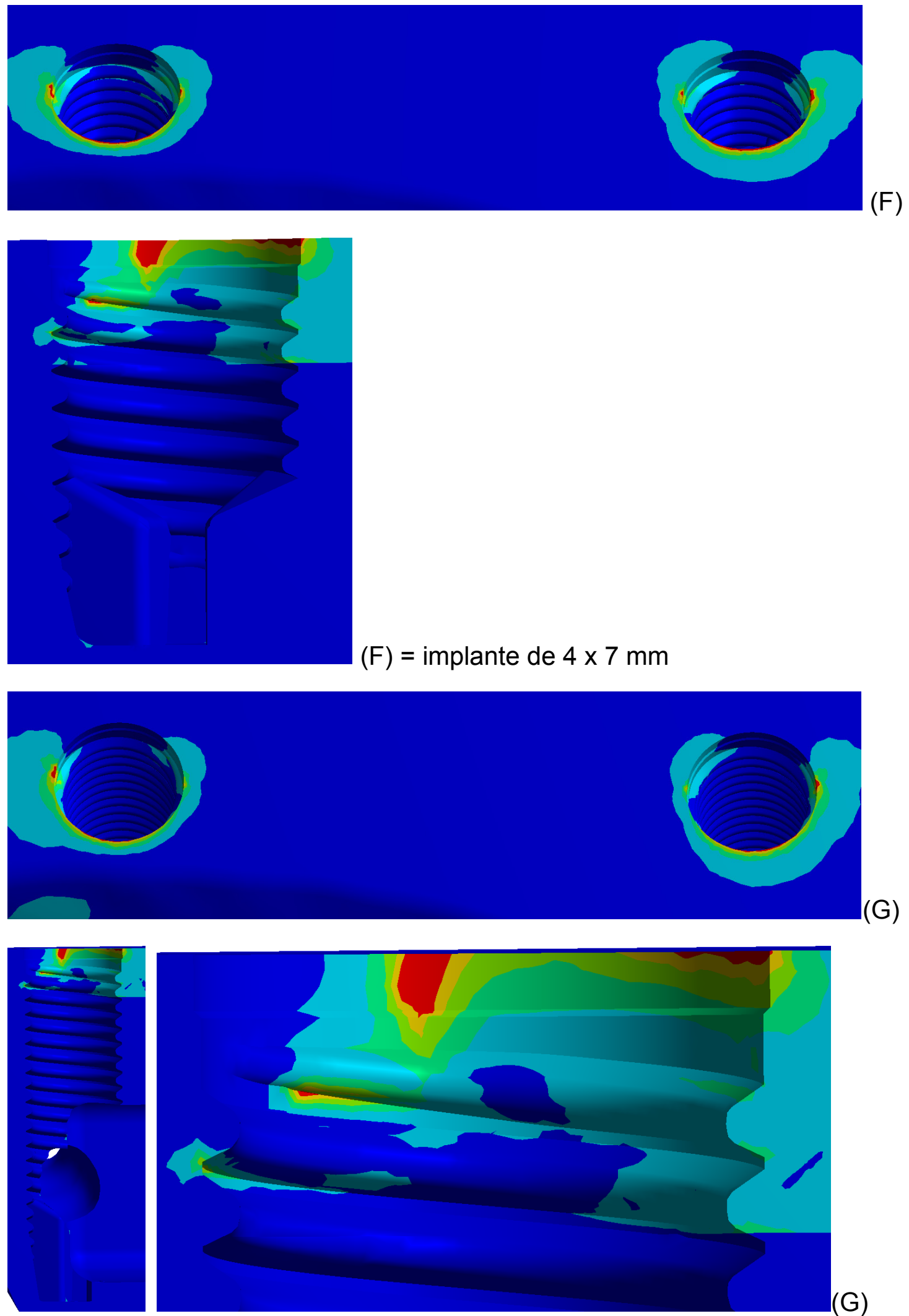

(G)

(G) = Implante de $4 \times 15 \mathrm{~mm}$ 

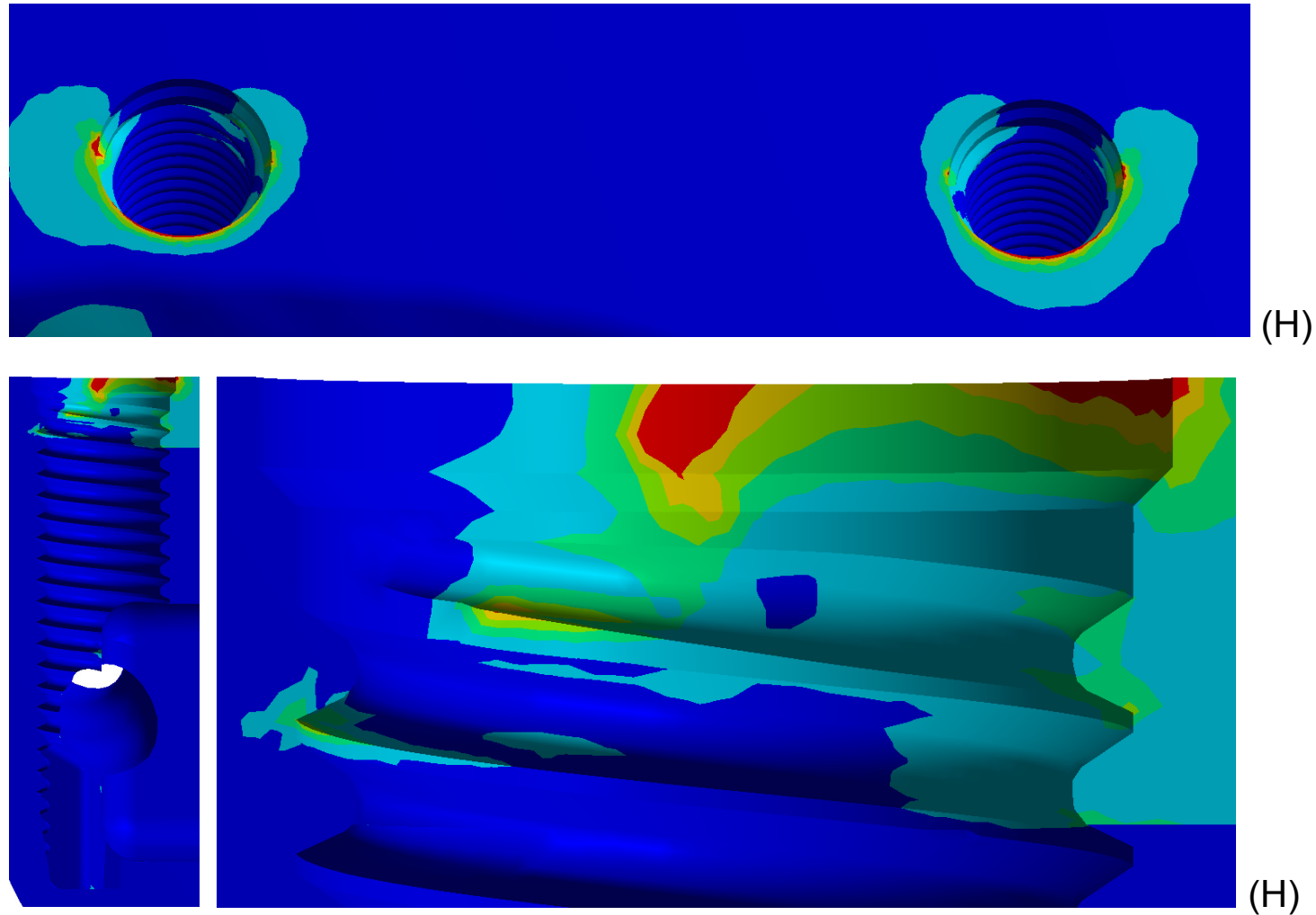

$(\mathrm{H})$

$(\mathrm{H})=$ Implante de $3.75 \times 15 \mathrm{~mm}$

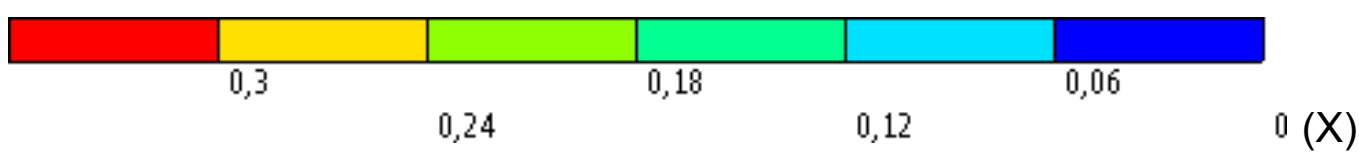

Figura 50: plotagem dos resultados no osso periimplantar pelo critério de Mohr-Coulomb, para implantes sob carga imediata e submetidos à carga oblíqua. As letras se referem aos resultados de cada modelo e o $\mathrm{X}$ a escala de cores para todos os resultados.

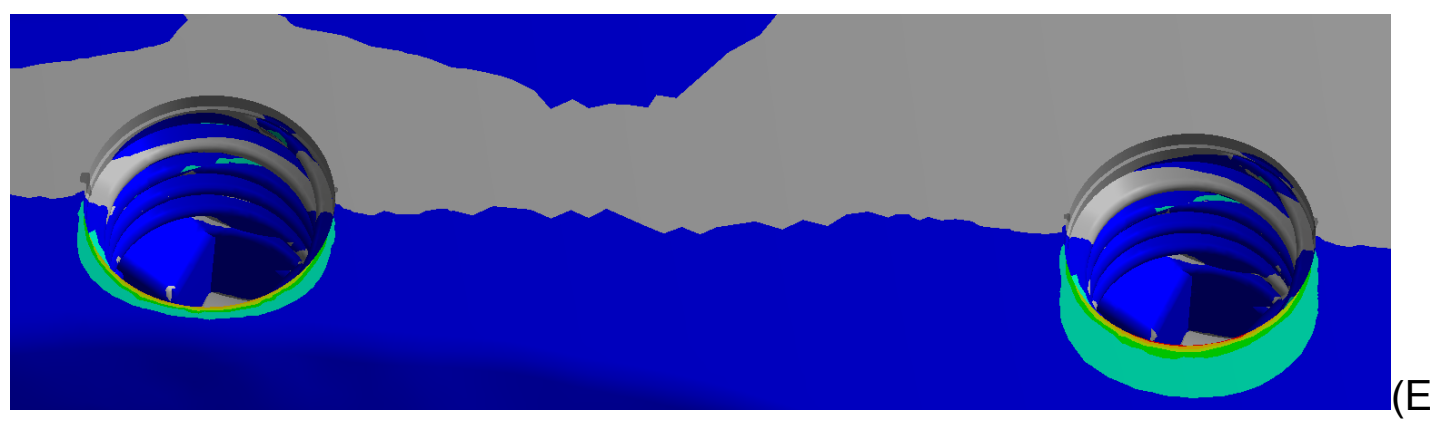

(E) 


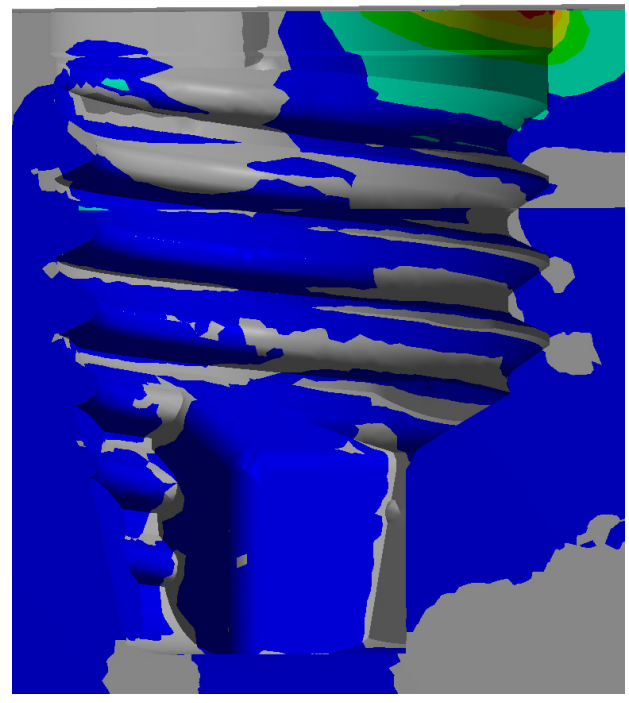

$(E)=$ implante de $5 \times 7 \mathrm{~mm}$

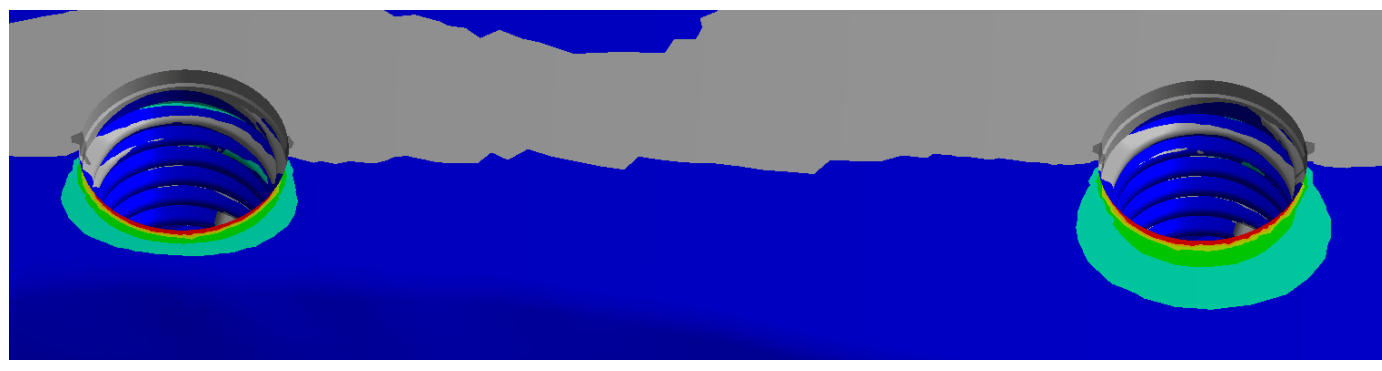

(F)

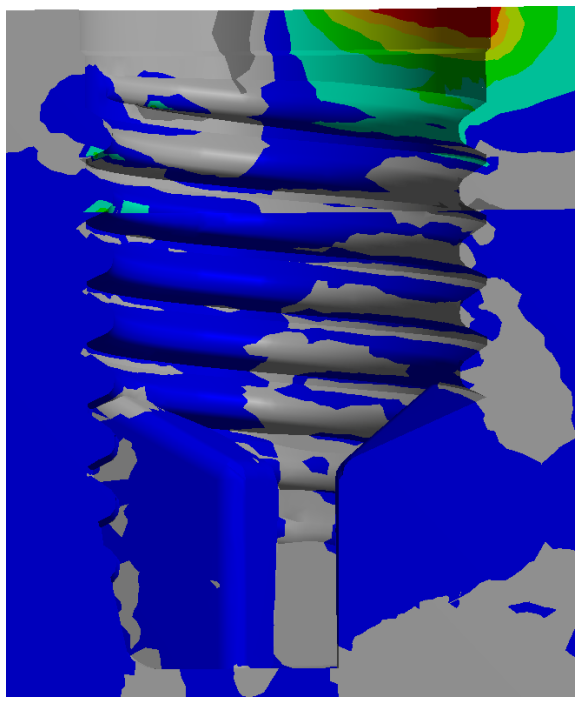

$(F)=$ implante de $4 \times 7 \mathrm{~mm}$

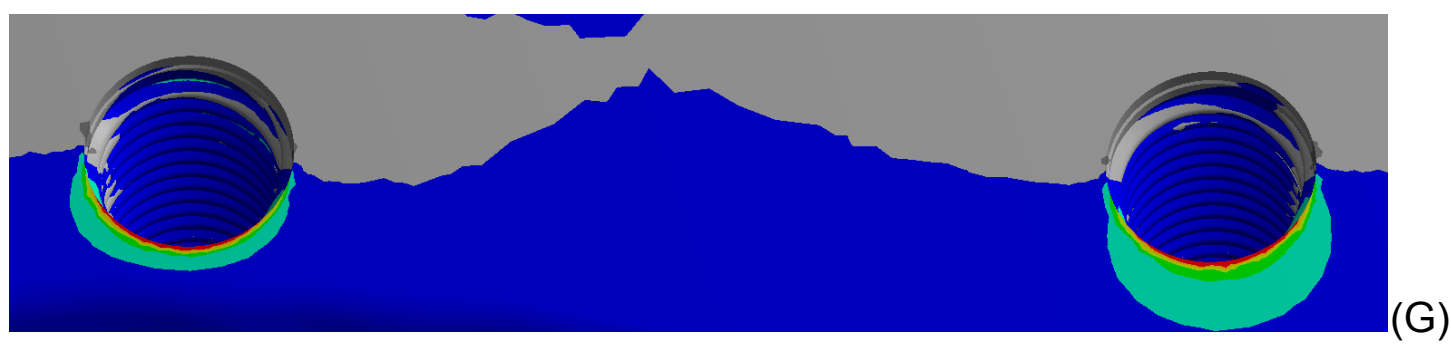



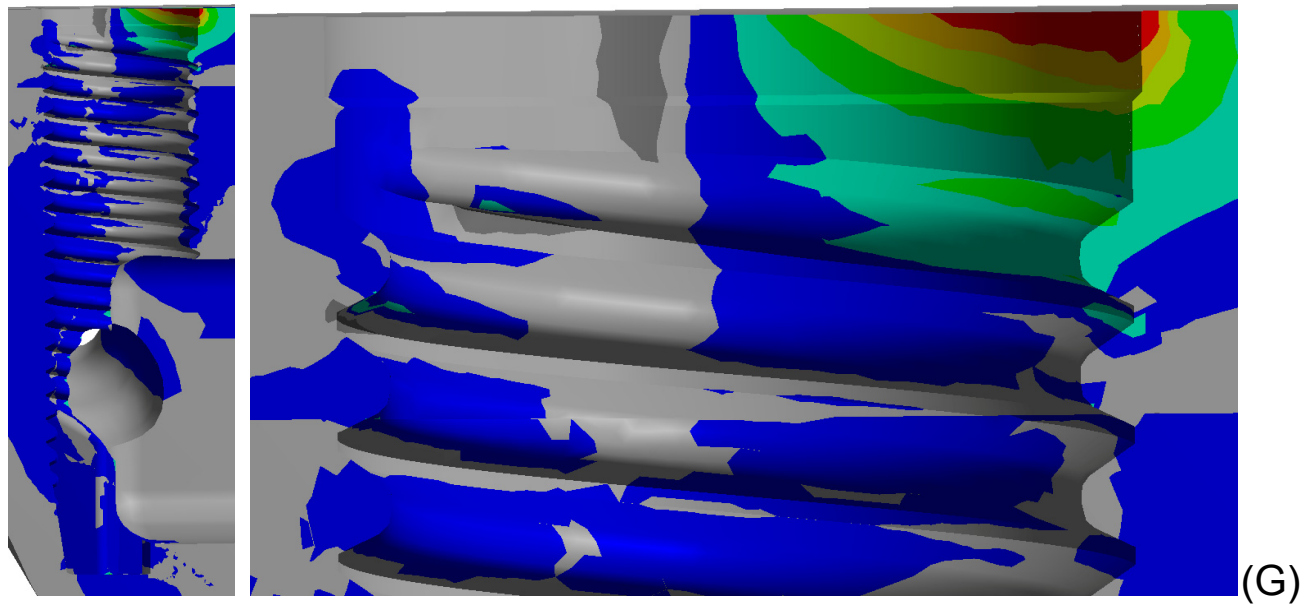

$(G)=$ implante de $4 \times 15 \mathrm{~mm}$
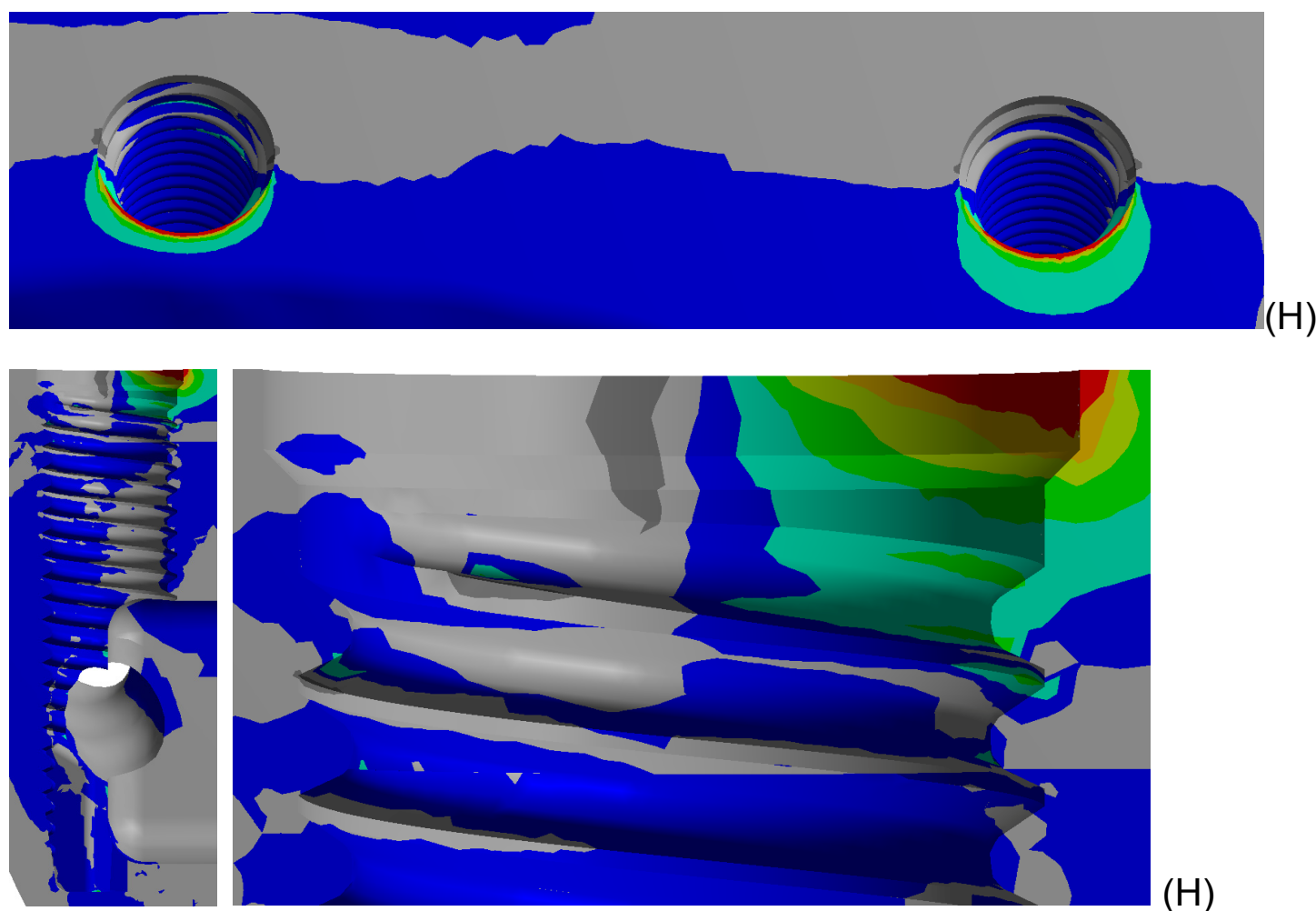

$(\mathrm{H})$

$(\mathrm{H})=$ implante de 3.75 por $15 \mathrm{~mm}$

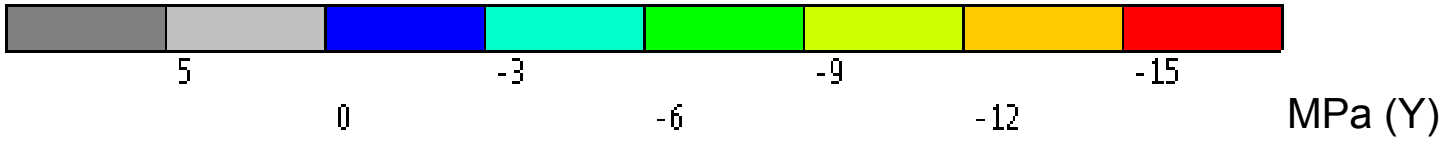

Figura 51: plotagem dos resultados no osso periimplantar pelo critério de tensão hidrostática, para implantes sob carga imediata e submetidos à carga oblíqua. As letras se referem aos resultados de cada modelo e o X a escala de cores para todos os resultados. 
Quando analisamos os resultados dos implantes sob carga imediata, submetidos à carga oblíqua, pelo critério do Mohr Coulomb e da tensão hidrostática compressiva, comparando o modelo $E$ (implante de $5 \times 7 \mathrm{~mm}$ ) com o modelo $\mathrm{F}$ (implante de $4 \times 7 \mathrm{~mm}$ ), pode-se notar uma significativa melhora nos resultados para o implante de maior diâmetro. Similarmente, ao se comparar o modelo $\mathrm{G}$ ( implante de $4 \times 15 \mathrm{~mm}$ ) com o modelo H (implante de $3.75 \times 15 \mathrm{~mm}$ ), o resultado foi mais favorável para o implante de maior diâmetro, embora com diferença menor do que entre os modelos $E$ (implante de $5 \times 7 \mathrm{~mm}$ ) e F (implante de $4 \times 7 \mathrm{~mm}$ ). De forma semelhante aos resultados dos implantes sob carga imediata submetidos à carga axial, esse fator pode ser explicado pelas diferenças na inserção óssea, com maior impacto da área de inserção na cortical da crista óssea.

Quando comparamos o modelo F (implante de $4 \times 7 \mathrm{~mm}$ ) com o modelo $\mathrm{G}$ (implante de $4 \times 15 \mathrm{~mm}$ ) pode-se observar que o aumento do comprimento somado a bicorticalidade também diminuiu o risco, mas com intensidade muito menor do que a variação no diâmetro.

Comparando todos os resultados de carga imediata, com a área de inserção óssea da tabela 4 , tanto sob cargas axiais quanto cargas oblíquas, pode-se teorizar que a área de inserção no osso cortical da crista tem maior impacto do que as demais inserções, incluindo o osso cortical do ápice, no caso dos implantes sob lateralização, e o osso medular. Desta forma a utilização de implantes curtos de maior diâmetro tem menor risco mecânico do que a lateralização do nervo alveolar inferior utilizando implantes de menor diâmetro com maior comprimento, na carga imediata. Mesmo que a inserção óssea seja quantitativamente maior, no caso dos implantes de maior comprimento, a posição dessa inserção parece ter efeito significativo, quando analisados tratamentos com carga imediata.

Outro fator digno de nota é a comparação dos resultados referentes às simulações com cargas oblíquas. Os modelos com implantes osseointegrados possuem resultados com intensidades maiores que os resultados com implantes sob carga imediata. Apesar da relação de contato existente entre 
osso e implante, no caso da carga imediata, favorecer o aparecimento de maiores picos, dois fatores auxiliaram para que os resultados fossem menores.

O primeiro se refere à área de inserção óssea, mostrada nos quadros 3 e 4, em que a área de inserção óssea dos implantes sob carga imediata é maior do que a dos implantes osseointegrados, devido à perda óssea da crista, comum em implantes osseointegrados.

O segundo fator se refere ao fulcro de rotação do implante. A perda óssea da crista além de diminuir a inserção óssea, também aumenta a alavanca existente entre o ponto de aplicação de força e o fulcro de rotação do implante, como pode ser visto na figura 51. Desta forma, esses dois fatores ocasionaram maiores picos de resultados nos implantes osseointegrados, sob carga oblíqua, mesmo que o contato entre implante e osso favoreça o contrário. 


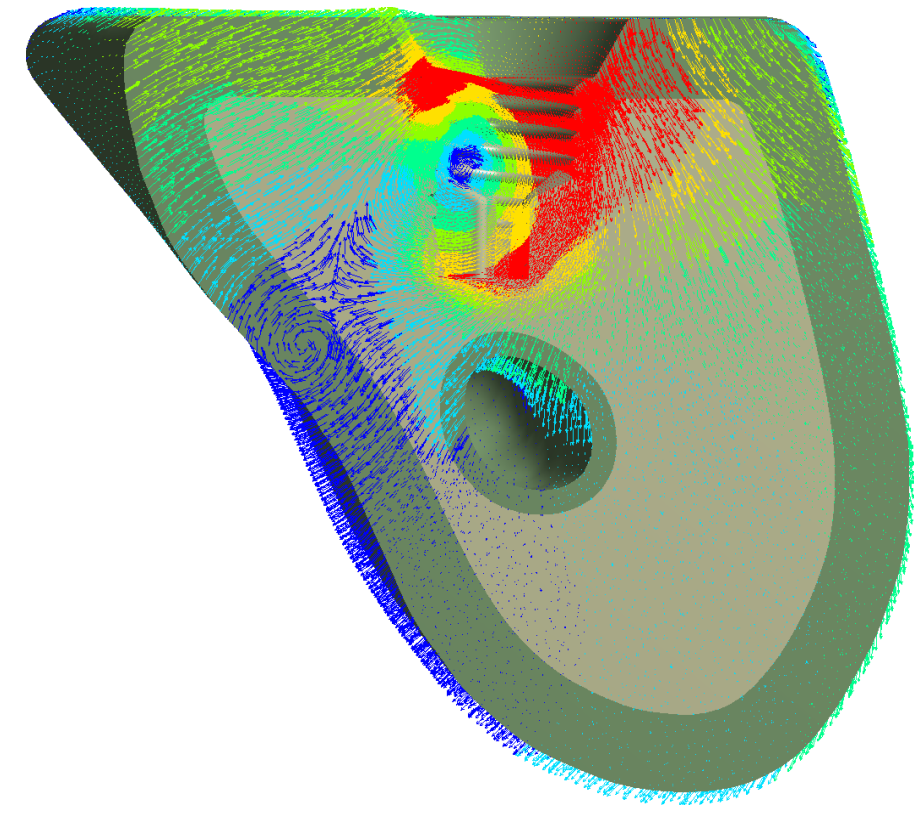

(1)

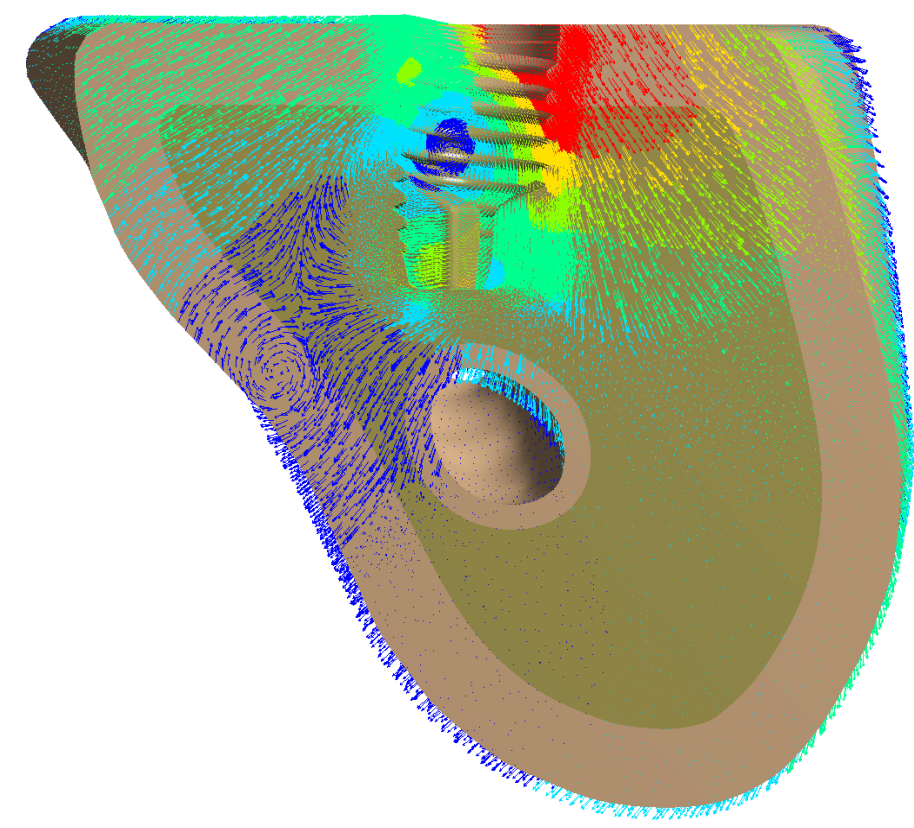

(3)

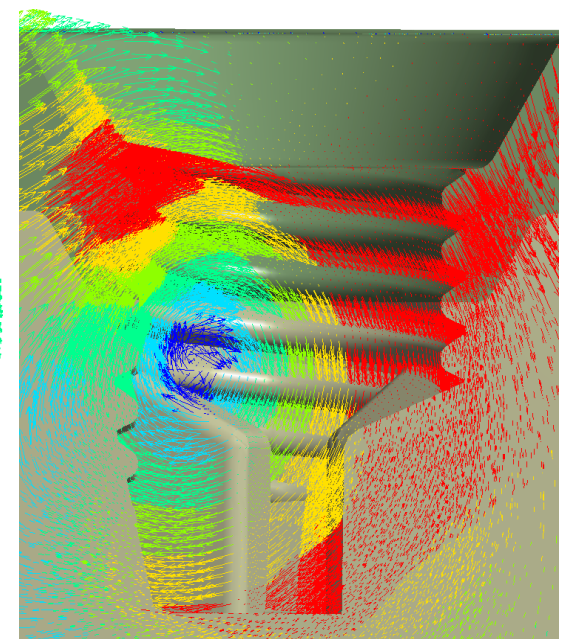

(2)

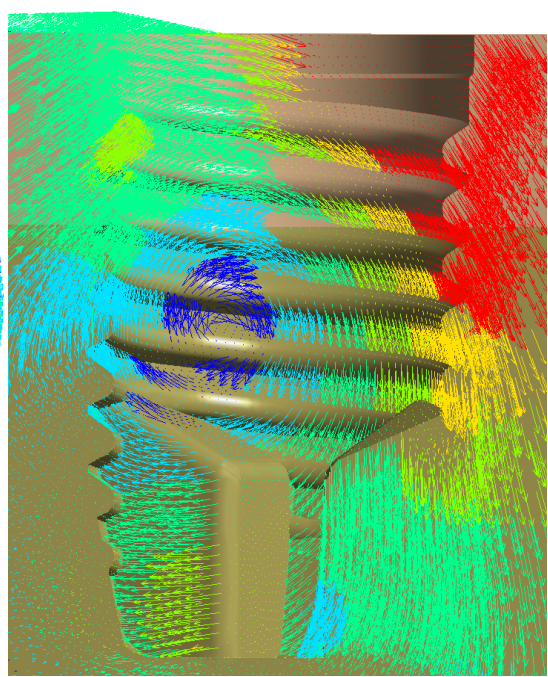

(4)

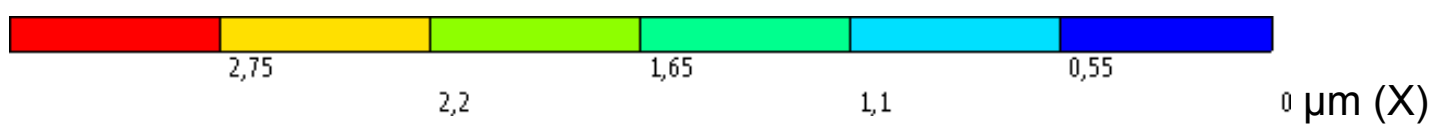

Figura 52: vista dos vetores de deslocamento nos modelos B (1 e 2) e F (3 e 4). Todos os resultados estão ajustados na mesma escala (X). Observe como o fulcro de rotação (representado pelo circulo azul na região periimplantar) no modelo osseointegrado (1 e 2) está mais para inferior do que no modelo sob carga imediata ( 3 e 4). 


\subsection{Resultados nos parafusos}

Para os resultados dos parafusos, critérios diferentes do osso periimplantar foram utilizados, de forma a avaliar as diferentes características que levam a sua fratura.

Quando consideramos materiais dúcteis, como o titânio dos parafusos, que reagem de forma relativamente semelhante a tensões de tração e compressão, até chegar ao seu limite de escoamento, para sua avaliação é indicado utilizar o critério de von Mises, também chamado de critério das tensões equivalentes, que utiliza as três tensões principais para a formulação do resultado. Além disso, por não distinguir entre tensões de tração ou compressão, seu resultado é sempre positivo. A fórmula para cálculo do resultado pode ser vista abaixo.

$$
\sigma_{e}=\frac{\sqrt{\left(\sigma_{1}-\sigma_{2}\right)^{2}+\left(\sigma_{2}-\sigma_{3}\right)^{2}+\left(\sigma_{3}-\sigma_{1}\right)^{2}}}{2}
$$

Onde $\sigma_{e}$ são as tensões de von Mises e $\sigma_{1}, \sigma_{2} e \sigma_{3}$ as tensões máximas, médias e mínimas respectivamente. Uma das principais utilizações desse critério é prever a deformação plástica em materiais dúcteis.

Embora a deformação plástica não leve necessariamente a um comprometimento estrutural, no caso dos parafusos de titânio para implantes dentários, é conhecido um fenômeno de corrosão química, devido à incorporação de hidrogênio e oxigênio no titânio, que torna o material friável/frágil (YOKOYAMA, ICHIKAWA et al., 2002). Dessa forma, embora o tipo de fratura dos parafusos, com pequena ou nenhuma deformação plástica, sugira mecanismos de fratura de materiais friáveis, a análise pelo critério de von Mises é indicada exatamente pelo fato da deformação plástica acelerar o 
processo de corossão (YOKOYAMA, ICHIKAWA et al., 2002), e conseqüentemente, adiantar a fratura por outros mecanismos.

Devido à forma como o parafuso é apertado e carregado, tensões de cisalhamento de alta intensidade são geradas. Considerando que essas tensões são as responsáveis por induzirem fraturas (YOKOYAMA, ICHIKAWA et al., 2002), sua análise está indicada.

Como citado anteriormente, o titânio passa do estado dúctil para um material com características friável/frágil. É propriedade comum dos materiais friáveis, que esses se tornem muito menos resistentes a tensões de tração do que de compressão. Por esse motivo, também foi citada a tensão máxima principal, ou pico de tração, entre os resultados. Entretanto, como a literatura não cita as tensões de tração como causadoras da fratura (YOKOYAMA, ICHIKAWA et al., 2002), e por não haver ainda clara definição sobre o papel das tensões de tração na fratura dos parafusos, esses resultados serão colocados como referência, mas não serão discutidos.

Para ajudar na interpretação dos dados, as tensões no parafuso, após simulações de calibragem de força de pré-tensão, mas sem carga mastigatória, foram colocadas como referência no quadro 9.

\begin{tabular}{|c|c|c|c|}
\hline & $\begin{array}{l}\text { von Mises } \\
(\mathrm{MPa})\end{array}$ & $\begin{array}{l}\text { Tração* } \\
\text { (MPa) }\end{array}$ & $\begin{array}{l}\text { Cisalhamento } \\
(\mathrm{MPa})\end{array}$ \\
\hline implante de $5 \times 7 \mathrm{~mm}$ & 389,09 & 529,11 & 180,86 \\
\hline implante de $4 \times 7 \mathrm{~mm}$ & 389,95 & 465,16 & 201,7 \\
\hline
\end{tabular}

* = tensão máxima principal

Ė interessante ressaltar que os modelos com implantes de $4 \times 7 \mathrm{~mm}$, $4 \times 15 \mathrm{~mm}$ e o de $3.75 \times 15 \mathrm{~mm}$ possuem o mesmo parafuso e a mesma plataforma, além de utilizarem exatamente a mesma malha, enquanto os modelos com implante de $5 \times 7 \mathrm{~mm}$, possuem parafuso geometricamente 
diferente, além de plataforma maior. Desta forma, mesmo que a calibragem da força nos parafusos seja feita para um critério, os demais critérios apresentam resultados e variações diferentes. Com esses conceitos em mente, acredita-se que a análise comparativa dos resultados referentes aos modelos com parafusos idênticos, seja melhor para avaliar as diferenças na espessura e comprimento do implante, e que outros fatores como geometria do parafuso e tamanho da plataforma podem afetar a análise comparativa com o parafuso do modelo A (implante de $5 \times 7 \mathrm{~mm}$ )e $\mathrm{E}$ (implante de $5 \times 7 \mathrm{~mm}$ ).

A figura 52 se refere à vista em corte dos resultados dos parafusos, presente nas figuras 53 a 61 .
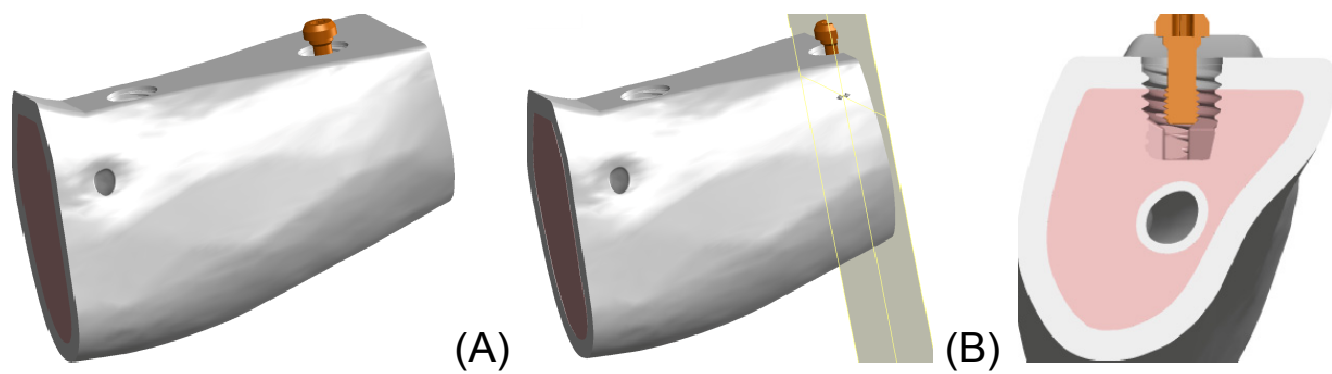

(C)

Figura 53: Vista do corte do parafuso, referente às figuras 53 a 61.

Os quadros 10 e 11, e a figura 54 se refere aos resultados no parafuso, dos implantes osseointegrados, sob carga axial. 


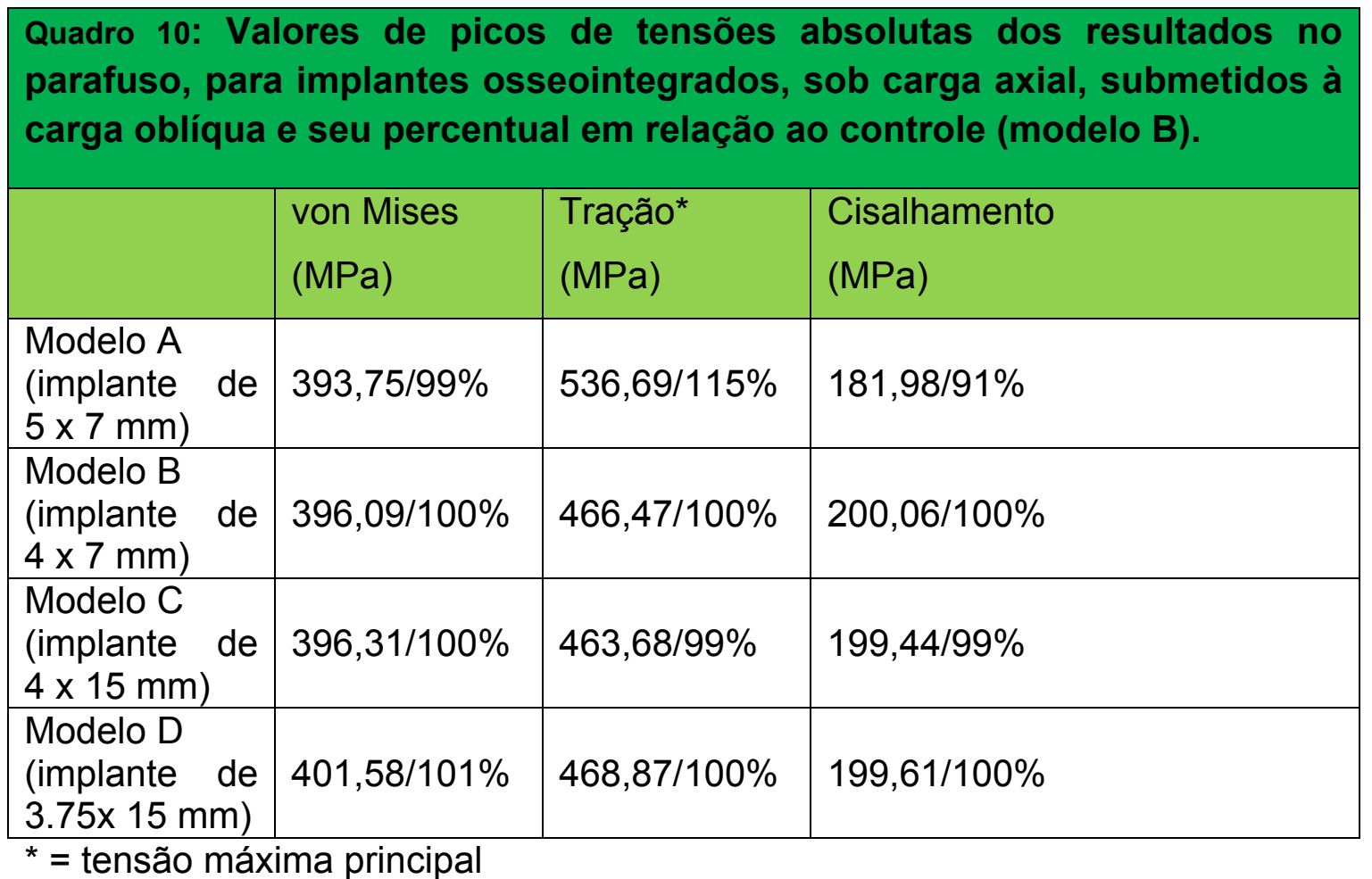

\begin{tabular}{|c|c|c|c|}
\hline & $\begin{array}{l}\text { von Mises } \\
\text { (MPa) }\end{array}$ & $\begin{array}{l}\text { Tração* } \\
\text { (MPa) }\end{array}$ & $\begin{array}{l}\text { Cisalhamento } \\
\text { (MPa) }\end{array}$ \\
\hline $\begin{array}{l}\text { Modelo A } \\
\text { (implante de } \\
5 \times 7 \mathrm{~mm} \text { ) }\end{array}$ & $4.66 / 76 \%$ & $7.58 / 578 \%$ & $1.12 / 168 \%$ \\
\hline $\begin{array}{l}\text { Modelo B } \\
\text { (implante de } \\
4 \times 7 \mathrm{~mm} \text { ) }\end{array}$ & $6.14 / 100 \%$ & $1.31 / 100 \%$ & $-1.64 / 100 \%$ \\
\hline $\begin{array}{l}\text { Modelo C } \\
\text { (implante de } \\
4 \times 15 \mathrm{~mm} \text { ) }\end{array}$ & $6,36 / 103 \%$ & $-1.48 /-12 \%$ & $-2.26 / 62 \%$ \\
\hline $\begin{array}{l}\text { Modelo } D \\
\text { (implante de } \\
3.75 \times 15 \mathrm{~mm} \text { ) }\end{array}$ & $11.63 / 189 \%$ & $3.71 / 283 \%$ & $-2.09 / 73 \%$ \\
\hline
\end{tabular}

* = tensão máxima principal 


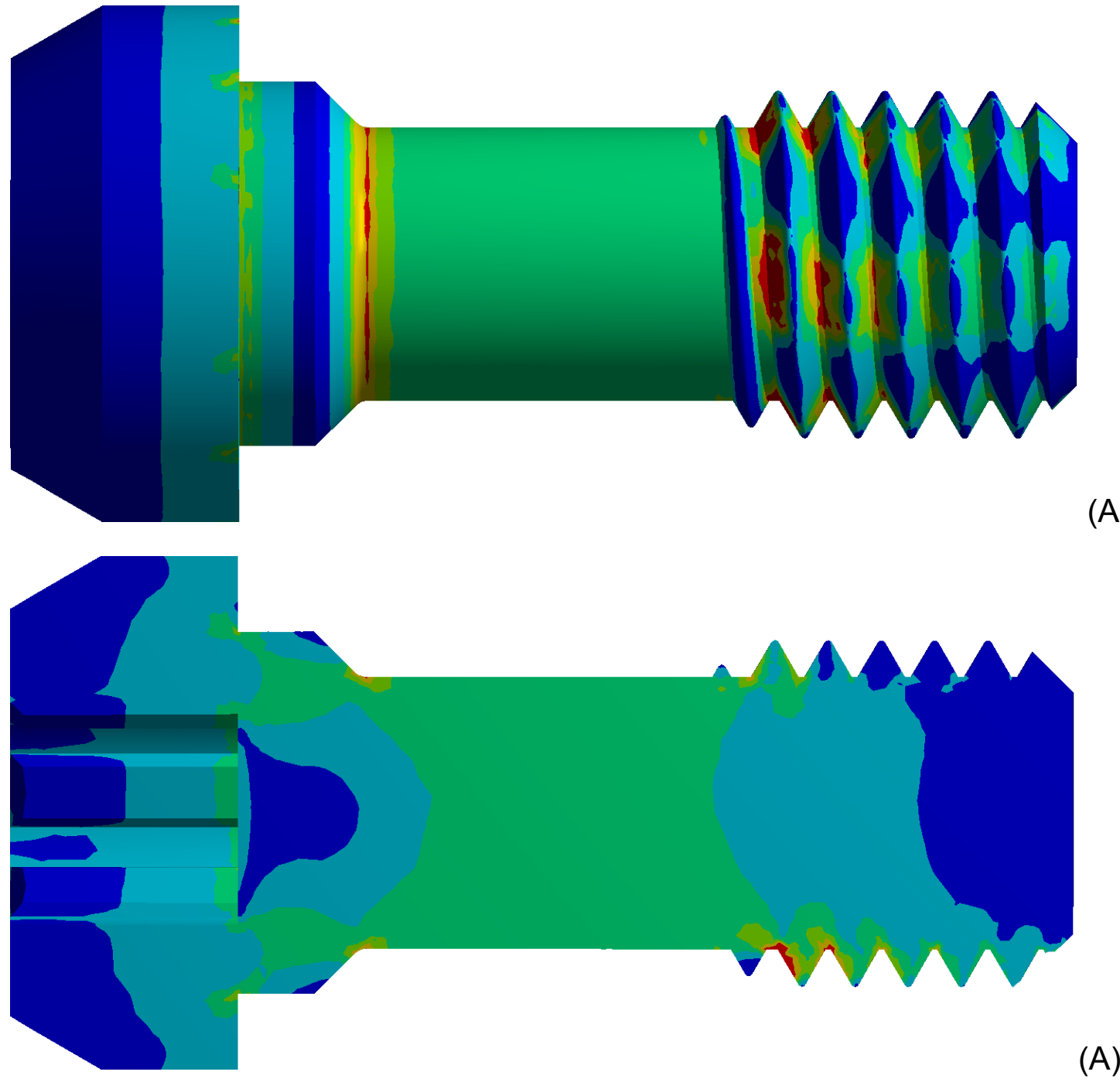

$(A)=$ implante de $5 \times 7 \mathrm{~mm}$

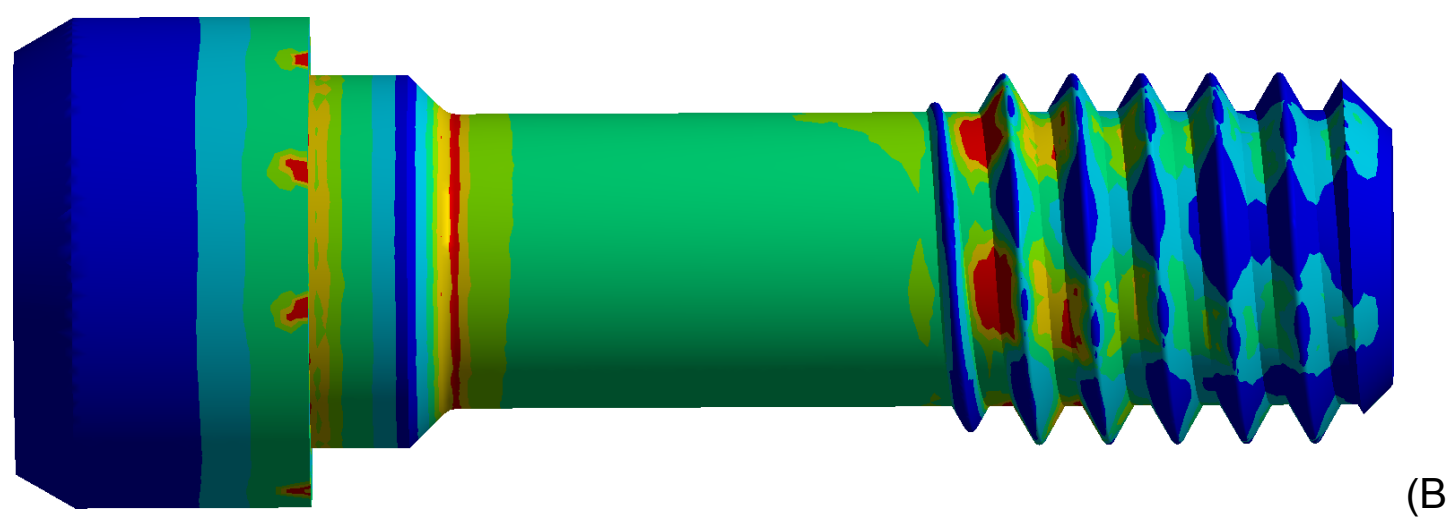

(B) 


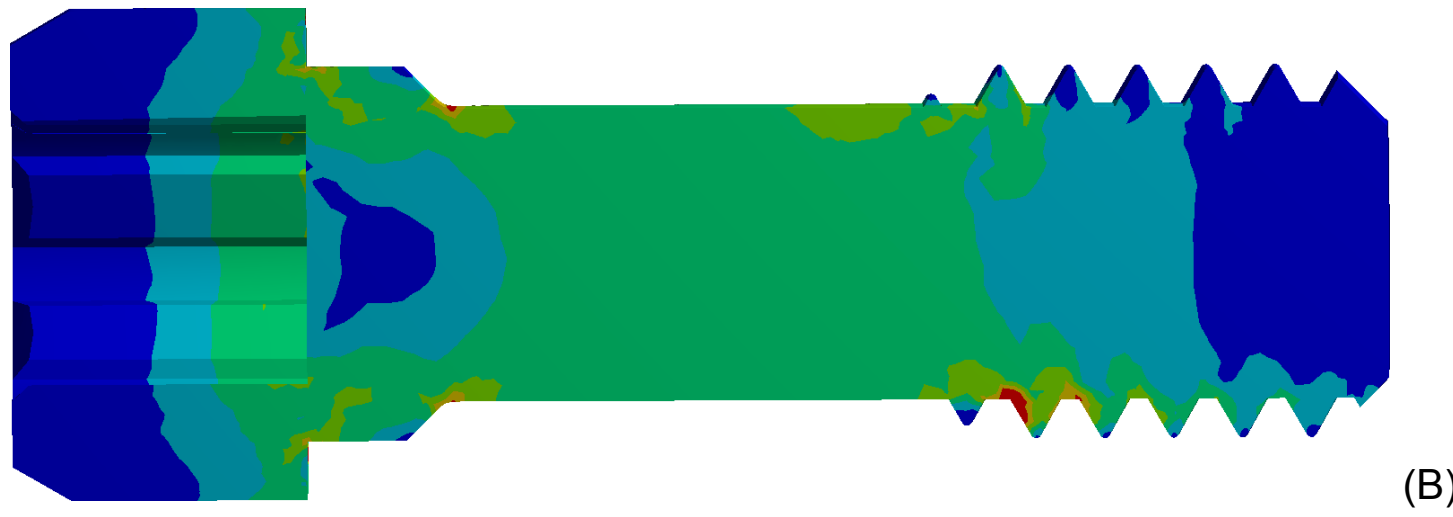

(B) = implante de $4 \times 7 \mathrm{~mm}$
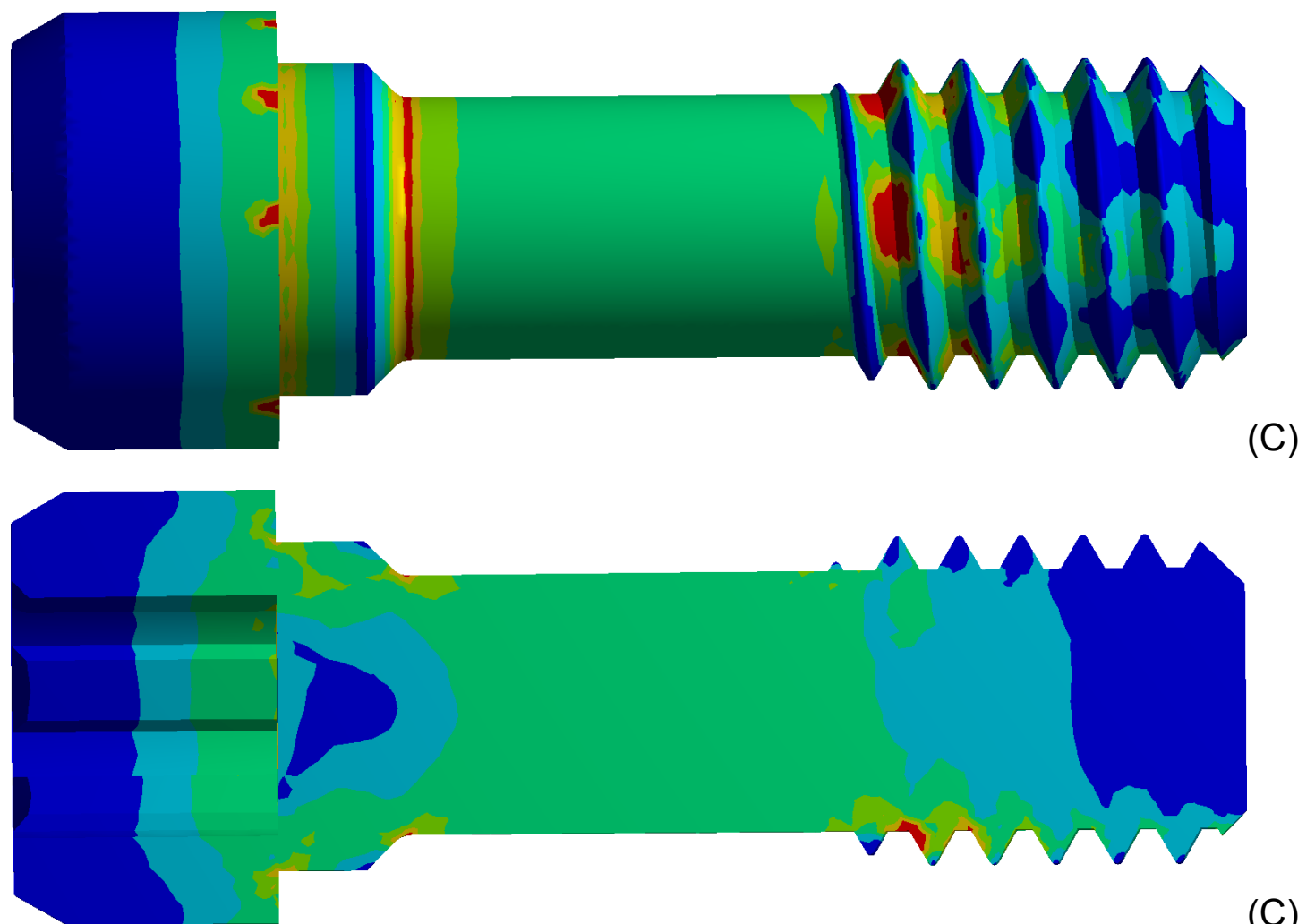

(C)

(C) $=$ implante de $4 \times 15 \mathrm{~mm}$

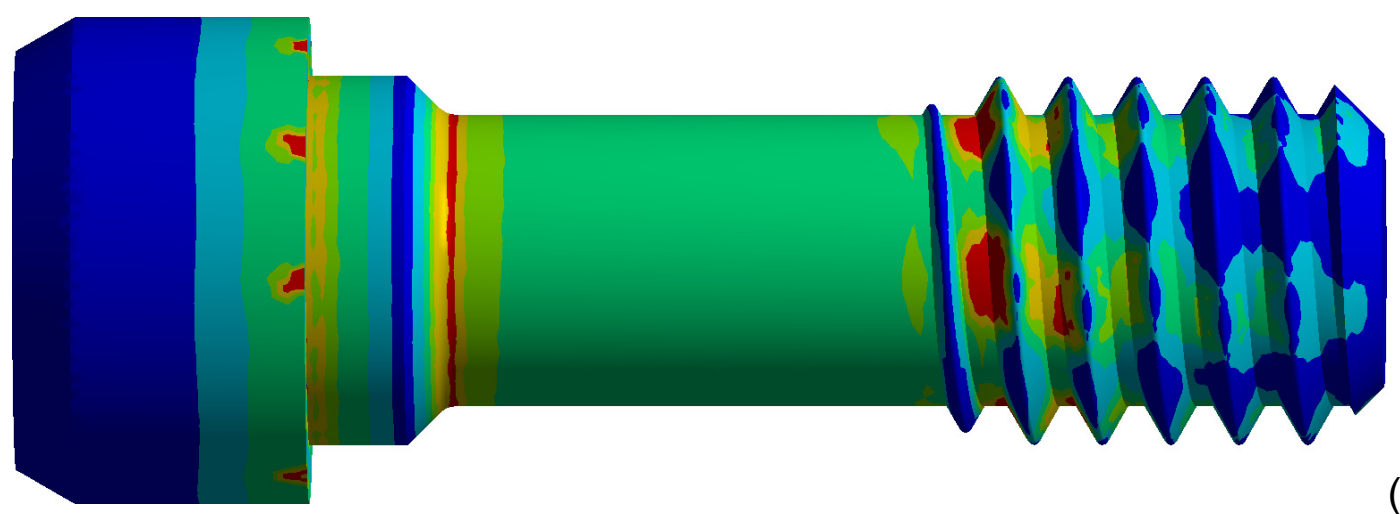




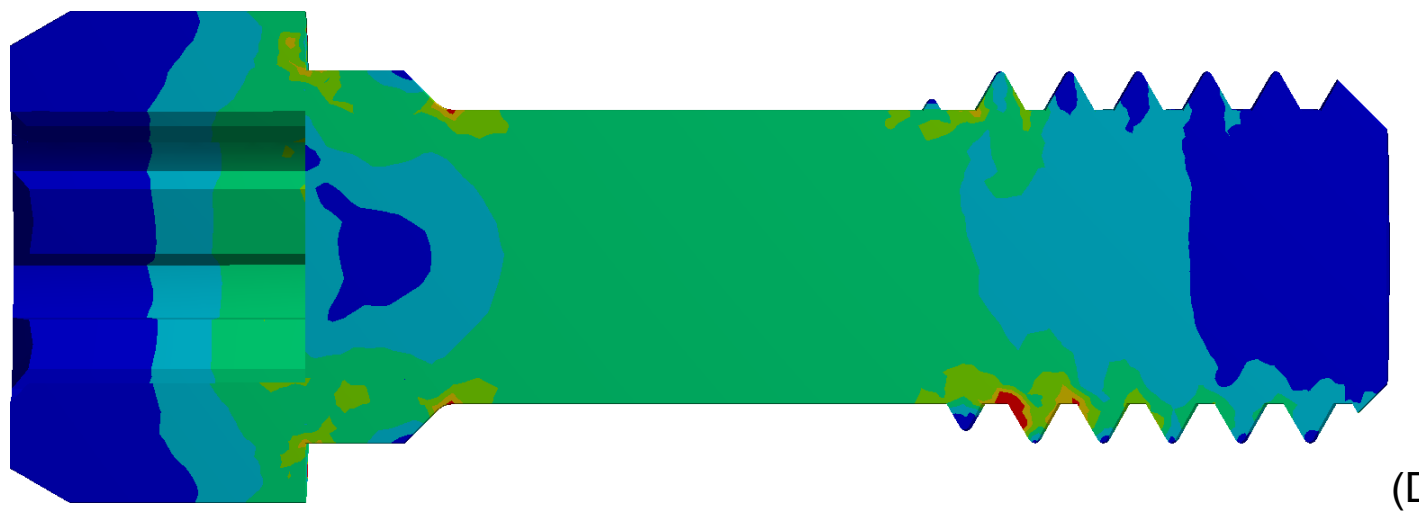

(D) $=$ Implante de $3.75 \times 15 \mathrm{~mm}$

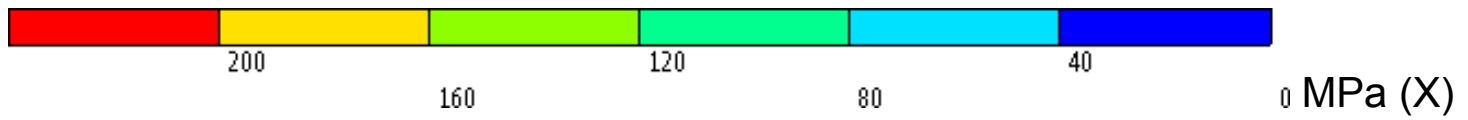

Figura 54: Plotagens dos resultados, no parafuso do elemento 37, para implantes osseointegrados, submetidos à carga axial, considerando a tensões pelo critério de von Mises. As letras se referem ao modelo de cada resultado. Todos os resultados estão ajustados na mesma escala (X).

Quanto aos resultados das tensões de cisalhamento, serão colocados exemplos de resultados na figura 55, porém não serão demonstrados todos os resultados, devido ao grande número de figuras necessárias e porque do ponto de vista de interpretação, todos os resultados são semelhantes, sendo que os picos de cisalhamento ocorreram sempre no ângulo da rosca com o corpo do parafuso, na sua porção superior.

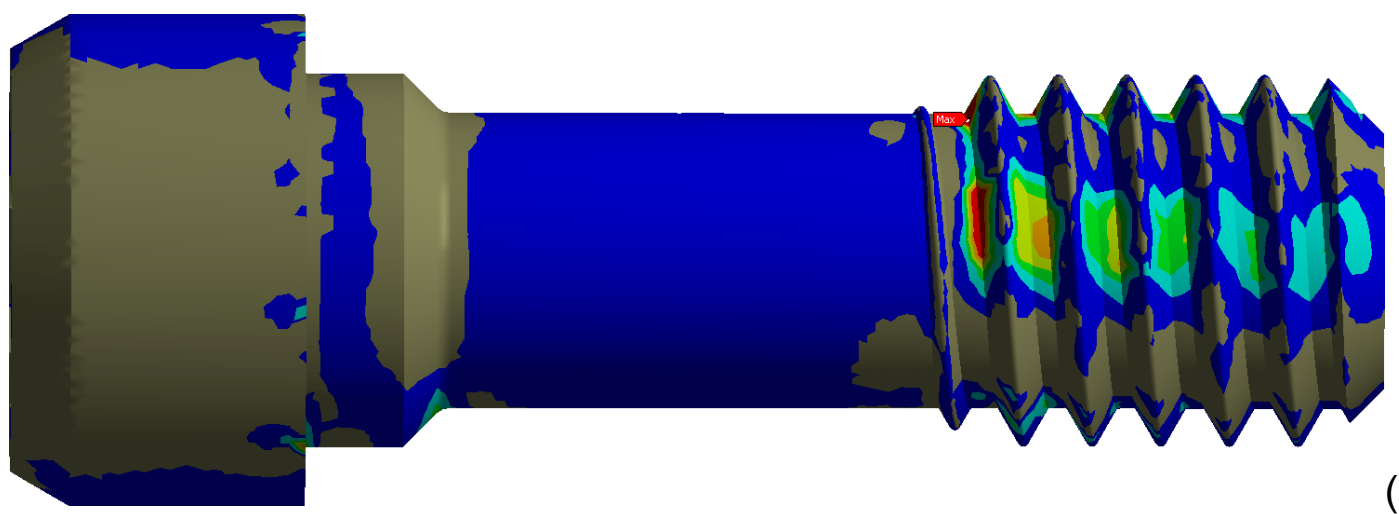




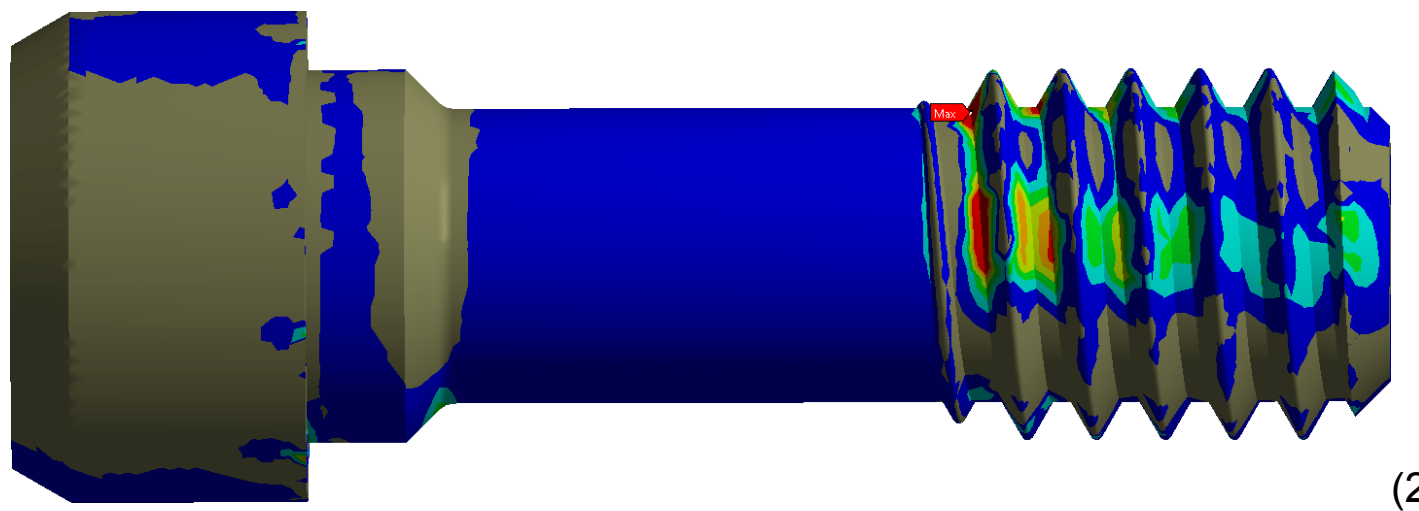

(2)

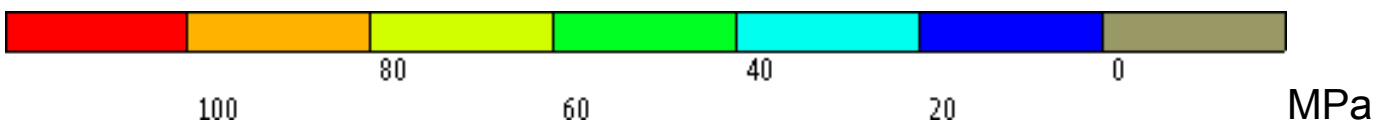

(3)

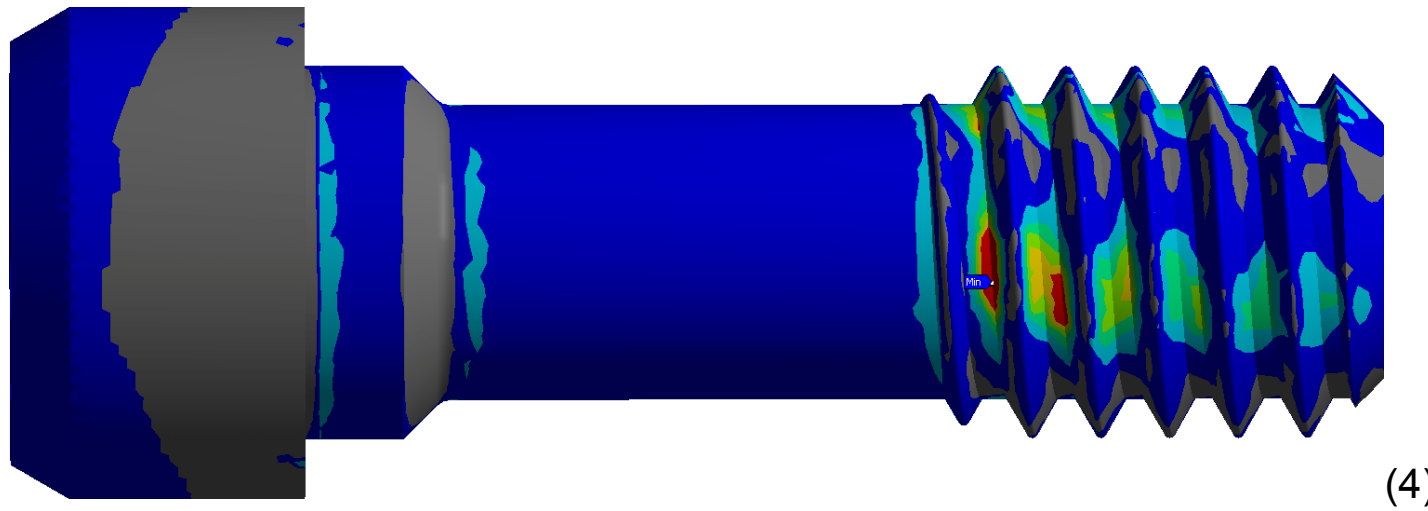

(4)

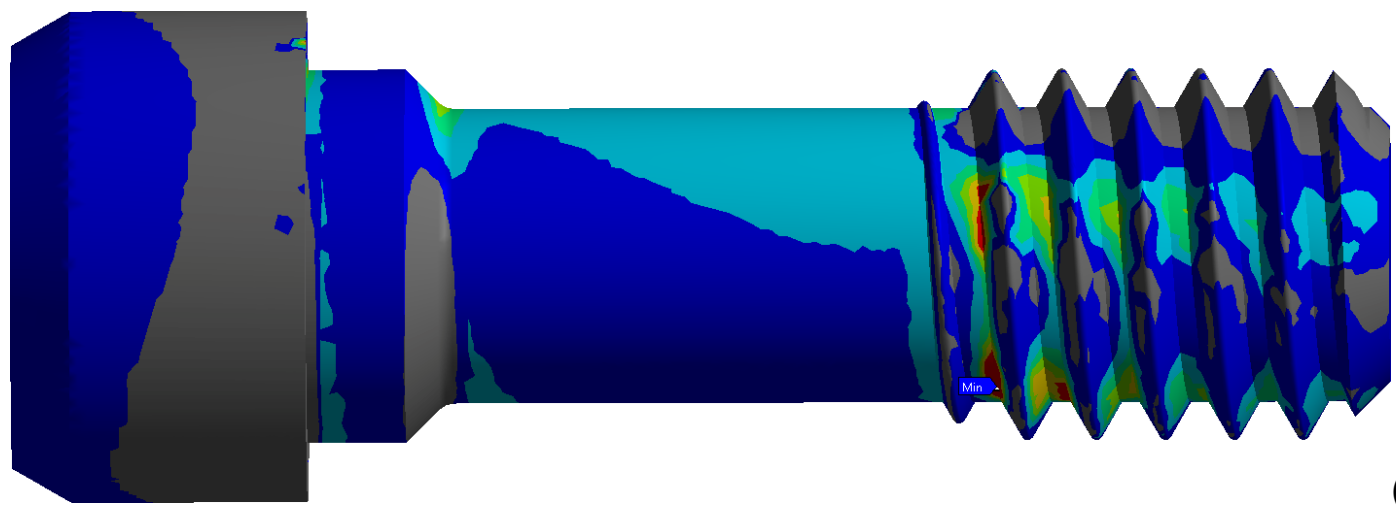

(5)

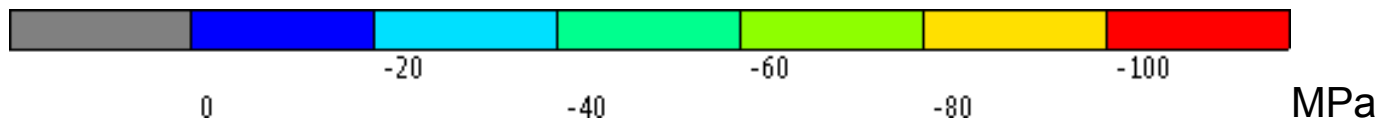

$\operatorname{MPa}(6)$

Figura 55: Plotagens dos resultados dos picos de cisalhamento, no parafuso do elemento 37 , referentes aos modelos $B$ (1 e 4) e F (2 e 5), com implantes osseointegrados. As setas indicam os locais de picos de tensão. A escala 3 se refere a 1 e 2 e a escala 6 se refere a 4 e 5 . Note que em todas as plotagens, os picos se localizam no ângulo superior das roscas do parafuso. 
Um fator que pode ser observado nos resultados é que a distribuição de tensões não são homogeneas na região das roscas, mas se concentram em zonas, intercaladas por regiões de baixa tensão. Considerando que o contato entre parafuso-implante não é perfeito, é esperado que algumas regiões demonstrem maior zona de contato, enquanto outras não possuem nenhum contato, formando fendas ou "gaps".

Quando da realização do trabalho, observou-se esse comportamento. A tentativa de minimizá-lo com maiores refinamentos da malha, chegou a um limite de elementos quadráticos de $0,1 \mathrm{~mm}$. De qualquer forma, o comportamento persistiu, só desaparecendo quando simulações com contatos lineares do tipo "bonded" eram configuradas, demonstrando que esse é um comportamento natural de superfícies justapostas sob pressão, mas não aderidas.

Novamente, a semelhança dos resultados do osso periimplantar, serão discutidas apenas as variações de intensidade.

Quando avaliamos os resultados do quadro 10, pode-se notar mínima diferença relativa entre os resultados apresentados. Dessa forma, a maior parte das tensões é proveniente do processo de pré-tensão do parafuso e não da carga mastigatória em si. Entretanto, mesmo que sejam pequenas, se considerarmos que essas variações nas tensões provenientes da carga mastigatória ocorrem repetidamente, elas são responsáveis parcialmente pela fratura do parafuso por um processo de fadiga, além da corrosão já mencionada.

Ao avaliarmos o quadro 11 , referente às tensões relativas do segundo passo de carga no parafuso, para implantes osseointegrados sob carga axial, ao comparamos os resultados pelo critério de von Mises do modelo $B$ (implante de $4 \times 7 \mathrm{~mm}$ ) com o $\mathrm{C}$ (implante de $4 \times 15 \mathrm{~mm}$ ), para avaliar o impacto no comprimento do implante, pode-se notar uma mínima diferença entre os resultados, em favor do modelo com menor comprimento (B). Por outro lado, pelo critério de cisalhamento, os resultados foram melhores para o modelo $\mathrm{C}$ (implante de $4 \times 15 \mathrm{~mm}$ ), mas por uma diferença percentual muito mais 
expressiva. Ou seja, no quesito comprimento do implante, os resultados foram contraditórios, entre os critérios analisados.

Se considerarmos que não existe uma clara definição sobre o impacto da deformação plástica, avaliada pelo critério de von Mises, e das tensões de cisalhamento no processo de fratura, fica difícil estabelecer conclusões considerando apenas esses resultados.

Quando comparados os resultados do modelo A (implante de $5 \times 7 \mathrm{~mm}$ ) com o B (implante de $4 \times 7 \mathrm{~mm}$ ) para se avaliar o impacto do diâmetro do implante nas concentrações de tensões, nota-se uma tendência de diminuição dos picos pelo critério de von Mises e um aumento pelo critério de cisalhamento. Entretanto, ao se avaliar o modelo C (implante de $4 \times 15 \mathrm{~mm}$ ) com o D (implante de $3.75 \times 15 \mathrm{~mm}$ ), que também avalia a alteração no diâmetro do implante, enquanto a tendência, pelo critério de von Mises, continuou a mesma, com melhores resultados para os implantes de maior diâmetro, os resultados de cisalhamento demonstraram o inverso da comparação entre o modelo $A$ (implante de $5 \times 7 \mathrm{~mm}$ ) e $B$ (implante de $4 \times 7 \mathrm{~mm}$ ), com melhores resultados para o implante de maior diâmetro.

Considerando que o comportamento do parafuso é complexo durante cargas axiais, que por um lado, comprimem o intermediário contra o implante, diminuindo a distância entre a cabeça do parafuso e suas roscas e ,teoricamente, diminuem as tensões induzidas, por outro lado, a reação de compressão do implante acarreta numa expansão lateral, comprimindo tanto o osso, quanto a região das roscas do parafuso internamente. Esse equilíbrio entre a diminuição das tensões pela diminuição do comprimento do parafuso e o aumento das tensões pela compressão das roscas é que fornecem o resultado, como pode ser visto nas figuras 56 e 57 . 


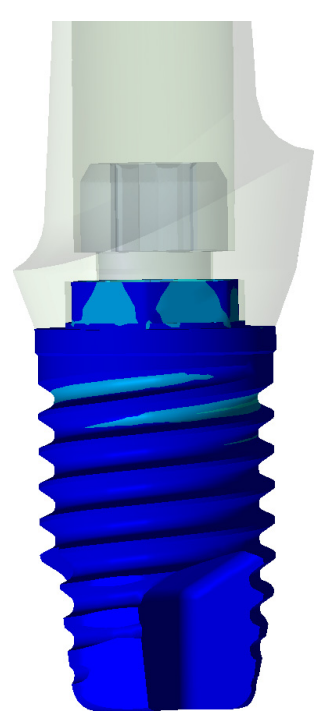

(A)

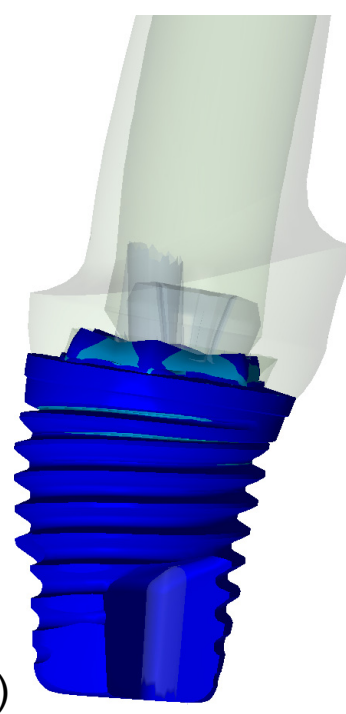

(B)

Figura 56: Tendência de deformação dos implantes sob carga axial. A = resultado do implante sem qualquer deformação. $B=$ resultado do implante com deformação multiplicada por 1000. Observe a tendência de expansão lateral do implante, quando a deformação é multiplicada para verificação das tendências.
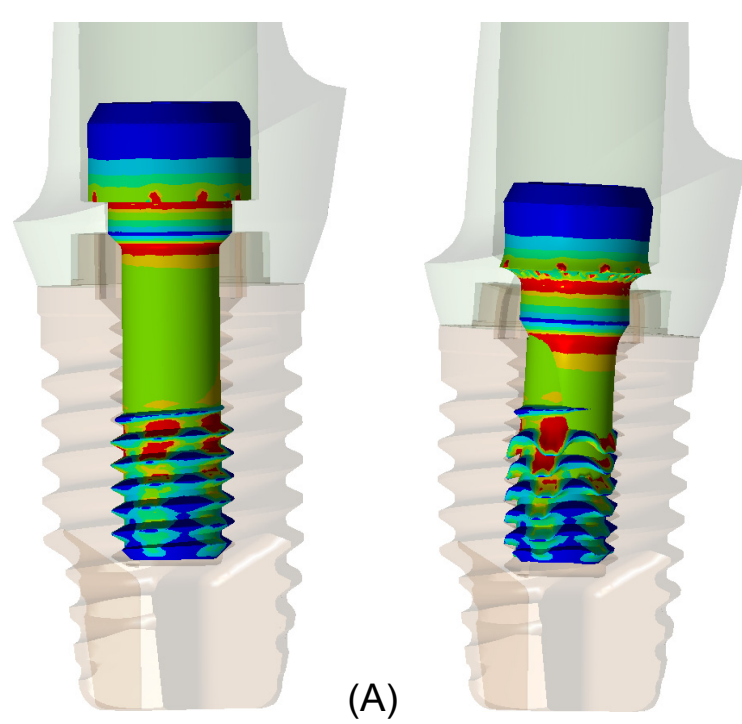

(B)

Figura 57: Tendência de deformação dos parafusos sob carga axial. $A=$ resultado do parafuso sem qualquer deformação. $B=$ resultado do parafuso com deformação multiplicada por 300 . Observe a tendência de aproximação entre a cabeça do implante e as roscas, quando a deformação é multiplicada para verificação das tendências. 
Dentre as variáveis analisadas, o maior comprimento e largura do implante diminuem a tendência de deformação do parafuso, por fornecer maior volume de titânio. Mas isso é válido tanto para a variação no comprimento do parafuso quanto da compressão das roscas. E desta forma os resultados acabam não tendo tendências claras dentre as variáveis analisadas.

Relembrando a discussão anterior, que o modelo $A$ (implante de $5 \times 7$ $\mathrm{mm}$ ) pode ter seus resultados afetados pelo tamanho da plataforma e geometria do parafuso, é prudente considerar apenas os resultados da comparação do modelo C (implante de 4x15 mm) com o D (implante de $3.75 \times 15 \mathrm{~mm}$ ). Desta forma, implantes de maior diâmetro apresentaram melhores resultados do que implantes similares de menor diâmetro. Contudo, não ficou claro, dentro desses resultados, se o aumento do comprimento é mais ou menos vantajoso que o aumento do diâmetro. De forma geral, devido ao processo mecânico envolvido sem claras tendências, uma avaliação caso a caso é recomendada.

Os quadros 12 e 13, e a figura 58, se refere aos resultados no parafuso, dos implantes sob carga imediata, submetidos à carga axial.

\begin{tabular}{|c|c|c|c|}
\hline & $\begin{array}{l}\text { Von Mises } \\
(\mathrm{MPa})\end{array}$ & $\begin{array}{l}\text { Tração* } \\
\text { (MPa) }\end{array}$ & $\begin{array}{l}\text { Cisalhamento } \\
\text { (MPa) }\end{array}$ \\
\hline $\begin{array}{l}\text { Modelo } \mathrm{E} \\
\text { (implante de } 5 \times 7 \\
\mathrm{~mm} \text { ) }\end{array}$ & $398,56 / 100 \%$ & $549,64 / 116 \%$ & $184,2 / 93 \%$ \\
\hline $\begin{array}{l}\text { Modelo F } \\
\text { (implante de } 4 \times 7 \\
\mathrm{~mm} \text { ) }\end{array}$ & $397,19 / 100 \%$ & $471,43 / 100 \%$ & $196,61 / 100 \%$ \\
\hline $\begin{array}{l}\text { Modelo G } \\
\text { (implante de } 4 \text { × } 15 \\
\mathrm{~mm} \text { ) }\end{array}$ & $396,95 / 99 \%$ & $467,95 / 99 \%$ & $195,8 / 99 \%$ \\
\hline $\begin{array}{l}\text { Modelo } \mathrm{H} \\
\text { (implante de } 3.75 x \\
15 \mathrm{~mm} \text { ) }\end{array}$ & $400,91 / 101 \%$ & $472,71 / 100 \%$ & $195,04 / 99 \%$ \\
\hline
\end{tabular}




\begin{tabular}{|l|l|l|l|}
\hline \multicolumn{4}{|l|}{$\begin{array}{l}\text { Quadro 13: Valores de picos de tensões relativas ao segundo passo de } \\
\text { carga, para implantes sob carga imediata, submetidos à carga axial e seu } \\
\text { percentual em relação ao controle (modelo F). }\end{array}$} \\
\hline & $\begin{array}{l}\text { Von Mises } \\
(\mathrm{MPa})\end{array}$ & $\begin{array}{l}\text { Tração* } \\
(\mathrm{MPa})\end{array}$ & \multicolumn{2}{l|}{ Cisalhamento (MPa) } \\
\hline $\begin{array}{l}\text { Modelo E } \\
\text { (implante de } 5 \times 7 \\
\text { mm) }\end{array}$ & $9.47 / 131 \%$ & $20.53 / 327 \%$ & $3.34 / 165 \%$ \\
\hline $\begin{array}{l}\text { Modelo F } \\
\text { (implante de } 4 \times 7 \\
\text { mm) }\end{array}$ & $7.24 / 100 \%$ & $6.27 / 100 \%$ & $-5.09 / 100 \%$ \\
\hline $\begin{array}{l}\text { Modelo G } \\
\text { (implante de } 4 \times 15 \\
\text { mm) }\end{array}$ & $7 / 96 \%$ & $2.79 / 44 \%$ & $-5.9 / 84 \%$ \\
\hline $\begin{array}{l}\text { Modelo H } \\
\text { (implante de } 3.75 \times \\
15 \text { mm) }\end{array}$ & $10.96 / 151 \%$ & $7.55 / 120 \%$ & $-6.66 / 69 \%$ \\
\hline
\end{tabular}

* = tensão máxima principal
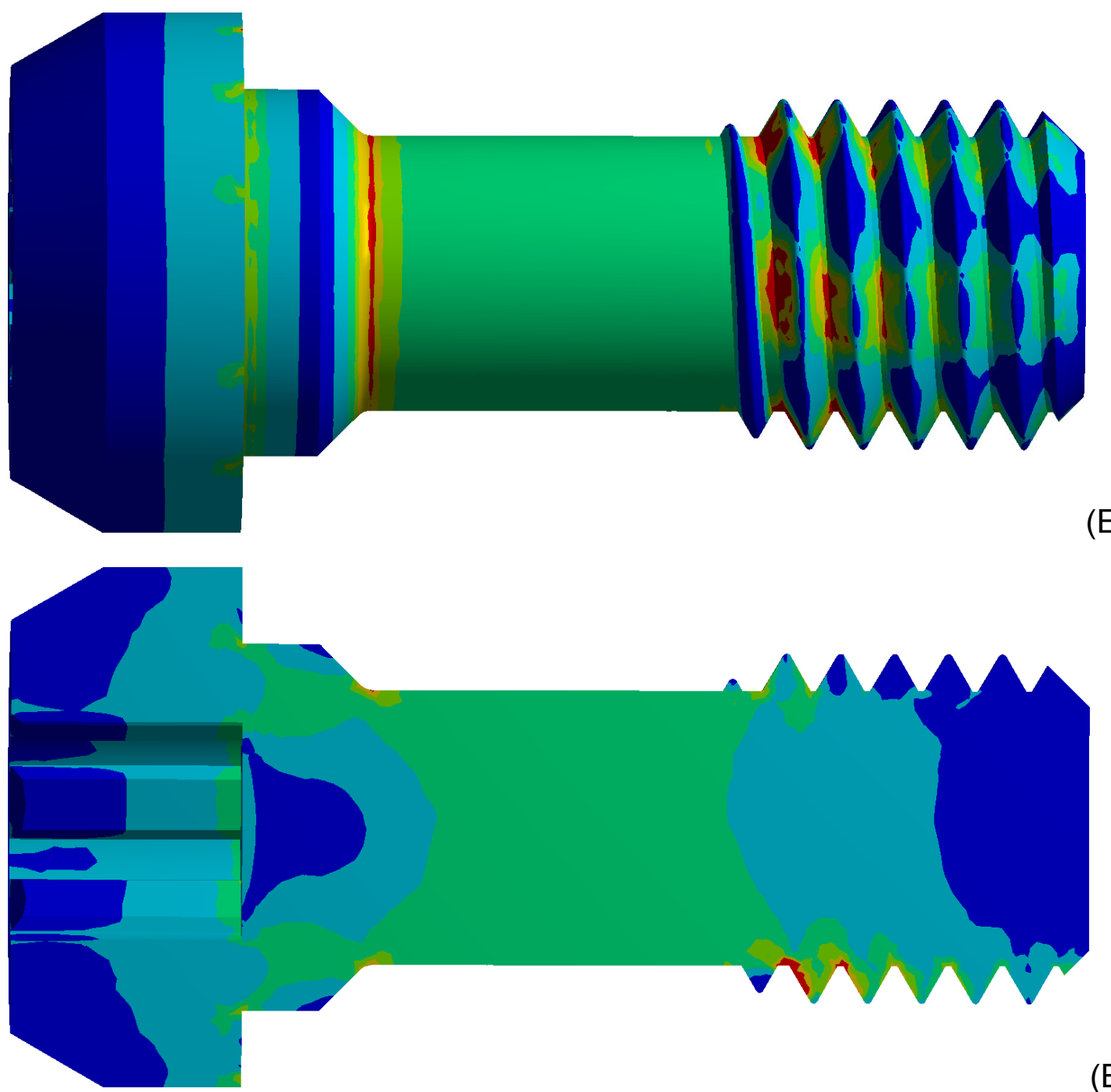

(E) 
$(E)=$ implante de $5 \times 7 \mathrm{~mm}$

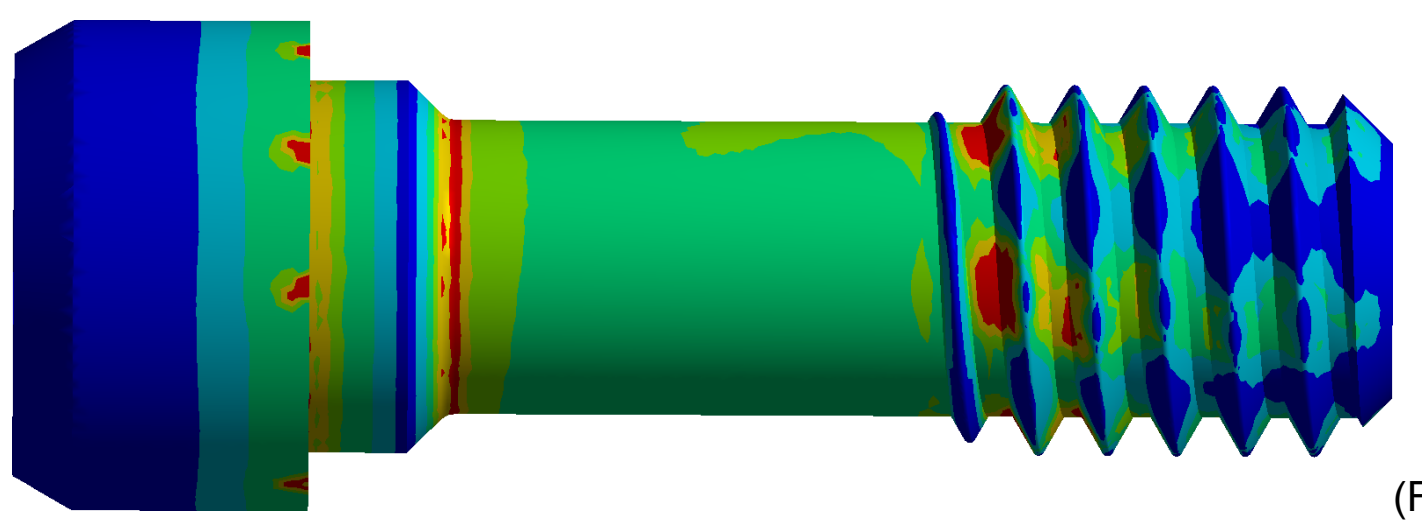

(F)

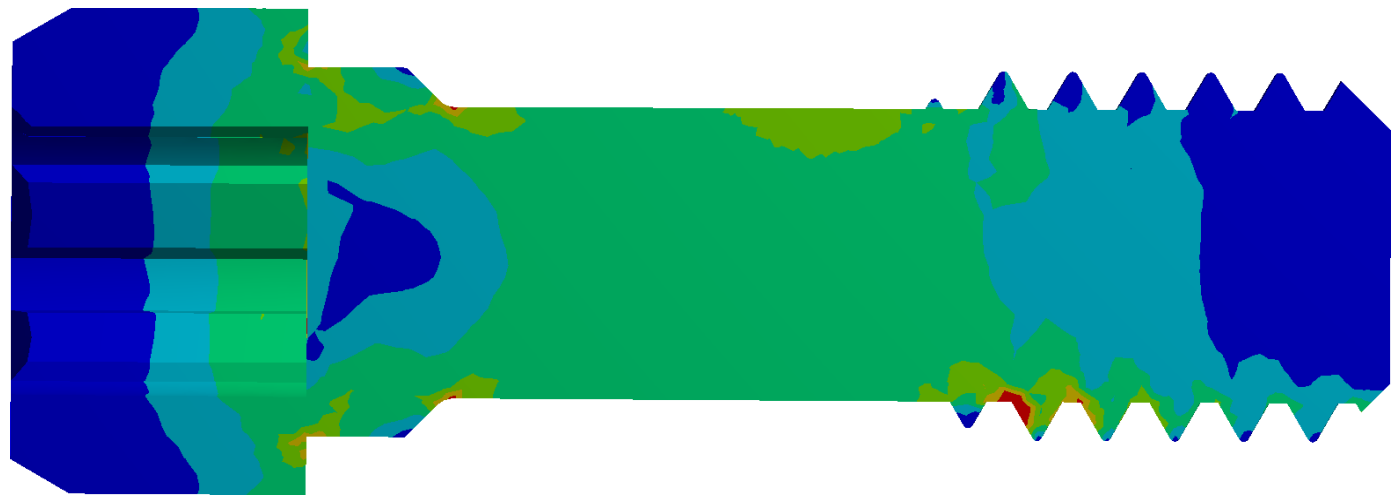

$(\mathrm{F})$

$(F)=$ implante de $4 \times 7 \mathrm{~mm}$
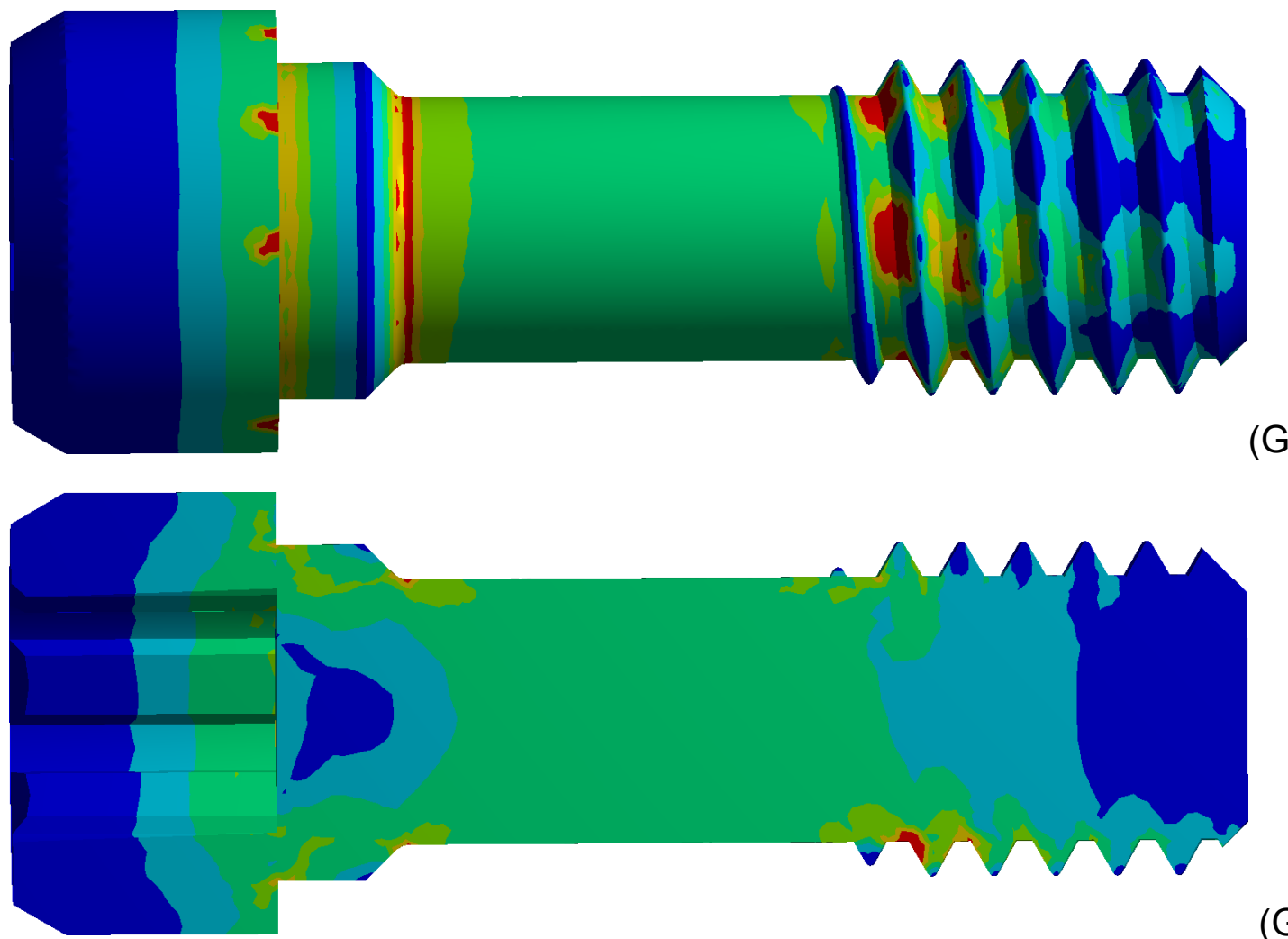

(G)

$(G)=$ implante de $4 \times 15 \mathrm{~mm}$ 


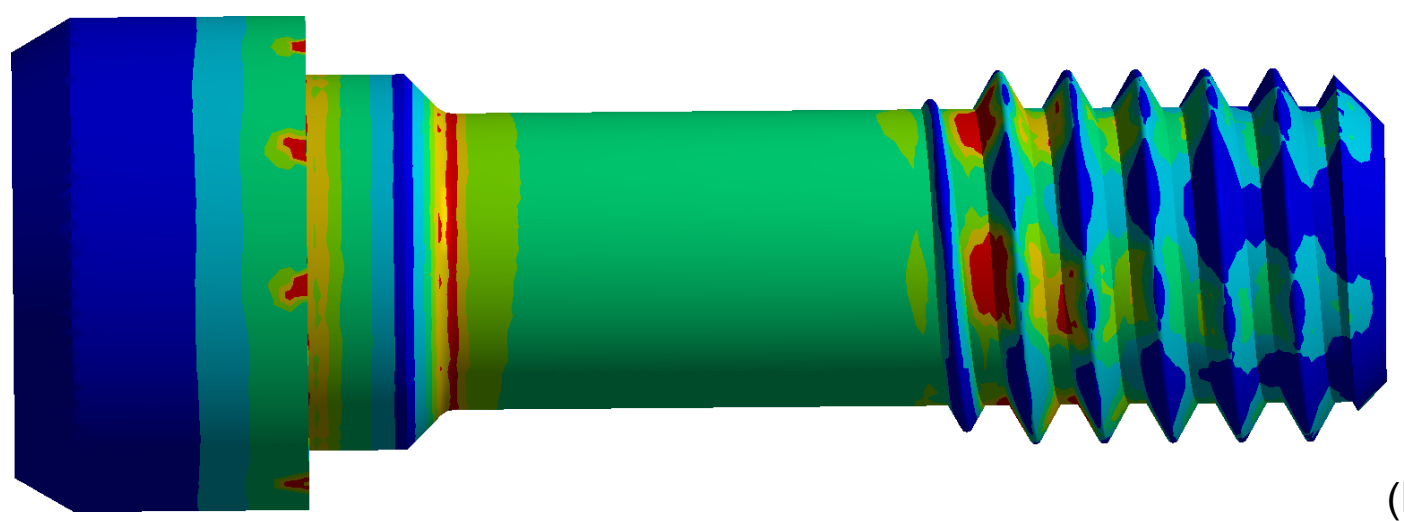

$(\mathrm{H})$

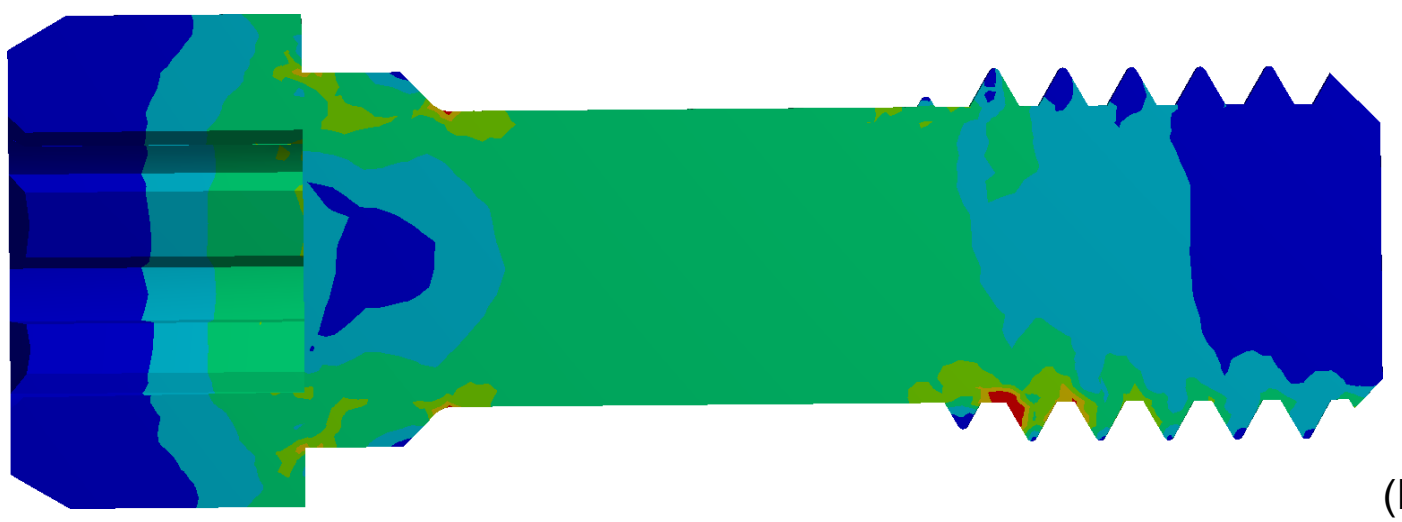

$(\mathrm{H})=$ Implante de $3.75 \times 15 \mathrm{~mm}$

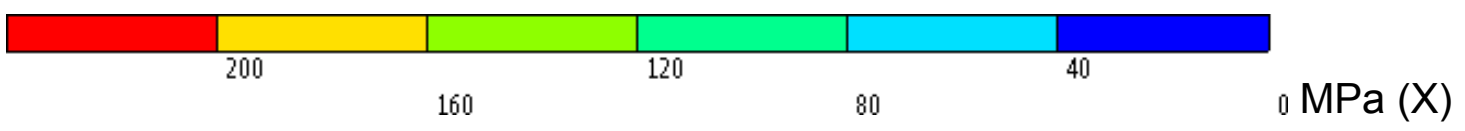

Figura 58: Plotagens dos resultados, no parafuso do elemento 37, para implantes sob carga imediata, submetidos à carga axial, considerando a tensões pelo critério de von Mises. As letras se referem ao modelo de cada resultado. Todos os resultados estão ajustados na mesma escala (X).

È válido lembrar que o critério de cisalhamento é provavelmente menos importante considerando implantes com carga imediata. O processo de fratura ocorre comumente após a corrosão do parafuso, processo esse que teoricamente não ocorre de forma significativa durante o estágio de osseointegração. Considerando a dinâmica da distribuição de tensões nesses casos, já comentada anteriormente, fica difícil indicar o efeito do diâmetro e do comprimento dos implantes, no processo de fratura, quando submetidos a cargas axiais. É necessário uma melhor compreensão do processo de 
corrosão, bem como do impacto distinto dos critérios abordados no presente trabalho, para melhor avaliação do risco de fratura do parafuso.

O quadro 12 demonstra a mesma tendência observada no quadro 10 , em que a maior parte das tensões é proveniente do processo de pré-tensão do parafuso.

Ao avaliarmos o quadro 13 , referente às tensões relativas do segundo passo de carga no parafuso, para implantes sob carga imediata, submetidos à carga axial, pelo critério de von Mises e de cisalhamento, comparando o modelo $\mathrm{F}$ (implante de $4 \times 7 \mathrm{~mm}$ ) com o $\mathrm{G}$ (implante de $4 \times 15 \mathrm{~mm}$ ), pode-se notar diminuição das tensões com aumento do comprimento. Entretanto, esse tendência não é absoluta ao compararmos o diâmetro dos implantes. Avaliando os resultados do modelo $E$ (Implante de $5 \times 7 \mathrm{~mm}$ ) com os do modelo $F$ (Implante de 4x7 mm), o aumento do diâmetro nos implantes acarretou maiores picos no parafuso, considerando ambos os critérios. Entretanto, ao compararmos o modelo $\mathrm{G}$ (Implante de $4 \times 15 \mathrm{~mm}$ ) com o modelo H (Implante de $3.75 \times 15 \mathrm{~mm}$ ) essa tendência se mostrou nos critério de cisalhamento, mas se inverteu no critério de von Mises.

Novamente, pelos critérios analisados, não existe clara tendência de risco para os parafusos, quando submetidos a carga axial, sendo uma análise caso a caso recomendada.

Os quadros 14 e 15, e a figuras 59 , se referem aos resultados no parafuso, dos implantes osseointegrados, sob carga oblíqua. 


\begin{tabular}{|c|c|c|c|}
\hline & $\begin{array}{l}\text { Von Mises } \\
\text { (MPa) }\end{array}$ & $\begin{array}{l}\text { Tração* } \\
\text { (MPa) }\end{array}$ & $\begin{array}{l}\text { Cisalhamento } \\
(\mathrm{MPa})\end{array}$ \\
\hline $\begin{array}{l}\text { Modelo A } \\
\text { (implante de } 5 \times 7 \\
\mathrm{~mm} \text { ) }\end{array}$ & $453,47 / 94 \%$ & $619,10 / 98 \%$ & $198,78 / 90 \%$ \\
\hline $\begin{array}{l}\text { Modelo B } \\
\text { (implante de } 4 \times 7 \\
\mathrm{~mm} \text { ) }\end{array}$ & $478,76 / 100 \%$ & $627,55 / 100 \%$ & $220,17 / 100 \%$ \\
\hline $\begin{array}{l}\text { Modelo C } \\
\text { (implante de } 4 \times 15 \\
\mathrm{~mm} \text { ) }\end{array}$ & $488,37 / 102 \%$ & $625,83 / 99 \%$ & $223,33 / 101 \%$ \\
\hline $\begin{array}{l}\text { Modelo } D \\
\text { (implante de } 3.75 x \\
15 \mathrm{~mm} \text { ) }\end{array}$ & $498,35 / 104 \%$ & $648,11 / 103 \%$ & $229,72 / 104 \%$ \\
\hline
\end{tabular}

* = tensão máxima principal

Quadro 15: Valores de picos de tensões relativas ao segundo passo de carga, para implantes osseointegrados, submetidos à carga oblíqua e seu percentual em relação ao controle (modelo B).

\begin{tabular}{|c|c|c|c|}
\hline & $\begin{array}{l}\text { Von Mises } \\
\text { (MPa) }\end{array}$ & $\begin{array}{l}\text { Tração* } \\
\text { (MPa) }\end{array}$ & $\begin{array}{l}\text { Cisalhamento } \\
(\mathrm{MPa})\end{array}$ \\
\hline $\begin{array}{l}\text { Modelo A } \\
\text { (implante de } 5 \times 7 \\
\mathrm{~mm} \text { ) }\end{array}$ & $64.38 / 72 \%$ & $89.99 / 55 \%$ & $17,92 / 97 \%$ \\
\hline $\begin{array}{l}\text { Modelo B } \\
\text { (implante de } 4 \times 7 \\
\mathrm{~mm} \text { ) }\end{array}$ & $88.81 / 100 \%$ & $162.39 / 100 \%$ & $18,47 / 100 \%$ \\
\hline $\begin{array}{l}\text { Modelo } C \\
\text { (implante de } 4 \times 15 \\
\mathrm{~mm} \text { ) }\end{array}$ & $98.42 / 111 \%$ & $160.67 / 99 \%$ & $21,63 / 117 \%$ \\
\hline $\begin{array}{l}\text { Modelo } D \\
\text { (implante de } 3.75 x \\
15 \mathrm{~mm} \text { ) }\end{array}$ & $108.4 / 122 \%$ & $182.95 / 112 \%$ & $28,02 / 151 \%$ \\
\hline
\end{tabular}

* = tensão máxima principal 


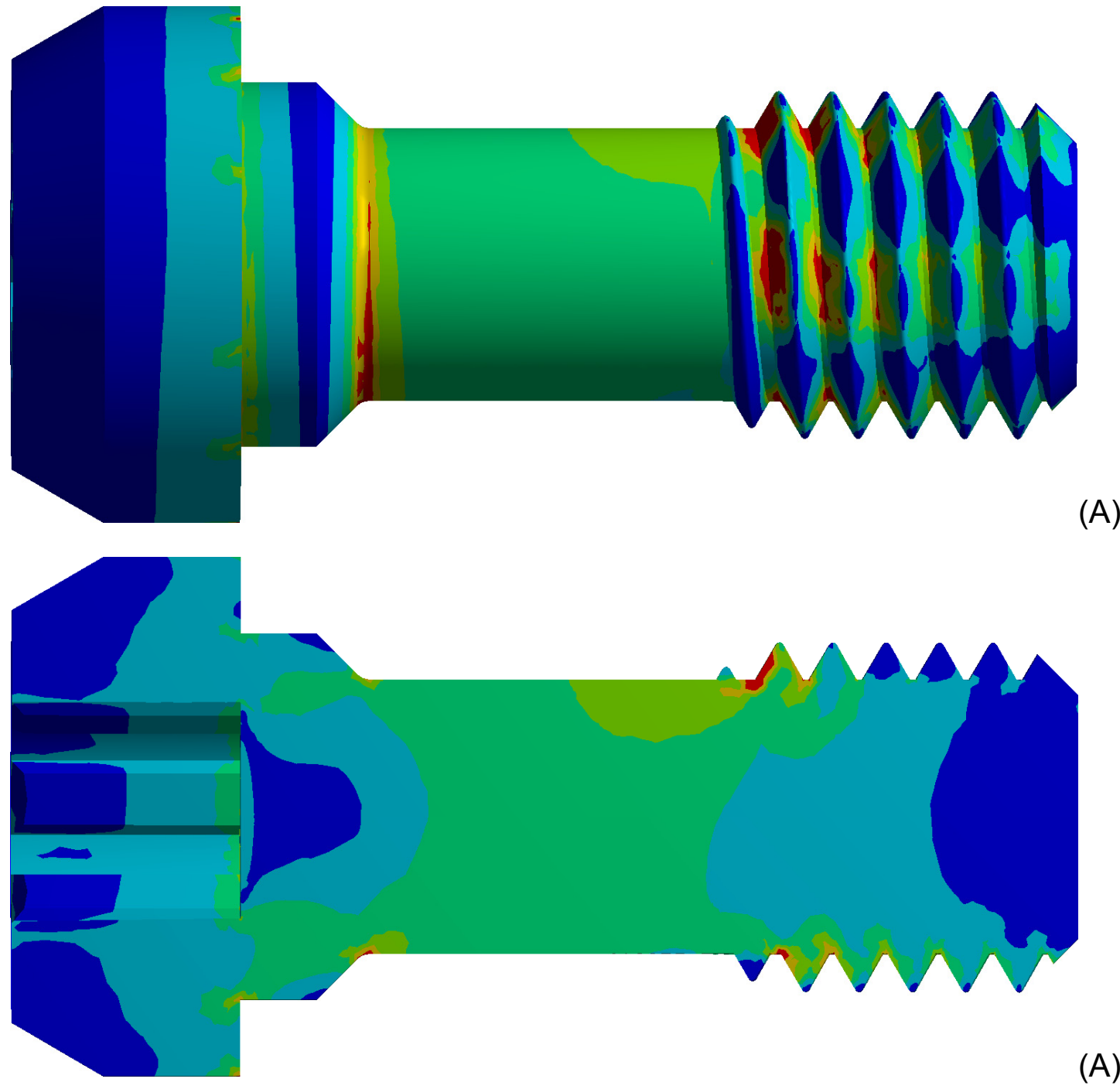

$=$ implante de $5 \times 7 \mathrm{~mm}$

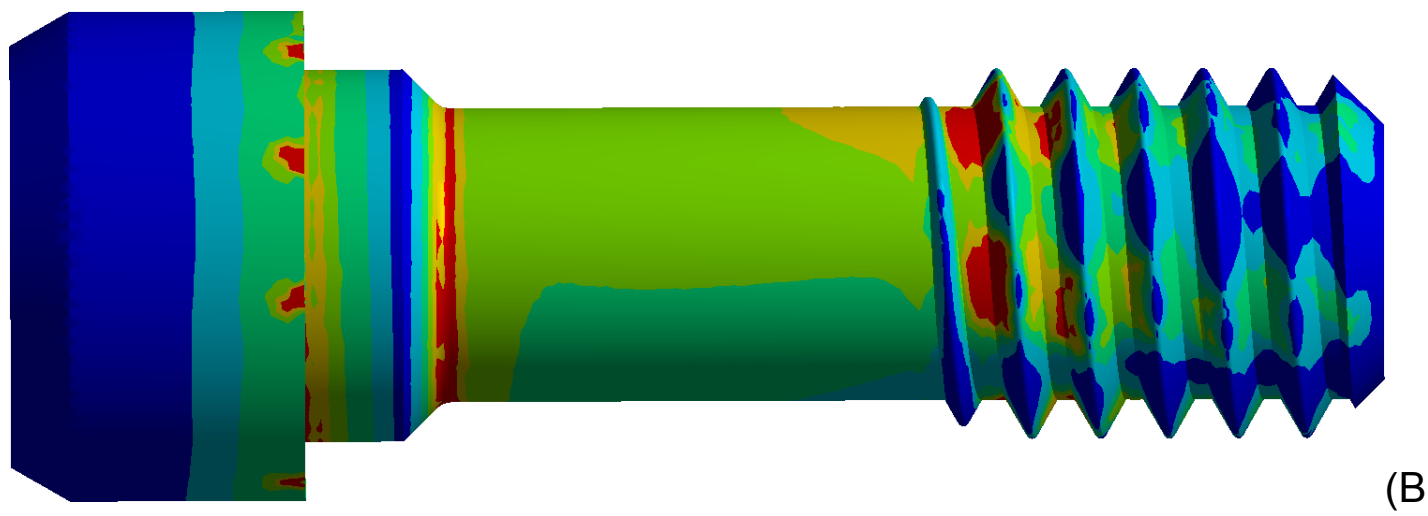




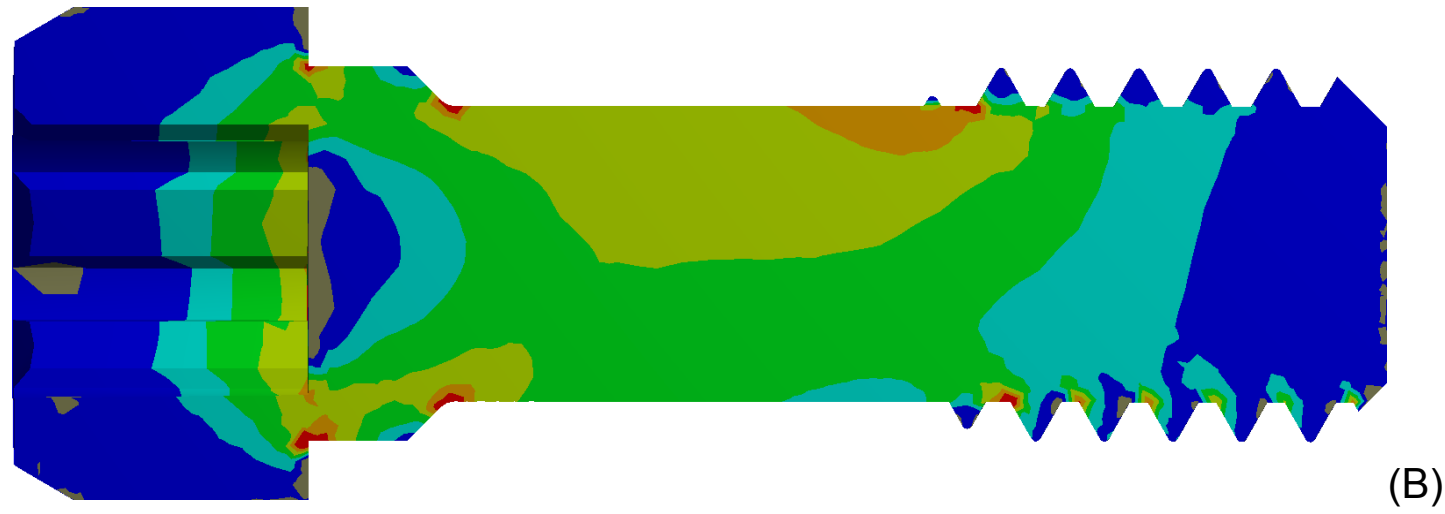

(B) = implante de $4 \times 7 \mathrm{~mm}$
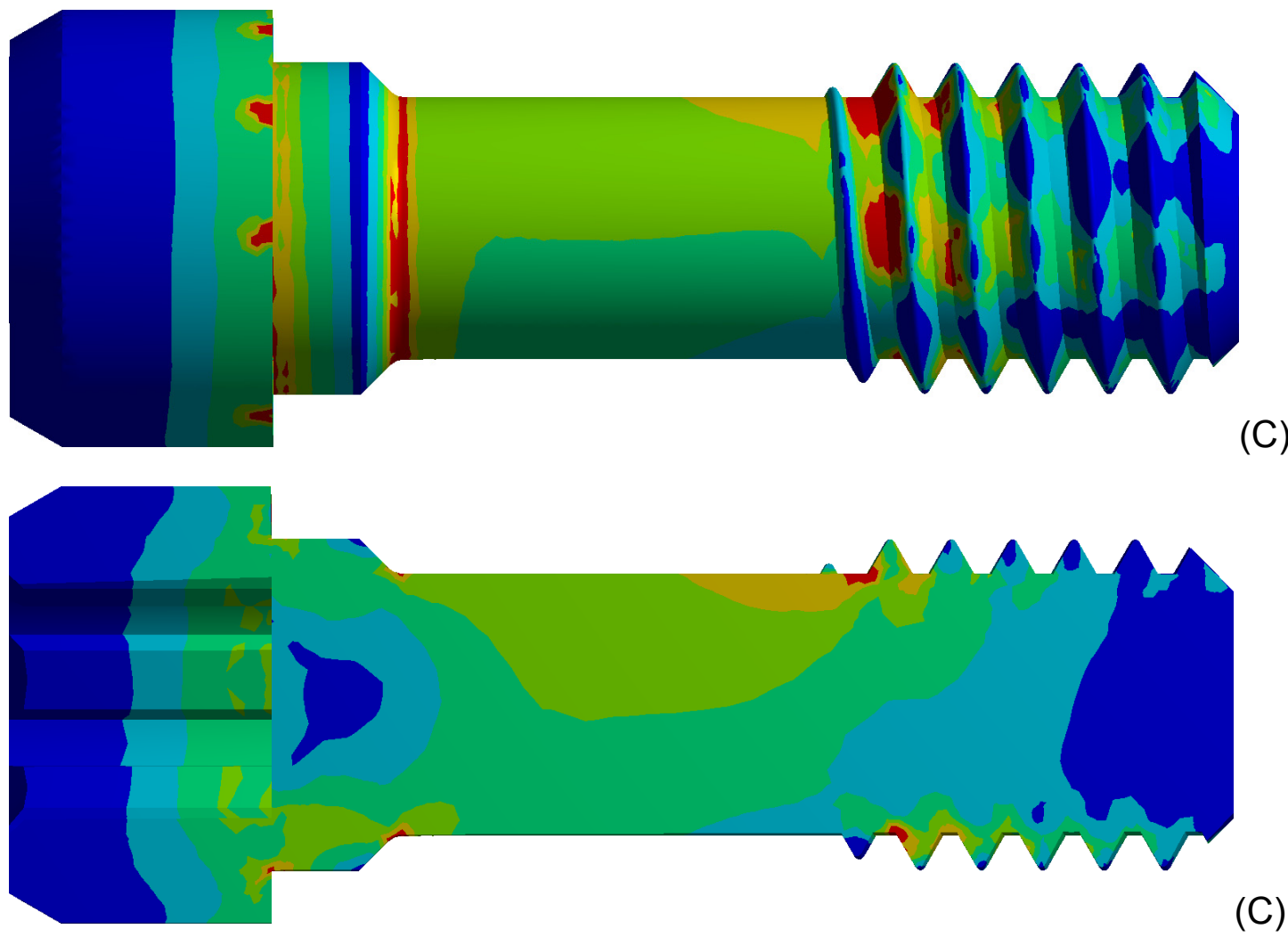

(C) $=$ implante de $4 \times 15 \mathrm{~mm}$

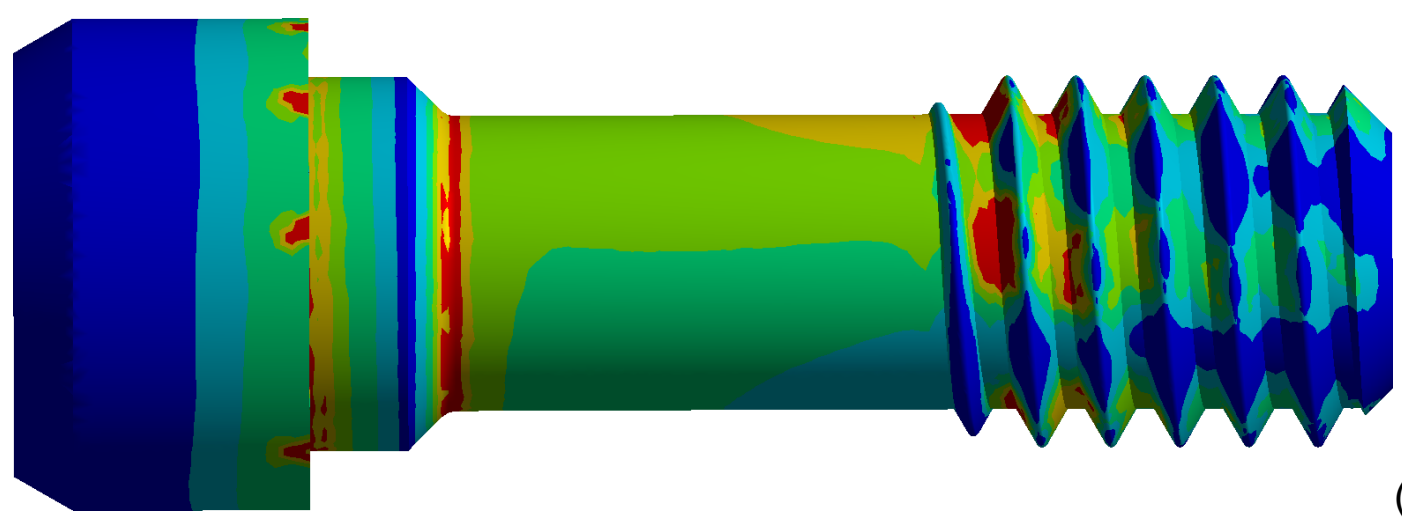

(D) 


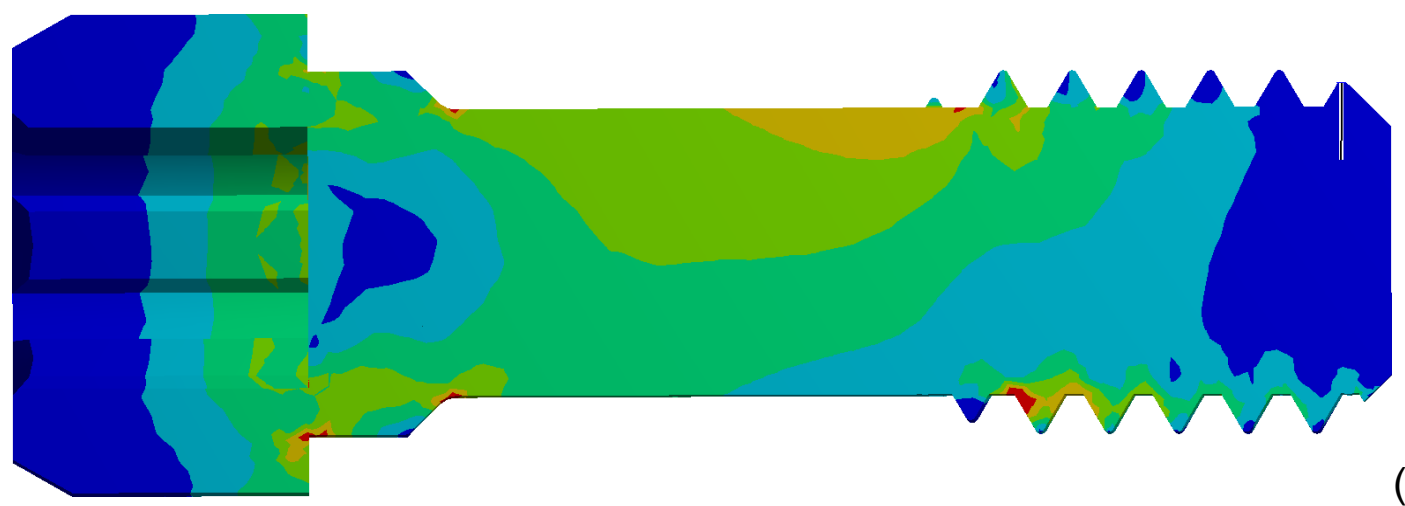

(D) = Implante de $3.75 \times 15 \mathrm{~mm}$

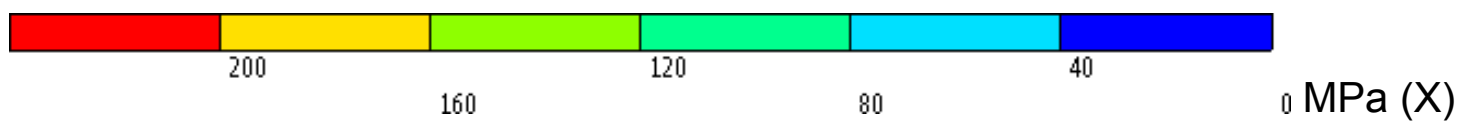

Figura 59: Plotagens dos resultados, no parafuso do elemento 37, para implantes osseointegrados, submetidos à carga oblíqua, considerando a tensões pelo critério de von Mises. As letras se referem ao modelo de cada resultado. Todos os resultados estão ajustados na mesma escala (X).

Ao analisarmos os resultados relativos ao segundo passo de carga, do quadro 15, para implantes osseointegrados, submetidos à carga oblíqua, comparando os resultados dos modelos A (Implante de $5 \times 7 \mathrm{~mm}$ ) com B (Implante de $4 \times 7 \mathrm{~mm}$ ) e C (Implante de $4 \times 15 \mathrm{~mm}$ ) com D (Implante de 3.75 x15 mm), verificamos que com o aumento do diâmetro diminuíram os picos de tensão, tanto para o critério de von Mises quanto do cisalhamento. Entretanto, quando consideramos o aumento do comprimento, a relação se inverte e o aumento do comprimento propicia picos maiores de tensão, ou seja, aumenta o risco de fratura.

Mecanicamente, quando aplicamos uma força oblíqua sobre o conjunto, o implante tem uma tendência de rotação dentro do alvéolo. Quando o implante é curto, essa rotação ocorre por todo o corpo do implante, de forma mais homogênea. Entretanto quando o implante é de maior comprimento, somado a bicorticalidade, a porção inferior do implante quase não sofre rotação, concentrando toda a tendência na porção superior e conseqüentemente, 
deformando mais essa região e aumentando as tensões no parafuso. Essas tendências podem ser vistas na figura 60 .
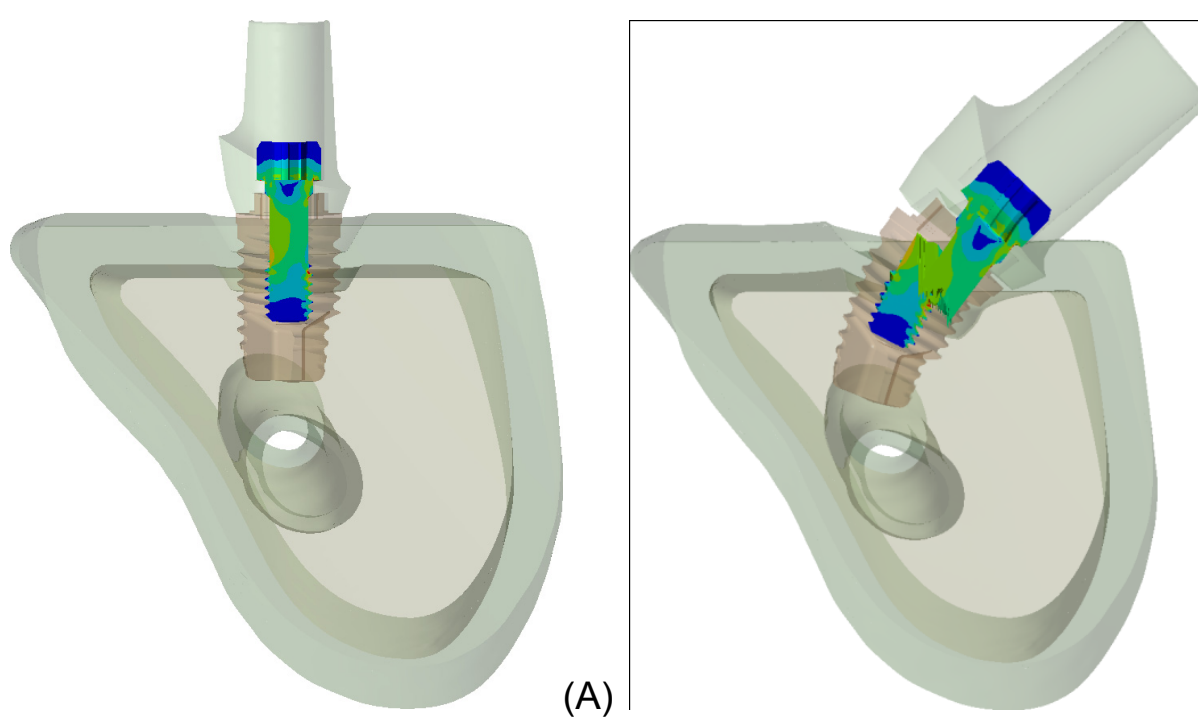

(B)
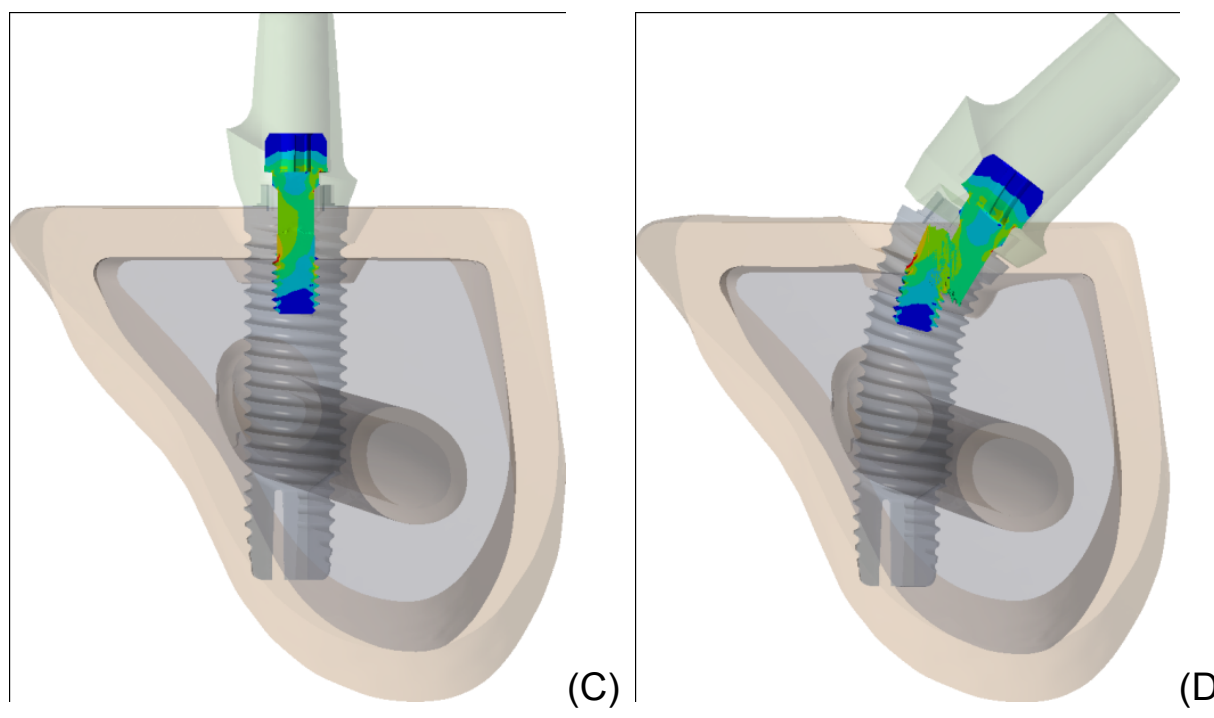

Figura 60: Tendência de deformação dos implantes sob carga oblíqua. $\mathbf{A}=$ resultado do implante curto sem qualquer deformação. $B=$ resultado do implante curto com deformação multiplicada por 300x. C = resultado do implante convencional sem qualquer deformação. $D=$ resultado do implante convencional com deformação multiplicada por 300x. Observe a tendência de rotação de todo $o$ implante curto (B) e de apenas a sua porção superior no implante convencional (D). 
O diâmetro também afeta essa tendência de rotação. Quanto maior o volume de titânio com o aumento do diâmetro, maior a resistência a torção da porção superior do implante, protegendo assim $o$ parafuso $e$ conseqüentemente diminuindo os picos de tensão na região. Essa tendência pode ser visto na figura 61 .
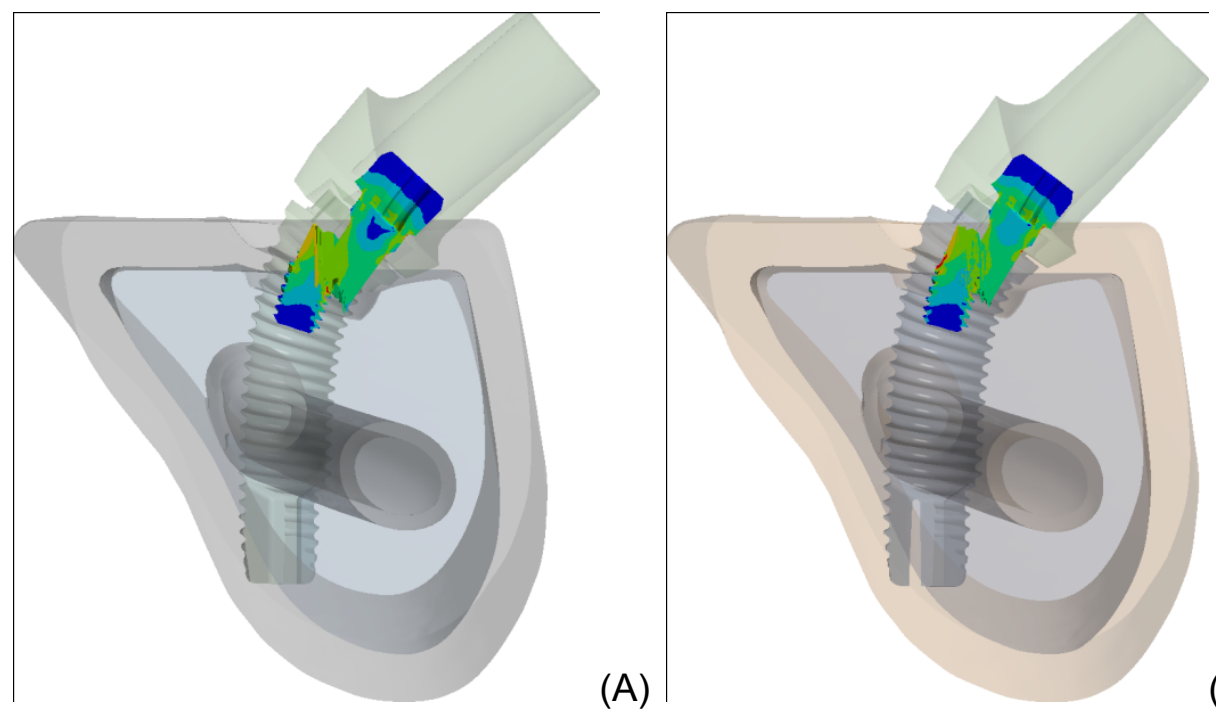

(B)

Figura 61: Tendência de deformação dos implantes sob carga oblíqua. A= Resultado do modelo $D$ (implante de $3.75 \times 15$ ) com deformação multiplicada por 300x. B = Resultado do modelo $C$ (implante de 4x15) com deformação multiplicada por $300 x$. Observe a maior torção da porção superior do implante no modelo $D$, devido a sua menor espessura.

Ao observarmos os resultados do quadro 15, quando comparados aos quadros dos resultados das cargas axiais, nota-se alterações aproximadamente 10 vezes maiores nos resultados de implantes osseointegrados sob carga oblíqua. Outro fator digno de nota é que as tendências estão mais claras nas cargas oblíquas, até porque 0 comportamento mecânico é diferente.

De forma geral, a utilização de implantes curtos e de maior diâmetro, em implantes osseointegrados, sob cargas oblíquas, acarreta menores concentrações de tensões e menor risco para a fratura do parafuso, quando 
comparado aos implantes de menor diâmetro e maior comprimento, sob tratamento de lateralização.

Os quadros 16 e 17, e a figura 62 , se referem aos resultados no parafuso, dos implantes sob carga imediata, submetidos à carga oblíqua.

\begin{tabular}{|l|l|l|l|}
\hline \multicolumn{3}{|l|}{$\begin{array}{l}\text { Quadro 16: valores de picos de tensões absolutas dos resultados no } \\
\text { parafuso, para implantes sob carga imediata, submetidos à carga oblíqua } \\
\text { e seu percentual em relação ao controle (modelo F). }\end{array}$} \\
\hline & $\begin{array}{l}\text { Von Mises } \\
\text { (MPa) }\end{array}$ & $\begin{array}{l}\text { Tração* } \\
(\mathrm{MPa})\end{array}$ & Cisalhamento (MPa) \\
\hline $\begin{array}{l}\text { Modelo E } \\
\text { (implante de } \\
5 \times 7 \mathrm{~mm} \text { ) }\end{array}$ & $448,28 / 97 \%$ & $606,45 / 102 \%$ & $194,62 / 92 \%$ \\
\hline $\begin{array}{l}\text { Modelo F } \\
\text { (implante de } \\
4 \times 7 \mathrm{~mm} \text { ) }\end{array}$ & $462,81 / 100 \%$ & $593,92 / 100 \%$ & $211,18 / 100 \%$ \\
\hline $\begin{array}{l}\text { Modelo G } \\
\text { (implante de } \\
4 \times 15 \mathrm{~mm} \text { ) }\end{array}$ & $474,89 / 102 \%$ & $602,09 / 101 \%$ & $216,13 / 102 \%$ \\
\hline $\begin{array}{l}\text { Modelo H } \\
\text { (implante de } \\
3.75 \times 15 \mathrm{~mm} \text { ) }\end{array}$ & $476,98 / 103 \%$ & $608,88 / 102 \%$ & $218,3 / 103 \%$ \\
\hline
\end{tabular}

* = tensão máxima principal 


\begin{tabular}{|c|c|c|c|}
\hline & $\begin{array}{l}\text { Von Mises } \\
(\mathrm{MPa})\end{array}$ & $\begin{array}{l}\text { Tração* } \\
\text { (MPa) }\end{array}$ & Cisalhamento (MPa) \\
\hline $\begin{array}{l}\text { Modelo E } \\
\text { (implante de } \\
5 \times 7 \mathrm{~mm} \text { ) }\end{array}$ & $59,19 / 81 \%$ & $77,34 / 60 \%$ & $13,76 / 145 \%$ \\
\hline $\begin{array}{l}\text { Modelo F } \\
\text { (implante de } \\
4 \times 7 \mathrm{~mm} \text { ) }\end{array}$ & $72,86 / 100 \%$ & $128,76 / 100 \%$ & $9,48 / 100 \%$ \\
\hline $\begin{array}{l}\text { Modelo G } \\
\text { (implante de } \\
4 \times 15 \mathrm{~mm} \text { ) }\end{array}$ & $84,94 / 116 \%$ & $136,93 / 106 \%$ & $14,43 / 152 \%$ \\
\hline $\begin{array}{l}\text { Modelo } \mathrm{H} \\
\text { (implante de } \\
3.75 \times 15 \mathrm{~mm} \text { ) }\end{array}$ & $87,03 / 119 \%$ & $143,72 / \%$ & $16,6 / 175 \%$ \\
\hline
\end{tabular}

* = tensão máxima principal

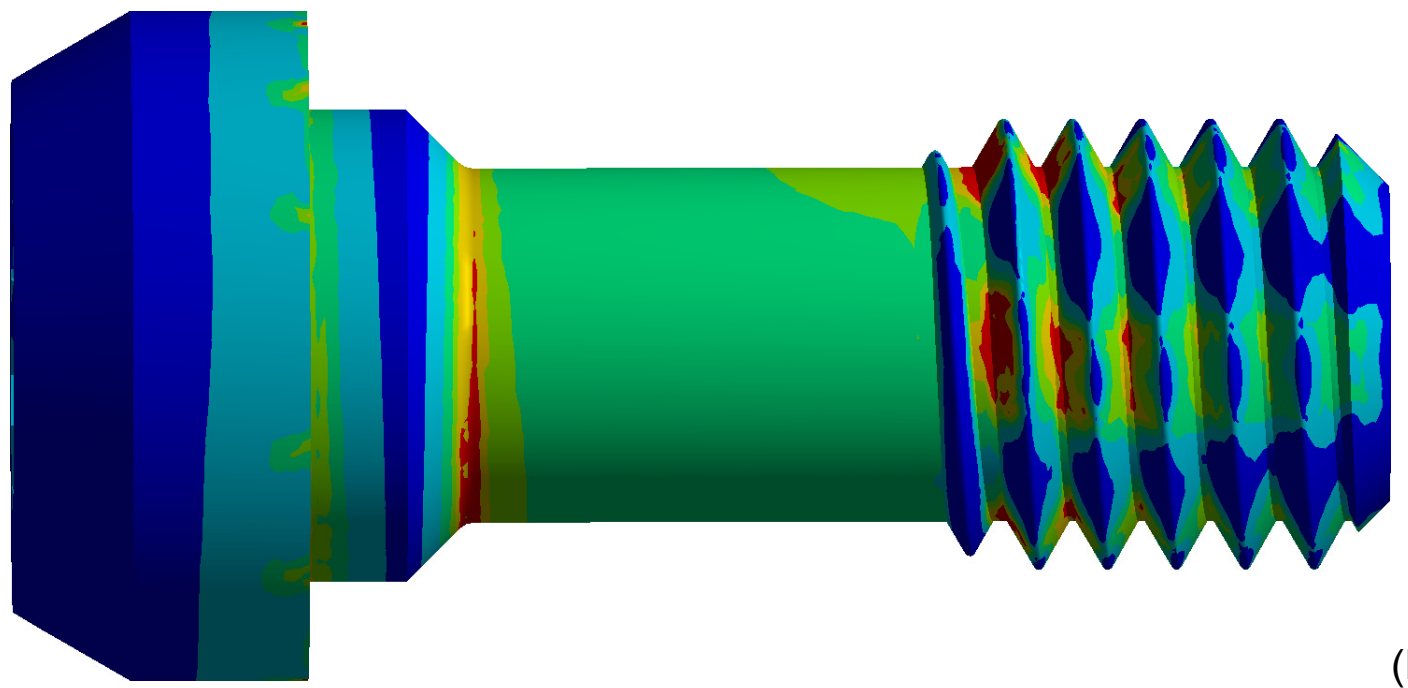

(E) 


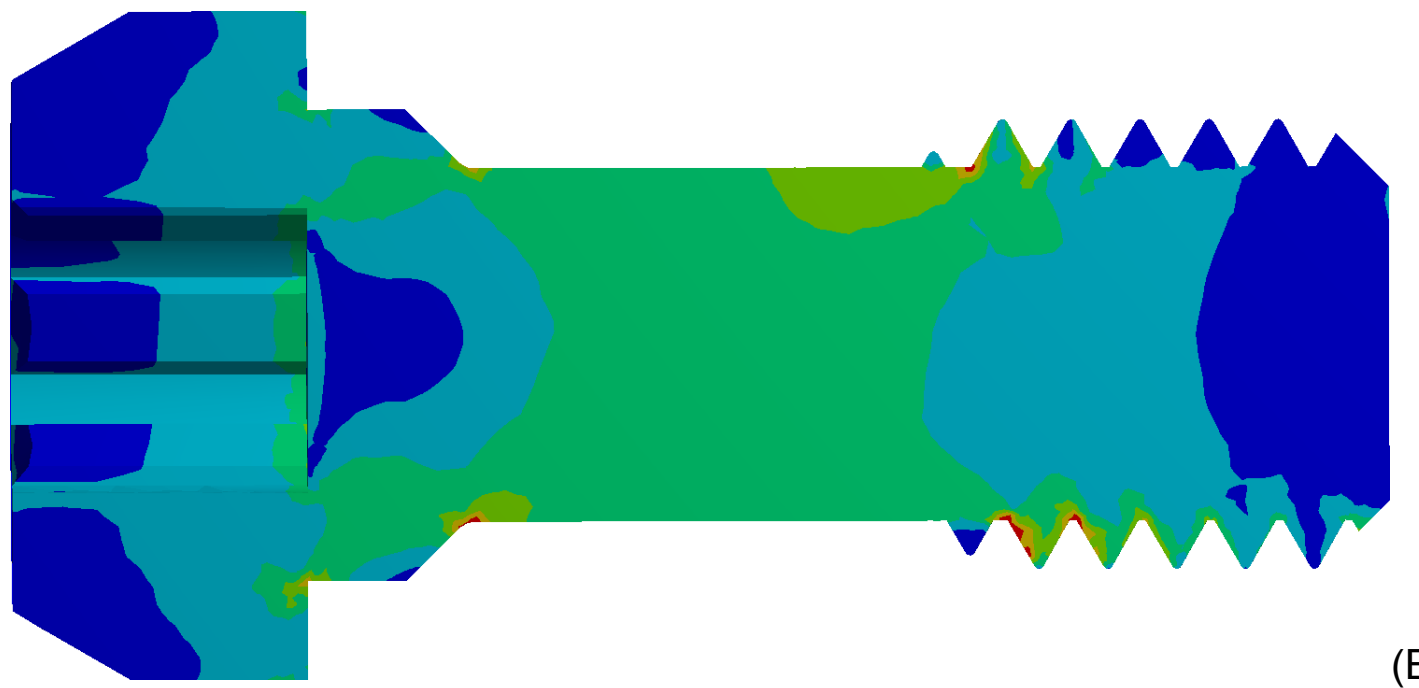

(E)

$=$ implante de $5 \times 7 \mathrm{~mm}$

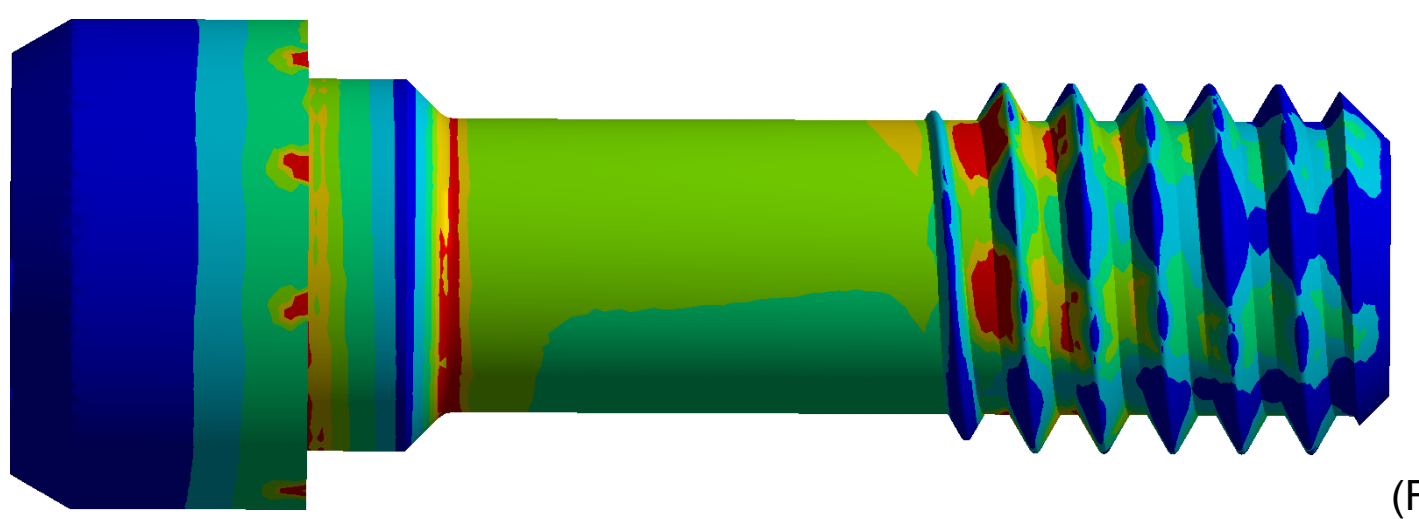

(F)

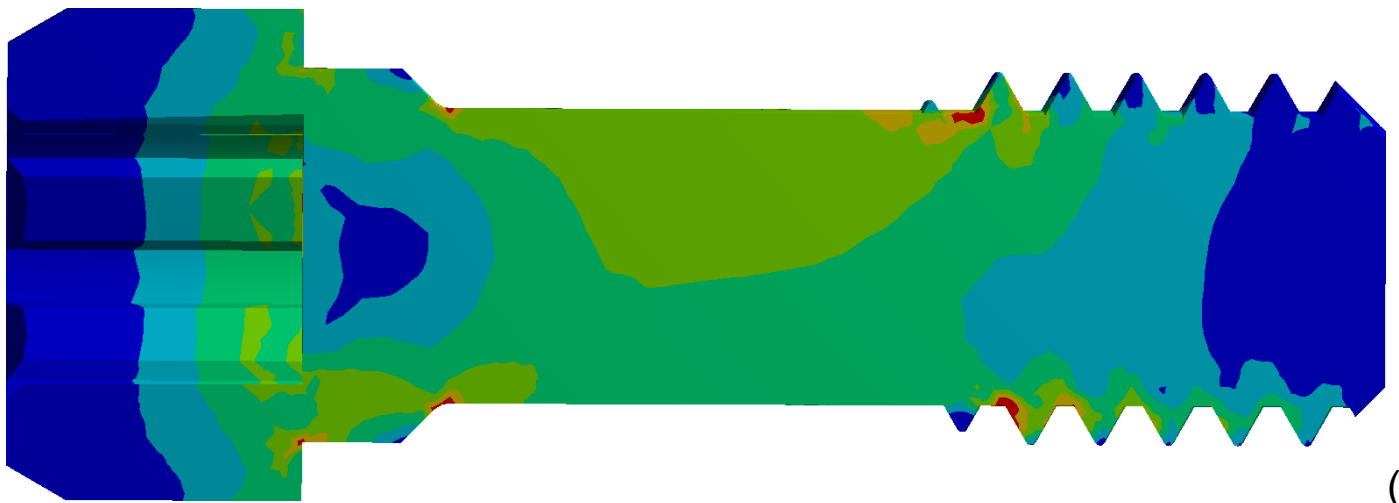

(F)

$(F)=$ implante de $4 \times 7 \mathrm{~mm}$ 


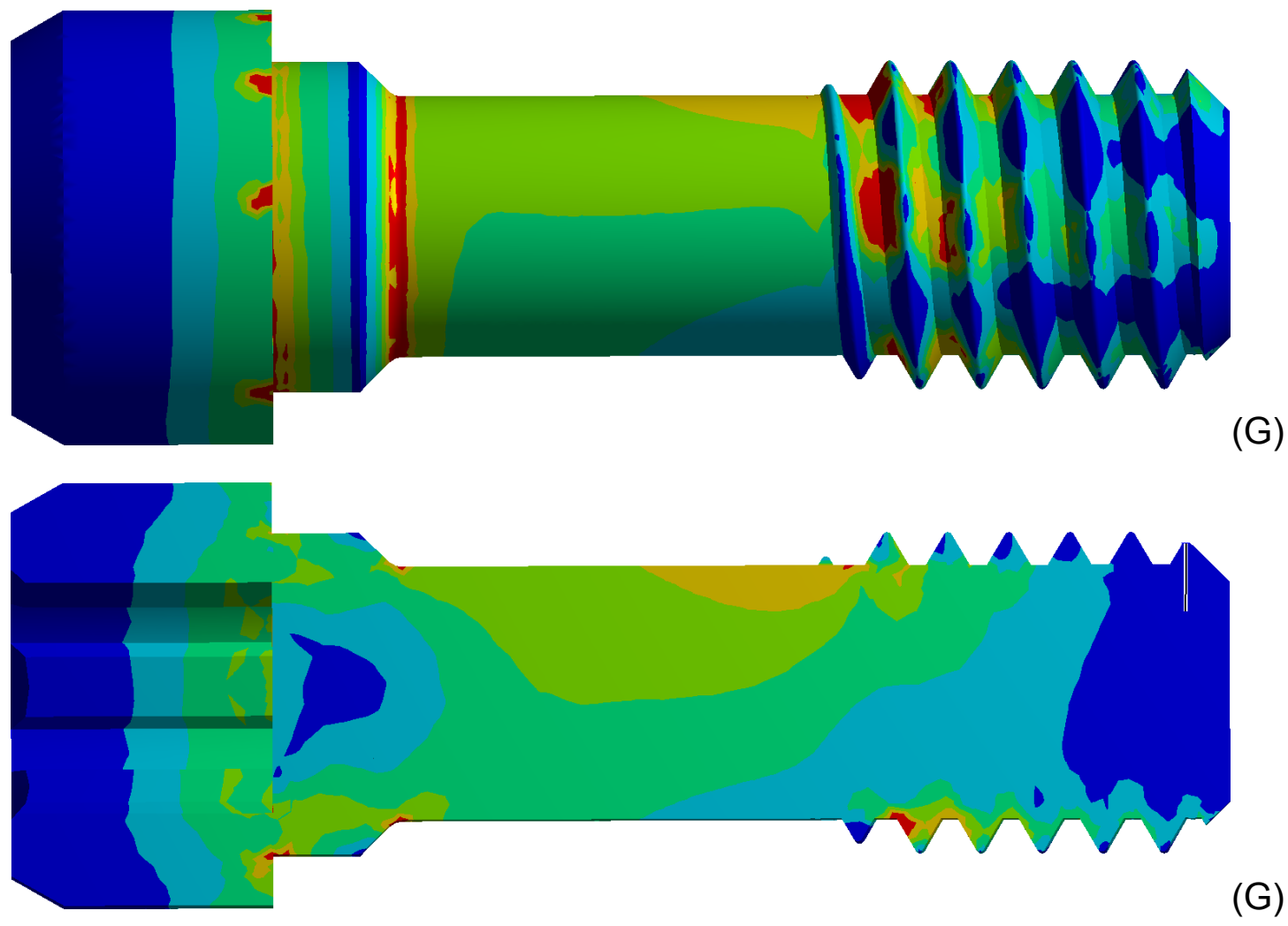

(G) = implante de $4 \times 15 \mathrm{~mm}$

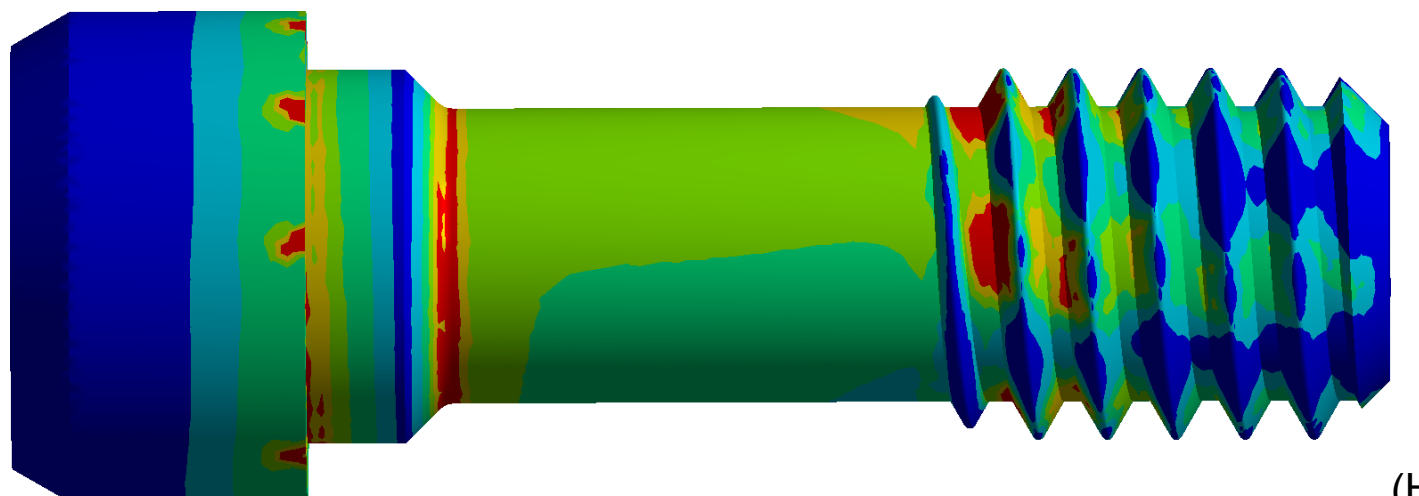

(H)

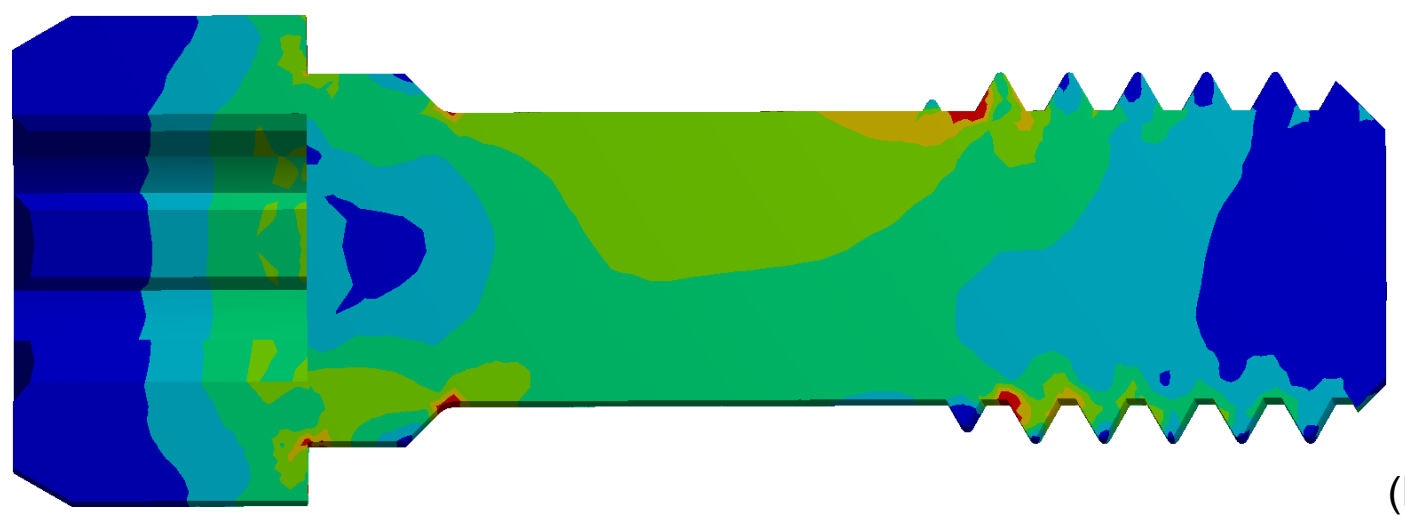

(H)

$(\mathrm{H})=$ Implante de $3.75 \times 15 \mathrm{~mm}$ 


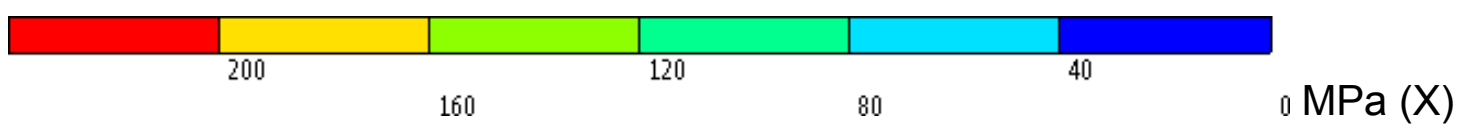

Figura 62: Plotagens dos resultados, no parafuso do elemento 37, para implantes sob carga imediata, submetidos à carga oblíqua, considerando a tensões pelo critério de von Mises. As letras se referem ao modelo de cada resultado. Todos os resultados estão ajustados na mesma escala (X).

Ao analisarmos os resultados relativos ao segundo passo de carga, do quadro 17, para implantes sob carga imediata, submetidos à carga oblíqua, embora os resultados sejam numericamente diferentes aos do parafuso com implantes osseointegrados, as tendências são semelhantes. $O$ aumento do comprimento do implante resultou em maiores picos de tensão no parafuso, e maior diâmetro do implante diminuem esses picos. A exceção está na comparação entre os resultados do modelo $\mathrm{E}$ (Implante de $5 \times 7 \mathrm{~mm}$ ) com o $\mathrm{F}$ (Implante de $4 \times 7 \mathrm{~mm}$ ), em que as tensões de cisalhamento do modelo $E$ foram maiores do que no modelo $F$ (Implante de $4 \times 7 \mathrm{~mm}$ ). Entretanto, como comentado anteriormente, outros fatores como a geometria e o tamanho da plataforma podem ter afetado esse resultado, sendo mais confiável a análise do modelo G (Implante de 4 x15 mm) com o H (Implante de 3.75 x15 mm) para essa avaliação.

É interessante ressaltar que os resultados dos parafusos com implantes osseointegrados, sob cargas oblíquas, foram todos maiores do que os resultados dos parafusos nos implantes sob carga imediata. Isso provavelmente ocorre devido aos mesmos motivos que acarretaram esse fenômeno no osso periimplantar, como explicado anteriormente. 


\section{Discussão}

Quando consideramos uma análise de elementos finitos, é importante ressaltar que se trata de uma análise complementar. Os resultados devem ser comparados com outras metodologias, a fim de possibilitar o melhor entendimento possível de determinada situação.

Deve-se lembrar que, assim como o método de elementos finitos possui limitações, outras metodologias também possuem. Mesmo os estudos clínicos, devido a suas dificuldades inerentes, muitas vezes possuem problemas como numero baixo da amostra, e conseqüentemente significância desfavorável da análise estatística, dificuldades de formar grupos padronizados, dificuldade de análise dos fatores de risco associados e controle limitado sobre os pacientes. Assim, em que pese a importância expressiva dos trabalhos clínicos na definição do real sucesso de qualquer proposta de trabalho, as muitas alternativas, como a aqui estudada, podem contribuir para elucidar os fatores envolvidos.

Considerando suas características, uma análise pelo método é limitada pelo grau de fidelidade dos modelos e nível de precisão utilizado nas configurações da simulação. Dessa forma, cada relação de contato foi cuidadosamente analisada e grande cuidado foi tido para realizar modelos os mais fiéis possíveis a situação clínica, utilizando técnicas avançadas de construção/reconstrução geométrica, que não favoreçam nenhuma das variáveis analisadas.

Mesmo assim, algumas dificuldades foram encontradas durante a realização do presente trabalho. Inicialmente, planejava-se modelar os implantes, com geometrias chamadas "groovies", referentes à canaletas existentes nas roscas dos implantes. Embora os modelos sólidos tenham sido gerados a princípio dessa forma, problemas foram encontrados durante a fase de discretização ${ }^{5}$ dos modelos. Diversos modelos apresentaram geometria

\footnotetext{
${ }^{5}$ Criação da malha.
} 
problemática e mesmo as malhas que foram geradas, proporcionaram péssima qualidade de elementos, principalmente nos implantes e osso periimplantar dos modelos com tratamento de lateralização do nervo alveolar inferior. Dessa forma a precisão do trabalho poderia ser comprometida. Portanto, foram removidas as canaletas em todos os modelos, para manter a padronização do trabalho, como pode ser visto na figura 63 .

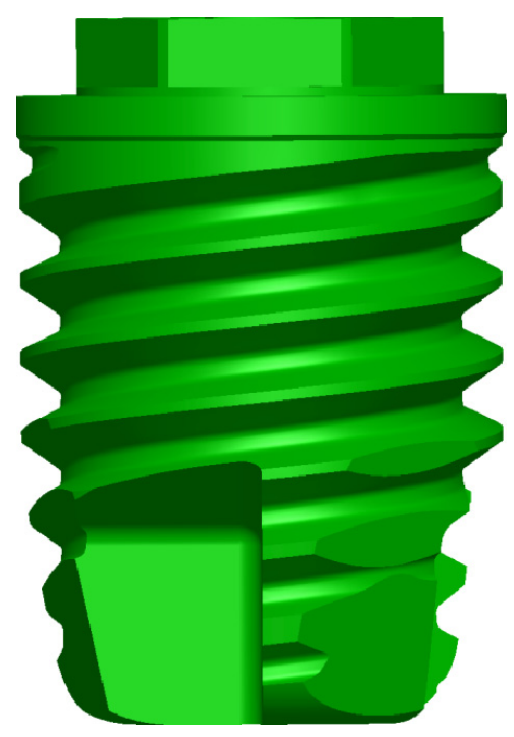

(A)

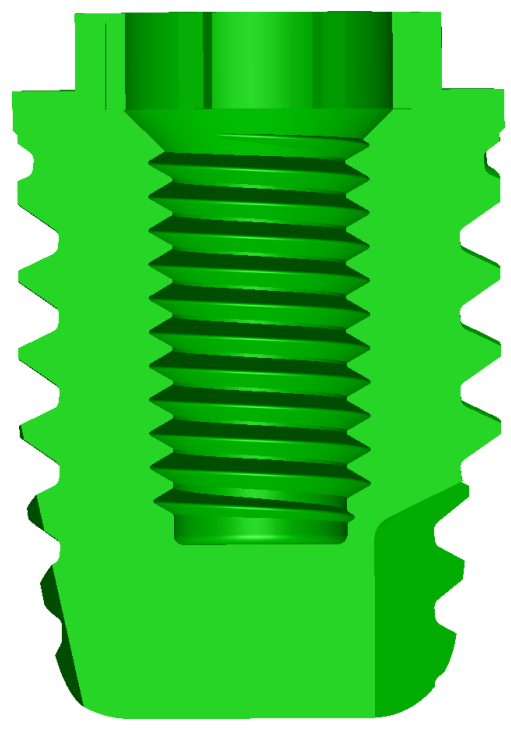

(B)
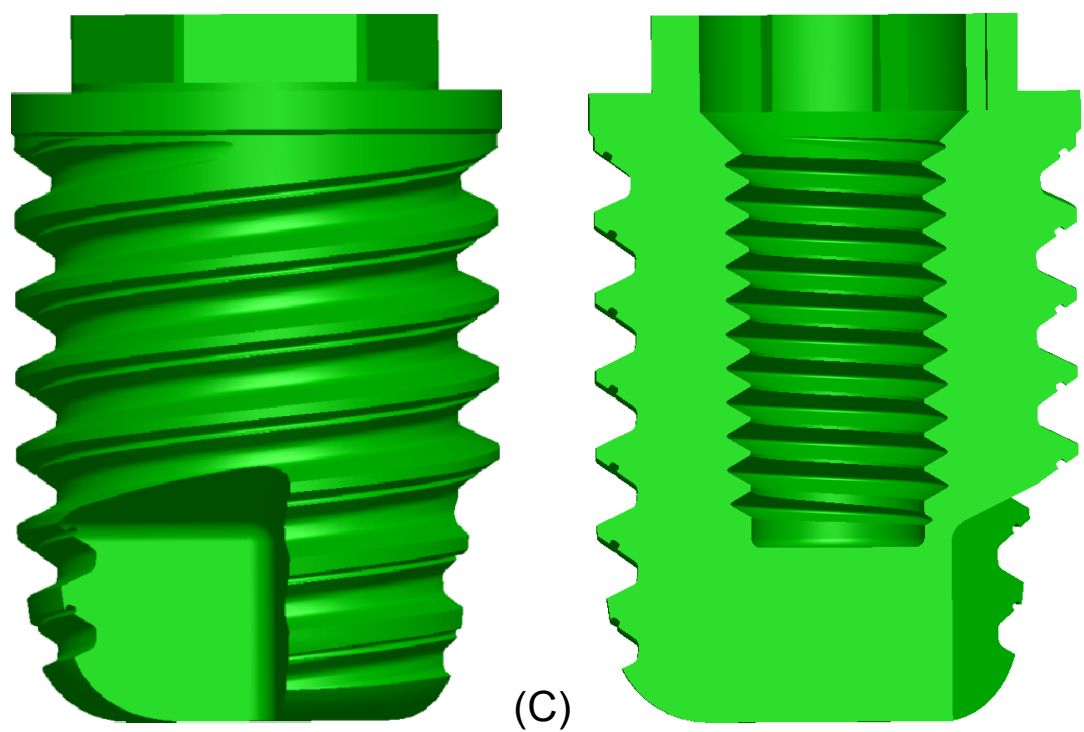

(D)

Figura 63: Vista do modelo implante de $5 \times 7 \mathrm{~mm}$, como foi utilizado na presente pesquisa (A e B) e como foi inicialmente modelado (C e D). 
Outro fator que teve que ser padronizado em todos os trabalhos, se refere à localização da posição em que a rosca penetra o osso. Quando aplicado a carga mastigatória nos modelos, existe uma tendência de concentração de tensões nas proximais, no caso da carga axial, e na vestibular/lingual, no caso das cargas oblíquas. Entretanto, a região de penetração da rosca gera uma geometria relativamente fina, propícia a concentração de tensões. Com a variação da carga e da posição da geometria fina, os resultados oscilaram significativamente, com favorecimento de alguns modelos em determinadas condições de carga, como pode ser visto na figura 64. Os modelos foram então refeitos, padronizando a posição de entrada da rosca no osso, para não favorecer nenhum dos tratamentos. Com base na revisão realizada, não existe nenhum trabalho na literatura odontológica que cite esse cuidado. 


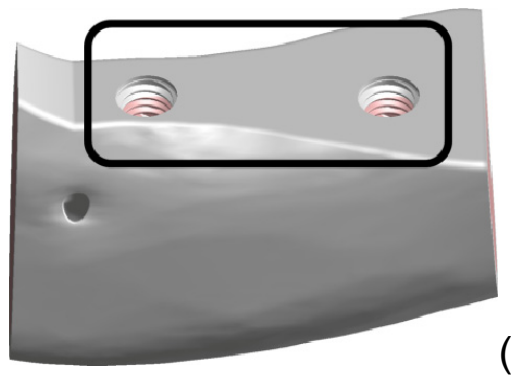

$(\mathrm{Y})$

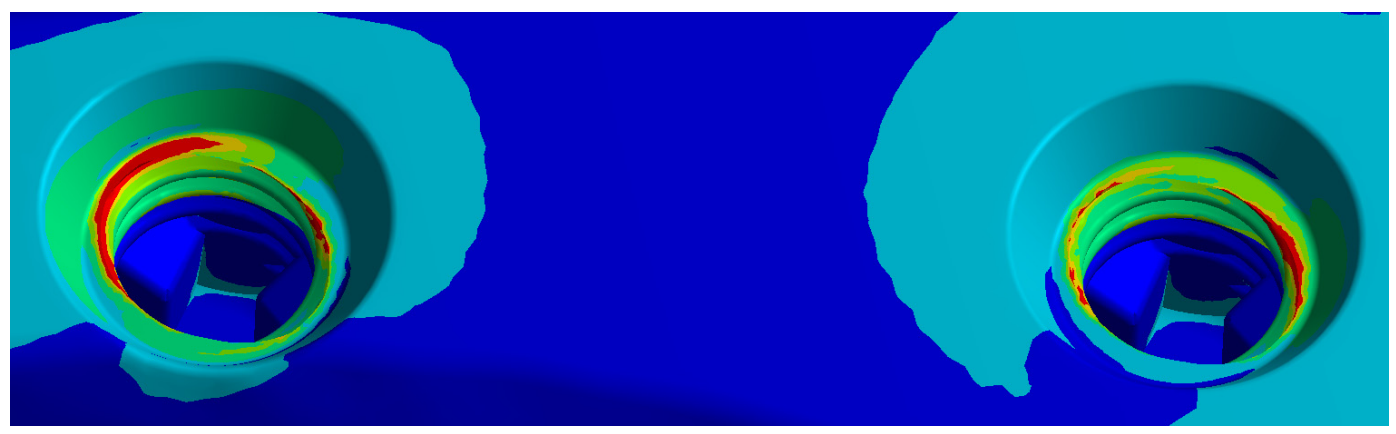

(A)

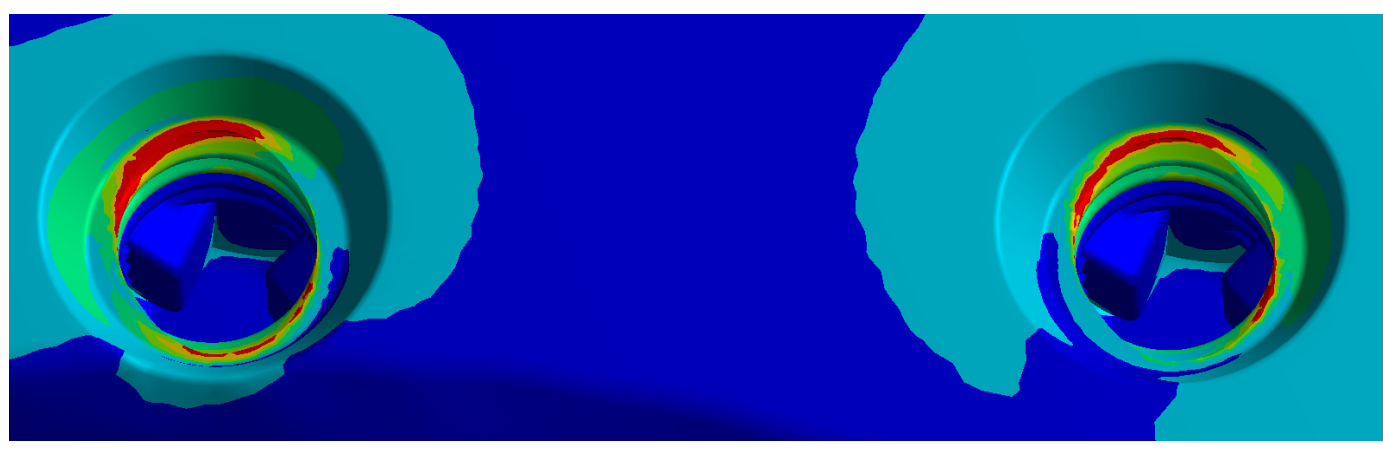

(B)

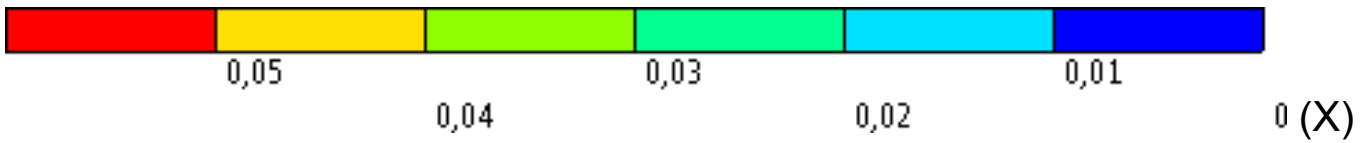

Figura 64: Resultados referentes à mesma simulação, mas sem padronização das roscas (A) e com padronização (B), ajustados na mesma escala $(X)$ sob o mesmo padrão de vista $(Y)$. Observe a diferença nos resultados simplesmente pela mudança na localização da área de penetração da rosca no osso.

As possíveis variações encontradas clinicamente são praticamente infinitas, como qualidade óssea, tipo e desenho da prótese, intensidade de carga mastigatória, entre outras. Entretanto, a metodologia e os modelos foram definidos de forma a se ter uma avaliação biomecânica, da forma mais padronizada possível, sem favorecer qualquer das simulações analisadas. $\mathrm{Na}$ situação clínica é provável que o profissional se depare com situações que 
favoreçam uma ou outra técnica, contudo, dentro de um estudo comparativo, é melhor que não tenha nenhuma tendência, sendo necessário julgamento do profissional quanto às possíveis variações encontradas clinicamente.

São comuns variações na metodologia de análise de elementos finitos, não só da forma como é realizada, mas principalmente, quanto aos critérios de análise dos resultados. Diversos estudos matemáticos utilizam critérios baseados em deformações (NATALI, PAVAN et al., 2006), tensões (NATALI, PAVAN et al., 2006), deslocamento/micromovimentação (NATALI, PAVAN et al., 2006) e pressão hidrostática, entre outros, para avaliação do impacto dos estímulos na remodelação óssea. Não há, dentro da literatura consultada, consenso sobre $\mathrm{o}$ assunto. Porém, diversos estudos trazem indícios importantes sobre os estímulos que regem o processo de remodelação óssea (HU, WANG et al., 2010; KOYAMA, MITSUl et al., 2008; TAYLOR, HAZENBERG et al., 2007) e como eles podem ser associados, para avaliar fatores de risco em tratamentos com implantes dentários.

Muitos autores utilizam as deformações, ao invés das tensões, para determinar processos de remodelação óssea (NATALI, PAVAN et al., 2006). Esse método é interessante em simulações que avaliam o processo ósseo ao longo do tempo, sendo o resultado a quantidade de massa óssea alterada. Contudo, em análises estáticas, em que o risco da perda óssea é avaliado, devido à diferença no módulo de elasticidade entre osso cortical e medular, a utilização de critérios de deformação pode levar a interpretações errôneas, uma vez que, picos de deformação no osso medular podem causar ganhos de massa óssea (LIAN, GUAN et al., 2010), enquanto picos de deformação no osso cortical têm maior probabilidade de levar a perda óssea, como comentado anteriormente.

Outro critério muito utilizado, na literatura odontológica, para análise do osso periimplantar, se refere ao critério de von Mises. Embora não se tenha definição e quantificação exata dos fatores que afetam o processo de remodelação/perda óssea, aparentemente não existe, um único indício científico que indique sua utilização para avaliação do risco de perda óssea. 
Quanto às simulações analisadas, é preciso lembrar que não existe consenso ou prova científica que determine o uso de uma ou outra opção de trabalho. Quando consideramos a utilização de implantes curtos, nos deparamos com implantes com menor índice de sobrevivência, utilizando implantes lisos, e com índices de sobrevivência comparáveis a convencionais quando utilizados implantes com tratamento de superfície. Todavia, esses implantes, com tratamento de superfície, não possuem comprovação científica a longo prazo, e há poucos estudos sobre o impacto de fatores de risco associados. Por outro lado, é um tratamento relativamente simples e de pequena morbidade.

Ao considerarmos o tratamento de lateralização, temos literatura mais vasta, até porque após a osseointegração, o implante da lateralização tem condição praticamente igual á de um implante semelhante que não sofreu lateralização. Já a dificuldade do procedimento e a morbidade do paciente, são bem maiores. Nesse contexto, o trabalho foi desenvolvido como comparação direta entre as técnicas.

Pode-se perguntar se a comparação de trabalhos clínicos individuais referentes a cada técnica seria suficiente para definição do melhor tipo de tratamento. Considerando o impacto que a experiência do operador, a localização, o paciente e o tipo de implante podem ter no tratamento, essa comparação representa apenas parte do problema, sendo necessária a comparação sobre condições semelhantes para obter respostas satisfatórias.

O presente trabalho demonstrou que tanto o aumento do comprimento, quanto o aumento do diâmetro, são benéficos para a diminuição do risco mecânico da perda óssea. Nesse contexto, pode-se perguntar se não seria mais prudente, aumentar tanto a largura quanto o comprimento do implante o máximo possível. Embora teoricamente seja possível, muitas vezes o profissional opta pelo uso de implantes curtos devido à simplicidade e menor morbidade da técnica, e portanto neste caso, continuaria limitado quanto ao comprimento do implante. 
Por outro lado, em casos de lateralização, devido a osteotomia da janela óssea, apenas uma porção relativamente fina é mantida superiormente. Durante a colocação de um implante de maior diâmetro é possível ocorrer à fratura dessa porção superior, comprometendo assim o tratamento. Considerando o maior nível de desgaste necessário para colocação de um implante de maior diâmetro, pode-se teorizar que o risco de fratura é diretamente proporcional ao diâmetro do implante nesses casos. Dessa forma, o profissional também fica limitado quanto ao diâmetro do implante na terapia com lateralização do nervo alveolar inferior.

Os artigos mais recentes sobre implantes curtos trazem índices de sucesso semelhantes a implantes convencionais (GOENE, BIANCHESI et al., 2005; TEN BRUGGENKATE, ASIKAINEN et al., 1998; WENG, JACOBSON et al., 2003), entretanto a maioria dos estudos ou utilizam critérios de exclusão rigorosos de pacientes, ou fornecem informações limitadas sobre os fatores de risco presente nos pacientes. Dessa forma, quando considerados pacientes que não possuam nenhum fator de risco associado, de acordo com a literatura, os dois tratamentos são previsíveis, com ótimos índices de sobrevivência.

Quanto à análise dos resultados propriamente ditos, nos implantes osseointegrados, considerando os modelos pesquisados, a lateralização do nervo alveolar inferior, e conseqüentemente o aumento do comprimento do implante somado a bicorticalidade, apresentou menor risco de perda óssea do que implantes curtos, mesmo considerando os de maior diâmetro. Embora a diferença tenha sido maior no caso das simulações sob carga axial, o aumento do comprimento somado a bicorticalidade, proporcionada pela lateralização, de forma geral, contribuiu mais na diminuição do risco.

Lembrando que, não existem comparações diretas, na literatura consultada. Aapenas poucas pesquisas podem realmente ser comparadas aos resultados aqui obtidos.

Ao compararmos o trabalho de Petrie e Willians (2005), em um estudo com o método de elementos finitos, analisando variações no comprimento e diâmetro de implantes osseointegrados, encontraram a mesma tendência de 
melhora na distribuição de tensões com o aumento das duas variáveis. Entretanto, o trabalho revelou melhora mais significativa dos resultados com o aumento do diâmetro, mesmo considerando que as variações nas medidas foram maiores, sendo de 3.5 a $6 \mathrm{~mm}$ no diâmetro e 5.75 a $23.5 \mathrm{~mm}$ no comprimento. É limitada a comparação devido aos modelos utilizados por Petrie e Williams, serem simplificados, sem roscas, e considerando único critério de risco, a deformação máxima principal, como mensurador do risco a perda óssea.

Quanto ao trabalho de Pierrisnard ET AL (2003), também com elementos finitos, os autores avaliaram a variação no comprimento e a bicorticalidade do implante. Tanto o aumento do comprimento, quanto a bicorticalidade, diminuiu os picos de tensões no osso periimplantar, embora por não mais que $7,4 \%$. Dessa forma, embora a tendência do trabalho seja a mesma do presente trabalho, o impacto da variação é bem diferente. As limitações também são semelhantes ao do trabalho de Petrie e Williams, onde, modelos simplificados, sem roscas, utilização de apenas uma carga oblíqua, e diferenças nos critérios de risco podem ter acarretado essas diferenças.

O trabalho de revisão de literatura de Renouard e Nisand (2006) relata piores índices de sobrevivência para implantes curtos lisos, mas índices de sobrevivência semelhantes a implantes convencionais quando da utilização de protocolos cirúrgicos adaptados e implantes com tratamento de superfície. Também relata piores índices de sucesso com implantes de maior diâmetro, relacionado, entre outros fatores, a colocação desses implantes em sítios onde o implante de menor diâmetro não obteve travamento. Entretanto, com novos desenhos de implantes e indicações clínicas adequadas, esses implantes obtiveram índices de sucesso semelhantes a implantes de menor diâmetro. Os resultados desta pesquisa estão de acordo com a revisão de Renouard e Nisand, em que implantes de maior diâmetro não apresentam maior risco de perda óssea.

Considerando os resultados do presente trabalho, para tratamentos de dois estágios, a terapia com implantes curtos estaria indicada, quando o 
paciente não tiver nenhum fator de risco associado e o profissional/paciente desejarem cirurgia de menor tempo clínico, de menor complexidade e morbidade. Entretanto, se o paciente tiver fatores de risco mecânico associados, como baixa qualidade óssea ou hábitos parafuncionais, e estiver disposto a aceitar a morbidade associada com o processo de lateralização, o procedimento torna-se indicado pelo menor risco mecânico.

É interessante ressaltar que muitas vezes, o paciente não tem conhecimento da sua condição, como é o caso de hábitos parafuncionais, e que mesmo esses podem ocorrer de forma súbita. É importante por parte do profissional a análise rigorosa do paciente, a fim de indicar o melhor tratamento possível. Dessa forma, por precaução, pode ser interessante a indicação da lateralização do nervo alveolar inferior, em caso de dúvidas quanto a existência de fatores de risco.

Quando analisamos o osso periimplantar em tratamentos de um estágio (carga imediata), diversas considerações adicionais podem ser feitas. Devido à ausência de osseointegração, o osso da crista torna-se mais importante, e as regiões inferiores demonstram menor papel na distribuição de tensões. Dessa forma, a tendência se inverte, sendo os implantes curtos, pela sua indicação de serem utilizados com maior diâmetro, os que representaram menor risco para a perda óssea.

É interessante considerar que, mesmo nos casos de carga imediata, a princípio, esse implante terá em longo prazo uma condição de implante osseointegrado. Por outro lado, fatores como a área de necrose após a cirurgia de $1 \mathrm{~mm}$ (ROBERTS, SMITH et al., 1984), a diminuição da massa óssea periimplantar inicial e conseqüentemente menor estabilidade, que leva a maiores riscos de problemas de mobilidade não infecciosa, 3 a 5 semanas após a colocação (BUCHS, LEVINE et al., 2001), demonstram que a carga imediata é mais sensível, principalmente se considerados fatores de risco associados. Portanto, o profissional deve considerar cuidadosamente $\mathrm{O}$ benefício de menor risco durante a fase de osseointegração, para maior risco a longo prazo, dependendo do tratamento selecionado. 
Os resultados da presente pesquisa também demonstraram que, o risco mecânico de um implante colocado com a lateralização do nervo alveolar inferior é semelhante, sendo ligeiramente menor, do que implantes curtos de mesmo diâmetro, mesmo considerando a perda óssea vestibular, típica do procedimento. Dessa forma, a carga imediata, em tratamentos de lateralização, se demonstrou viável, embora mais estudos sejam necessários para comprovar essa viabilidade.

É interessante lembrar também, do risco de perda óssea na crista sem levar ao comprometimento do implante. Embora essa perda seja menos importante na região posterior, do que é na região anterior, ela não é desejável.

De forma geral, e considerando os implantes analisados, em pacientes com fatores de risco mecânico associados, a lateralização do nervo alveolar inferior tem menor risco de perda óssea em implantes osseointegrados. Já na carga imediata, a utilização de implantes curtos de maior diâmetro está indicada, seja pelo menor risco mecânico, seja porque ainda são necessários mais estudos para confirmar a eficácia da carga imediata, na técnica de lateralização do nervo alveolar inferior.

Quando consideramos os resultados dos parafusos, conceitos adicionais devem ser ressaltados. Enquanto a perda óssea no implante leva ao comprometimento do tratamento, no parafuso esse comprometimento só será observado, caso ocorra fratura desse parafuso. Entretanto, diferente da situação óssea, é possível um plano de manutenção, de forma a trocar periodicamente esses parafusos a fim de evitar a fratura.

Sobre a literatura referente aos parafusos, para uma análise comparativa com os resultados apresentados na presente pesquisa, os artigos encontrados se limitam a avaliar somente a pré-tensão no parafuso sem cargas mastigatórias, ou a avaliar a tensão no parafuso sem configurar a pré-tensão. Dessa forma, as comparações são limitadas.

Considerando a pesquisa de Pierrisnard et al (2003) com o método de elementos finitos tridimensional, em que foram analisadas as tensões nos parafusos, frente a implantes de diferentes comprimentos e ancoragem mono e 
bicortical, sob carga oblíqua, os resultados demonstraram a mesma tendência observada no presente estudo, em que o aumento do comprimento aumenta os picos de tensão no parafuso. Novamente, embora as tendências fossem semelhantes, a intensidade de variação diferiu muito. A ausência de prétensão no parafuso, modelos simplificados, sem roscas e tipos de contatos utilizados entre os componentes da simulação podem justificar essa diferença.

Nos trabalhos com o método de elementos finitos que analisam a prétensão no parafuso (GUDA, ROSS et al., 2008; LANG, KANG et al., 2003), os resultados foram semelhantes, em que grandes picos de tensão são resultantes da pré carga, entretanto, pela ausência da carga mastigatória, maiores discussões comparativas e sobre o impacto clínico não são possíveis.

Quanto a estudos in vitro, se considerarmos o fenômeno de corrosão, e que este é um dos principais fatores que levam a fratura do parafuso (YOKOYAMA, ICHIKAWA et al., 2002), a análise é limitada. O planejamento inicial, para o presente trabalho, era de simulações de fadiga, dentro do método de elementos finitos. Entretanto, por não serem encontradas informações sobre o impacto da corrosão no meio bucal ao longo do tempo, a simples análise de fadiga com informações de ligas sem corrosão não seriam válidas clinicamente, e portanto não foram realizadas. Mesmo no presente trabalho, embora tenha sido utilizado o critério de cisalhamento, para avaliar o risco a fratura no processo de corrosão, as propriedades do titânio utilizado, como módulo de elasticidade e coeficiente de Poisson, são de uma liga de titânio sem corrosão. Dessa forma, são necessários mais estudo sobre o tema, até porque os poucos estudos na odontologia que abordam o fenômeno num ambiente intrabucal, ainda são limitados quanto às informações disponíveis.

De qualquer forma, considerando a presente pesquisa, os resultados das cargas axiais não forneceram tendência clara quanto a tratamentos de maior ou menor risco para o parafuso, sendo recomendada análise caso a caso. Já a carga oblíqua evidenciou tendência clara, que tratamentos com implantes de maior diâmetro e menor comprimento tem risco menor de fratura do parafuso. 
Considerando os resultados apresentados, tanto do osso periimplantar quanto do parafuso, apesar do amplo cuidado na confecção dos modelos virtuais, todos os indícios revelados por investigações numérico/computacionais devem ser comprovados por casuísticas clínicas de longo prazo. Comparações clínicas diretas, entre implantes curtos e lateralização do nervo alveolar inferior são recomendadas, embora de difícil execução, principalmente se considerarmos o estudo de grupos com fatores de risco. Dessa forma, metodologias alternativas, de melhor viabilidade, como o presente trabalho, estão indicadas como referência na ausência de estudos in vivo.

Quanto ao comportamento do parafuso, um melhor entendimento do processo de corrosão no meio bucal, seria de grande auxílio para desenvolver tratamentos de superfície que minimizem essa corrosão e definir períodos de trocas periódicas preventivas desses parafusos, a fim de minimizar o risco a fratura. 


\section{Conclusões}

Considerando a presente pesquisa, com a análise comparativa entre implantes curtos, com implantes colocados pela técnica de lateralização do nervo alveolar inferior, em próteses parciais fixas de três elementos posteriores, simuladas através do método de elementos finitos, as seguintes conclusões podem ser obtidas:

- Implantes osseointegrados, colocados pela técnica de lateralização do nervo alveolar inferior, apresentaram menores riscos de perda óssea do que implantes curtos.

- Para implantes sob carga imediata, implantes curtos apresentaram menor risco de perda óssea, do que implantes colocados pela técnica de lateralização do nervo alveolar inferior.

- Tratamentos com menor risco de fratura dos parafusos, sob cargas mastigatórias axiais, não puderam ser determinados, dentro dos limites dessa pesquisa.

- Parafusos sob cargas mastigatórias oblíquas apresentaram menor risco de fratura, com o aumento do diâmetro e diminuição do comprimento dos implantes.

- Implantes curtos de maior diâmetro apresentaram o menor risco à fratura do parafuso dentre os modelos analisados, sob cargas mastigatórias oblíquas.

- O protocolo de carga imediata, em implantes colocados pela técnica de lateralização do nervo alveolar inferior, tem risco mecânico ligeiramente menor, do que implantes curtos de mesmo diâmetro, colocados em condições semelhantes. 


\section{Referências}

Anusavice, K. J. Direct restorative materials. In: (Ed.). Phillips' Science of Dental Materials: Saunders, 2003. Direct restorative materials, p.608

Arlin, M. L. Short dental implants as a treatment option: results from an observational study in a single private practice. Int J Oral Maxillofac Implants, v.21, n.5, Sep-Oct, p.769-776. 2006.

Balshi, T. J. e G. J. Wolfinger. Immediate loading of Branemark implants in edentulous mandibles: a preliminary report. Implant Dent, v.6, n.2, Summer, p.83-88. 1997.

Bayraktar, H. H., E. F. Morgan, et al. Comparison of the elastic and yield properties of human femoral trabecular and cortical bone tissue. J Biomech, v.37, n.1, Jan, p.27-35. 2004.

Belser, U. C., M. I. Macentee, et al. Fit of three porcelain-fused-to-metal marginal designs in vivo: a scanning electron microscope study. J Prosthet Dent, v.53, n.1, Jan, p.24-29. 1985.

Benzing, U. R., H. Gall, et al. Biomechanical aspects of two different implant-prosthetic concepts for edentulous maxillae. Int J Oral Maxillofac Implants, v.10, n.2, Mar-Apr, p.188-198. 1995.

Bovi, M. Mobilization of the inferior alveolar nerve with simultaneous implant insertion: a new technique. Case report. Int J Periodontics Restorative Dent, v.25, n.4, Aug, p.375-383. 2005.

Boyer, R., G. Welsch, et al. Material Properties Handbook: Titanium Alloys. Materials Park OH: ASM International. 1994

Branemark, P. I., P. Engstrand, et al. Branemark Novum: a new treatment concept for rehabilitation of the edentulous mandible. Preliminary results from a prospective clinical follow-up study. Clin Implant Dent Relat Res, v.1, n.1, p.2-16. 1999.

Brocard, D., P. Barthet, et al. A multicenter report on 1,022 consecutively placed ITI implants: a 7-year longitudinal study. Int J Oral Maxillofac Implants, v.15, n.5, SepOct, p.691-700. 2000.

Brunski, J. B., D. A. Puleo, et al. Biomaterials and biomechanics of oral and maxillofacial implants: current status and future developments. Int $\mathbf{J}$ Oral Maxillofac Implants, v.15, n.1, Jan-Feb, p.15-46. 2000.

Buchs, A. U., L. Levine, et al. Preliminary report of immediately loaded Altiva Natural Tooth Replacement dental implants. Clin Implant Dent Relat Res, v.3, n.2, p.97-106. 2001.

Chiapasco, M., F. Ferrini, et al. Dental implants placed in expanded narrow edentulous ridges with the Extension Crest device. A 1-3-year multicenter follow-up study. Clin Oral Implants Res, v.17, n.3, Jun, p.265-272. 2006. 
Chrcanovic, B. R. e A. L. Custodio. Inferior alveolar nerve lateral transposition. Oral Maxillofac Surg, v.13, n.4, Dec, p.213-219. 2009.

Craig, R. G. Restorative Dental Materials. St. Louis: Mosby. 1985

Daculsi, G., R. Z. Legeros, et al. Scanning and transmission electron microscopy, and electron probe analysis of the interface between implants and host bone. Osseocoalescence versus osseo-integration. Scanning Microsc, v.4, n.2, Jun, p.309-314. 1990.

Das Neves, F. D., D. Fones, et al. Short implants--an analysis of longitudinal studies. Int J Oral Maxillofac Implants, v.21, n.1, Jan-Feb, p.86-93. 2006.

Davidson, P. L., P. D. Milburn, et al. Biological adaptive control model: a mechanical analogue of multi-factorial bone density adaptation. J Theor Biol, v.227, n.2, Mar 21, p.187-195. 2004.

Degidi, M., A. Piattelli, et al. Immediately loaded short implants: analysis of a case series of 133 implants. Quintessence Int, v.38, n.3, Mar, p.193-201. 2007a.

Wide-diameter implants: analysis of clinical outcome of 304 fixtures. $\mathbf{J}$ Periodontol, v.78, n.1, Jan, p.52-58. 2007b.

Dellinges, M. A. e O. C. Tebrock. A measurement of torque values obtained with handheld drivers in a simulated clinical setting. J Prosthodont, v.2, n.4, Dec, p.212-214. 1993.

Eggers, G., J. Klein, et al. Piezosurgery: an ultrasound device for cutting bone and its use and limitations in maxillofacial surgery. Br J Oral Maxillofac Surg, v.42, n.5, Oct, p.451-453. 2004.

Engelke, W., O. A. Decco, et al. In vitro evaluation of horizontal implant micromovement in bone specimen with contact endoscopy. Implant Dent, v.13, n.1, Mar, p.88-94. 2004.

Eser, A., K. Akca, et al. Nonlinear finite element analysis versus ex vivo strain gauge measurements on immediately loaded implants. Int J Oral Maxillofac Implants, v.24, n.3, May-Jun, p.439-446. 2009.

Eskitascioglu, G., A. Usumez, et al. The influence of occlusal loading location on stresses transferred to implant-supported prostheses and supporting bone: A threedimensional finite element study. J Prosthet Dent, v.91, n.2, Feb, p.144-150. 2004.

Ferrigno, N., M. Laureti, et al. Inferior alveolar nerve transposition in conjunction with implant placement. Int J Oral Maxillofac Implants, v.20, n.4, Jul-Aug, p.610-620. 2005.

Fischer, K. e T. Stenberg. Three-year data from a randomizd, controlled study of early loading of single-stage dental implants supporting maxillary full-arch prostheses. Int $\mathbf{J}$ Oral Maxillofac Implants, v.21, n.2, Mar-Apr, p.245-252. 2006.

Friberg, B., K. Grondahl, et al. Long-term follow-up of severely atrophic edentulous mandibles reconstructed with short Branemark implants. Clin Implant Dent Relat Res, v.2, n.4, p.184-189. 2000. 
Friberg, B., T. Jemt, et al. Early failures in 4,641 consecutively placed Branemark dental implants: a study from stage 1 surgery to the connection of completed prostheses. Int J Oral Maxillofac Implants, v.6, n.2, Summer, p.142-146. 1991.

Frost, H. M. Bone "mass" and the "mechanostat": a proposal. Anat Rec, v.219, n.1, Sep, p.1-9. 1987.

Gentile, M. A., S. K. Chuang, et al. Survival estimates and risk factors for failure with 6 x 5.7-mm implants. Int J Oral Maxillofac Implants, v.20, n.6, Nov-Dec, p.930-937. 2005.

Goene, R., C. Bianchesi, et al. Performance of short implants in partial restorations: 3year follow-up of Osseotite implants. Implant Dent, v.14, n.3, Sep, p.274-280. 2005.

Goheen, K. L., S. G. Vermilyea, et al. Torque generated by handheld screwdrivers and mechanical torquing devices for osseointegrated implants. Int $\mathbf{J}$ Oral Maxillofac Implants, v.9, n.2, Mar-Apr, p.149-155. 1994.

Grant, B. T., F. X. Pancko, et al. Outcomes of placing short dental implants in the posterior mandible: a retrospective study of 124 cases. J Oral Maxillofac Surg, v.67, n.4, Apr, p.713-717. 2009.

Greenstein, G. e D. Tarnow. The mental foramen and nerve: clinical and anatomical factors related to dental implant placement: a literature review. J Periodontol, v.77, n.12, Dec, p.1933-1943. 2006.

Griffin, T. J. e W. S. Cheung. The use of short, wide implants in posterior areas with reduced bone height: a retrospective investigation. J Prosthet Dent, v.92, n.2, Aug, p.139-144. 2004.

Gross, M., D. Kozak, et al. Manual closing torque in five implant abutment systems: an in vitro comparative study. J Prosthet Dent, v.81, n.5, May, p.574-578. 1999.

Grunder, U. Immediate functional loading of immediate implants in edentulous arches: two-year results. Int J Periodontics Restorative Dent, v.21, n.6, Dec, p.545-551. 2001.

Guda, T., T. A. Ross, et al. Probabilistic analysis of preload in the abutment screw of a dental implant complex. J Prosthet Dent, v.100, n.3, Sep, p.183-193. 2008.

Haack, J. E., R. L. Sakaguchi, et al. Elongation and preload stress in dental implant abutment screws. Int J Oral Maxillofac Implants, v.10, n.5, Sep-Oct, p.529-536. 1995.

Hagi, D., D. A. Deporter, et al. A targeted review of study outcomes with short (< or $=7$ $\mathrm{mm}$ ) endosseous dental implants placed in partially edentulous patients. $\mathbf{J}$ Periodontol, v.75, n.6, Jun, p.798-804. 2004.

Hall, D. R., W. T. Nakayama, et al. Elastic Constants of Three Representative Dental Cements. J Dent Res, v.59, n.2, p.390. 1973. 
Hart, R. T., D. T. Davy, et al. A computational method for stress analysis of adaptive elastic materials with a view toward applications in strain-induced bone remodeling. $\mathbf{J}$ Biomech Eng, v.106, n.4, Nov, p.342-350. 1984.

Hazelwood, S. J., R. Bruce Martin, et al. A mechanistic model for internal bone remodeling exhibits different dynamic responses in disuse and overload. J Biomech, v.34, n.3, Mar, p.299-308. 2001.

Hirsch, J. M. e P. I. Branemark. Fixture stability and nerve function after transposition and lateralization of the inferior alveolar nerve and fixture installation. $\mathbf{B r} \mathbf{J}$ Oral Maxillofac Surg, v.33, n.5, Oct, p.276-281. 1995.

Holmes, D. C., A. M. Diaz-Arnold, et al. Influence of post dimension on stress distribution in dentin. J Prosthet Dent, v.75, n.2, Feb, p.140-147. 1996.

Horiuchi, K., H. Uchida, et al. Immediate loading of Branemark system implants following placement in edentulous patients: a clinical report. Int $\mathbf{J}$ Oral Maxillofac Implants, v.15, n.6, Nov-Dec, p.824-830. 2000.

$\mathrm{Hu}, \mathrm{K}$., C. Wang, et al. High pressure may inhibit periprosthetic osteogenesis. J Bone Miner Metab, v.28, n.3, May, p.289-298. 2010.

Jensen, O. e D. Nock. Inferior alveolar nerve repositioning in conjunction with placement of osseointegrated implants: a case report. Oral Surg Oral Med Oral Pathol, v.63, n.3, Mar, p.263-268. 1987.

Johns, R. B., T. Jemt, et al. A multicenter study of overdentures supported by Branemark implants. Int J Oral Maxillofac Implants, v.7, n.4, Winter, p.513-522. 1992.

Kan, J. Y., J. L. Lozada, et al. Endosseous implant placement in conjunction with inferior alveolar nerve transposition: an evaluation of neurosensory disturbance. Int $\mathbf{J}$ Oral Maxillofac Implants, v.12, n.4, Jul-Aug, p.463-471. 1997.

Karlsson, S. The fit of Procera titanium crowns. An in vitro and clinical study. Acta Odontol Scand, v.51, n.3, Jun, p.129-134. 1993.

Khullar, S. M., P. Brodin, et al. Preliminary study of low-level laser for treatment of longstanding sensory aberrations in the inferior alveolar nerve. J Oral Maxillofac Surg, v.54, n.1, Jan, p.2-7; discussion 7-8. 1996.

Khullar, S. M., B. Emami, et al. Effect of low-level laser treatment on neurosensory deficits subsequent to sagittal split ramus osteotomy. Oral Surg Oral Med Oral Pathol Oral Radiol Endod, v.82, n.2, Aug, p.132-138. 1996.

Kong, L., Z. Gu, et al. Biomechanical optimization of implant diameter and length for immediate loading: a nonlinear finite element analysis. Int J Prosthodont, v.22, n.6, Nov-Dec, p.607-615. 2009.

Kotsovilis, S., I. Fourmousis, et al. A systematic review and meta-analysis on the effect of implant length on the survival of rough-surface dental implants. J Periodontol, v.80, n.11, Nov, p.1700-1718. 2009. 
Koyama, Y., N. Mitsui, et al. Effect of compressive force on the expression of inflammatory cytokines and their receptors in osteoblastic Saos-2 cells. Arch Oral Biol, v.53, n.5, May, p.488-496. 2008.

Lang, L. A., B. Kang, et al. Finite element analysis to determine implant preload. J Prosthet Dent, v.90, n.6, Dec, p.539-546. 2003.

Levine, M. H., A. L. Goddard, et al. Inferior alveolar nerve canal position: a clinical and radiographic study. J Oral Maxillofac Surg, v.65, n.3, Mar, p.470-474. 2007.

$\mathrm{Li}$, J., H. Li, et al. A mathematical model for simulating the bone remodeling process under mechanical stimulus. Dent Mater, v.23, n.9, Sep, p.1073-1078. 2007.

Lian, Z., H. Guan, et al. Effect of bone to implant contact percentage on bone remodelling surrounding a dental implant. Int J Oral Maxillofac Surg, v.39, n.7, Jul, p.690-698. 2010.

Lin, D., Q. Li, et al. Dental implant induced bone remodeling and associated algorithms. J Mech Behav Biomed Mater, v.2, n.5, Oct, p.410-432. 2009.

Ludema, K. C. Friction Wear Lubrification: a Textbook in Tribology: CRC-Press. 1996. 272 p.

Malo, P., M. De Araujo Nobre, et al. Short implants placed one-stage in maxillae and mandibles: a retrospective clinical study with 1 to 9 years of follow-up. Clin Implant Dent Relat Res, v.9, n.1, Mar, p.15-21. 2007.

Malo, P., A. Nobre Mde, et al. A pilot study of complete edentulous rehabilitation with immediate function using a new implant design: case series. Clin Implant Dent Relat Res, v.8, n.4, p.223-232. 2006.

Malo, P., B. Rangert, et al. All-on-4 immediate-function concept with Branemark System implants for completely edentulous maxillae: a 1-year retrospective clinical study. Clin Implant Dent Relat Res, v.7 Suppl 1, p.S88-94. 2005.

Mcglumphy, E. A., D. A. Mendel, et al. Implant screw mechanics. Dent Clin North Am, v.42, n.1, Jan, p.71-89. 1998.

Mclean, J. W. e J. A. Von Fraunhofer. The estimation of cement film thickness by an in vivo technique. Br Dent J, v.131, n.3, Aug 3, p.107-111. 1971.

Mcnamara, B. P., D. Taylor, et al. Computer prediction of adaptive bone remodelling around noncemented femoral prostheses: the relationship between damage-based and strain-based algorithms. Med Eng Phys, v.19, n.5, Jul, p.454-463. 1997.

Metzger, M. C., K. H. Bormann, et al. Inferior alveolar nerve transposition--an in vitro comparison between piezosurgery and conventional bur use. J Oral Implantol, v.32, n.1, p.19-25. 2006.

Misch, C. E., J. Steignga, et al. Short dental implants in posterior partial edentulism: a multicenter retrospective 6-year case series study. J Periodontol, v.77, n.8, Aug, p.1340-1347. 2006. 
Naert, I., G. Koutsikakis, et al. Biologic outcome of implant-supported restorations in the treatment of partial edentulism. part I: a longitudinal clinical evaluation. Clin Oral Implants Res, v.13, n.4, Aug, p.381-389. 2002.

Natali, A. N., P. G. Pavan, et al. Analysis of bone-implant interaction phenomena by using a numerical approach. Clin Oral Implants Res, v.17, n.1, Feb, p.67-74. 2006.

Nedir, R., M. Bischof, et al. A 7-year life table analysis from a prospective study on ITI implants with special emphasis on the use of short implants. Results from a private practice. Clin Oral Implants Res, v.15, n.2, Apr, p.150-157. 2004.

Oatis, D. Analyzing Bolt Pretension in the Ansys workbench Platform. Ansys Advantage, v.l, n.4, p.28-29. 2007.

Peleg, M., Z. Mazor, et al. Lateralization of the inferior alveolar nerve with simultaneous implant placement: a modified technique. Int J Oral Maxillofac Implants, v.17, n.1, Jan-Feb, p.101-106. 2002.

Petrie, C. S. e J. L. Williams. Comparative evaluation of implant designs: influence of diameter, length, and taper on strains in the alveolar crest. A three-dimensional finiteelement analysis. Clin Oral Implants Res, v.16, n.4, Aug, p.486-494. 2005.

Pierrisnard, L., F. Renouard, et al. Influence of implant length and bicortical anchorage on implant stress distribution. Clin Implant Dent Relat Res, v.5, n.4, p.254-262. 2003.

Qian, L., M. Todo, et al. Effects of implant diameter, insertion depth, and loading angle on stress/strain fields in implant/jawbone systems: finite element analysis. Int $\mathbf{J}$ Oral Maxillofac Implants, v.24, n.5, Sep-Oct, p.877-886. 2009.

Reina, J. M., J. M. Garcia-Aznar, et al. Numerical estimation of bone density and elastic constants distribution in a human mandible. J Biomech, v.40, n.4, p.828-836. 2007.

Renouard, F. e D. Nisand. Impact of implant length and diameter on survival rates. Clin Oral Implants Res, v.17 Suppl 2, Oct, p.35-51. 2006.

Roberts, W. E., R. K. Smith, et al. Osseous adaptation to continuous loading of rigid endosseous implants. Am J Orthod, v.86, n.2, Aug, p.95-111. 1984.

Romeo, E., M. Ghisolfi, et al. Short (8- $\mathrm{mm})$ dental implants in the rehabilitation of partial and complete edentulism: a 3- to 14-year longitudinal study. Int J Prosthodont, v.19, n.6, Nov-Dec, p.586-592. 2006.

Rosenquist, B. Implant Placement in Combination With Nerve Transpositioning: Experience With the First 100 cases. Int $\mathbf{J}$ Oral Maxillofac Implants, n.9, p.522-531. 1994.

Schrotenboer, J., Y. P. Tsao, et al. Effect of platform switching on implant crest bone stress: a finite element analysis. Implant Dent, v.18, n.3, Jun, p.260-269. 2009.

Singh, R. e N. B. Dahotre. Corrosion degradation and prevention by surface modification of biometallic materials. J Mater Sci Mater Med, v.18, n.5, May, p.725751. 2007. 
Skf, G. Bolt-tightening Handbook S. L. M. P. Technologies. Montigny-le-Bretinneux France 2001.

Steflik, D. E., P. J. Hanes, et al. Transmission electron microscopic and high voltage electron microscopic observations of the bone and osteocyte activity adjacent to unloaded dental implants placed in dogs. J Periodontol, v.63, n.5, May, p.443-452. 1992.

Stellingsma, K., G. M. Raghoebar, et al. The extremely resorbed mandible: a comparative prospective study of 2-year results with 3 treatment strategies. Int $\mathbf{J}$ Oral Maxillofac Implants, v.19, n.4, Jul-Aug, p.563-577. 2004.

Sulaiman, F., J. Chai, et al. A comparison of the marginal fit of In-Ceram, IPS Empress, and Procera crowns. Int J Prosthodont, v.10, n.5, Sep-Oct, p.478-484. 1997.

Tawil, G. e R. Younan. Clinical evaluation of short, machined-surface implants followed for 12 to 92 months. Int J Oral Maxillofac Implants, v.18, n.6, Nov-Dec, p.894-901. 2003.

Taylor, D., J. G. Hazenberg, et al. Living with cracks: damage and repair in human bone. Nat Mater, v.6, n.4, Apr, p.263-268. 2007.

Ten Bruggenkate, C. M., P. Asikainen, et al. Short (6-mm) nonsubmerged dental implants: results of a Multicenter clinical trial of 1 to 7 years. Int $\mathbf{J}$ Oral Maxillofac Implants, v.13, n.6, Nov-Dec, p.791-798. 1998.

Testori, T., L. Wiseman, et al. A prospective multicenter clinical study of the Osseotite implant: four-year interim report. Int J Oral Maxillofac Implants, v.16, n.2, Mar-Apr, p.193-200. 2001.

Tillitson, E. W., R. G. Craig, et al. Friction and wear of restorative dental materials. J Dent Res, v.50, n.1, Jan-Feb, p.149-154. 1971.

Tolstunov, L. Implant zones of the jaws: implant location and related success rate. $\mathbf{J}$ Oral Implantol, v.33, n.4, p.211-220. 2007.

Van Den Bogaerde, L., G. Pedretti, et al. Early function of splinted implants in maxillas and posterior mandibles using branemark system machine surface implants: an 18 month prospective clinical multicenter study. Clin Implant Dent Relat Res, v.5, p.2128. 2002.

Vasconcelos Jde, A., G. B. Avila, et al. Inferior alveolar nerve transposition with involvement of the mental foramen for implant placement. Med Oral Patol Oral Cir Bucal, v.13, n.11, Nov, p.E722-725. 2008.

Wadu, S. G., B. Penhall, et al. Morphological variability of the human inferior alveolar nerve. Clin Anat, v.10, n.2, p.82-87. 1997.

Wang, R. F., B. Kang, et al. The dynamic natures of implant loading. J Prosthet Dent, v.101, n.6, Jun, p.359-371. 2009.

Weng, D., Z. Jacobson, et al. A prospective multicenter clinical trial of 3i machinedsurface implants: results after 6 years of follow-up. Int J Oral Maxillofac Implants, v.18, n.3, May-Jun, p.417-423. 2003. 
Wheeler, S. L. Implant complications in the esthetic zone. J Oral Maxillofac Surg, v.65, n.7 Suppl 1, Jul, p.93-102. 2007.

Winkler, S., H. F. Morris, et al. Implant survival to 36 months as related to length and diameter. Ann Periodontol, v.5, n.1, Dec, p.22-31. 2000.

Winkler, S., K. Ring, et al. Implant screw mechanics and the settling effect: overview. J Oral Implantol, v.29, n.5, p.242-245. 2003.

Yokoyama, K., T. Ichikawa, et al. Fracture mechanisms of retrieved titanium screw thread in dental implant. Biomaterials, v.23, n.12, Jun, p.2459-2465. 2002.

Yoshimoto, M., B. J. Konig, et al. A light and scanning electron microscopy study of bone healing following inferior alveolar nerve lateralization: an experimental study in rabbits. Int J Oral Maxillofac Implants, v.23, n.3, May-Jun, p.457-462. 2008.

You, J., C. E. Yellowley, et al. Substrate deformation levels associated with routine physical activity are less stimulatory to bone cells relative to loading-induced oscillatory fluid flow. J Biomech Eng, v.122, n.4, Aug, p.387-393. 2000.

Zarone, F., R. Sorrentino, et al. Evaluation of the biomechanical behavior of maxillary central incisors restored by means of endocrowns compared to a natural tooth: a 3D static linear finite elements analysis. Dent Mater, v.22, n.11, Nov, p.1035-1044. 2006. 